\title{
THE ORNL MODULATING HEAT PUMP DESIGN TOOL - MARK IV USER'S GUIDE
}

\author{
C. K. Rice
}




\section{DOCUMENT AVAILABILITY}

Reports produced after January 1, 1996, are generally available free via the U.S. Department of Energy (DOE) Information Bridge:

Web site: http://www.osti.gov/bridge

Reports produced before January 1, 1996, may be purchased by members of the public from the following source:

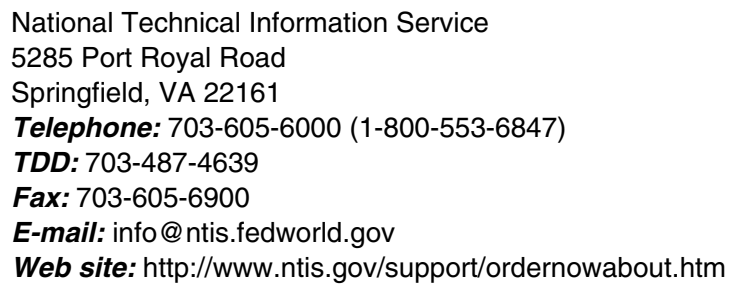

Reports are available to DOE employees, DOE contractors, Energy Technology Data Exchange (ETDE) representatives, and International Nuclear Information System (INIS) representatives from the following source:

Office of Scientific and Technical Information

P.O. Box 62

Oak Ridge, TN 37831

Telephone: 865-576-8401

Fax: 865-576-5728

E-mail: reports@adonis.osti.gov

Web site: http://www.osti.gov/contact.html

This report was prepared as an account of work sponsored by an agency of the United States government. Neither the United States government nor any agency thereof, nor any of their employees, makes any warranty, express or implied, or assumes any legal liability or responsibility for the accuracy, completeness, or usefulness of any information, apparatus, product, or process disclosed, or represents that its use would not infringe privately owned rights. Reference herein to any specific commercial product, process, or service by trade name, trademark, manufacturer, or otherwise, does not necessarily constitute or imply its endorsement, recommendation, or favoring by the United States government or any agency thereof. The views and opinions of authors expressed herein do not necessarily state or reflect those of the United States government or any agency thereof. 


\title{
THE ORNL MODULATING HEAT PUMP DESIGN TOOL - \\ MARK IV USER'S GUIDE
}

C. K. Rice

June 1991

Prepared for the

U.S. DEPARTMENT OF ENERGY

\author{
Prepared by \\ OAK RIDGE NATIONAL LABORATORY \\ P.O. Box 2008 \\ Oak Ridge, Tennessee 37831-6285 \\ managed by \\ UT-Battelle, LLC \\ for the \\ U.S. DEPARTMENT OF ENERGY \\ under contract DE-AC05-00OR22725
}





\section{TABLE OF CONTENTS}

Page

LIST OF FIGURES $\ldots \ldots \ldots \ldots \ldots \ldots \ldots \ldots \ldots \ldots \ldots \ldots \ldots \ldots \ldots \ldots$

LIST OF TABLES $\ldots \ldots \ldots \ldots \ldots \ldots \ldots \ldots \ldots \ldots \ldots \ldots \ldots \ldots \ldots \ldots \ldots \ldots$

LIST OF APPENDIX LISTINGS $\ldots \ldots \ldots \ldots \ldots \ldots \ldots \ldots \ldots \ldots \ldots \ldots \ldots \ldots$

EXECUTIVE SUMMARY $\ldots \ldots \ldots \ldots \ldots \ldots \ldots \ldots \ldots \ldots \ldots \ldots \ldots \ldots$

Overview Of New Features $\ldots \ldots \ldots \ldots \ldots \ldots \ldots \ldots \ldots \ldots \ldots \ldots \ldots \ldots$

Validations and Applications $\ldots \ldots \ldots \ldots \ldots \ldots \ldots \ldots \ldots \ldots \ldots \ldots \ldots \ldots \ldots \ldots \ldots \ldots \ldots$

VARIABLE-SPEED COMPRESSORS $\ldots \ldots \ldots \ldots \ldots \ldots \ldots \ldots \ldots \ldots$

Basic Compressor Representation $\ldots \ldots \ldots \ldots \ldots \ldots \ldots \ldots \ldots \ldots \ldots \ldots \ldots \ldots \ldots$

Modulating Compressor Performance $\ldots \ldots \ldots \ldots \ldots \ldots \ldots \ldots \ldots \ldots$

Compressor Map-Fitting Program $\ldots \ldots \ldots \ldots \ldots \ldots \ldots \ldots \ldots \ldots \ldots \ldots \ldots$

Modulating Drive Options $\ldots \ldots \ldots \ldots \ldots \ldots \ldots \ldots \ldots \ldots \ldots \ldots \ldots \ldots \ldots$

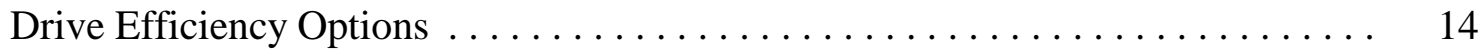

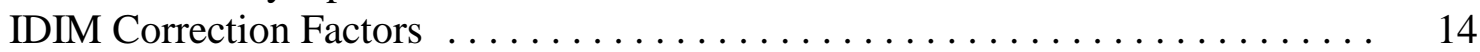

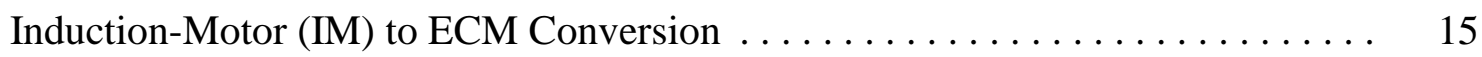

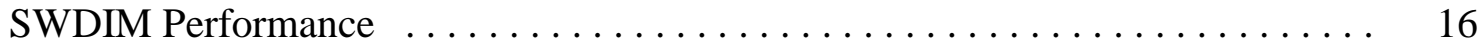

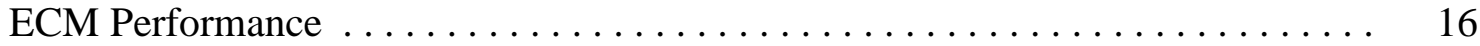

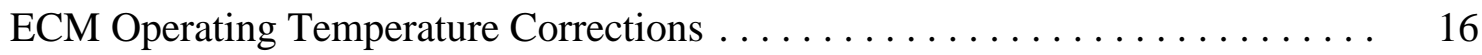

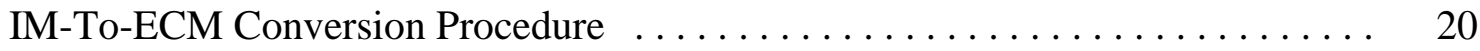

Secondary Effects of Reduced Suction Gas Superheating . . . . . . . . . . . . 20

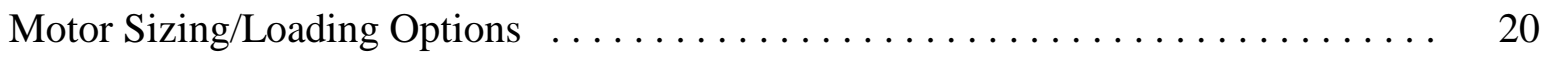

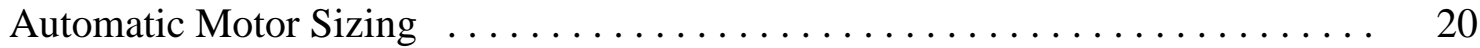

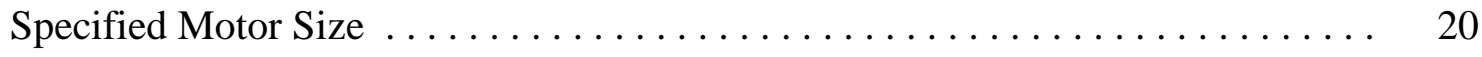


VARIABLE-SPEED BLOWERS $\ldots \ldots \ldots \ldots \ldots \ldots \ldots \ldots \ldots \ldots \ldots \ldots \ldots \ldots$

Modulating Blower Performance $\ldots \ldots \ldots \ldots \ldots \ldots \ldots \ldots \ldots \ldots \ldots \ldots \ldots \ldots \ldots \ldots$

Modeling Perspective Relative To That For The Compressor $\ldots \ldots \ldots \ldots \ldots 21$

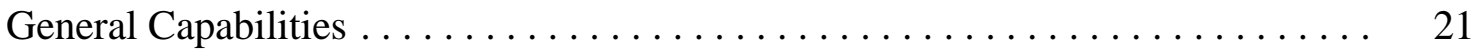

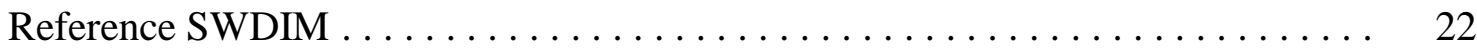

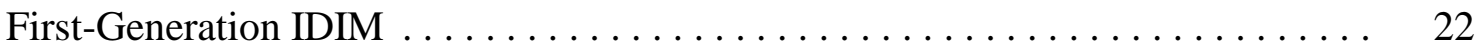

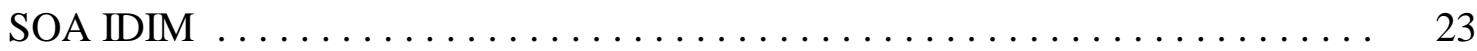

ECM Indoor Blower and Outdoor Fan Performance .............. 23

Further Discussion of Blower and Fan Modeling Capabilities $\ldots \ldots \ldots \ldots \ldots \ldots$

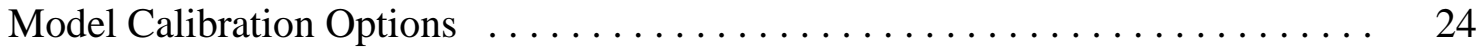

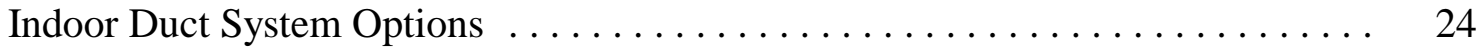

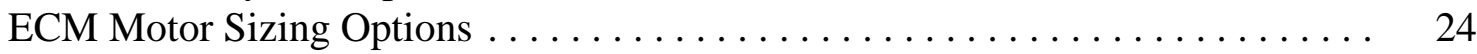

AIR-SIDE CORRELATIONS FOR MODULATION AND

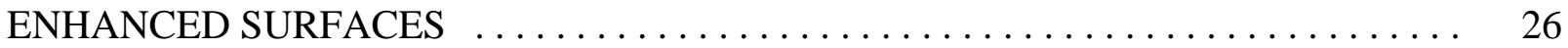

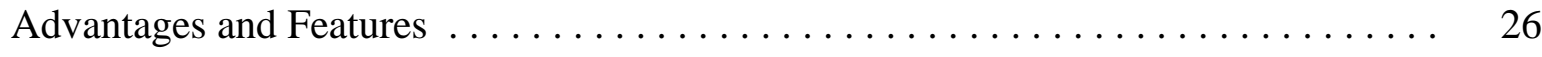

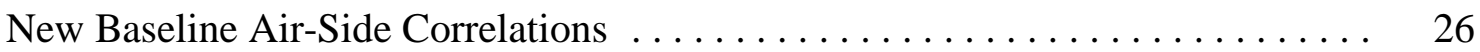

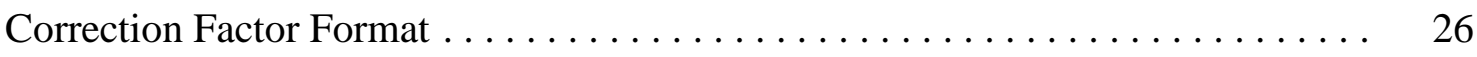

New Geometry and Flow-Dependent Correction Factors $\ldots \ldots \ldots \ldots \ldots \ldots$

Further Improvements In Pressure Drop Calculations . . . . . . . . . . . . . . . 27

CHARGE INVENTORY AND RELATED WIDE-RANGE

FLOW CONTROL OPTIONS $\ldots \ldots \ldots \ldots \ldots \ldots \ldots \ldots \ldots \ldots \ldots \ldots \ldots \ldots \ldots$

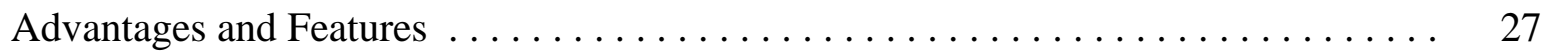

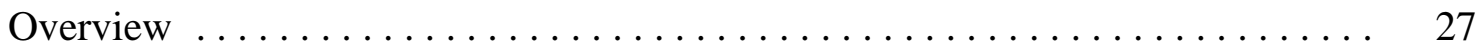

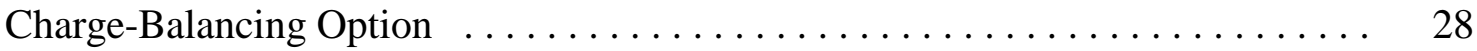

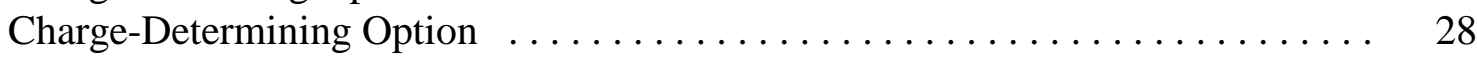

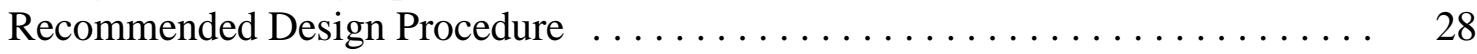

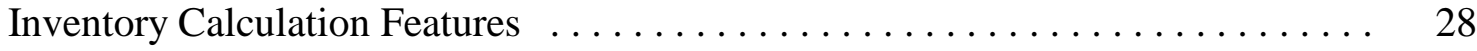

Modeling Interrelationships Between Refrigerant Charge and System Flow Control . . . . . . . . . . . . . . . . . . . . . . . . 29 
CHARGE INVENTORY AND RELATED WIDE-RANGE

FLOW CONTROL OPTIONS (continued)

Discussion of TXV Modeling With and Without A

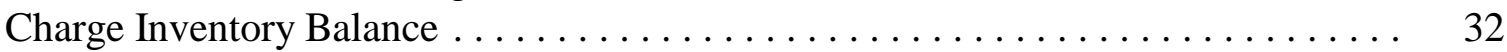

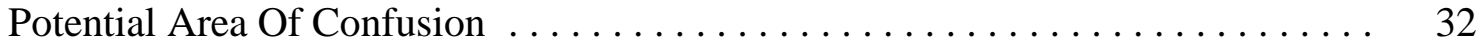

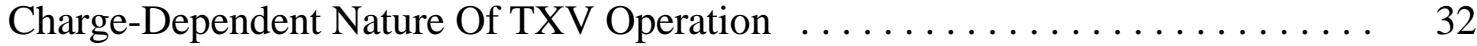

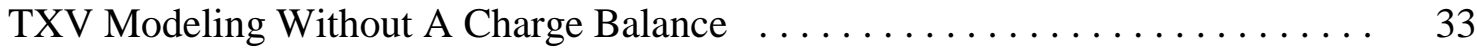

Explicit-Versus-Implicit TXV Modeling With A Charge Balance .......... 36

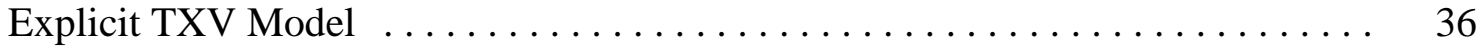

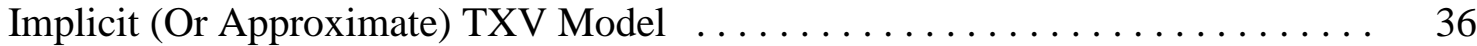

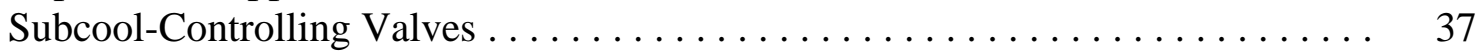

Adjustable- vs Fixed-Opening Flow Controls $\ldots \ldots \ldots \ldots \ldots \ldots \ldots \ldots$

MODEL VALIDATIONS, LIMITATIONS, AND RECOMMENDATIONS $\ldots \ldots \ldots$

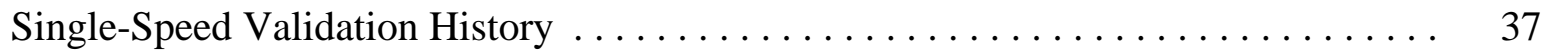

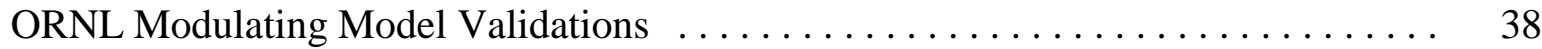

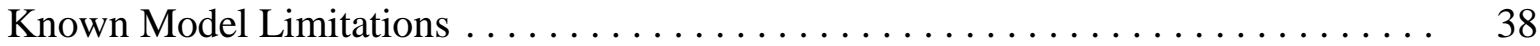

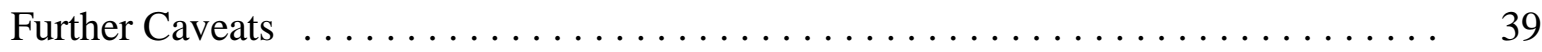

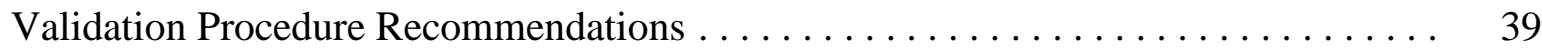

PARAMETRIC PERFORMANCE MAPPING $\ldots \ldots \ldots \ldots \ldots \ldots \ldots \ldots \ldots$

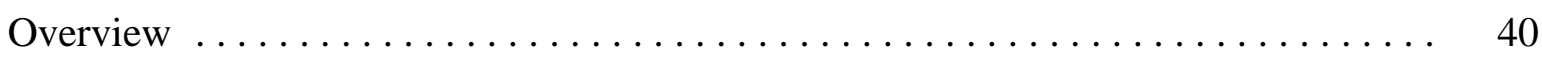

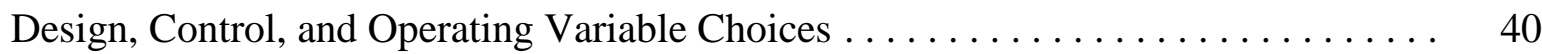

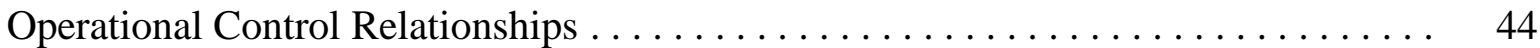

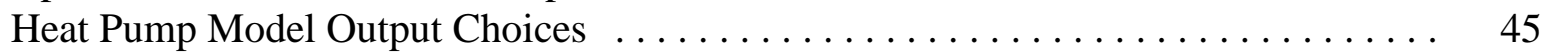

MODULATING APPLICATIONS-TO-DATE $\ldots \ldots \ldots \ldots \ldots \ldots \ldots \ldots$

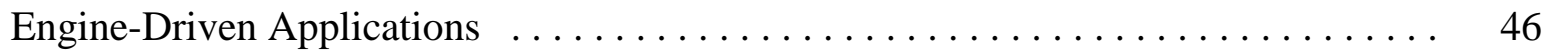

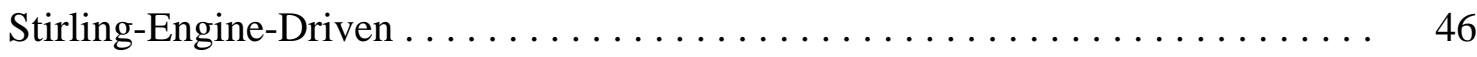

Internal-Combustion-Engine-Driven $\ldots \ldots \ldots \ldots \ldots \ldots \ldots \ldots \ldots \ldots \ldots \ldots \ldots$

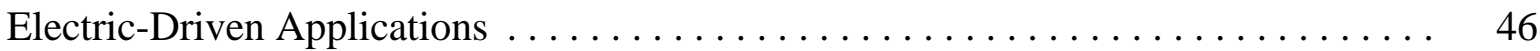

As An Aid To Experimental Testing . . . . . . . . . . . . . 46

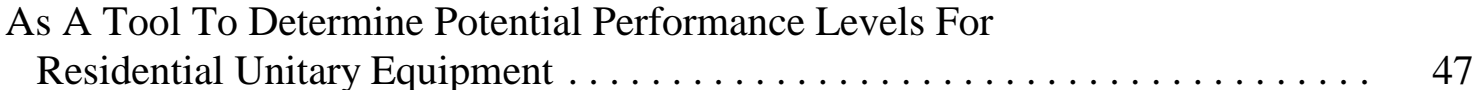

As A Tool To Assess Potential Of Variable-Speed-Drives For

Commercial Unitary Equipment $\ldots \ldots \ldots \ldots \ldots \ldots \ldots \ldots \ldots \ldots \ldots \ldots$ 
USE WITH ALTERNATIVE REFRIGERANTS $\ldots \ldots \ldots \ldots \ldots \ldots \ldots \ldots \ldots \ldots$

MODEL AVAILABILITY $\ldots \ldots \ldots \ldots \ldots \ldots \ldots \ldots \ldots \ldots \ldots \ldots \ldots \ldots \ldots \ldots$

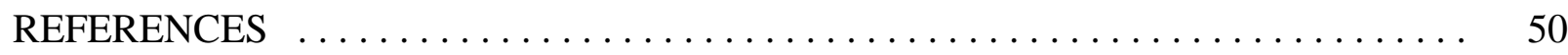

APPENDIX A: CONTOUR SELECTION DATA FILE 'CONCHZ' $\ldots \ldots \ldots \ldots \ldots$

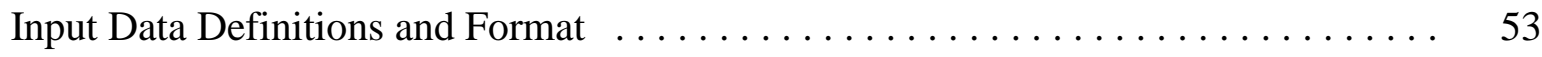

Sample Input File $($ Regular and Annotated) $\ldots \ldots \ldots \ldots \ldots \ldots \ldots \ldots \ldots \ldots \ldots$

APPENDIX B: HEAT PUMP SPECIFICATION DATA FILE 'HPDATA' $\ldots \ldots \ldots \ldots$

Input Data Definitions and Format $\ldots \ldots \ldots \ldots \ldots \ldots \ldots \ldots \ldots \ldots \ldots \ldots \ldots \ldots$

Sample Input File (Regular and Annotated) $\ldots \ldots \ldots \ldots \ldots \ldots \ldots \ldots$

APPENDIX C: SAMPLE PROGRAM RESULTS $\ldots \ldots \ldots \ldots \ldots \ldots \ldots$

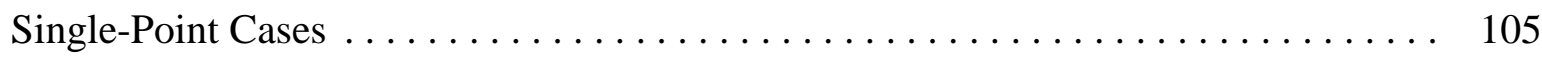

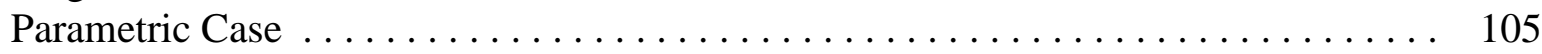

APPENDIX D: DEFINITION OF CONSTANTS ASSIGNED IN BLOCK DATA . . . . 149

APPENDIX E: DESCRIPTION OF NEW SUBROUTINES ADDED

SINCE THE MARK III VERSION $\ldots \ldots \ldots \ldots \ldots \ldots \ldots \ldots \ldots \ldots$

APPENDIX F: DESCRIPTION OF SUBROUTINES USED FOR

THE BASIC ORNL HEAT PUMP MODEL . . . . . . . . . . 161

APPENDIX G: COMPRESSOR-MAP-FITTING PROGRAM 'MAPFIT' $\ldots \ldots \ldots \ldots$

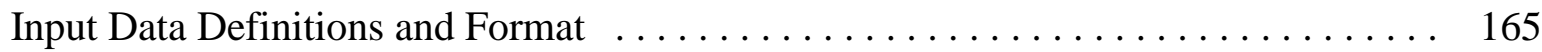

Sample Input File (Regular and Annotated) $\ldots \ldots \ldots \ldots \ldots \ldots \ldots \ldots \ldots \ldots$

Sample Output Listing and File (Regular and Annotated) . . . . . . . . . . 165

APPENDIX H: AMBIENT/SPEED/CONTROL DATA FILE 'CONTRL' FOR

SELECTED AND DUAL-MODE AMBIENT-vs-SPEED

PERFORMANCE MAPPING ................... 189

Input Data Definitions and Format $\ldots \ldots \ldots \ldots \ldots \ldots \ldots \ldots \ldots \ldots \ldots \ldots$

Sample Input File (Regular and Annotated) $\ldots \ldots \ldots \ldots \ldots \ldots \ldots \ldots \ldots$ 


\section{LIST OF FIGURES}

Figure

Page

1 Compressor Isentropic Efficiency As a Function of Evaporating and Condensing Temperatures At $30 \mathrm{~Hz}$ Frequency

— From Curve-Fits To Basic Power and Refrigerant Mass Flow Rate Data . . . .

2 Compressor Volumetric Efficiency As a Function of Pressure Ratio and Condensing Pressure At $30 \mathrm{~Hz}$ Frequency

— From Curve-Fits To Basic Power and Refrigerant Mass Flow Rate Data . . .

3 Compressor Isentropic Efficiency As a Function of

Evaporating and Condensing Temperatures At $30 \mathrm{~Hz}$ Frequency

— From Curve-Fits To Derived Isentropic Efficiency Values . . . . . . . . . .

4 Compressor Volumetric Efficiency As a Function of

Pressure Ratio and Condensing Pressure At $30 \mathrm{~Hz}$ Frequency

— From Curve-Fits To Derived Volumetric Efficiency Values . . . . . . . . . . .

5 Compressor Isentropic Efficiency As a Function of

Evaporating and Condensing Temperatures At $20 \mathrm{~Hz}$ Frequency

— From Curve-Fits To Derived Isentropic Efficiency Values . . . . . . . . . . .

6 Compressor Isentropic Efficiency As a Function of Evaporating and Condensing Temperatures At $45 \mathrm{~Hz}$ Frequency

— From Curve-Fits To Derived Isentropic Efficiency Values . . . . . . . . . .

7 Compressor Isentropic Efficiency As a Function of Evaporating and Condensing Temperatures At $60 \mathrm{~Hz}$ Frequency

— From Curve-Fits To Derived Isentropic Efficiency Values . . . . . . . . . . . .

8 Compressor Isentropic Efficiency As a Function of

Evaporating and Condensing Temperatures At $75 \mathrm{~Hz}$ Frequency

— From Curve-Fits To Derived Isentropic Efficiency Values . . . . . . . . . .

9 Compressor Isentropic Efficiency As a Function of

Evaporating and Condensing Temperatures At $90 \mathrm{~Hz}$ Frequency

- From Curve-Fits To Derived Isentropic Efficiency Values . . . . . . . . . . .

10 Modulating, Sine-Wave-Driven, Induction Motor (SWDIM) Efficiency

— Reference 3-Phase, 2-Pole, 2.75 Hp Compressor Motor . . . . . . . . . . . . .

11 Modulating, Sine-Wave-Driven, Induction Motor (SWDIM) Slip Difference

— Reference 3-Phase, 2-Pole, $2.75 \mathrm{Hp}$ Compressor Motor . . . . . . . . . . . . . 


\section{LIST OF FIGURES (continued)}

Figure

Page

12 Modulating Drive (Motor and Inverter) Efficiency of a

Permanent-Magnet, Electronically-Commutated Motor (PM-ECM)

— Reference 3-Phase, 4-Pole, 3 Hp Compressor Motor ..............

13 Modulating Drive (Motor and Inverter) Efficiency of a

Permanent-Magnet, Electronically-Commutated Motor (PM-ECM)

— Reference 3-Phase, 12-Pole, 1/5 Hp Blower Motor . . . . . . . . . . . . .

14 Solution Logic of ORNL Modulating HPDM

With Charge-Determining Option Selected

15 Solution Logic of ORNL Modulating HPDM

With Charge-Balancing Option Selected ....................

16 Sample Refrigerant Charge Distribution Within a Heat Pump

as Predicted by the ORNL Charge Inventory Model $\ldots \ldots \ldots \ldots \ldots \ldots . \ldots 34$

17 Sample Heat Exchanger Exit Conditions and Accumulator Level

Predicted As a Function Of Ambient With Capillary Tube Flow Control

Using the ORNL Charge Inventory Model

18 Overall Structure of ORNL Modulating

Contour Data Generating Program — MODCON

19 Detailed Structure of ORNL Modulating Heat Pump Design Model

20 Structure of Thermodynamic Supporting Routines

for Refrigerant and Air Properties 


\section{LIST OF TABLES}

Table

Page

1 Efficiency Degradation Multipliers For Compressor First-Generation IDIMs . . . 14

2 Efficiency Degradation Multipliers For Compressor SOA IDIMs . . . . . . . 15

3 Reference SWDIM Efficiency For Blower Applications $\ldots \ldots \ldots \ldots \ldots \ldots \ldots$

4 Efficiency Degradation Multipliers For Blower First-Generation IDIMs $\ldots . . .23$

5 Efficiency Degradation Multipliers For Blower State-Of-The-Art IDIMs . . . . . 23

6 Definitions Of Charge Inventory Output Variables $\ldots \ldots \ldots \ldots \ldots \ldots \ldots \ldots$

A.1 Description of CONCHZ Input Data to MODCON Program $\ldots \ldots \ldots \ldots \ldots$

A.2 Key to Independent Contour Variables Available for Selection in Input Data File CONCHZ . . . . . . . . . . . . . . . . . . . . 59

A.3 Key to Steady-State Dependent Contour Variables

Available for Selection in Input Data File CONCHZ . . . . . . . . . . . . . 61

A.4 Key to Seasonal Dependent Contour Variables

Available for Selection in Input Data File CONCHZ . . . . . . . . . . . . . 65

A.5 Description of Output Contour Data File From MODCON $\ldots \ldots \ldots \ldots \ldots$

B.1 Description of HPDATA Input to the MODCON Program $\ldots \ldots \ldots \ldots \ldots$

H.1 Description of Optional CONTRL Input Data to MODCON Program $\ldots \ldots \ldots 191$ 



\section{LIST OF APPENDIX LISTINGS}

Listing Page

A.1 Sample Contour Selection Data File 'CONCHZ' . . . . . . . . . . . . . . . . . 69

A.2 Annotated Sample Contour Selection Data File 'CONCHZ' . . . . . . . . . . 73

B.1 Sample Heat Pump Specification File 'HPDATA'

$-95^{\circ} \mathrm{F}$ Design Cooling Condition $\ldots \ldots \ldots \ldots \ldots \ldots \ldots \ldots \ldots \ldots \ldots \ldots \ldots \ldots \ldots \ldots$

B.2 Sample Heat Pump Specification File 'HPDATA'

$-47^{\circ} \mathrm{F}$ Off-Design Heating Condition . . . . . . . . . . . . . . . . .

B.3 Annotated Sample Heat Pump Specification File 'HPDATA'

— $95^{\circ} \mathrm{F}$ Design Cooling Condition $\ldots \ldots \ldots \ldots \ldots \ldots \ldots \ldots \ldots \ldots \ldots \ldots \ldots$

C.1 Sample Single-Point Heat Pump Model Run

— $95^{\circ}$ F Design Cooling Condition — Summary Output . . . . . . . . . . 107

C.2 Sample Single-Point Heat Pump Model Run

- $47^{\circ} \mathrm{F}$ Off-Design Heating Condition — Summary Output

C.3 Sample Parametric Heat Pump Model Run - Heating Mode,

Compressor Frequency Vs Ambient — Abbreviated Output Listing .

C.4 Sample Parametric Heat Pump Model Run - Heating Mode,

Compressor Frequency Vs Ambient — Output Contour Data

Generation File

G.1 Input Format Description for MAPFIT Program $\ldots \ldots \ldots \ldots \ldots \ldots \ldots \ldots$

G.2 Sample Input File for MAPFIT Program $\ldots \ldots \ldots \ldots \ldots \ldots \ldots \ldots \ldots$

G.3 Sample Input File for MAPFIT Program — Annotated . . . . . . . . . . . 173

G.4 Sample Output Listing for MAPFIT Program $\ldots \ldots \ldots \ldots \ldots \ldots \ldots \ldots$

G.5 Output Format Description for MAPFIT Program $\ldots \ldots \ldots \ldots \ldots \ldots$. . . . 183

G.6 Sample Output File for MAPFIT Program $\ldots \ldots \ldots \ldots \ldots \ldots \ldots \ldots \ldots$

G.7 Sample Output File for MAPFIT Program - Annotated . . . . . . . . . 187 


\section{LIST OF APPENDIX LISTINGS (continued)}

Listing Page

H.1 Sample Control Data File 'CONTRL' -

Selected Heating And Cooling Ambients With

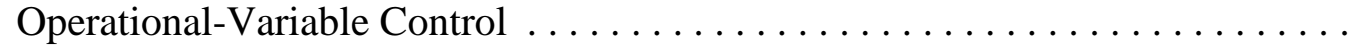

H.2 Annotated Sample Control Data File 'CONTRL' -

Selected Heating and Cooling Ambients With

Operational-Variable Control . . . . . . . . . . . . . . . . . . . 


\section{THE ORNL MODULATING HEAT PUMP DESIGN TOOL - \\ MARK IV USER'S GUIDE}

\section{EXECUTIVE SUMMARY}

The ORNL Modulating Heat Pump Design Tool consists of a Modulating HPDM (Heat Pump Design Model) and a parametric-analysis (contour-data generating) front-end. Collectively the program is also referred to as MODCON which is in reference to the modulating and the contour data generating capabilities. The program was developed by Oak Ridge National Laboratory for the Department of Energy to provide a publicly-available system design tool for variable- and singlespeed heat pumps.

\section{Overview Of New Features}

MODCON predicts the steady-state heating and cooling performance of variable-speed electricdriven vapor compression air-to-air heat pumps for a wide range of system configuration and operational variables. Engine-driven vapor-compression heat pump systems can also be modeled with appropriate engine models supplied by the user. The present model is an extension of the (single-speed) ORNL Mark III HPDM (Fischer and Rice 1988) with the following key additional capabilities and improvements:

- variable-speed electric-driven compressors and/or fans with four levels of drive technology,

- substantially improved and extended air-side heat exchanger correlations for modulating applications,

- a refrigerant charge inventory option allowing the user to either specify or determine the required charge,

- provision for variable-opening flow controls used in modulating heat pumps, e.g., pulse-width-modulated (PWM) valves, stepper motors, thermal electric valves (TEV's) and thermal expansion valves (TXV's),

- provision for input selection of refrigerant and the addition of R134a to the refrigerant choices, and

- automated means to conduct parametric performance mappings of selected pairs of independent design variables. 
The user can generate steady-state performance data sets at fixed ambients or as a function of ambient temperature. The range of selection options includes:

- 52 design and control variables for parametric analysis,

- 8 user-defined operational control relationships as functions of compressor speed or ambient temperature, and

- $\quad$ over 100 possible heat pump model output parameters.

Basic modulating compressor performance is represented by the use of performance maps at discrete speeds with interpolations and extrapolations as necessary to represent a continuous range of speed control. Continuously-variable-speed operation of both induction-motor and electronicallycommutated-motor (ECM) types are modeled. Compressor motor performance of both types can be simulated based on a specified motor size or, alternatively, each motor can be sized automatically by the model to operate at a required percentage of rated load.

For modulating blowers and fans, required modulated power can be computed from first principles or referenced to a specified nominal power at design speed. For ECM blowers and fans, a full range of motor sizing options is also available.

The combination of the above capabilities provides a general tool for system configuration design and operational control of variable-speed heat pumps. The tool can be used to automate the generation of extensive simulation datasets for design studies. These datasets, once generated, can be accessed independently by other engineers to plot and analyze selected dependent performance variables of interest in two- or three-dimensional space. The program execution time is sufficiently fast so that a parametric evaluation in two variables can be performed in less than 30 seconds on a Pentium III, $300 \mathrm{MHZ}$ PC. An example of the use of the model for a complete design analysis of a ECM-driven variable-speed system is given by Rice (1992).

\section{Validations and Applications}

Modulating model validations were conducted on an initial version of the ORNL Modulating HPDM using measurements on a modified commercially-available variable-speed heat pump tested at ORNL. The model was compared to experimental trends with respect to compressor and indoor blower speeds and also the basis of absolute COPs and capacities. The trends in COP and capacity were generally well predicted as reported by Miller (1988a).

The results of the absolute comparisons over a range of speeds and ambients indicated that best model agreement was obtained at the lower speeds in both heating and cooling mode, with increasing performance overpredictions (to maximums of about $10 \%$ in both COP and capacity) occurring at higher speeds. This increase in model overprediction with speed occurs because of limitations of the simplified models of refrigerant circuitry with the higher subcooled (and/or superheated), more heavily loaded heat exchanger conditions. 
Different versions of the single-speed model have been validated by various researchers for both single-speed and dual-stroke heat pumps. The single-speed model has also been used by others in the simulation of variable-speed engine-driven heat pumps (Fischer 1986b, Monahan 1986, and Rusk 1990). With one exception, the validations of the original single-speed version in both nonmodulating and modulating applications of sizes from 2 to 10 tons capacity have been reported as satisfactory to excellent.

The electric-driven version has been used as 1) an aid in the experimental evaluation of optimal hardware control, 2) as a tool to determine potential performance levels for residential unitary equipment, and 3) as a tool to assess the potential of variable-speed drives for commercial unitary equipment.

The program has also been modified to be used with newer HFC refrigerant alternatives such as R134a. With this capability, the ORNL Modulating Heat Pump Design Tool is ready to be utilized for the equipment redesign issues facing heat pump manufacturers in the coming decade.

\section{VARIABLE-SPEED COMPRESSORS}

\section{Basic Compressor Representation}

Manufacturers' compressor performance maps based on calorimeter tests are the starting point for the modulating compressor model. These maps at a given drive frequency are functions of compressor inlet and exit conditions - typically defined by evaporating and condensing saturation temperatures and suction superheat. The map-based option for compressor representation is the only choice developed for the modulating model (the other possible choice being the loss-and-efficiency model discussed previously in the ORNL report by Fischer and Rice 1983). Positive displacement compressors of reciprocating, rotary, and scroll type for which manufacturers' map data are available can be modeled. Single-speed, multiple-speed, and continuously-variable-speed compressors can be accommodated if the appropriate performance maps are available.

With some adjustments, both low and high-side-cooled compressors with varying amounts of suction superheat can be handled. As in earlier versions of the ORNL HPDM, the default suction gas superheat corrections are somewhat specific to reciprocating compressors but can be generalized by suitable adjustment of superheat correction factors set in BLOCK DATA. These corrections as well as newer adjustments for motor efficiency effects on suction gas superheat assume low-side motor cooling as the default. However, this assumption can also be changed by suitable adjustment of BLOCK DATA parameters.

\section{Modulating Compressor Performance}

Compressor performance as a function of speed is represented by the use of maps at discrete frequencies with interpolations and extrapolations as necessary to represent a continuous range of speed control. The modulating HPDM requires the user to input compressor map-based coefficients for power and mass flow rate (or alternatively, for derived isentropic and volumetric efficiency based 
on compressor shell conditions) as functions of operating conditions at each speed for which sufficient data are available.

In cases where minimal data are available, curve fits to the derived efficiency values have been found to often give more reliable interpolations and extrapolations over speed than similar representations based on basic power and mass flow data. All the curve fit representations are biquadratic functions of condenser and evaporator saturation temperatures except for volumetric efficiency. Because of this, all extrapolations of polynomial curve fits are inherently suspect and should be tested for acceptable behavior outside of the fitting data range. The latter is a linear function of pressure ratio and a quadratic function of discharge pressure. The specific forms of the curve-fitting equations are given in Table B.1 describing the required heat pump specification file. Further description of the power and mass flow rate equations can be found in the ORNL report by Fischer and Rice (1983).

The interpolations in power and refrigerant mass flow rate (or in isentropic and volumetric efficiency) are presently done linearly with frequency. This can be rather easily changed to quadratic if desired by changing the value of NPT from 2 to 3 in the CMPMAP subroutine. Extrapolations, if necessary, are always done linearly.

\section{Compressor Map-Fitting Program}

A compressor-map-fitting program is provided with the HPDM to fit compressor manufacturers' available map data into either of the above representations. Appendix G describes the input data and format requirements for the curve-fit program. Sample plots of curve fits by the two methods to compressor data of a specified frequency of $30 \mathrm{~Hz}$ are shown in Figures 1 - 4. In Figures 5-9, curve fits to isentropic efficiency at other frequencies $(20,45,60,75$, and $90 \mathrm{~Hz})$ are shown. All plots are for a reference sine-wave-driven, induction motor (SWDIM) compressor calorimeter-tested at ORNL by Miller (1989) and supplemented by data provided by the manufacturer. The curve-fit coefficients for this compressor are included in the sample data sets of Appendix B.

The map-fitting program also prints tabular results comparing the individual data points to their corresponding curve fit values. Additional tables are generated for the direct power and mass flow rate curve-fits showing the differences between the resultant isentropic and volumetric efficiencies versus the values derived directly from the map data. With this information, the user can judge which curve-fitting approach is more suitable for their data.

The map-fitting program can be run for any number of speeds and will create a data file of curve-fit coefficients of the format required by the heat pump specification file. This file can be imported into an existing heat pump data file with only minor editing required. The program can also convert the maps to superheat or return gas temperature conditions other than those for which compressor map data are available. 
RECIP VS-A/2.75 COMPRESSOR PERFORMANCE, DATA AND FIT, $30 \mathrm{HZ}$ ISENTROPIC EFFICIENCY
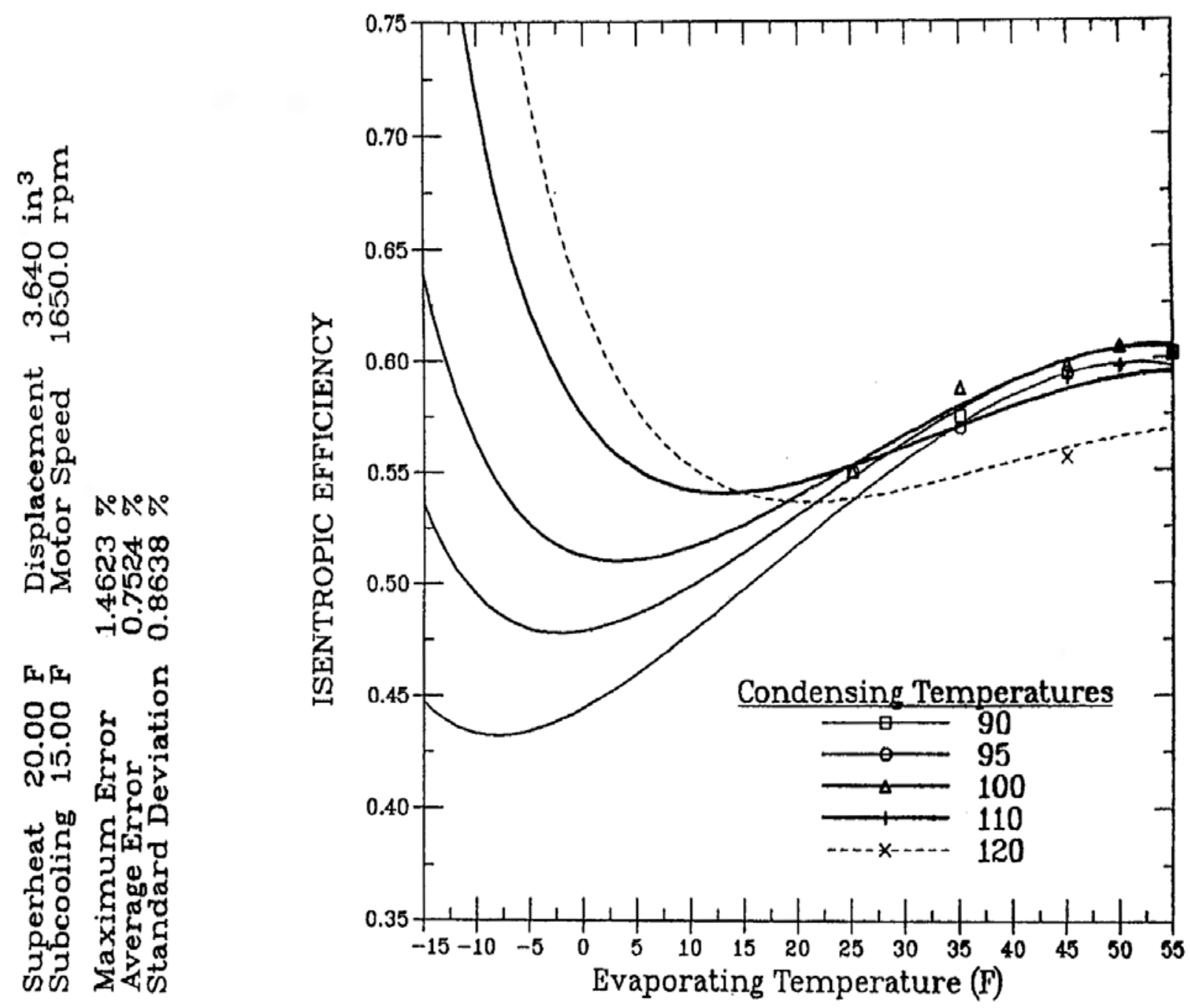

Figure 1. Compressor Isentropic Efficiency As a Function of Evaporating and Condensing Temperatures At $30 \mathrm{~Hz}$ Frequency — From Curve-Fits To Basic Power and Refrigerant Mass Flow Rate Data. 
RECIP VS-A/2.75 COMPRESSOR PERFORMANCE, DATA AND FIT', $30 \mathrm{HZ}$ VOLUMETRIC EFFICIENCY
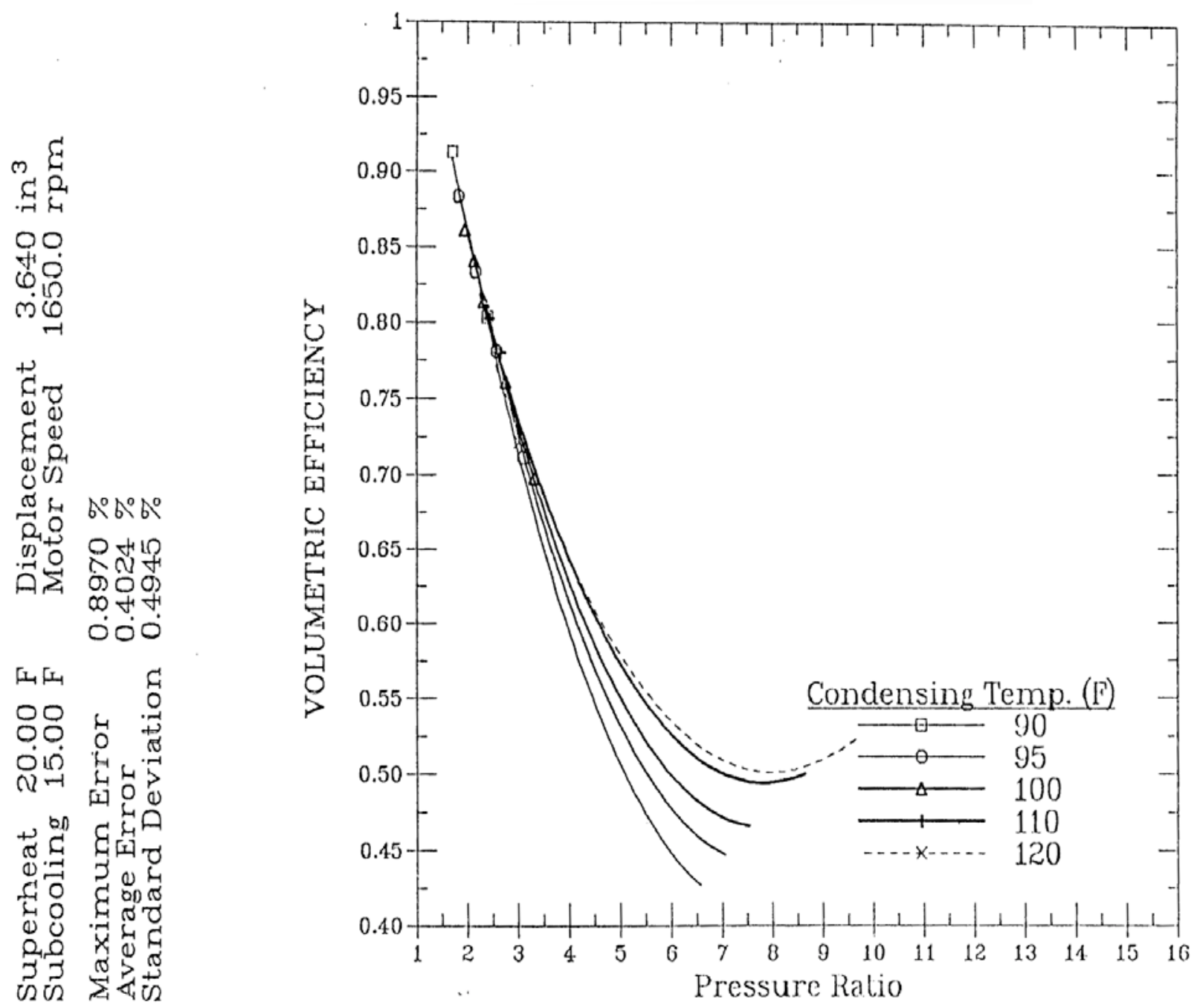

Figure 2. Compressor Volumetric Efficiency As a Function of Pressure Ratio and Condensing Pressure At $30 \mathrm{~Hz}$ Frequency — From Curve-Fits To Basic Power and Refrigerant Mass Flow Rate Data. 
RECIP VS-A/2.75 COMPRESSOR PERFORMANCE, RAW DATA AND FIT, $30 \mathrm{HZ}$ ISEN'TROPIC EFFICIENCY

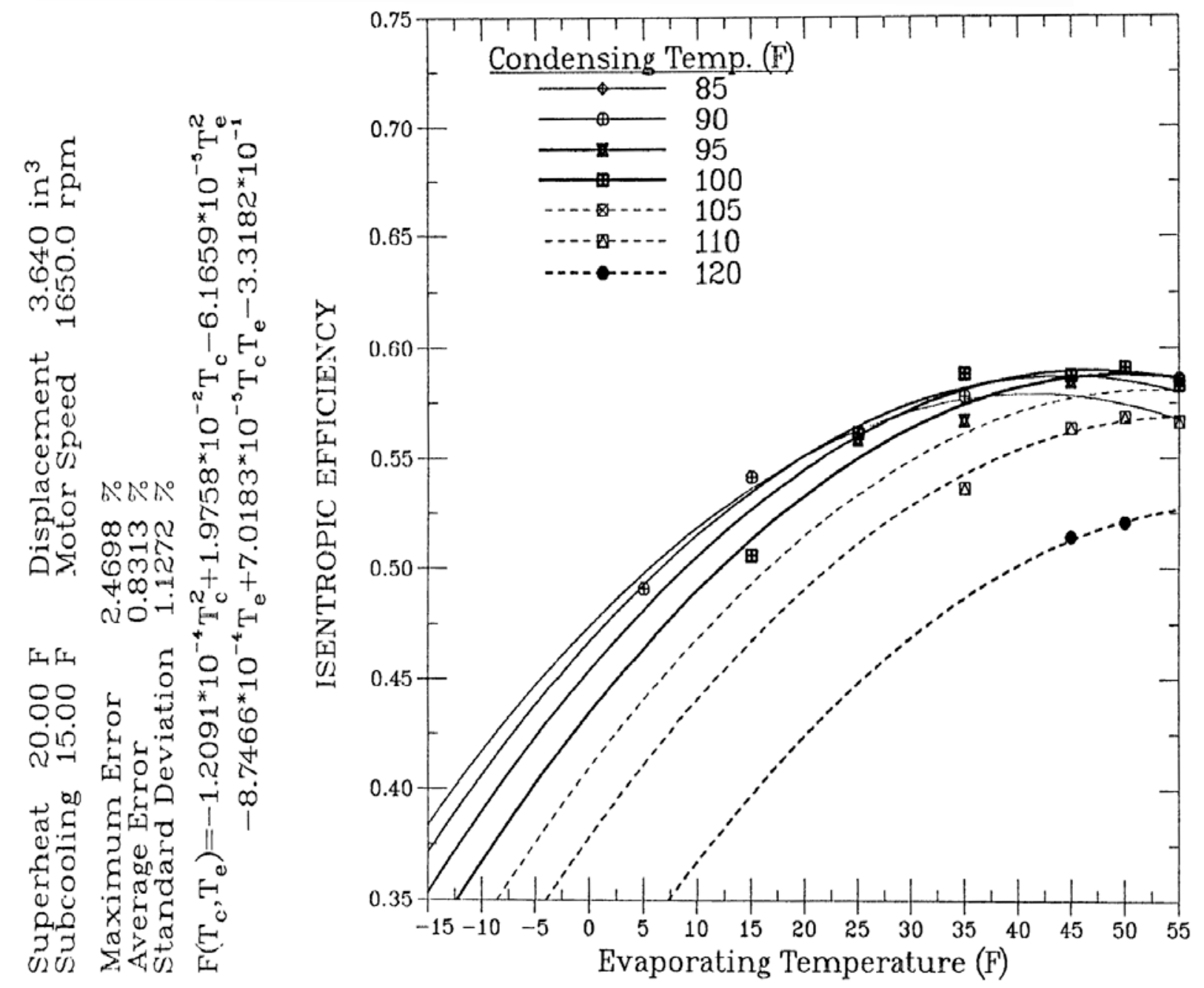

Figure 3. Compressor Isentropic Efficiency As a Function of Evaporating and Condensing Temperatures At $30 \mathrm{~Hz}$ Frequency — From Curve-Fits To Derived Isentropic Efficiency Values. 
RECIP VS-N/2.75) COMPRESSOR PERFORMANCE, RAW DATA AND FIT, $30 \mathrm{HZ}$ VOLUMETRIC EFFICIENCY
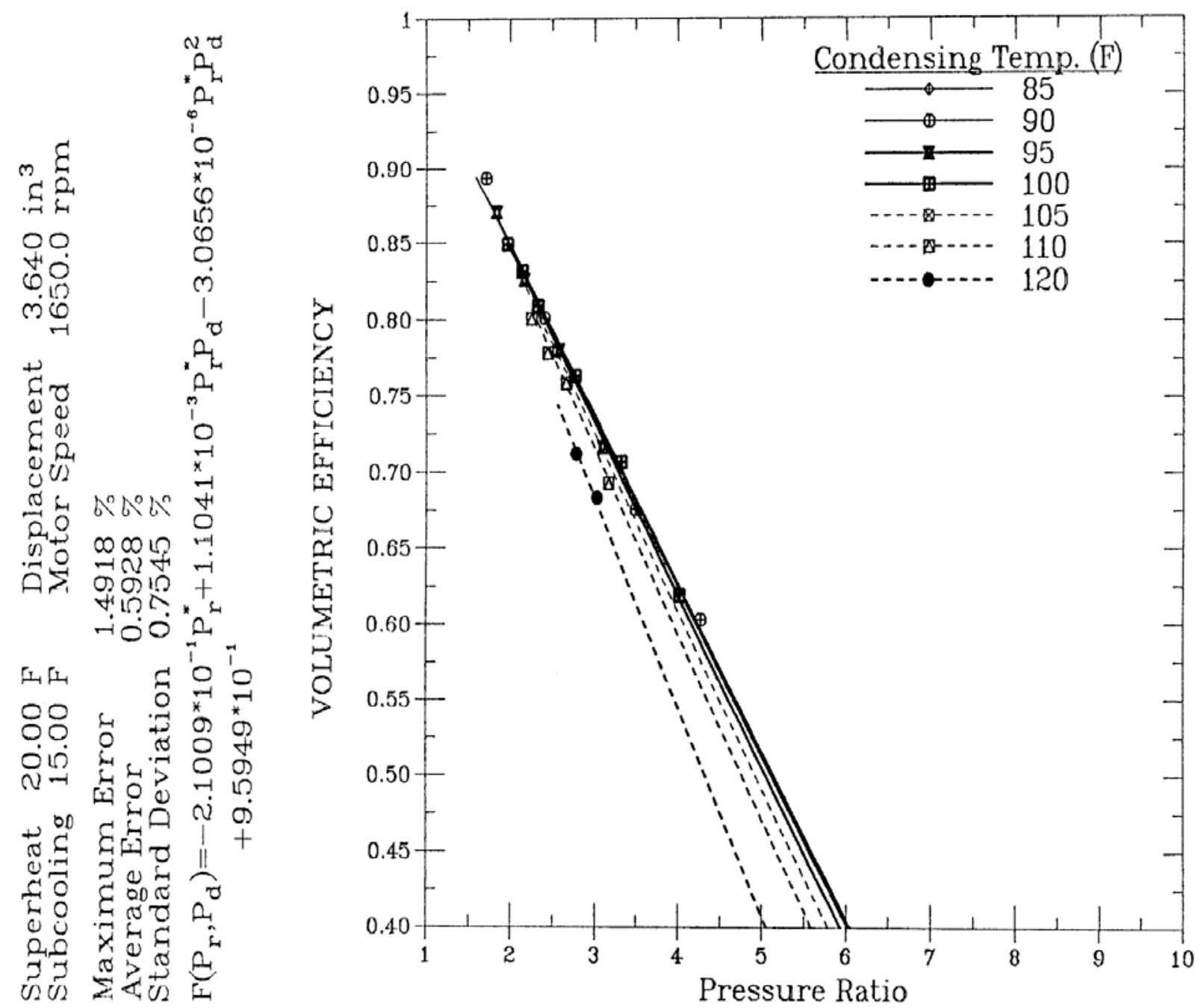

Figure 4. Compressor Volumetric Efficiency As a Function of Pressure Ratio and Condensing Pressure At $30 \mathrm{~Hz}$ Frequency — From Curve-Fits To Derived Volumetric Efficiency Values. 
RECIP VS-A/2.75 COMPRESSOR PERFORMANCE, RAW DATA AND FIT, $20 \mathrm{HZ}$ ISENTROPIC EFFICIENCY

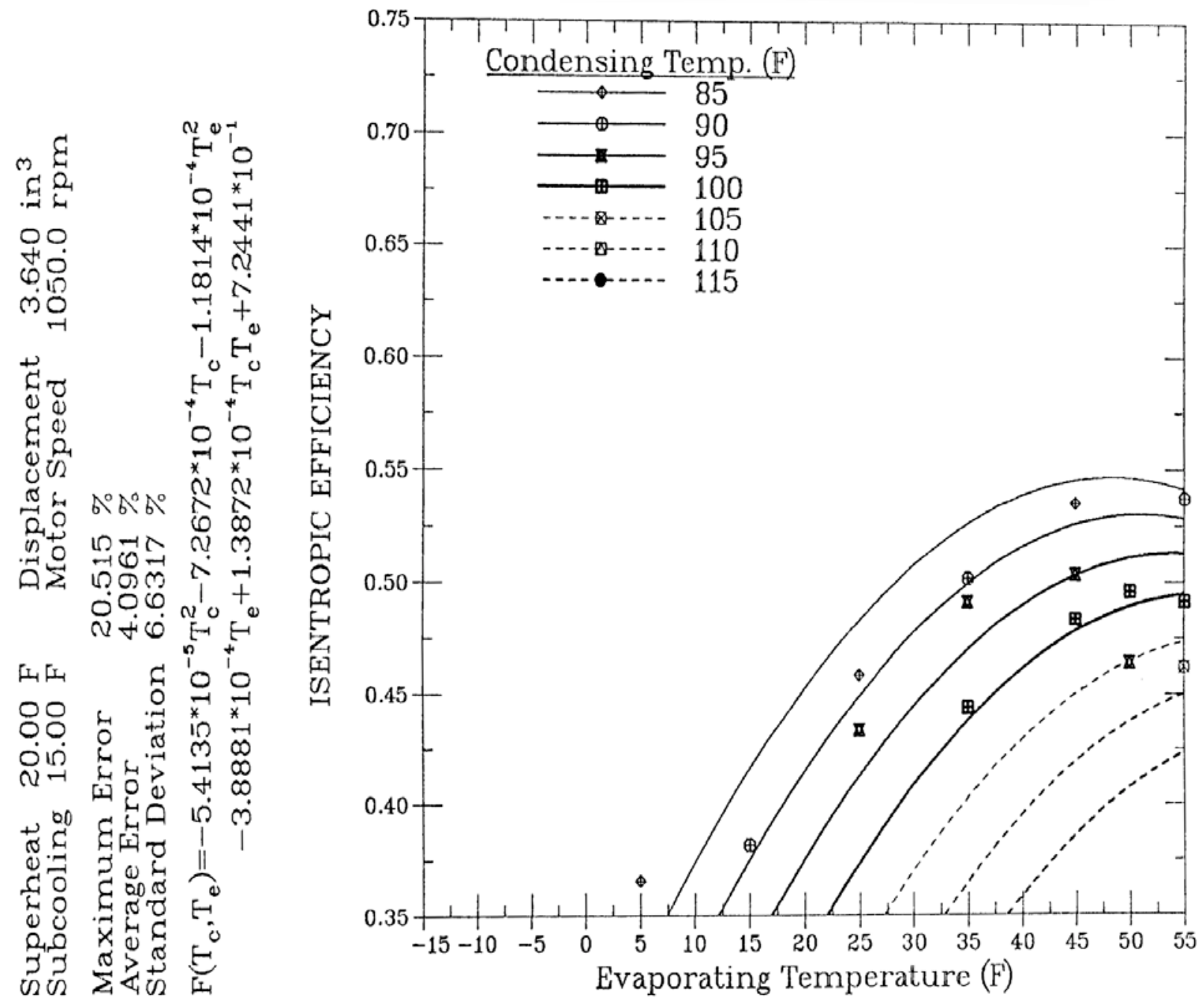

Figure 5. Compressor Isentropic Efficiency As a Function of Evaporating and Condensing Temperatures At $20 \mathrm{~Hz}$ Frequency — From Curve-Fits To Derived Isentropic Efficiency Values. 
RECIP VS-A/2.75 COMPRESSOR PERFORMANCE, RAW DATA AND FIT, 45 HZ ISENTROPIC EFFICIENCY

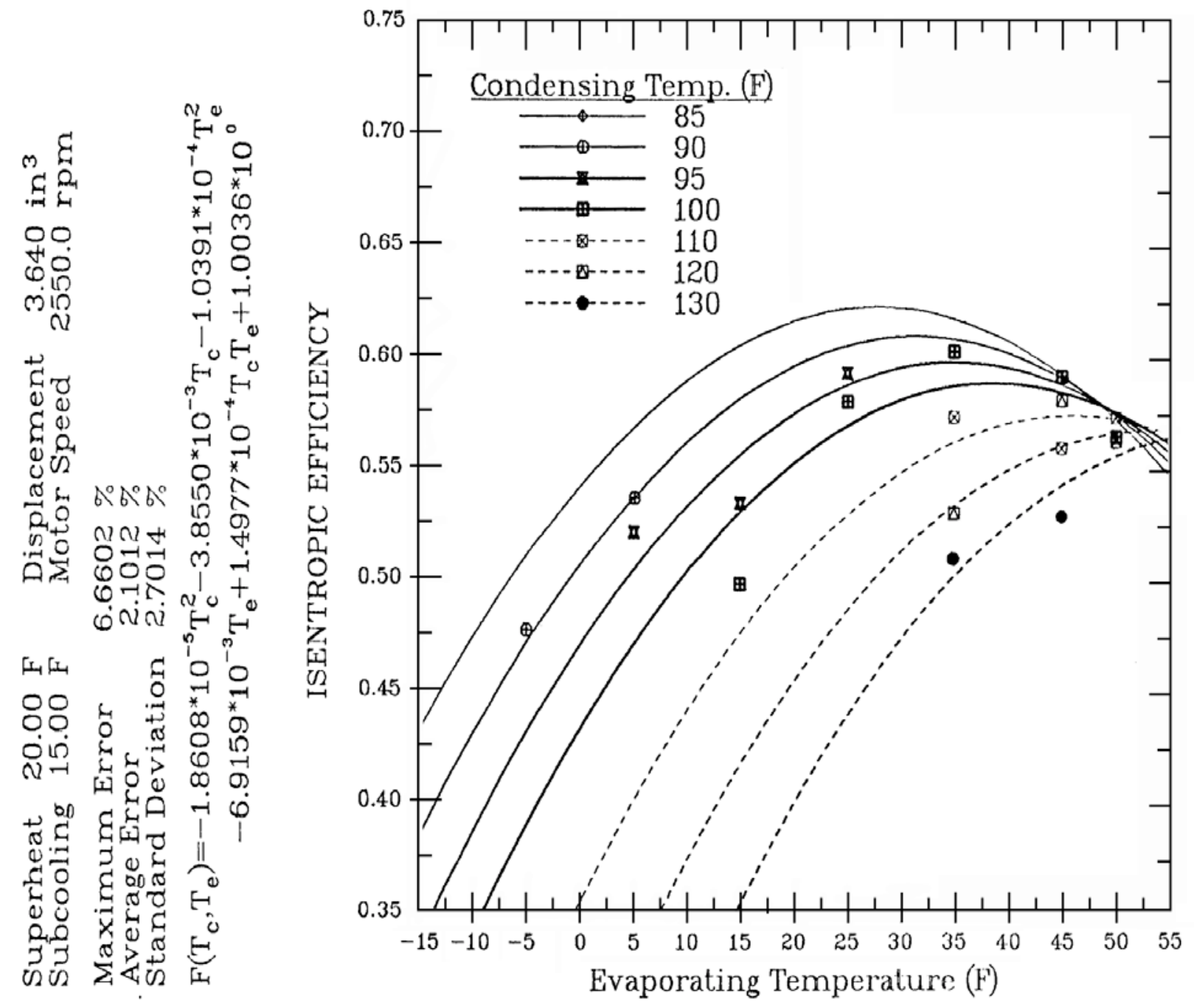

Figure 6. Compressor Isentropic Efficiency As a Function of Evaporating and Condensing Temperatures At $45 \mathrm{~Hz}$ Frequency — From Curve-Fits To Derived Isentropic Efficiency Values. 
RECIP VS-A/2.75 COMPRESSOR PERFORMANCE, RAW DATA AND FIT, $60 \mathrm{HZ}$ ISENTROPIC EFFICIENCY

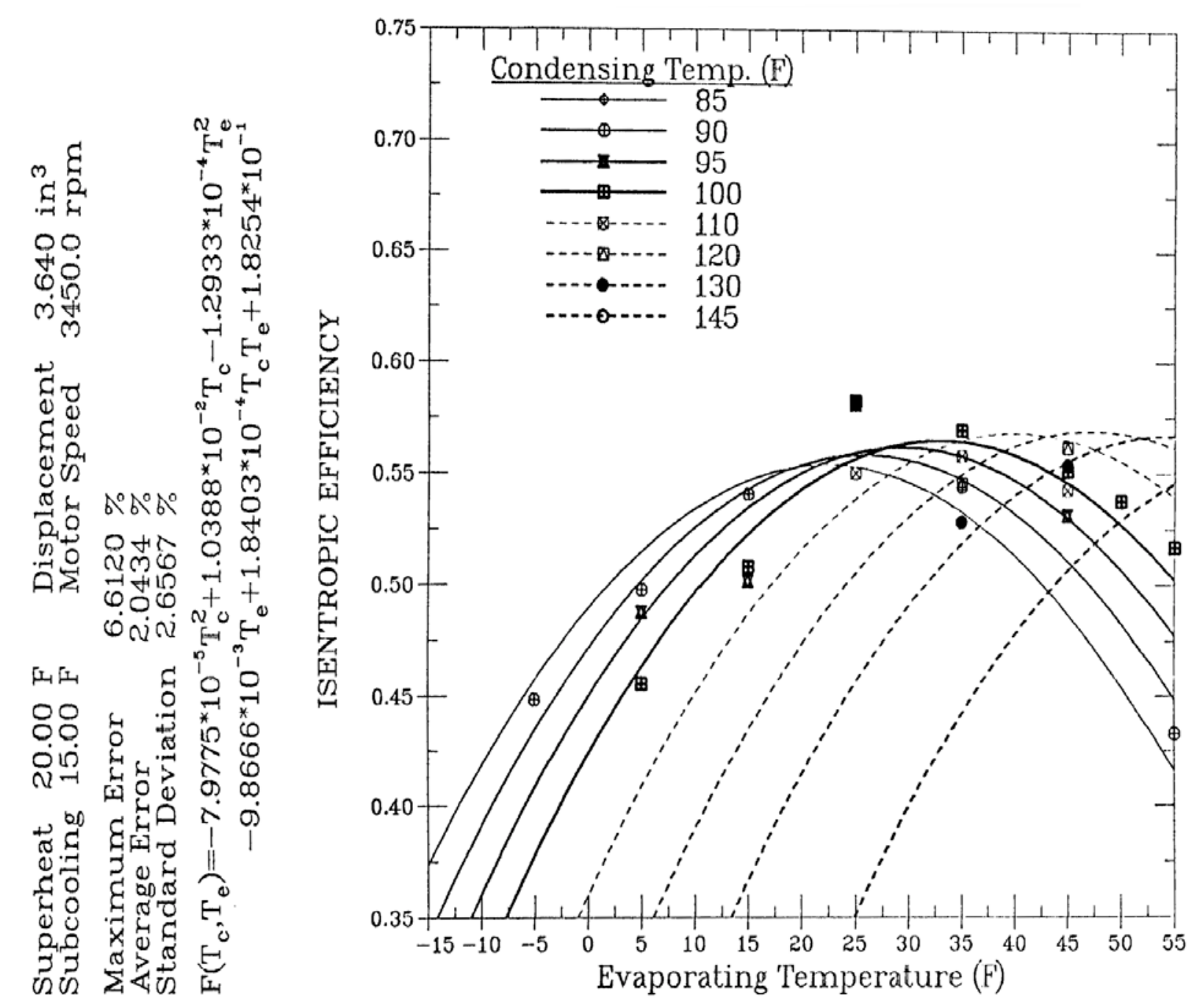

Figure 7. Compressor Isentropic Efficiency As a Function of Evaporating and Condensing Temperatures At $60 \mathrm{~Hz}$ Frequency — From Curve-Fits To Derived Isentropic Efficiency Values. 
RECIP VS-A/2.75 COMPRESSOR PERFORMANCE, RAW DATA AND FIT, 75 HZ ISENTROPIC EFFICIENCY

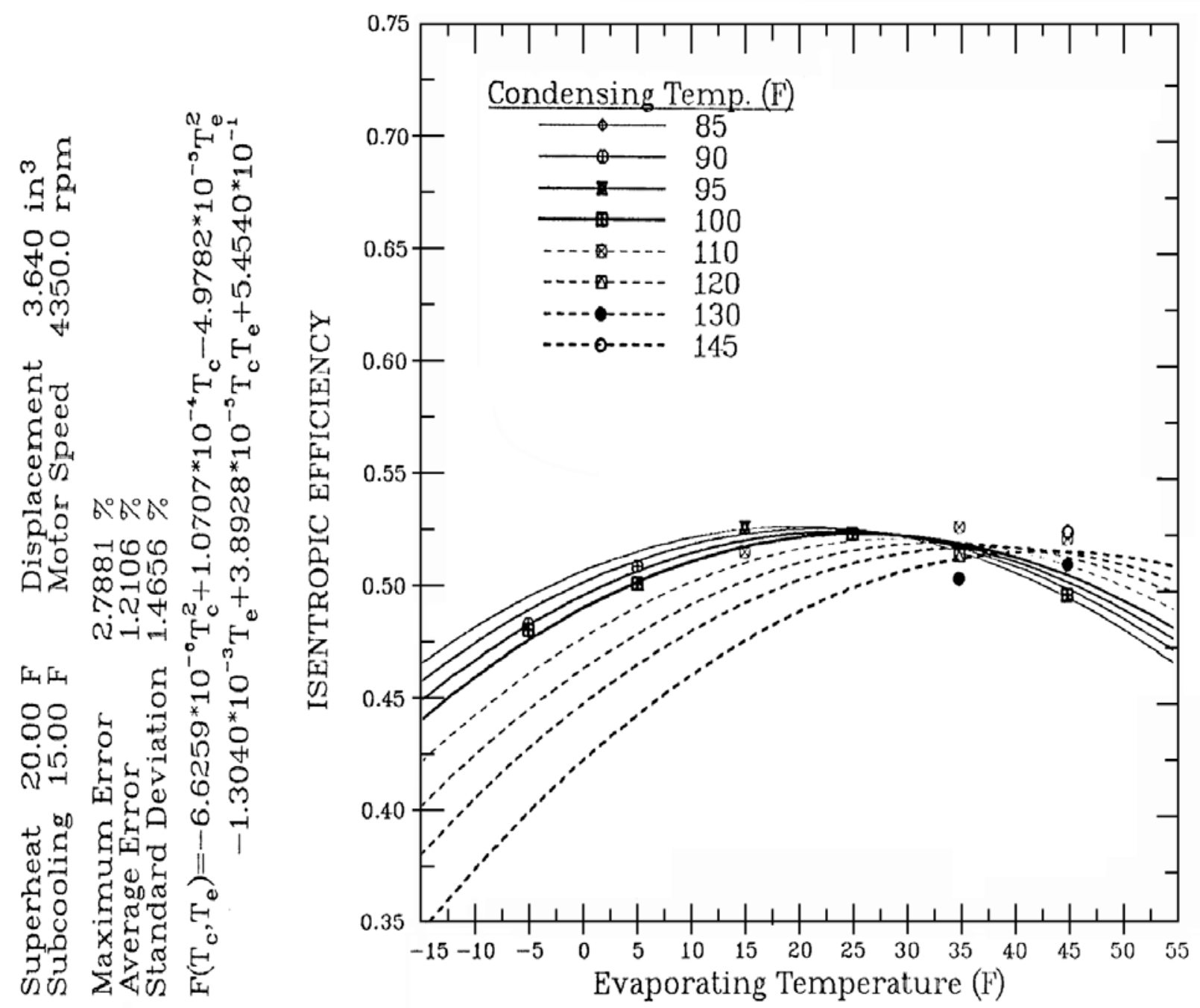

Figure 8. Compressor Isentropic Efficiency As a Function of Evaporating and Condensing Temperatures At $75 \mathrm{~Hz}$ Frequency — From Curve-Fits To Derived Isentropic Efficiency Values. 
RECIP VS-A/2.75 COMPRESSOR PERFORMANCE, RAW DATA AND FIT, $90 \mathrm{HZ}$ ISENTROPIC EFFICIENCY

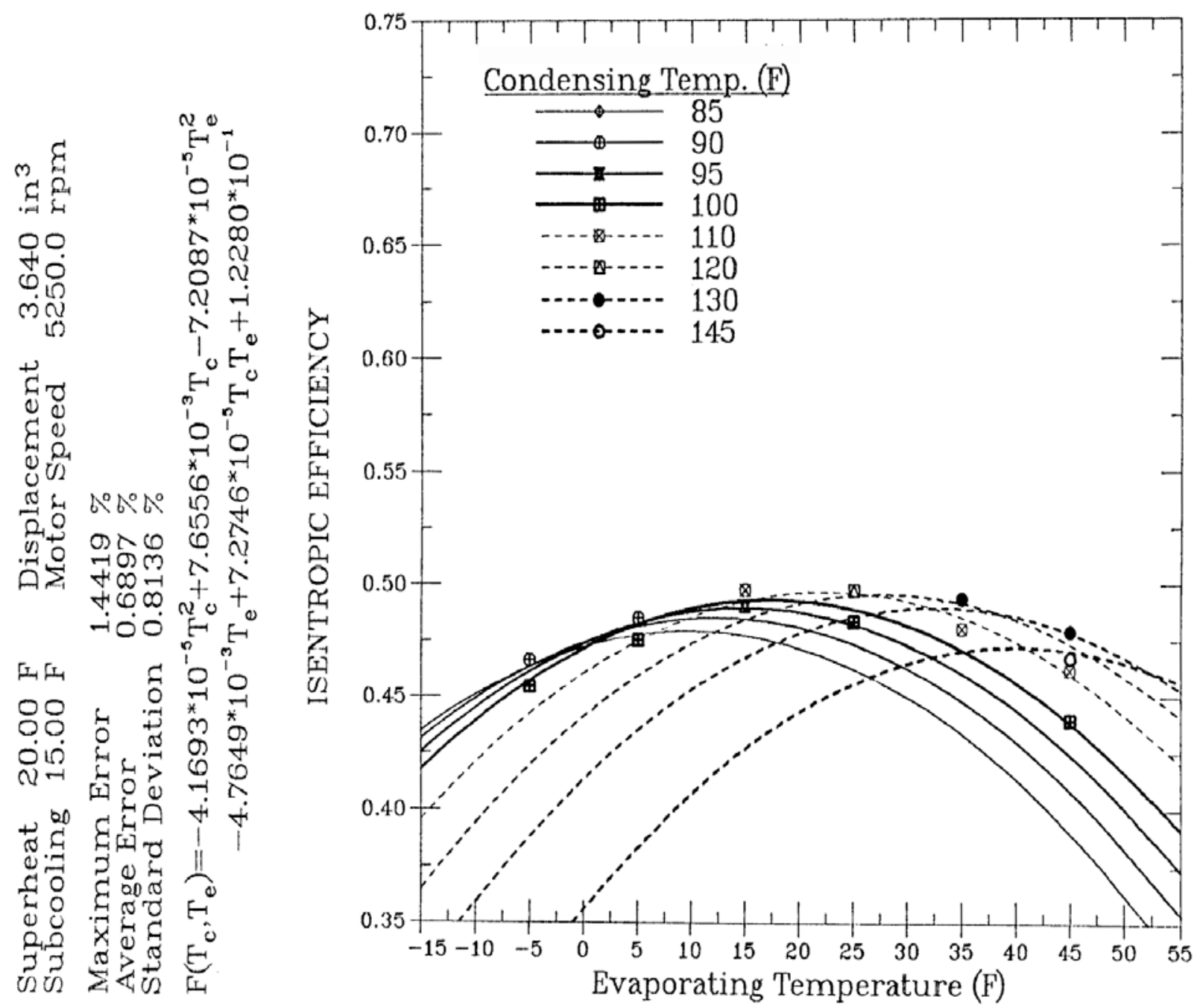

Figure 9. Compressor Isentropic Efficiency As a Function of Evaporating and Condensing Temperatures At $90 \mathrm{~Hz}$ Frequency — From Curve-Fits To Derived Isentropic Efficiency Values. 


\section{Modulating Drive Options}

Drive Efficiency Options. Four drive efficiency conversion options are available in the program. They are:

1) a moderate-efficiency inverter drive (first-generation IDIM),

2) a high-efficiency inverter drive (state-of-the-art IDIM),

3) an ideal sine-wave-driven induction motor (SWDIM) [limiting case for modulating induction motor],

4) an electronically commutated motor (ECM)

The user-supplied compressor data can be for an inverter-driven system (either IDIM or ECM) or for a reference SWDIM compressor. The user selects whether this base compressor map is to remain unmodified or be converted to one of the above drive types.

If a conversion is to be made, the user must be especially careful to properly identify the supplied map with one of the four types so that the most accurate conversion is made. The potential error involved in such conversions is reduced if the base map data is for a SWDIM drive. This is typically obtained by testing the compressor with a variable-frequency motor-generator set. The SWDIM option is also useful in evaluating the total system loss resulting from the direct (inverter) and indirect (increased motor inefficiency and suction gas superheat) losses of inverter-driven induction motors.

IDIM Correction Factors. Efficiency reduction factors for first-generation IDIMs were based on comparative 2.75 -ton hermetic reciprocating compressor tests using alternately a voltage-sourceinverter (VSI) and a motor-generator (m-g) set (the SWDIM reference) as described by Miller (1988b). From these tests conducted at representative modulating conditions, the following efficiency multipliers of Table 1 were determined for the combined motor and inverter efficiency of first-generation IDIMs relative to SWDIM efficiency:

Table 1. Efficiency Degradation Multipliers For Compressor First-Generation IDIMs

\begin{tabular}{ccc}
\hline Drive Frequency & Heating Mode & Cooling Mode \\
\hline 15 & 0.621 & 0.625 \\
30 & 0.784 & 0.809 \\
45 & 0.840 & 0.860 \\
60 & 0.868 & 0.841 \\
75 & 0.878 & 0.83 (est.) \\
90 & 0.879 & 0.82 (est.) \\
\hline
\end{tabular}


By the nature of the tests, these factors include any suction gas heating differences between the two drive types.

Similar multipliers were developed for the state-of-the-art IDIM option using bench efficiency data on high-efficiency VSI inverter drives and model simulations of the corresponding reference SWDIM efficiency — both obtained from Lloyd (1987). The efficiency degradation multipliers obtained from this information in shown in Table 2.

\section{Table 2. Efficiency Degradation Multipliers For} Compressor SOA IDIMs

\begin{tabular}{ccc}
\hline Drive Frequency & Heating Mode & Cooling Mode \\
\hline 15 & 0.82 (est.) & 0.78 (est.) \\
30 & 0.87 & 0.872 \\
45 & 0.908 & 0.915 \\
60 & 0.921 & 0.919 \\
75 & 0.929 & 0.920 (est.) \\
90 & 0.946 & 0.920 (est.) \\
\hline
\end{tabular}

By the nature of this data, these factors do not include any suction gas heating differences between the two drive types - although as these degradation factors are closer to unity, this secondary effect would be expected to be small. In all the above cases, the motors were 2-pole with nominal speeds of $3450-3500 \mathrm{rpm}$.

Induction-Motor (IM) to ECM Conversion. The user can have the program simulate the replacement of the drive used in an IDIM or SWDIM compressor drive with a PM-ECM drive. This replacement option will allow the same basic modulating compressor characteristics to be applied with a different drive characteristic. In this way, calorimeter data with existing compressors and drives can be used with more advanced drive combinations.

Most compressor maps are available only for induction-motor (IM) drives. Many of these are for single-speed motors (equivalent to the SWDIM option but only for one or at most two frequencies, i.e., 50 and $60 \mathrm{~Hz}$ ). The variable-speed compressor data are usually for IDIMs of either the PWM or VSI type. Variable-speed SWDIM data are rather scarce. However, as this latter type of data has fewer uncertainties with regard to the level of inverter-waveform-related losses, it is preferred for cases where a conversion of motor type is required.

To make such a conversion, it was necessary to provide to the model representative SWDIM and ECM performance at least as a function of drive frequency. However, to avoid having to preselect an appropriate torque vs speed profile for the drives and to further provide for motor sizing generality, complete mappings of representative SWDIM and ECM performance as a function of normalized drive frequency and torque were incorporated. 
SWDIM Performance. Performance information on a representative sine-wave-driven induction motor were obtained from Zigler (1987). He generated simulated sine-wave performance maps on an existing variable-speed motor for which the basic motor characteristics were well known and for which standard motor efficiency test data were available at the standard motor rating temperature of $77^{\circ} \mathrm{F}\left(25^{\circ} \mathrm{C}\right)$.

From these empirical simulations, motor efficiency and slip were provided for a $2.75 \mathrm{hp}(2.05 \mathrm{~kW})$, 2-pole, 3-phase motor over a range of frequencies from 15 to $90 \mathrm{~Hz}$, a range of torques from 20 to $200 \%$ of nominal, and a range of voltages from $90 \%$ to $110 \%$ of nominal. Nominal torque was at $60 \mathrm{~Hz}$ frequency $(3450 \mathrm{rpm})$. All simulated values were for estimated typical rotor and stator temperatures in a hermetic compressor environment. Motor windage and friction losses were not included in the motor efficiency values. Contour plots of the SWDIM performance mappings for motor efficiency and slip are shown in Figures 10 and 11.

To provide further analysis flexibility, the motor data were generalized in the model to apply to a normalized speed range of 25 to $150 \%$ of nominal and for motor sizes other than the original $2.75 \mathrm{hp}$ $(2.05 \mathrm{~kW})$. However, the original basis for the data are provided here so that users can make their own judgements as to whether or not such generalizations are sufficiently accurate for their specific analysis purposes.

The SWDIM motor for which data were provided was, in fact, the same model motor used in the reference SWDIM compressor tested by Miller (1989). Therefore, when used together, these two data sets provide a most consistent basis for extraction of the SWDIM performance and replacement with ECM efficiency characteristics.

ECM Performance. Dynamometer performance data were obtained from Young (1990) on a production 4-pole, $3 \mathrm{hp}(2.24 \mathrm{~kW}) \mathrm{ECM}$ for a range of compressor speed and torque. As there is no motor slip in an ECM motor, speed is directly proportional to drive frequency. Therefore, for ECMs, only motor efficiency as a function of speed and torque is needed to characterize motor performance.

The range of motor speed was from 1000 to $6250 \mathrm{rpm}$ with a nominal speed of 5400 for a normalized speed range of 0.2 to 1.15 of nominal. The torque range was from about 20 to $190 \%$ of the nominal value. No windage and friction losses were included as for the SWDIM case; however, estimated magnetization losses due to the permanent magnet rotor were included.

Similarly as for the SWDIM motor data, the ECM performance data were generalized to apply for nominal speeds and motor sizes other than that for which the data were available. Contours of compressor ECM drive efficiency as a function of speed and fractional load are shown in Figure 12.

ECM Operating Temperature Corrections. The ECM data were taken at the standard motor rating temperature of $77^{\circ} \mathrm{F}\left(25^{\circ} \mathrm{C}\right)$. Therefore, to properly apply the data to a hermetic application, correction factors for motor temperature effects were developed. These were based on information provided by Zigler (1987) and supplemented by Young (1990) and are functions of stator and rotor temperature, winding resistances, the motor current vs torque relationship, and magnet flux temperature coefficients. Appropriate values for these parameters are specified in BLOCK DATA 


\section{MOTOR EFFICIENCY (\%) -- REFERENCE 3-PHASE, 2.75 HP COMPRESSOR SWDIM}

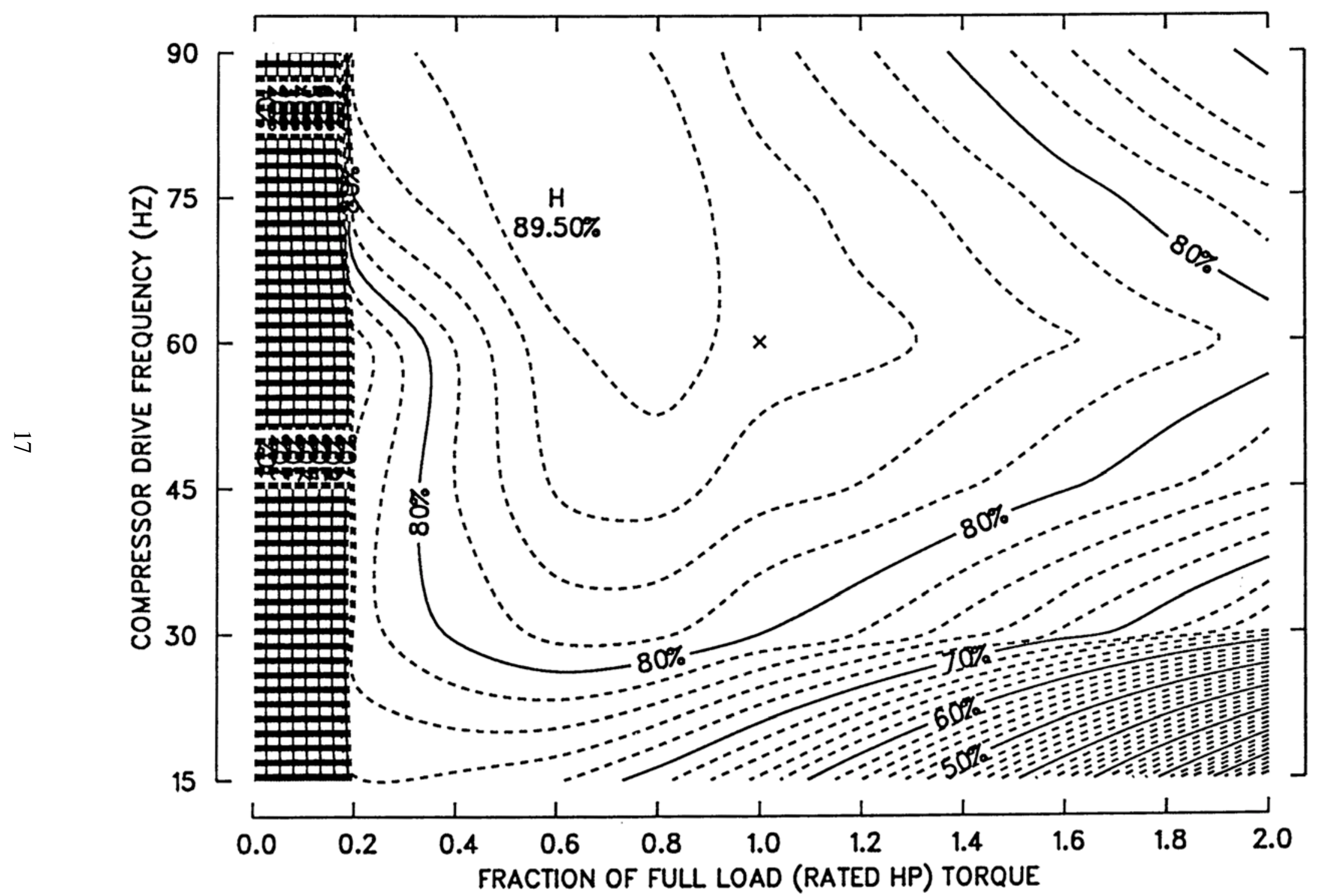

Figure 10. Modulating, Sine-Wave-Driven, Induction Motor (SWDIM) Efficiency — Reference 3-Phase, 2-Pole, 2.75 Hp Compressor Motor. 
SLIP DIFFERENCE (RPM) -- REFERENCE 3-PHASE, 2.75 HP COMPRESSOR SWDIM

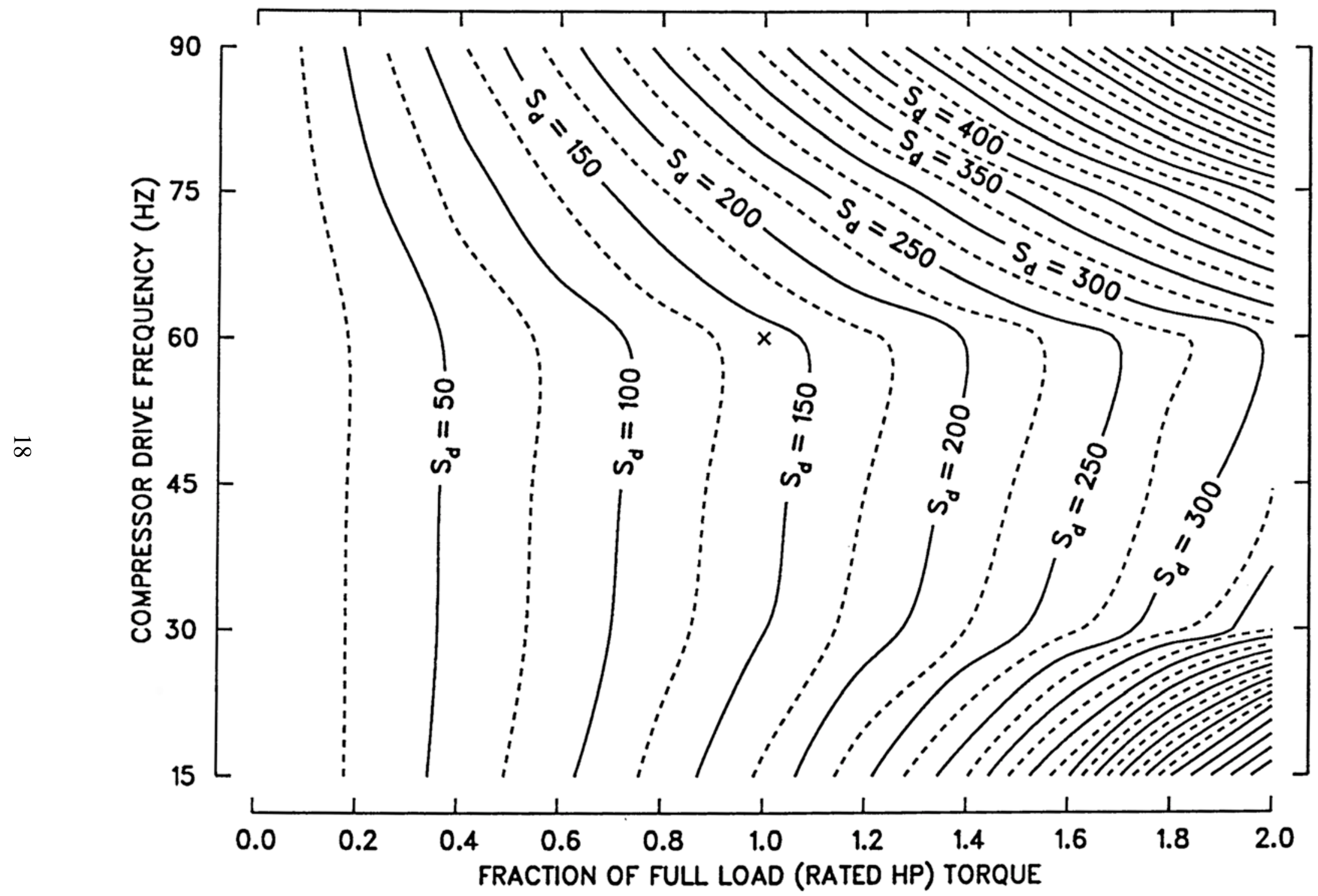

Figure 11. Modulating, Sine-Wave-Driven, Induction Motor (SWDIM) Slip Difference - Reference 3-Phase, 2-Pole, $2.75 \mathrm{Hp}$ Compressor Motor. 


\section{MODULATING-DRIVE EFFICIENCY -- COMPRESSOR PM-ECM, 4-POLE, 3 HP, NO W/F}

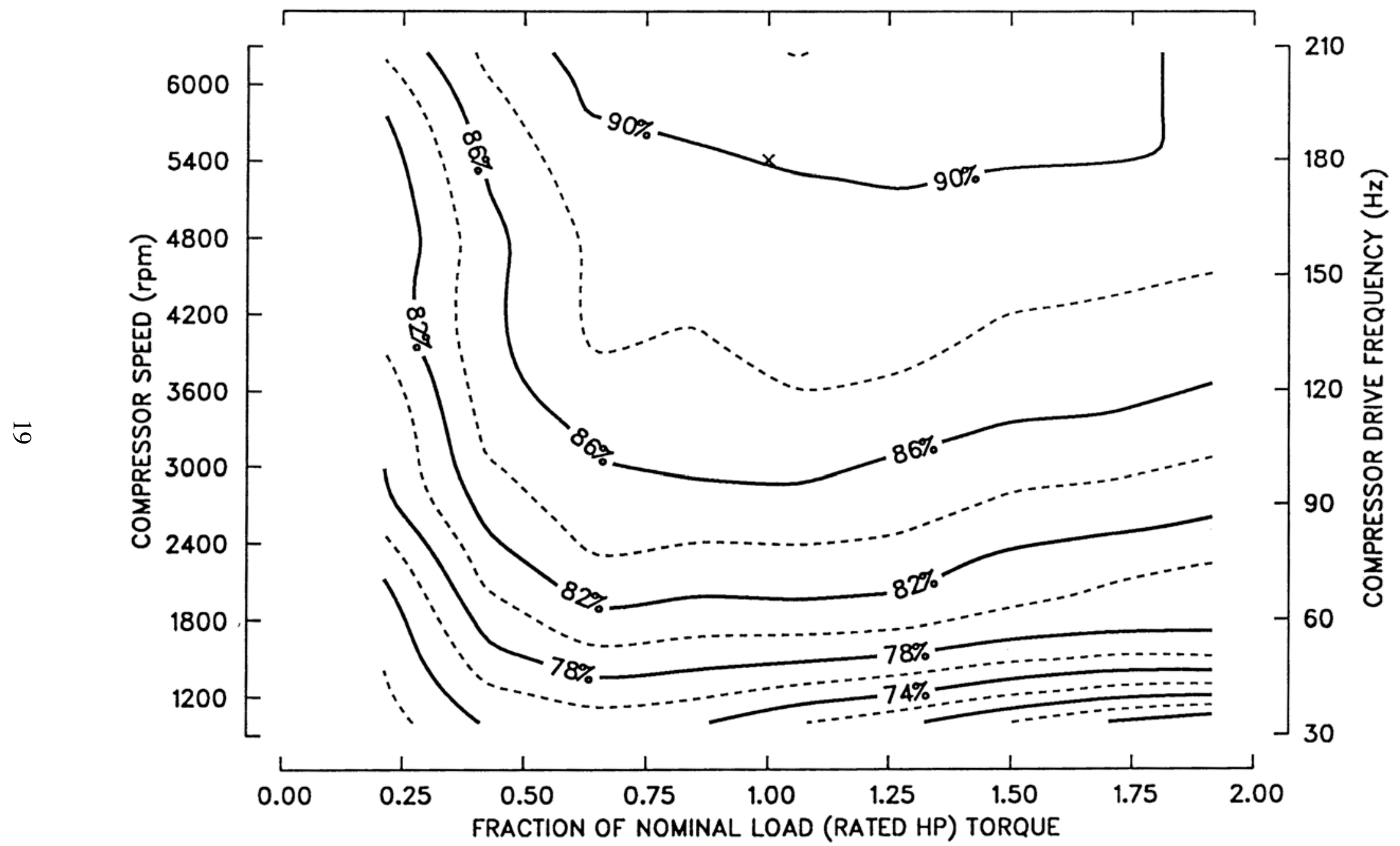

Figure 12. Modulating Drive (Motor and Inverter) Efficiency of a Permanent-Magnet, Electronically-Commutated Motor (PM-ECM) - Reference 3-Phase, 4-Pole, 3 Hp Compressor Motor. 
for two nominal-speed designs; the corrections for other nominal speeds are determined by interpolation.

IM-To-ECM Conversion Procedure. For given compressor operating conditions and operating frequency, the model first calculates the compressor input power for the base compressor map. Given frequency and drive input power, the motor operating speed, torque and efficiency can be found by iteration using the reference SWDIM performance maps (and the efficiency corrections for direct and indirect inverter losses, depending on the type of compressor drive). The computed torque and the specified frequency are next used with the ECM performance map to calculate the efficiency of the replacement motor. This difference in efficiency is then applied to the power requirements predicted from the baseline compressor map. Corrections for the differences in speed between the SWDIM and the ECM operating at the same frequency are also applied to the power and refrigerant mass flow rate values.

Secondary Effects of Reduced Suction Gas Superheating. An approximate method was also developed to adjust for the performance effects of reduced suction gas superheating with the more efficient ECM motor. The reduction in motor losses resulting from the use of a more efficient motor is calculated and an estimated portion of this is used to reduce suction gas heating from a computed baseline level. The effect of this estimated superheat reduction on ideal compression work is applied as a secondary correction ratio to the overall isentropic efficiency. The result is an approximate measure of the compounded benefit of conversion to the more efficient ECM drive.

\section{Motor Sizing/Loading Options}

Compressor motor performance of either IDIM, SWDIM, and ECM types can be simulated based on a specified motor size or, alternatively, each motor can be sized automatically by the model to operate at a required percentage of rated load.

Automatic Motor Sizing. In this option, users can investigate alternative motor sizing choices by directly selecting the degree of loading (percent of rated torque) at which they would like the motor to operate on the appropriate motor efficiency curve. This percentage is then specified in place of motor size and the model will determine the required size to maintain motor operation at this loading.

This approach is advantageous when users know where they would like the motor to operate on its performance curve (i.e., the specific motor sizing strategies they would like to evaluate) and would like to maintain that point (and efficiency) while various system configurations and/or operating variables (such as airflow rates) are being evaluated. Then once the system configuration is decided upon, the program determines the required motor size.

Specified Motor Size. This option is most useful once the motor size has been fixed by a previous design analysis or when only certain sizes are available for consideration. The user directly specifies the desired motor size (in hp) for the selected drive type. The model uses the chosen size along with the selected nominal speed to compute a nominal torque. This rated torque is then compared to the required operating torque to determine the resultant fractional loading on the motor. The motor 
performance curves are then used to determine the motor efficiency and speed (for IMs) at the operating torque and drive frequency ratios.

In this approach, the motor efficiency at a given speed will change as the system configuration and operating conditions change. Specified motor sizes are the preferred approach at off-design conditions during the design process and at all operating conditions once the system design has been finalized. It should be noted that if a compressor base displacement is scaled manually by the user, the specified motor size should be scaled similarly.

A recommended procedure for sizing compressor motors and simulating off-design performance for a modulating application using these options has been presented by Rice (1992).

\section{VARIABLE-SPEED BLOWERS}

\section{Modulating Blower Performance}

Modeling Perspective Relative To That For The Compressor. The modeling of variable-speed drives for blowers and fans is somewhat more straightforward than for compressors. This is because a combined blower(or fan)/motor/drive performance map is not required to be provided by the user as in the case of the compressor. Blower/fan performance is instead handled separately from that of the motor/drive combination.

Whereas compressor efficiency (both isentropic and volumetric) varies with speed, to a close approximation, blower and fan efficiencies remain constant with speed (from the fan laws). Therefore the modeling assumptions and options provided for modeling blower and fan efficiencies discussed by Fischer and Rice (1983) hold equally well for modulating air flows.

The primary added capability in the new model which relates to blower- and fan-only efficiencies is the new option of being able to specify a nominal power from an existing system and have the program internally compute and apply the implicit impeller efficiency (based on the calculated airside pressure drop) to a new drive type.

General Capabilities. For modulating blowers and fans, the required fan power can be computed from first principles or referenced to a specified nominal power at design speed. The conversionoption categories available for modulating blowers and fans is similar in type to that provided for the compressor drives - first generation and SOA IDIM, SWDIM, and ECM. For all drive types, the program will compute the required motor size (when the model is run at nominal speed). However, only for ECM blowers and fans is the full range of motor sizing options available comparable to that provided for all drive types in the case of compressors.

The blower/fan drive models are based on:

- first-generation IDIM and SWDIM blower drive efficiency data derived from ORNL tests of a modulating heat pump conducted by Miller (1988b), and 
- SOA IDIM versus SWDIM comparative efficiency data obtained from a motor manufacturer (Lloyd 1987),

Reference SWDIM. The reference SWDIM data built into the model was taken from combined blower and motor tests of Miller (1988b) on a three-phase, six-pole, $1 / 3 \mathrm{hp}(0.25 \mathrm{~kW})$ air handler. A variable-frequency motor-generator was used for the baseline test and the volts/ $\mathrm{Hz}$ ratio of the motor was adjusted at each tested frequency to maintain best efficiency.

A nominal efficiency of $75 \%$ was obtained from the motor manufacturer and used to determine a blower-only efficiency of $28 \%$ at nominal speed. By assuming the blower efficiency was constant with speed, motor efficiencies were derived from measured blower power for the range of tested frequencies from $25 \mathrm{~Hz}$ to $60 \mathrm{~Hz}$. As the tests were performed in an actual air handler unit, the appropriate fan load for a modulating application was automatically provided.

The resultant reference SWDIM efficiencies taken from a curve-fit and extrapolation (where shown as estimated) of the derived efficiency points are tabulated in Table 3 as a function of drive frequency. The function FANSWV contains a curve-fit representation of these data points.

Table 3. Reference SWDIM Efficiency For Blower Applications

\begin{tabular}{cc}
\hline Drive Frequency & SWDIM Efficiency \\
\hline 15 & 0.40 (est.) \\
20 & 0.52 (est.) \\
25 & 0.584 \\
30 & 0.637 \\
35 & 0.680 \\
40 & 0.712 \\
45 & 0.732 \\
50 & 0.745 \\
55 & 0.750 \\
60 & 0.750 \\
\hline
\end{tabular}

First-Generation IDIM. The same procedure was used to derive drive efficiencies from similar airhandler tests over a slightly wider speed range conducted by Miller (1988b) on the same motor with a first-generation VSI inverter drive. The derived IDIM efficiencies were divided by their corresponding SWDIM values to obtain efficiency degradation factors due to the direct and indirect inverter losses (Miller 1988b). These multipliers are given in Table 4 - a curve fit of which is built into the model in function FANFGN. 
Table 4. Efficiency Degradation Multipliers

For Blower First-Generation IDIMs

\begin{tabular}{cc}
\hline Drive Frequency & Multiplier \\
\hline 15 & 0.13 (est.) \\
20 & 0.23 (est.) \\
25 & 0.36 \\
30 & 0.47 \\
35 & 0.56 \\
40 & 0.62 \\
45 & 0.69 \\
50 & 0.75 \\
55 & 0.80 \\
60 & 0.82 \\
\hline
\end{tabular}

SOA IDIM. For state-of-the-art (SOA) IDIMs, bench test efficiency data taken under representative fan loading conditions were obtained from a motor manufacturer (Lloyd 1987). The corresponding SWDIM performance at the same conditions was also estimated by the manufacturer. From these data, consistent degradation factors for the SOA IDIMs were obtained. The resultant degradation factors for SOA IDIMs are shown in Table 5 - a curve-fit representation of which is contained in function FANSOA.

Table 5. Efficiency Degradation Multipliers For Blower State-Of-The-Art IDIMs

\begin{tabular}{cc}
\hline Drive Frequency & Multiplier \\
\hline 15 & 0.32 (est.) \\
20 & 0.45 (est.) \\
25 & 0.58 \\
30 & 0.66 \\
35 & 0.73 \\
40 & 0.78 \\
45 & 0.83 \\
50 & 0.86 \\
55 & 0.89 \\
60 & 0.92 \\
\hline
\end{tabular}

ECM Indoor Blower and Outdoor Fan Performance. For both the indoor blower and outdoor fan modulating drives, an efficiency map obtained from Young (1990) for a 12-pole, 1/5 hp (0.15 kW) production ECM as a function of speed and torque was used. The range of motor speed was from 300 to $1300 \mathrm{rpm}$ with a nominal speed of 1200 for a normalized speed range of 0.2 to 1.15 of nominal. The torque range was from about 20 to $160 \%$ of the nominal value. Windage and friction 
losses were included as were magnetization losses due to the permanent magnet rotor. A plot of the blower ECM performance mapping is shown in Figure 13.

The torque range for the $1 / 5 \mathrm{hp}$ ECM was generalized in the model to be applicable for other nominal motor sizes as specified by the user. The ECM speed range was not normalized, however, as it was felt that it would be less likely to have a range of fan motors designed for different nominal speeds available (in contrast to the compressor where a redesigned motor would have more potential for energy savings). By not normalizing the blower ECM speed range, it was also possible to more easily simulate the more common use of different speed taps on a single ECM drive to meet different application requirements with the same nominal speed design. In this way, the same basic drive design can be applied to indoor blowers and outdoor fans with different nominal speeds (e.g. $1080 \mathrm{rpm}$ for the blower and $825 \mathrm{rpm}$ for the outdoor fan).

\section{Further Discussion of Blower and Fan Modeling Capabilities}

Model Calibration Options. As noted earlier, there are two options for computing modulating blower or fan power - by first principles or based on a baseline nominal power input. For a specified operating frequency and drive type, the first principles approach uses model-calculated air flow, pressure drops, and blower and blower drive efficiencies to directly calculate required fan power based on the given indoor or outdoor unit air-side configuration. If the computed values do not agree closely enough with available test data, the input values of blower efficiency and/or the coil/system pressure drop multipliers can be adjusted at one test condition in each mode (to account for wet-to-dry coil effects) to calibrate the model.

An alternative approach which can be more convenient when comparing to existing hardware is to specify known nominal power values for the indoor and/or outdoor units and the associated drive types. The model will compute the proper modulating fan power based on the fan laws and the ratio of drive efficiencies between the baseline and the selected drive types at the specified operating frequency. In this alternative approach, the calculated system pressure drop is not used directly in the fan power calculations but is used to compute the implied blower efficiency and the required motor size.

Indoor Duct System Options. The options for specifying the indoor duct system have been enhanced to provide more convenient ways to control the external pressure drop seen by the indoor blower for nominal design conditions. In place of a specified duct size, a fixed external pressure drop can now be specified to meet ARI minimum requirements (ARI 1989) or to agree with a measured value for a given test setup. The required duct size is also computed in this case so that this value can, in turn, be specified for an off-design-point calculation (Rice 1992).

Coil and indoor system (which includes the built-in heater and filter correlations) pressure drop multipliers have been added to the input to provide further model calibration capability.

ECM Motor Sizing Options. For the blower and fan motors, speed versus torque maps are supplied only for the ECM drives. As a result, motor size or loading selections are possible only for the ECMs. Otherwise, these options work the same as for the compressor case. A recommended 
MODULATING-DRIVE EFFICIENCY -- BLOWER/FAN PM-ECM, 12-POLE, $1 / 5 \mathrm{HP}, \mathrm{W} / \mathrm{F}$

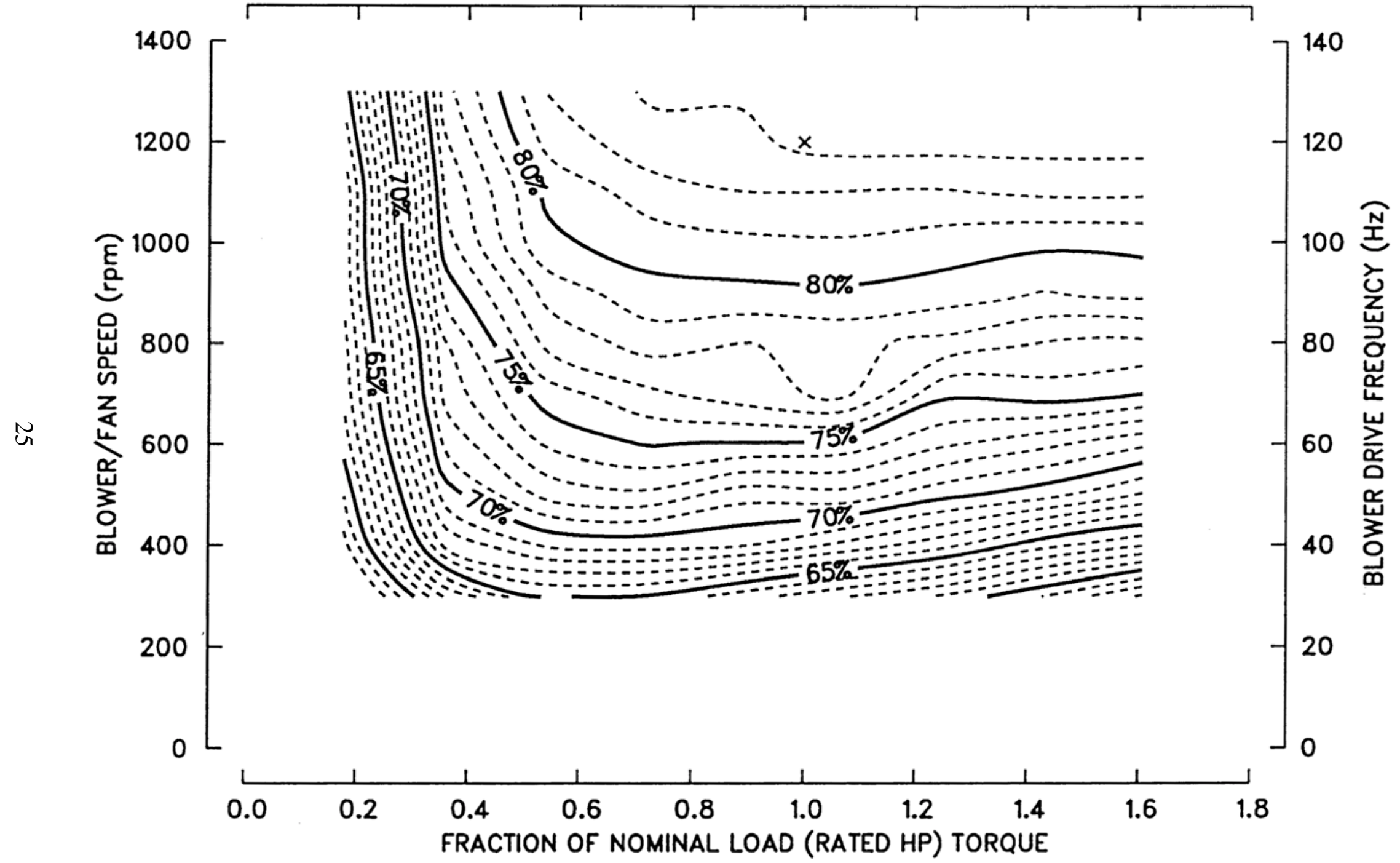

Figure 13. Modulating Drive (Motor and Inverter) Efficiency of a Permanent-Magnet, Electronically-Commutated Motor (PM-ECM) — Reference 3-Phase, 12-Pole, 1/5 Hp Blower Motor. 
approach to sizing ECM blower and fan motors and simulating off-design performance for a modulating application using these options has been presented by Rice (1992).

\section{AIR-SIDE CORRELATIONS FOR MODULATION AND ENHANCED SURFACES}

\section{Advantages and Features}

A major update of air-side heat transfer and pressure drop calculations was completed for improved prediction for modulating air flows based on work by Gray and Webb (1986). Other heat exchanger modeling improvements included the addition of augmentation treatments of wavy and louvered surfaces dependent on Reynolds number and fin pattern specifics. The calculation of coil entrance and exit losses is now done explicitly rather than as just a percentage of the calculated loss.

The benefits of these changes are:

- improved low flow correlations over those used in the ORNL Mark III Model,

- $\quad$ added flow and geometry -dependent augmented surface analysis, and

- more consistent treatment of ancillary air-side pressure losses

New Baseline Air-Side Correlations. The baseline air-side heat transfer and pressure drop correlations (McQuiston 1981) used in the ORNL Mark III HPDM (Fischer and Rice 1983) were replaced by more accurate representations by Gray and Webb (1986). These newer correlations developed for plain fin-and-tube heat exchangers are especially improved at low Reynolds numbers and for prediction of the row effect. This is primarily because Gray and Webb made corrections for experimental error in the original data taken by earlier researchers which had been used by McQuiston. Furthermore, the correlations are much better behaved at low flow rates, as are extrapolations beyond the available test range — which are sometimes needed with modulating applications when exploring the design envelope.

Correction Factor Format. The Gray and Webb smooth-fin correlations were used as the new reference base for plain, wavy, and louvered fin options in the ORNL Modulating HPDM. All augmented surface correlations were represented as correction factors (multipliers), of varying degrees of complexity, to the reference smooth fin equations. This is an especially useful format as most reported data on improved surfaces are for a limited number of tube size, spacing, and row configurations. The referencing of all the correlations to the general model for plain fins adds both generality and consistency to the correlation predictions.

New Geometry and Flow-Dependent Correction Factors. The wavy- and louvered-fin enhancement choices are now offered at two levels of complexity. The first level is as was done in the Mark III Model where constant multipliers are applied to the (new) baseline plain-fin equations. The second level choices are to use multiplier correlations which are now dependent on Reynolds number and fin pattern specifics. For wavy (zig-zag) fins, correlations developed for ORNL by Beecher and Fagan of Westinghouse R \& D Center (1987) were used. For simple louvered fin patterns, the 
multiplier correlations obtained from Makayama and Xu (1983) were used. These second-level options require additional user input to specify the details of the fin patternations.

Further Improvements In Pressure Drop Calculations. The air-side pressure-drop correlations were further revised, beyond the change to newer reference plain-fin correlations, to improve the consistency of the calculations for the various options. Explicit calculations were added of entrance and exit pressure losses and velocity head loss using expansion and contraction coefficients and methodology from Kays and London (1974). User-supplied pressure-drop adjustment factors were also added for optional application to the overall coil pressure drops and the indoor system pressure drop.

\section{CHARGE INVENTORY AND RELATED WIDE-RANGE FLOW CONTROL OPTIONS}

\section{Advantages and Features}

Overview. A summary of the advantages of the charge inventory capability are as follows:

- Allows the user to either specify or determine refrigerant charge,

- Enables more realistic off-design predictions for a range

of flow control types, and

- Accommodates variable-opening flow control devices needed for modulating heat pumps

— e.g., PWM valve, stepper motor, TEV's and TXV's.

A major new feature of the ORNL Modulating HPDM is refrigerant charge (mass) inventory capability. This capability can be used in the HPDM in two ways. The user can either specify or determine the refrigerant charge requirements. In the first option, the user specifies the refrigerant charge and requires the model to adjust the operating conditions so that the system requires exactly that amount of active charge (charge balancing). The latter approach is to specify desired operating conditions and have the model calculate the required charge to obtain those conditions (charge determining).

The charge-balancing procedure is more useful in simulating system performance with predetermined flow control hardware over a range of off-design operating conditions. The chargedetermining alternative is useful in evaluating system charge and storage requirements in the design phase when the equipment is being evaluated for (or being controlled to obtain) optimum condenser subcooling or flow control sizing and evaporator superheat levels over a range of operating conditions.

The charge inventory feature can also be turned off completely. In this case, the model calculations are essentially the same as for the Mark III version. 
Charge-Balancing Option. With a charge inventory balance, one can predict the effects of a given charge level on systems with little or no charge storage capacity or predict the levels at which overor under-charging effects begin to occur. The additional information about system charge-balancing requirements enables more realistic off-design predictions for a range of flow control approaches. Existing and advanced (or idealized) variable-opening flow control devices, which are more necessary in modulating systems, can be modeled more directly with the addition of a charge balance (which determines required condenser subcooling or evaporator superheat levels).

From a computational perspective, use of a charge balance requires an additional outermost iterative loop in the heat pump solution scheme. As such, the model run-time is increased approximately by the number of times the outermost loop must be repeated to obtain agreement between the specified and the calculated refrigerant charge. On each successive iteration, the evaporator exit superheat or the condenser exit subcooling is adjusted (depending on the flow control type specified) so as to bring the calculated and specified charges into agreement.

Charge-Determining Option. In contrast, the charge-determining alternative has much less computational overhead - at most a factor of about two. This option provides the designer with feedback on how various heat exchanger size and control options affect the charge requirements but without prematurely limiting the range of possible system operating conditions with an additional charge constraint. Both the added flexibility and computational speed of the charge-determining approach make it a more suitable choice for initial scoping and more general system design optimization studies.

Recommended Design Procedure. Once the optimum control conditions of the system are established, over a range of operating conditions without the constraints of charge inventorybalancing, the charge and flow control requirements of the idealized design can be evaluated and approaches prescribed to approximate this in hardware. (Valve sizing information for various types is provided in the model output.) At this stage, the charge-balancing model can be brought into effective use to evaluate the refrigerant charge levels needed for various flow-control types and sizings to most closely approach the thermodynamically-optimum design over the range of required operating conditions. In this way, the available charge inventory options can be used in combination to find a design which is not only workable but which also obtains the best performance out of the available hardware.

Flow diagrams of the HPDM solution logic for the charge-determining and the charge-balancing options are shown in Figures 14 and 15. The various options of specified flow control or heat exchanger exit conditions with and without a specified charge are discussed at some length in the sections to follow.

Inventory Calculation Features. The charge inventory calculational model includes the following features :

- user choice of inventory method ranging from simplified to SOA (Rice 1987). The simplified analytical formulation is provided for first-level analysis as it is much faster than the other more accurate methods that are included but which require numerical integration (Rice 1987), 
- tabulations of the steady-state on- and off-cycle charge distributions in a heat pump, and

- a j-tube accumulator model adapted from the NIST mixed — refrigerant heat pump simulation (Domanski, 1985, 1986).

More specifics of the inventory choices and the accumulator model requirements can be found in the description of the HPDATA input file in Appendix B. Details of the available inventory methods, covering the different possible void fraction models and heat flux assumptions can be found in the paper by Rice (1987). Recent heat pump validation tests with the different methods have been reported by Damasceno et al (1991).

\section{Modeling Interrelationships Between Refrigerant Charge and System Flow Control}

As discussed in the preceding section, the inclusion of charge inventory capability in the ORNL Modulating HPDM allows the user to either determine or specify the refrigerant charge inventory. The various options for specifying flow control devices or heat exchanger exit conditions with and without a specified charge are discussed in this section with reference to the flow diagrams shown in Figures 14 and 15. The charge-determining path is taken when refrigerant charge is not specified while the charge-balancing route is taken if a refrigerant charge level is provided.

If the refrigerant charge is not specified, the user must define, as input, values for

1) compressor inlet superheat and

2) either condenser exit subcooling directly or specific flow control devices (indirectly determining condenser subcooling).

If the refrigerant charge is specified, the user may only specify one of the above categories with the remaining category to be determined by a system charge balance. Otherwise, the system would be overspecified. From a thermodynamic cycle perspective, either compressor inlet superheat or condenser exit subcooling must be left as a free parameter to be determined by charge balancing when the refrigerant charge is an additional given quantity. If the compressor inlet superheat is specified, the cycle is considered low-side-determined while if condenser exit subcooling (or a flow control device) is specified the cycle is high-side-determined.

These choices are made in the HPDATA input data file (Appendix B) on Lines \#4 and \#5 where the Charge Inventory / Superheat Data and the Charge Inventory Calculational Data are specified. Related specification of condenser subcooling or specific flow control devices is made by the user under Flow Control Device Data on Line \#6. 


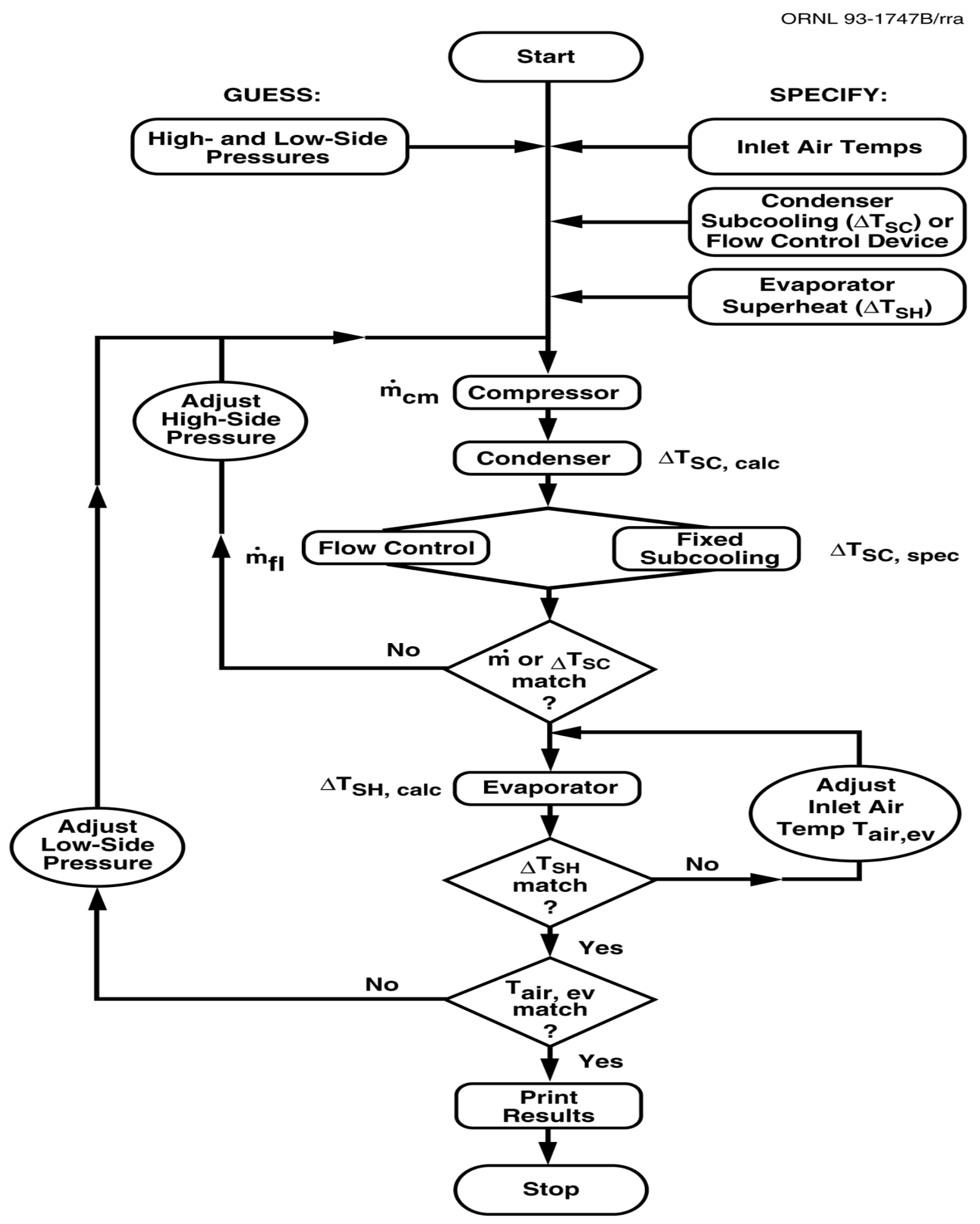

Figure 14. Solution Logic of ORNL Modulating HPDM With Charge-Determining Option Selected. 


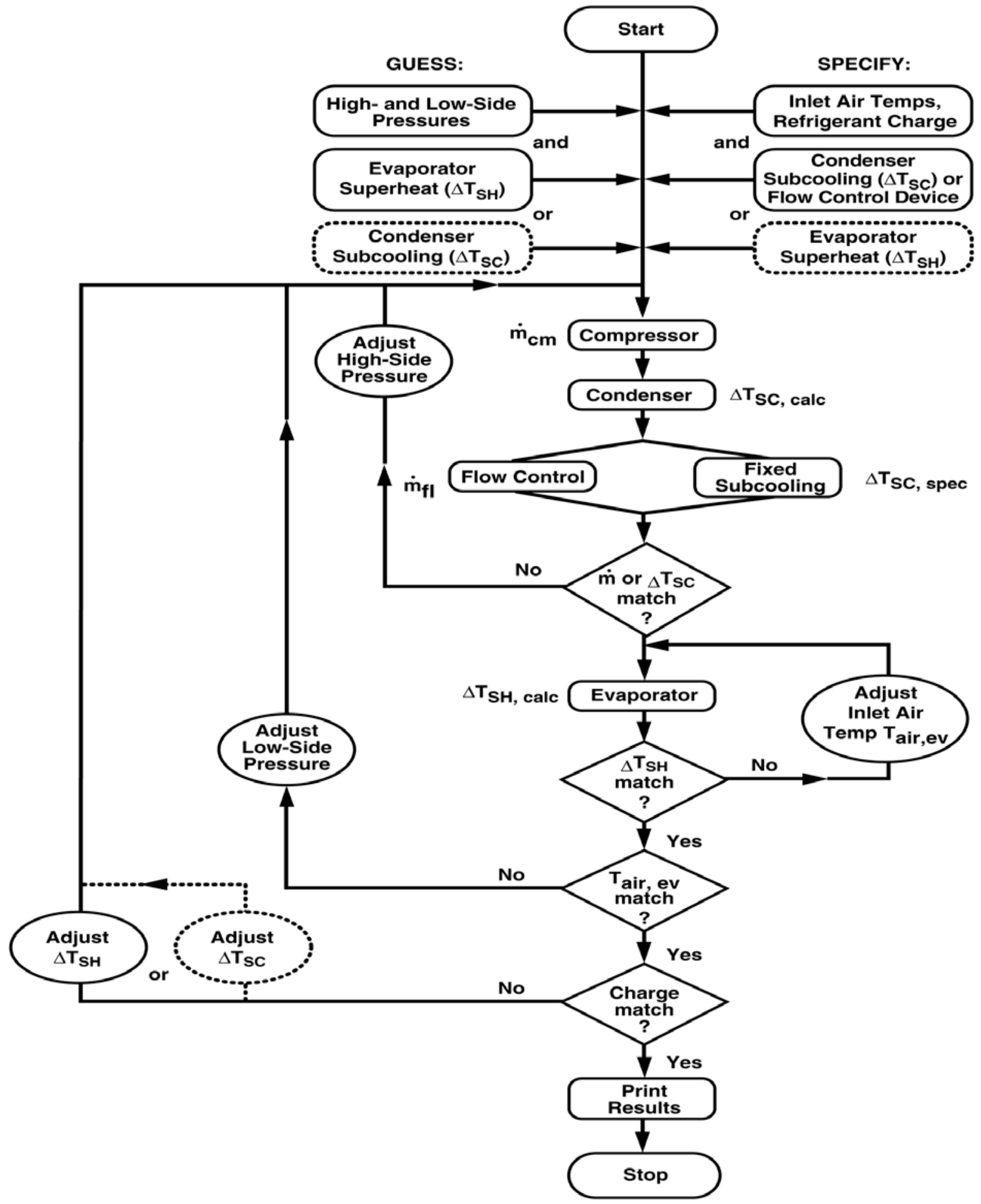

Figure 15. Solution Logic of ORNL Modulating HPDM With Charge-Balancing Option Selected. 
If the refrigerant charge is to be determined,

$\begin{array}{lll}\text { then } & \text { ICHRGE } & \text { is set to } 0 \text { on Line \#4 } \\ \text { and } & \text { IMASS } & \text { is set to } 1 \text { on Line \#5. }\end{array}$

If the refrigerant charge is specified on Line \#4 as REFCHG),

then ICHRGE is set to 1 or 2 on Line \#4

and either compressor inlet superheat

or condenser exit subcooling

is determined, respectively.

The refrigerant charge inventory values which are calculated for each system component and tabulated in the program output are given in Table 6. Listings C. 1 and C. 2 contain examples of computed charge inventory values as listed in Table 6. Figures 16 and 17 provide some sample results using the charge inventory model for a heat pump system with capillary tubes and a suction line accumulator.

If no refrigerant charge calculations are desired,

then ICHRGE must be set to 0 on Line \#4

and IMASS is also set to 0 on Line \#5.

In this latter case, the program runs as fast as the ORNL Mark III single-speed model and no chargerelated output is provided.

\section{Discussion of TXV Modeling With And Without A Charge Inventory Balance}

Potential Area Of Confusion. A potential point of confusion in both the single-and variable-speed ORNL heat pump models is the modeling of systems with thermal expansion valves (TXV's). Such valves are often described as maintaining the compressor inlet superheat at a constant value. Because of this generalization, users of the single-speed model (without a charge inventory balance) often specify a TXV valve and a constant compressor inlet superheat value and expect the model to properly represent behavior of such a system over a range of operating conditions.

In reality, a TXV does not hold superheat at a constant value but requires that the superheat vary above a prescribed minimum value as the operating conditions change. While the superheat value required for proper control of the TXV does not vary a great deal (maybe 7 to $10 \mathrm{~F}^{\circ}$ ), the important point from a system modeling perspective is that the change in TXV opening is tied to the change in superheat value from one ambient condition to the next.

Charge-Dependent Nature Of TXV Operation. As ambient conditions change and the TXV tries to maintain a design value of superheat, the condenser subcooling must change to adjust for the new saturation temperatures and new amounts of refrigerant in the two-phase regions of the heat exchangers. This is accomplished as the TXV adjusts its opening trying to bring the superheat back as close as possible to its previous value until a new balance is obtained. This change in opening and thereby superheat with ambient is dependent on the system charge balance. Thus the change in TXV opening with ambient is charge-determined. 
Table 6. Definitions Of Charge Inventory Output Variables

LINE \#1 Descriptive Title Identifying Void Fraction Model Used

(as selected with MVOID on card 4 of the HPDATA specification file)

LINE \#2

TREFMS

SSMSHI

SSMSLO

LINE \#3

TMASSC

TMASSE

CMPMAS

XMASLL

ACCMAS

SSVPLO

SSVPHI

LINE \#4

EQMSHI

EQMSLO

XMSLQ

XEQUIL

LINE \#5

VOLHI

VOLLOW

VOLCND

VOLEVP

VOLCMP

VOLACC

XLEVEL
Refrigerant Mass Totals (Steady-State)

Total calculated steady-state refrigerant mass in the heat pump (lbm)

Steady-state refrigerant mass in the high side of the unit (lbm)

Steady-state refrigerant mass in the low side of the unit (lbm)

\section{Refrigerant Mass By Component (Steady-State)}

Steady-state refrigerant mass in the condenser (lbm)

Steady-state refrigerant mass in the evaporator (lbm)

Steady-state refrigerant mass in the compressor can (lbm)

Steady-state refrigerant mass in the liquid lines (lbm)

Steady-state refrigerant mass in the accumulator (lbm)

Steady-state refrigerant mass in the low-side vapor lines (lbm)

Steady-state refrigerant mass in the high-side vapor lines (lbm)

\section{Refrigerant Mass Totals (Off-Cycle Equilibrium)}

High-side refrigerant mass in the heap pump at off-cycle equilibrium (lbm) Low-side refrigerant mass in the heap pump at off-cycle equilibrium (lbm) Low-side refrigerant liquid in the heap pump at off-cycle equilibrium (lbm)

Low-side refrigerant quality in the heap pump at off-cycle equilibrium

TXV Modeling Without A Charge Balance. In the single-speed model, which lacks a charge inventory balance, specification of a TXV valve and constant superheat for a range of ambient conditions results in modeling a TXV operating at a fixed opening. Such a specification is suitable only for making a single design point calculation and should be avoided if the intent is to model a TXV system over a range of ambients.

An alternative approach to modeling such a system (without use of the charge inventory model) is to specify an approximate average compressor inlet superheat and a range of condenser subcooling values appropriate for different ambients. These would be obtained from experimental data on an operating TXV system. Runs of the model set up in this way could serve as a basis for model validation of overall system performance predictions. Predicted TXV sizes for such a system would 


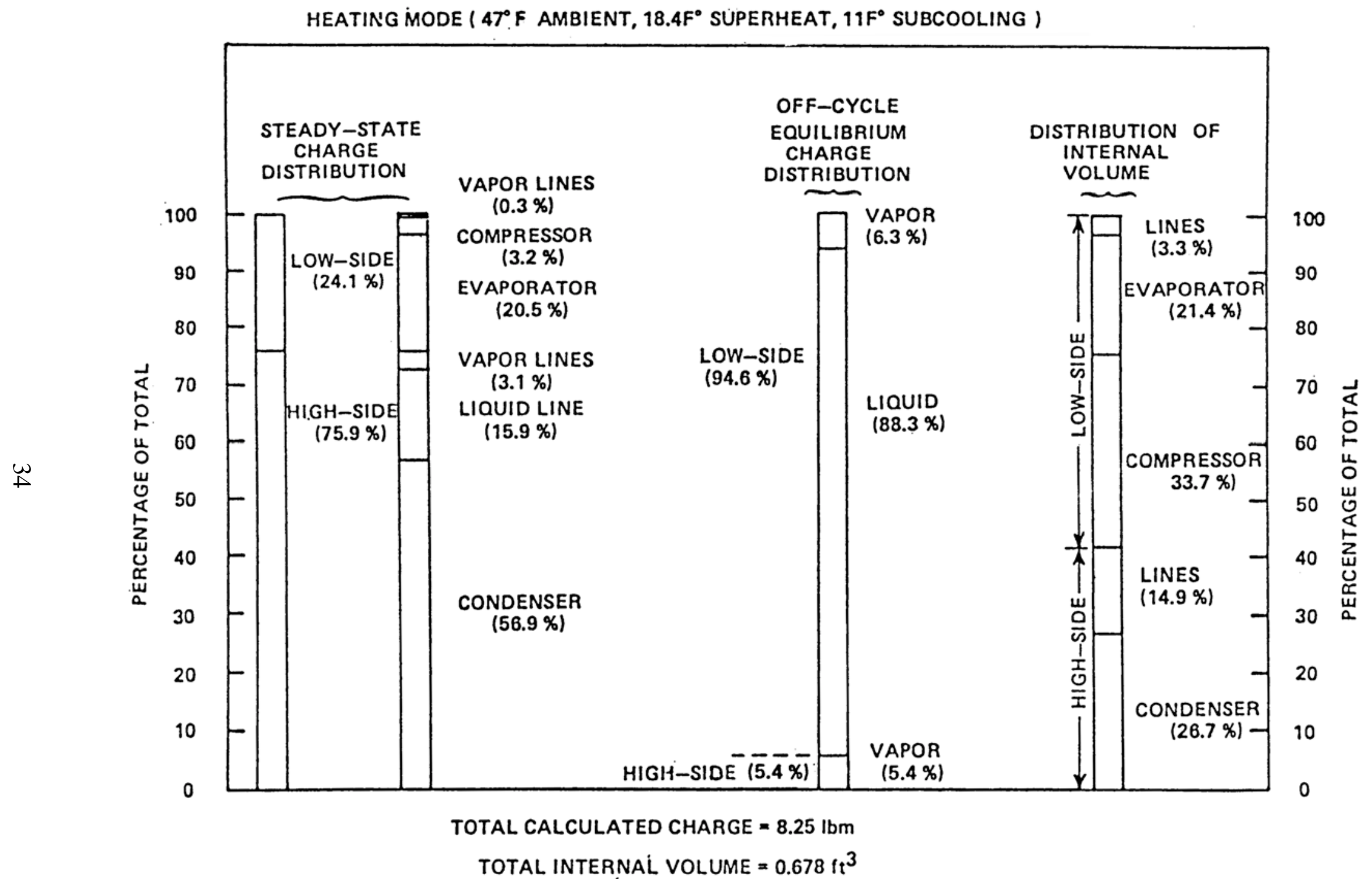

Figure 16. Sample Refrigerant Charge Distribution Within a Heat Pump as Predicted by the ORNL Charge Inventory Model. 

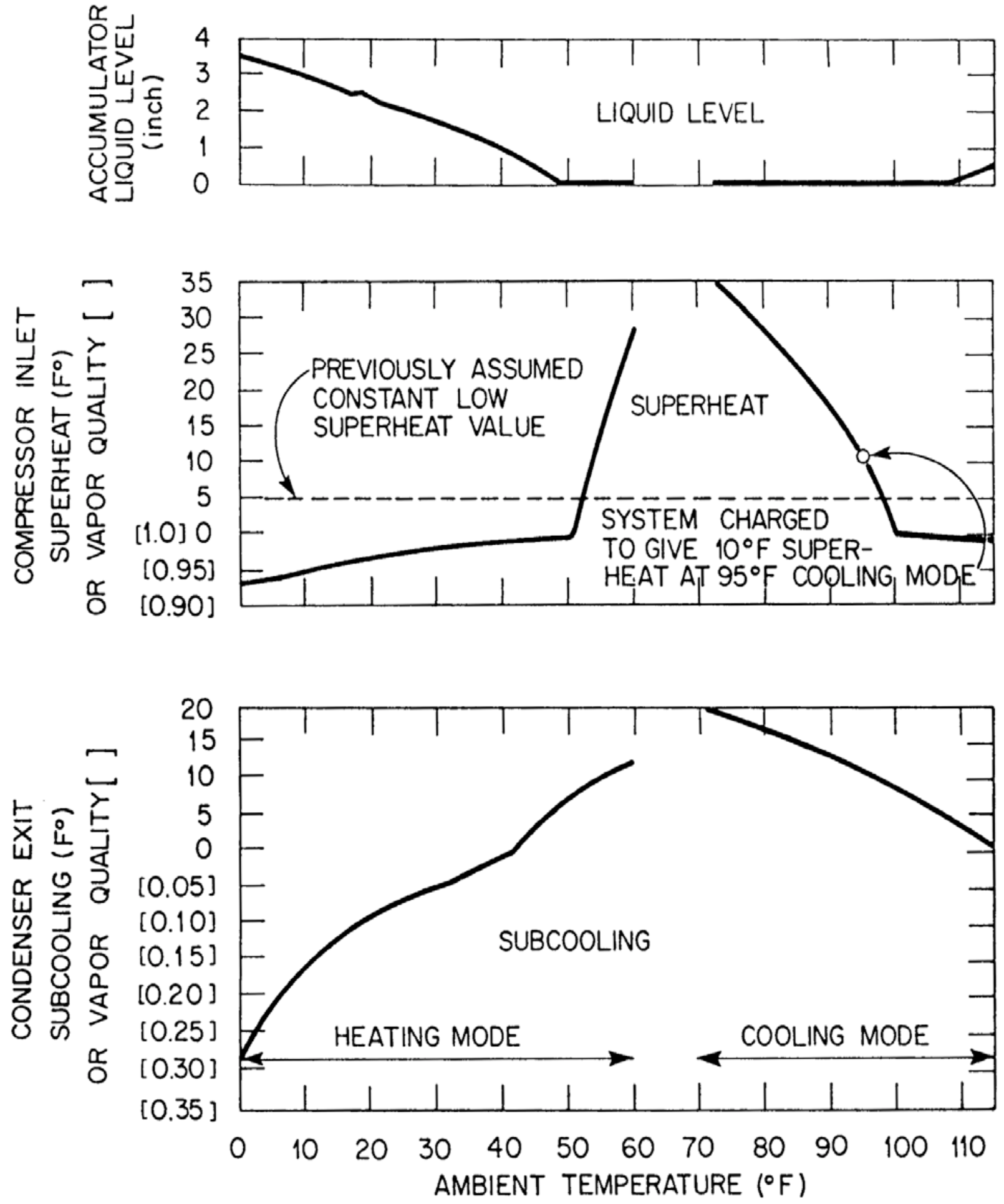

Figure 17. Sample Heat Exchanger Exit Conditions and Accumulator Level Predicted As a Function Of Ambient With Capillary Tube Flow Control Using the ORNL Charge Inventory Model. 
then be compared to the actual valve used in the operating system. The obvious disadvantage of the above approach is that experimental data over a range of ambient conditions are needed to accurately simulate such a system.

Explicit-Versus-Implicit TXVModeling With A Charge Balance. With the inclusion of the charge inventory model, an additional known, the total refrigerant charge, is available for use in place of knowledge of low-side superheat (when modeling non-adjustable, subcool-controlling or superheatcontrolled valves explicitly) or high-side subcooling (superheat-controlling valves) to completely determine the system operating conditions. With reasonable values specified for TXV size and total refrigerant charge, a TXV system can be explicitly modeled (as superheat-controlled) over a range of ambient conditions. Alternatively, a TXV-controlled-system can be implicitly modeled (as superheat-controlling) by using an approximate fixed design value for superheat and specifying the total system charge. This latter approach would be preferred for a system where not much information is available about the TXV and/or distributor lines that may be used with it. In either case, the refrigerant charge model should be calibrated to a known design point (as was done by Domanski 1983 and by Damasceno et al 1991) to insure the best possible predictions.

Explicit TXV Model. With a TXV size and a total refrigerant charge specified, the model will try to adjust the superheat level until the overall refrigerant mass calculation agrees with the specified charge. However, care should be taken when specifying refrigerant charge and TXV sizes so that the values given will result in superheat values within the specified TXV operating range. A safe way to approach such a simulation is by using as a starting point refrigerant charge values and TXV sizes predicted from a previous model run where reasonable values of low-side superheat and high-side subcooling were specified at a design point condition.

Also, by nature, the explicit TXV model tends to be rather unstable, since small changes in superheat result in large changes in valve opening. To prevent the model from trying to close the TXV valve completely during the course of the refrigerant mass iteration, we presently recommend that an initial guess for superheat be used which is only about $1^{\circ} \mathrm{F}$ above the static superheat setting given on Line \#6 of the input data. This should give an initial iteration point with a large degree of condenser subcooling and thereby a higher refrigerant charge requirement than specified for normal operation. Solution bracketing and subsequent iterations should then head in the safe direction away from total valve closure.

Implicit (Or Approximate) TXV Model. Using the ORNL charge inventory model, a fixed-charge system with constant low-side superheat can also be modeled directly. In this case, the condenser subcooling is allowed to float to meet system requirements over a range of ambient conditions. Over a certain range of ambient conditions, a properly-sized TXV system may be approximated by this control option. (Just what range can be determined by tabulating the computed required TXV sizes over the range of ambient conditions and determining if this range of sizes could be handled with one valve about its design point.) This approach is recommended for first-cut and idealized TXV analyses and as a way to obtain good estimates of valve size and range requirements before running with the explicit TXV model. Recent advanced valves such as the pulse-width-modulated (PWM) valve as well as stepper motor and TEV valves controlled by low-side thermistors may be able to more closely approach the performance predicted for this control option over a broader range of ambients. 
Subcool-Controlling Valves. Systems which control on condenser subcooling can be simulated by specifying refrigerant charge and subcooling. In this case, the low-side superheat is allowed to float to meet the system fixed-charge requirements.

\section{Adjustable- vs Fixed-Opening Flow Controls}

For fixed-opening flow control choices such as capillary tubes and short-tube orifices, an accumulator is needed to act as a storage reservoir for extra refrigerant at extreme ambients in heating and cooling mode. Otherwise, the values of low-side superheat and/or high-side subcooling can become excessive at these conditions.

With adjustable-opening flow control valves, the need for an accumulator is minimized from the perspective of the influence of fixed-charge requirements on the system steady-state operating conditions. Such valves can maintain acceptable values of superheat and subcooling over a widerange of ambient conditions. However, to provide the final degree of freedom to maintain optimum values of subcooling and superheat over a wide range of speeds and ambients, some type of charge reservoir would still be required.

Adjustable-opening valves as modeled in the ORNL program must be controlled by low-side superheat or high-side subcooling. The system performance with adjustable-opening valves controlling on other system parameters, such as compressor discharge temperature, cannot be handled at present unless their effects can be translated into a relationship for high-side subcooling or low-side superheat as a function of ambient temperature.

\section{MODEL VALIDATIONS, LIMITATIONS, AND RECOMMENDATIONS}

Single-Speed Validation History. Different versions of the single-speed model have been validated by various researchers for both single-speed (Dabiri 1982, Fischer and Rice 1983, Fischer and Rice 1985, Damasceno et al. 1990) and dual-stroke (Fagan et al.1987) heat pumps. The single-speed model has also been used in the simulation of variable-speed engine-driven heat pumps (Fischer 1986b, Monahan 1986, and Rusk 1990). With the exception of the results obtained by Damasceno (1990), the validations of the original single-speed version in both nonmodulating and modulating applications of sizes from 2 to 10 tons capacity have been reported as satisfactory to excellent. 
ORNL Modulating Model Validations. Limited model validations were conducted on an initial ${ }^{1}$ version of the ORNL Modulating HPDM using ORNL-obtained system laboratory data (Miller 1987 and 1988a) on a modified ${ }^{2}$ commercially-available variable-speed heat pump. The model was compared to experimental trends with respect to compressor and indoor blower speeds and also the basis of absolute COPs and capacities. The trends in COP and capacity were generally well predicted as shown and discussed by Miller (1988a).

The results of the absolute comparisons over a range of speeds and ambients indicated that best model agreement was obtained at the lower speeds in both heating and cooling mode, with increasing performance overpredictions ${ }^{3}$ (to maximums of about $10 \%$ in both COP and capacity) occurring at higher speeds. This increase in model overprediction with speed occurs because of limitations of the simplified circuiting models with the higher subcooled (and/or superheated), more heavily loaded heat exchanger conditions.

Known Model Limitations. This moderate overprediction at high subcooling and/or superheat conditions is consistent with the assumptions inherent in the original heat exchanger model formulation developed by Hiller and Glicksman (1976) — who sought a model to represent the most efficient cross-flow circuiting arrangement with respect to the single and two-phase refrigerant regions. Heat exchanger modeling simplifications include the assumption of equivalent parallel refrigerant circuiting and that efficient coil circuiting is maintained in all operation modes relative to the air flow direction.

Occasionally, these assumptions can be violated rather significantly at the more loaded operating conditions in existing heat pump designs, generally due to complex circuiting patterns used by some manufacturers to meet their design requirements within the limitations of refrigerant-flow-reversing heating and cooling mode operation. (This is because in a heat pump, the circuiting arrangements must serve double-duty with a reversal of refrigerant flow direction between heating and cooling. Consequently, the model should have better general applicability to air-conditioning-only units.)

\footnotetext{
${ }^{1}$ The main difference (relating to the validation results) between the initial model and the present version was in the compressor map representation formulas. Triquadratic curve fits (with drive frequency as the third variable) to available calorimeter and application data (Miller 1988b) for a motor-generator-driven reciprocating compressor were used in the initial model validations. However, a later evaluation by the author of the triquadratic-curve-fits to the compressor data available at that time (Miller 1988a) indicated that some significant efficiency trends with speed were not being represented adequately. Through experience gained from different curve fitting attempts to later reciprocating and scroll data, improved representations were achieved and implemented in the first distribution version of the modulating HPDM. These representations generally improved the absolute validation comparisons given by Miller (1988a), especially in the heating mode, where initial underpredictions were mainly due to compressor-data curve-fitting errors.

${ }^{2}$ The unit was modified to allow manual control of the expansion valve opening and to be modulated by a motor-generator set rather than the originally-supplied inverters.

${ }^{3}$ Some heating mode underpredictions also occurred but these were later traced to problems in an originally-used triquadratic curve-fit to the compressor map.
} 
These non-optimal air-to-refrigerant flow arrangements usually occur as a result of operating conditions and speeds which require higher levels (and therefore greater occupied coil fractions) of condenser subcooling and evaporator superheat. These non-ideal flow arrangements cannot be fully accounted for in the more-simplified heat exchanger representation.

Further Caveats. Further difficulties can result if the equivalent number of refrigerant circuits is not chosen carefully for each heat exchanger — resulting in poor predictions of refrigerant-side pressure drops. In the tests reported by Damasceno (1990), for a system with capillary tube flow control, the heating COP at $47^{\circ} \mathrm{F}$ was surprisingly underpredicted by almost $10 \%$ while at $95^{\circ} \mathrm{F}$ in cooling, the COP was more expectedly overpredicted by $8 \%$. Insufficient information on coil circuiting and flow control was provided in the paper to fully determine the cause of the excessive amount of condenser subcooling predicted in their heating test cases. However, it appears that the choice of the number of equivalent circuits in the heat exchangers was not selected appropriately and that the low-side pressure drop of the test unit was excessively large. This may account for why the model underpredicted the heating COP in this instance instead of overpredicting as is more often the case.

The results of Damasceno (1990) do point out that the model should be used with caution if trying to predict the absolute and/or relative performance over a wide-efficiency-range with existing equipment. The ORNL Heat Pump Models were developed primarily for economical, generalized, system design analysis of high-efficiency electric air-to-air heat pumps. As such, the models are not always well suited for detailed simulation purposes of all possible configurations and operating conditions of existing unitary equipment. In these cases, more detailed (and consequently longer running) models such as those developed by Domanski $(1983,1986)$ may be more appropriate.

Validation Procedure Recommendations. The circuiting simplifications in the ORNL models can be overcome to a large degree for many heat pumps (at least with regard to coil pressure-drop calculations) by judicious selection of an appropriate number of equivalent circuits. This can initially be calculated algebraically by the user (similarly to equivalent resistance in parallel electrical circuits) based on the relative lengths (resistance) of the various subcircuits to determine an equivalent-network-based number of circuits (which can be a non-integer value). As a further refinement, we presently recommend to program users that, if coil pressure drop data are available, the number of equivalent circuits for each coil should be adjusted for best agreement with these data - using separate sets of adjusted circuit numbers for heating and cooling modes because of the flow reversal effects on circuit equivalence.

Validations should also be done, at least initially, using as much experimental data as is available on the unit. For example, if measured values are available for compressor inlet superheat and condenser exit subcooling, these should be used for the initial or first-level heat exchanger validations. The agreement of the compressor map with the measured compressor data over the range of expected, operating conditions should be tabulated and any observed trends of over- or underpredictions in power or mass flow rate identified. Specific flow control devices and the refrigerant charge used in the unit can then be added in second- and perhaps third-level validations. Charge calibration procedures (for both heating and cooling modes) such as those discussed by Damasceno et al (1991) are recommended as well to correct for various uncertainties in the charge calculation process. 
With this sequential approach, the accuracy of the various heat exchanger, compressor, flow-control, and charge inventory models can be individually evaluated and possibly corrected for on a component basis rather than on a system basis. Adjustments made at the component level are more likely to be more broadly applicable over one manufacturer's line of equipment than externally applied system correction factors. Some user-specified adjustment factors to the refrigerant- and airside heat transfer and pressure drop predictions for the individual coils have been provided in the latest version.

\section{PARAMETRIC PERFORMANCE MAPPING}

Overview. A key to the effective use of single-speed or modulating design models is a convenient yet flexible means to parametrically evaluate the effect of design, control, and operating variables. Such a "front-end" program is now included with the modulating HPDM for use in steady-state nominal- and off-design analysis. A flow diagram of the structure of the parametric front-end, the possible input and output data sets, and the connections to basic heat pump model routines are shown in Figures 18, 19, and 20. Parametric evaluation of seasonal and annual performance using the ORNL APF/Loads Model was planned to follow (as can be seen as dotted lines in the provided flow chart) but this portion has been deferred indefinitely.

The front-end program allows use of the modulating HPDM to parametrically generate sets of steady-state performance data suitable either for tabulation, for plotting y vs $\mathrm{x}_{1}$ for families of $\mathrm{x}_{2}$, or for plotting $\mathrm{y}$-contours for ranges of $\mathrm{x}_{1} \mathrm{vs}_{2}$. Such data, once generated on a reasonably-fast PC, workstation, or minicomputer, can be later analyzed with generally available PC 2-dimensional x-y or contouring packages or with 3-D visualization programs.

The parametric, or contour-data generating, front-end provides an automated means to conduct parametric performance mappings of selected pairs of independent design variables. The user can generate steady-state performance data sets at fixed ambients or as a function of ambient temperature. The range of selection options includes:

- 52 design, control, and operating (independent) variables for parametric analysis,

- 9 user-defined operational control relationships as functions of compressor speed or ambient temperature, and

- $\quad$ over 100 possible heat pump model output (dependent) parameters.

Design, Control, and Operating Variable Choices. The 52 independent variable choices can be classified under two main headings:

- $\quad$ flow rate or ambient variables and

- heat exchanger area variables 


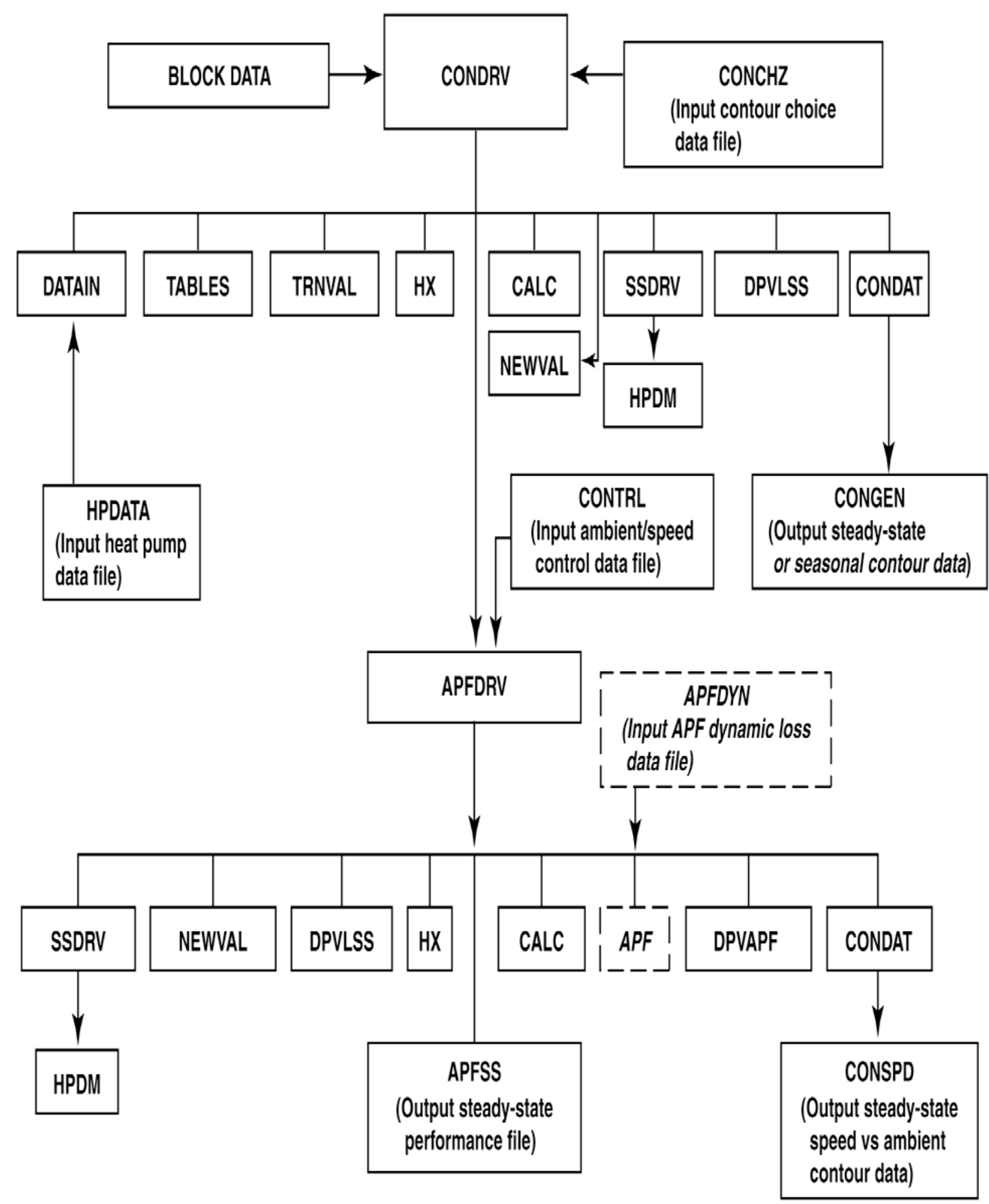

Figure 18. Overall Structure of ORNL Modulating Contour Data Generating Program MODCON. 


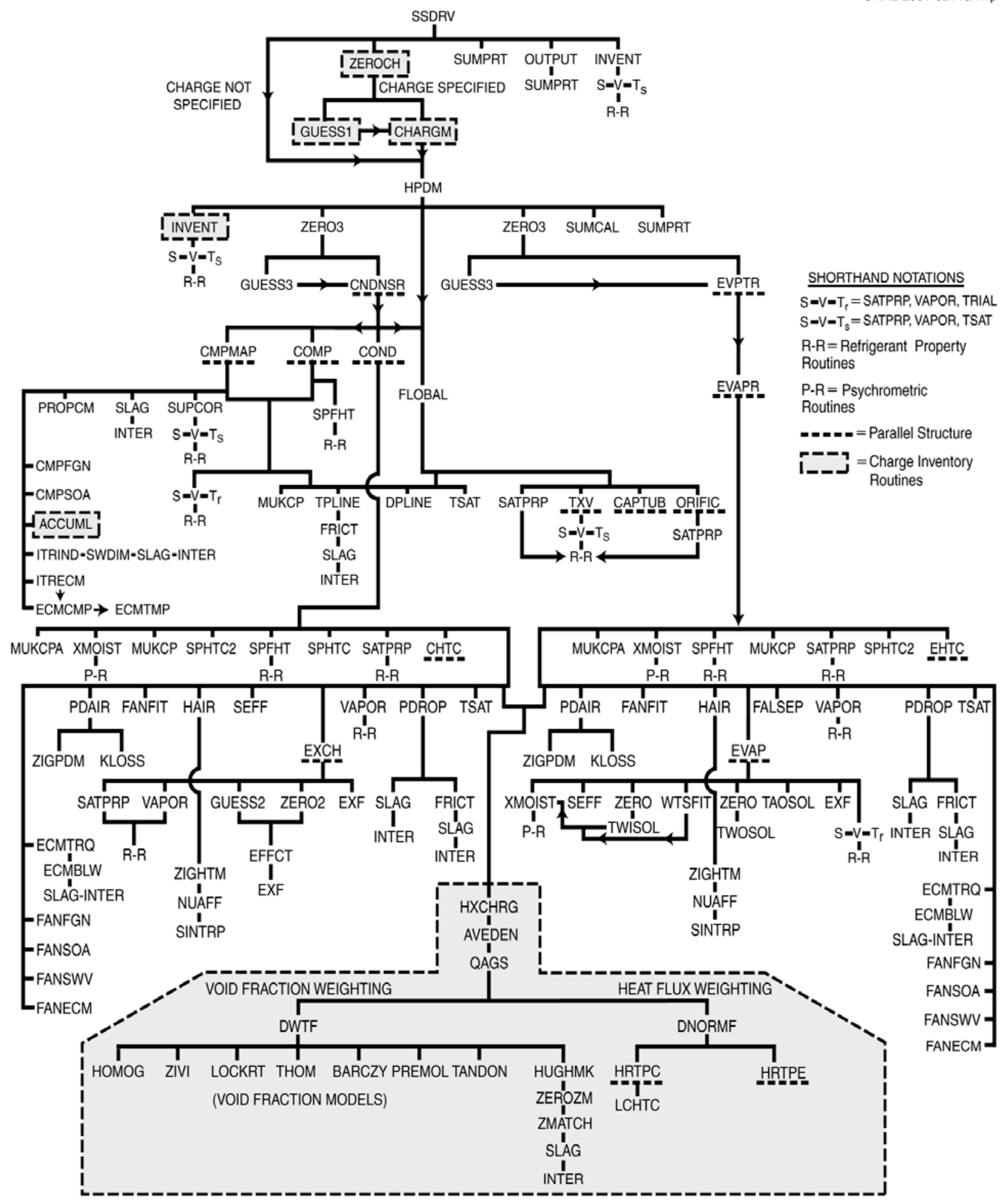

Figure 19. Detailed Structure of ORNL Modulating Heat Pump Design Model. 


\section{REEPIGERANT \\ THERMOOYNAMIC PROPERTY \\ ROUTNES *}

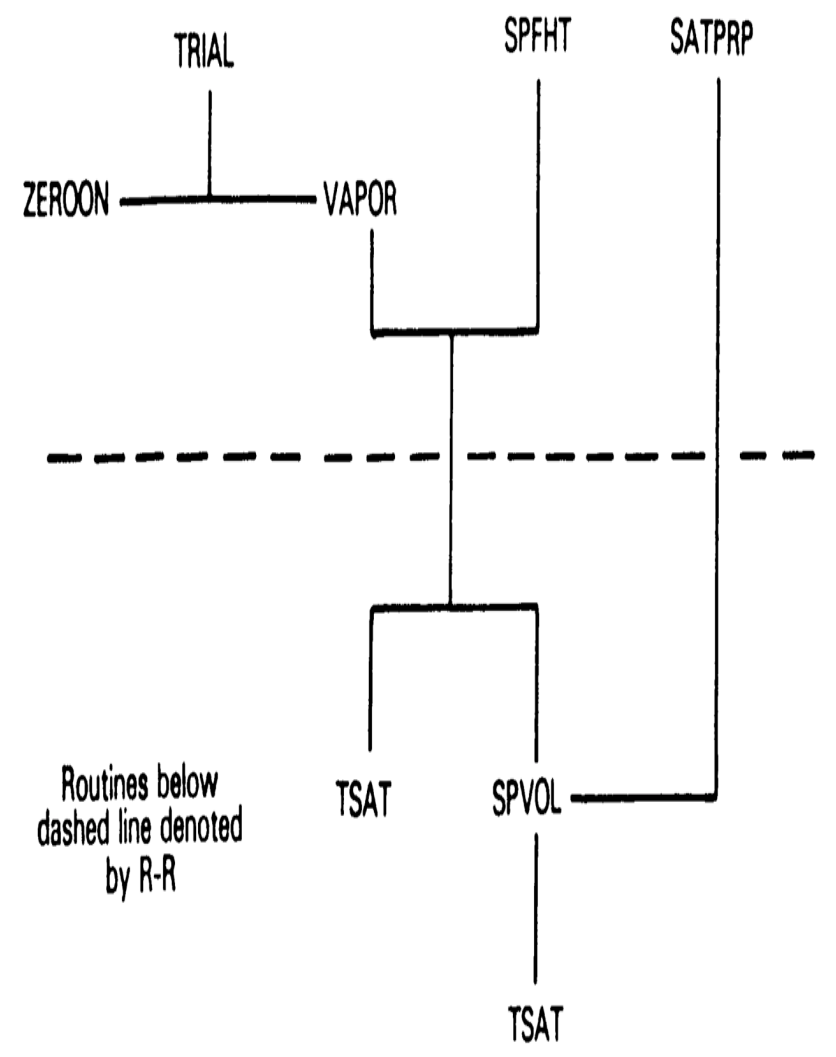

PSYCHROMETRC

ROUTNES

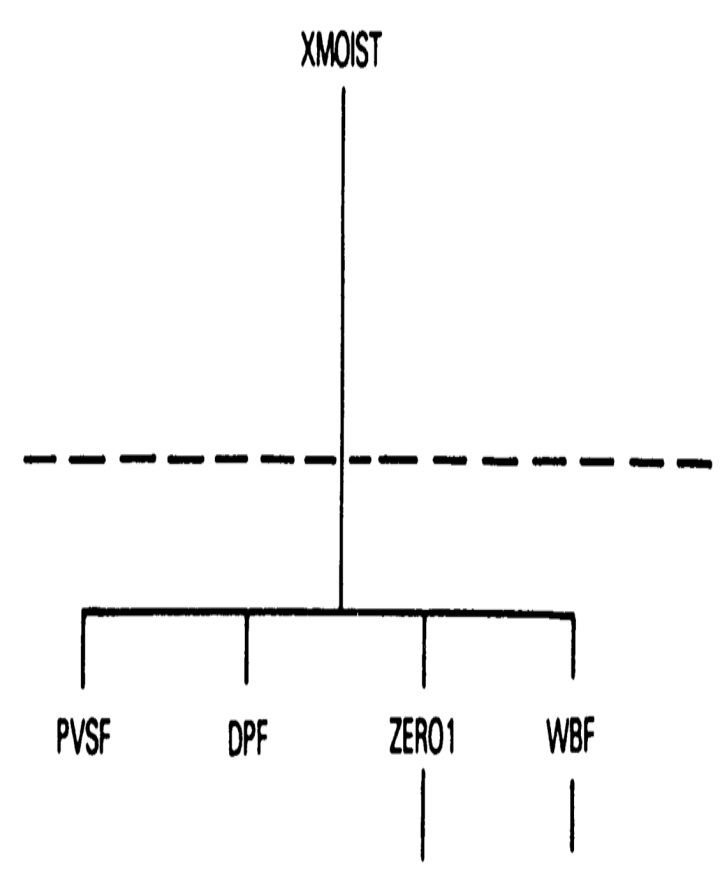

Routines bolow dashed line denoted

by P-A

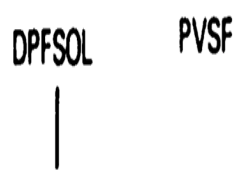

PVSF

\section{- Subroutine TABLLS must be \\ called once to initialize \\ the refrigerant property \\ constants}

Figure 20. Structure of Thermodynamic Supporting Routines for Refrigerant and Air Properties. 
Under the flow rate and ambient variables heading the following categories are covered:

- nominal refrigerant and air flows,

- nominal compressor and fan motor sizing,

- refrigerant- and air-side modulation variables,

- refrigerant flow/charge control, and

- air-side conditions

Twenty-five of the 52 independent design variables are in these categories. The remaining 27 are heat exchanger area variables either -

- with total area changing

- such as frontal areas, number of rows, fin pitch, or

— total area multipliers — with constant fan power maintained

- or with total area fixed

- either with the indoor to outdoor area-split held constant

- by making individual coil tradeoffs with two parameters varying

— or with the area-split changing

- by making tradeoffs over both coils with one, two, or three heat exchanger parameters varying

A listing of the individual parameters available for independent control are given in Table A.2 of the input data description to the CONCHZ data file in Appendix A.

Operational Control Relationships. When either of the selected pair of independent parameters are ambient temperature or compressor speed, the user can simultaneously adjust up to 5 additional control variables. The available control variables are:

- compressor inlet superheat,

- condenser exit subcooling,

- indoor blower frequency,

- outdoor fan frequency, or

- building load.

User-defined operational control relationships can be defined in either the CONCHZ or the CONTRL input data sets as linear functions of compressor frequency and/or ambient temperature. 
Heat Pump Model Output Choices. The user selects in the CONCHZ routine which of the more than 100 available model output values to include in the generated contour data file. The available output parameters are included in Table A.3 of Appendix A. The available categories of data include the following:

- general heat pump performance data

(COPs, EERs, total and sensible capacities, supply air temperatures)

- heat pump power requirements

(total, compressor, fans, I'R)

- refrigerant-side conditions

(saturation temperatures, flow rate, pressure drops, heat transfer coefficients)

- compressor values (speed, torque, efficiencies, motor size)

- for the selected compressor

- for the base compressor

- compressor drive conversion factors

- indoor coil and blower values

(flow rate, speed, torque, efficiencies, motor size, air-side heat transfer and pressure drop)

- outdoor coil and fan values (flow rate, speed, torque, efficiencies, motor size, air-side heat transfer and pressure drop)

- charge and flow control requirements

- flow control parameters

(refrigerant temperatures and superheat and subcooling at potential control locations)

- indoor air-side pressure-drop-related values (indoor-component pressure-drop contributions and required duct size)

- additional derived compressor efficiency values

- additional dehumidification parameters

Up to 15 additional output parameters can be added to the model by the user in subroutine DPVLSS without having to increase the array sizes specified within the program. 


\section{MODULATING APPLICATIONS-TO-DATE}

The ORNL steady-state heat pump models have been applied to a number of modulating applications to date. Somewhat curiously, more outside uses of the models for modulating applications (that we have been made aware of) have been for engine-driven heat pumps rather than for electric-driven. This can perhaps be attributed in part to the wider availability of variable-speed data for open compressors than for hermetics. ${ }^{4}$ This lack of publicly available data for variable-speed hermetic compressor was a significant factor in the ORNL laboratory testing of various IDIM and SWDIM compressor drives as reported by Miller (1987, 1988a, 1988b).

\section{Engine-Driven Applications}

Stirling-Engine-Driven. Through a DOE Work-For-Others contract with Borg-Warner, ORNL adapted the Mark III HPDM to a variable-speed (1000 to $3000 \mathrm{rpm}$ ) Stirling-engine-driven heat pump application. This adaptation was accomplished using proprietary Borg-Warner/Stirling Power Systems (SPS) engine, compressor, and radiator representations for a 10-ton commercial system. The modified model was transferred to Borg Warner for their use in system design and control analysis for the Gas Research Institute (GRI) as reported by Monahan (1986).

Internal-Combustion-Engine-Driven. We also provided the Mark III HPDM to Battelle Columbus Laboratory for another variable-speed engine-driven heat pump application (again 1000 to $3000 \mathrm{rpm}$ ) under development for GRI. The ORNL program was selected by Fischer (1986a) as best suited to Battelle's needs after review of available heat pump models and modified by their staff to model residential internal-combustion, engine-driven gas-fired heat pumps for use in another GRI development project (Fischer 1986b).

A third variable-speed engine-driven project using the ORNL Mark III model was conducted by Rusk et al (1990) of Iowa State University. These researchers combined an extensive internal combustion model with the ORNL program and reported performance values and trends with ambient temperature which agreed well with earlier work reported by others using proprietary models.

\section{Electric-Driven Applications}

At ORNL, different versions of the modulating model have been used in analytical studies and as an aid in developing and guiding an experimental test plan on a variable-speed breadboard system.

As An Aid To Experimental Testing. Before the breadboard tests described by Miller (1987) were actually conducted, the modulating model was used to conduct a parametric evaluation of the optimal control scheme for the selected control variables of indoor and outdoor fan speed, condenser

\footnotetext{
${ }^{4}$ No doubt there is also an element of greater openness in the reporting of research on the enginedriven variable-speed units which are not yet commercially marketed - in contrast to the electricdriven field where discussion of variable-speed research is more guarded.
} 
subcooling and flow control openings at appropriate ambient and compressor speed combinations. The charge requirements over the range of conditions planned for the tests were also evaluated.

The predicted control-variable optimums were used to narrow the required test ranges for the control variables to those which would most likely bracket the final experimentally determined values. The range of charge requirements similarly predicted were used to guide the experimental test procedure by indicating under which speed and operating conditions the unit should be charged. ${ }^{5}$ Using the model in this manner, the experimental testing required to find the system optimums was minimized. As noted earlier in the section on validation, the model did a credible job of predicting the trends in COP and capacity - as well as the relative charge requirements of the system.

As A Tool To Determine Potential Performance Levels For Residential Unitary Equipment. The present version of the modulating design tool was used by Rice (1992) in a benchmark analysis to predict the maximum performance potential of a near-term modulating residential-size heat pump. Continuously-variable-speed ECMs were assumed to modulate the compressor and the indoor and outdoor fans with ambient temperature in conjunction with existing modulating reciprocating compressor technology. The modulating heat pump design tool was used to optimize such an ECM Benchmark heat pump using speed ranges and total heat exchanger sizes per-unit-capacity equivalent to that used by the highest-SEER-rated variable-speed unit presently on the market. Parametric steady-state performance optimization was conducted at a nominal design cooling ambient of $95^{\circ} \mathrm{F}$ $\left(35^{\circ} \mathrm{C}\right)$ and three off-design ambients of $82^{\circ} \mathrm{F}\left(27.8^{\circ} \mathrm{C}\right)$ cooling and 47 and $17^{\circ} \mathrm{F}\left(8.3\right.$ and $\left.-8.3^{\circ} \mathrm{C}\right)$ heating.

The purpose of this near-term benchmark analysis was two-fold. One purpose was to evaluate the potential performance improvement predicted by a modulating heat pump model with high-efficiency heat exchangers and drives and current reciprocating compressor technology. The second was to demonstrate a methodology for using a modulating heat pump design tool for such a system design analysis.

With regard to the first purpose, a potential increase in steady-state cooling performance ranging from 12 to $24 \%$ was found depending on the sensible-to-total capacity ratio constraints imposed. Steady-state heating performance improvements of 32 to $39 \%$ were also predicted compared to the reference commercially available residential unit.

Relating to the demonstration purpose, the experience with the benchmark analysis suggests that a reasonably-optimized modulating system can be obtained using the-four-point design approach presented there. Comparing this most recent design approach with a black-box optimization approach conducted in an earlier assessment of variable-speed potential (Rice and Fischer 1985), it was found that the present approach was intuitively superior with regard to maintaining engineering control of the design process and by providing a visual (and tabular) mapping of the design objectives and constraints about the vicinity of the optimums.

\footnotetext{
${ }^{5}$ As the test unit had a suction-line accumulator, the predicted point of maximum required active charge was used as the charging condition. At the other conditions of lesser required charge, the accumulator was sufficient to store the excess.
} 
As A Tool To Assess Potential Of Variable-Speed-Drives For Commercial Unitary Equipment. The present version of the modulating design tool is also currently being used by an EPRI contractor to assess the potential of existing and advanced variable-speed-drives and control strategies for commercial air-conditioners and heat pumps. In this analysis, special attention is being given to the motor sizing strategies by making use of the sizing options and the torque mapping capabilities unique to the ORNL modulating design tool. Some of these capabilities were demonstrated previously by Rice (1988a) where an earlier version of the modulating model was used to determine torque requirements and potential efficiency levels for modulating drives in both heating and cooling modes of operation.

\section{USE WITH ALTERNATIVE REFRIGERANTS}

The program has been modified to be capable of using the HFC R134a as a refrigerant. The equations and coding necessary to add R134a using a modified form of the Martin-Hou (Martin 1959) equation of state (EOS) were provided by an industry user of the program (Spatz 1990). Correlations for the thermophysical properties needed by the model were also included. (With these additions, the model can use EOS coefficients for two variations of the Martin-Hou EOS format.) The available thermodynamic property routines have been described by Kartsounes and Erth (1971) and are shown in Figure 20.

The user input has also been modified in the latest version of the modulating model to specify the refrigerant type directly. This is in anticipation of the increased need to evaluate refrigerant alternatives to R22. Presently, only five refrigerants (R12, R22, R114, R502, and R134a) are available to be called directly in the program although thermophysical properties for R11, R13, R21, $\mathrm{R} 23, \mathrm{R} 113$, and C318 are also included in subroutine MUKCP. Use of any of these other refrigerants in the model requires only that the appropriate thermodynamic EOS constants given by Downing (1974) be added to the TABLES subroutine and that compressor maps for these refrigerants be available. The user should be aware that the flow control device models are also somewhat specific to R22, R12, and R502 (in the case of cap tubes and TXVs) and to R22 for short-tube orifices and therefore condenser subcooling should be specified in lieu of specific devices until the flow control models can be further generalized by the user.

Newer pure or azeotropic refrigerant alternatives to R22 can be added with minimal effort as their thermodynamic and thermophysical properties become available. Provided that compressor performance maps are also available for these candidate alternative refrigerants, the program could be used to determine their comparative performance in optimally configured-and-controlled singleor variable-speed air-to-air heat pump systems.

\section{MODEL AVAILABILITY}

The modulating design tool described in this report is available for use by the HVAC research and development community. An executable version for MS-DOS personal computers is provided. 
The source program in FORTRAN can be made available under certain conditions and is modularized so that manufacturers with proprietary compressor, motor, and/or drive information can customize the program to their needs.

The author can be contacted directly (e-mail: riceck@ornl.gov) regarding specifics on how copies of the model can be obtained for research and development purposes. It is hoped that the description of the model capabilities in this report and the demonstration in a companion document (Rice 1992) of the use of the modulating design tool for the design of high-efficiency modulating heat pumps will encourage U.S. manufacturers to obtain the program and investigate further its use for this purpose. 


\section{REFERENCES}

Air-Conditioning and Refrigeration Institute. 1989. Standard for Unitary Air-Conditioning and AirSource Heat Pump Equipment, Standard 210/240-89. Arlington, Virginia

D. T. Beecher and T. J. Fagan, "The Effects of Fin Pattern on the Air-Side Heat Transfer Coefficient in Plate Finned-Tube Heat Exchangers," ASHRAE Transactions, 93, Pt. 2, 1987.

Dabiri, A. E., 1982. "A Steady-State Computer Simulation Model for Air-To-Air Heat Pumps", ASHRAE Transactions, 88, Pt. 2, pp. 973-987.

Damasceno, G. S., Goldschmidt, V. W., and Rooke, S. P., 1990. "Comparison of Three Steady-State Heat Pump Computer Models", ASHRAE Transactions, 96, Pt. 2.

Damasceno, G. S., Domanski, P.A., Rooke, S. P., Goldschmidt, V. W., 1991. "Refrigerant Charge Effects On Heat Pump Performance”, ASHRAE Transactions, 97, Pt. 1.

Domanski, P.A., 1985. Personal communication, National Institute of Standards and Technology, Building Equipment Division, Gaithersburg, Maryland, August.

Domanski, P.A., 1986. Modeling Of a Heat Pump Charged With a Non-Azeotropic Refrigerant Mixture, NBS Technical Note 1218, National Bureau of Standards / U. S. Department of Commerce, January.

Domanski, P.A., 1988. Recommended Procedure for Rating and Testing of Variable Speed Air Source Unitary Air Conditioners and Heat Pumps, NBSIR 88-3781, National Bureau of Standards, May.

Downing, R. C., 1974. "Refrigerant Equations", ASHRAE Transactions, 80, Pt.2.

Fagan, T. J., Lucheta, R. A., and Beecher, D.T., 1987. Oak Ridge National Laboratory Heat Pump Performance Prediction Computer Code: Additions and Verification, Westinghouse Research Report 87-9J8-MATHP-R1, November.

Fischer, R. D., 1986a. State-of-the-Art Review of Vapor-Compression Heat Pump System Models, Task 2.1-Technical Report, GRI, February 1986.

Fischer, R. D., 1986b. Gas Engine Heat Pump Cycle Analysis, Volume I. Model Description and Generic Analysis, GRI-86/0235, October.

Fischer, S. K. and Rice, C. K. 1983. The Oak Ridge Heat Pump Models: I. A Steady-State Computer Design Model for Air-to-Air Heat Pumps, ORNL/CON-80/R1, August.

Fischer, S. K. and Rice, C. K. 1985. "System Design Optimization and Validation for Single-Speed Heat Pumps", ASHRAE Transactions, 91, Pt. 2B, pp. 509-523. 
Fischer, S. K., Rice, C. K., and Jackson, W. L., 1988. The Oak Ridge Heat Pump Model: Mark III Version Program Documentation, ORNL/TM-10192, Oak Ridge National Laboratory, March.

Gray, D. L. and Webb, R. L., 1986. "Heat Transfer and Friction Correlations for Plate Finned-Tube Heat Exchangers Having Plain Fins," Proc. Eighth International Heat Transfer Conference, San Francisco, Heat Transfer 1986, Vol. 6, pp. 2745-2750, Hemisphere: New York

Hiller, C. C. and Glicksman, L. R., 1976. Improving Heat Pump Performance via Compressor Capacity Control - Analysis and Test, Vols. I and II, MIT Energy Laboratory Report No. MITEL 76-001.

Lloyd, J. D., 1987, Personal communication, Emerson Electric Company, Electronic Speed Control Division, Hazelwood, Missouri, April.

Kartsounes, G. T. and Erth, R. A., 1971. "Computer Calculation of the Thermodynamic Properties of Refrigerants 12, 22, and 502", ASHRAE Transactions, 77, Pt. 2.

Kays, W. M. and London, A. L., 1974. Compact Heat Exchangers, McGraw-Hill, New York.

Martin, J. J., 1959. "Correlations and Equations Used in Calculating Thermodynamic Properties of 'Freon' Refrigerants", Thermodynamic and Transport Properties of Gases, Liquids, and Solids, ASME, New York City, p.110.

Makayama, W. and Xu, L. P. , 1983. "Enhanced Fins for Air-Cooled Heat Exchangers -Heat Transfer and Friction Factor Correlations," Proc. ASME-JSME Thermal Engineering Joint Conference, Hawaii, March 1983, eds. Yasuo Mori and Wen-Jei Yang, New York.

Miller, W. A. 1987. "Steady-State Refrigerant Flow and Airflow Control Experiments Conducted on a Continuously Variable Speed Air-to-Air Heat Pumps", ASHRAE Transactions, 93, Pt. 2, pp. 1191-1204.

Miller, W. A. 1988a. "Laboratory Capacity Modulation Experiments, Analyses, and Validation", Proceedings of the 2nd DOE/ORNL Heat Pump Conference: Research and Development on Heat Pumps for Space Conditioning Applications, CONF-8804100, Washington, D.C., April, pp. 7-21.

Miller, W.A. 1988b. "Modulating Heat Pump Component and Adjustable Speed Drive Efficiencies Measured In The Laboratory", ASHRAE Transactions, 94, Pt. 1, pp. 874-891.

Miller, W.A. 1988c. "Laboratory Examination and Seasonal Analyses of the Dynamic Losses for a Continuously Variable Speed Heat Pump", ASHRAE Transactions, 94, Pt. 2, pp. 1246-1268.

Miller, W.A. 1989. Personal communication, Oak Ridge National Laboratory, Energy Division, Oak Ridge, Tennessee, January. 
Monahan, R. E., 1986. Phase 1-B Development of Kinematic Stirling/Rankine Commercial GasFired Heat Pump System, Final Report, GRI-86/0192, July.

Rice, C. K. and Fischer, S. K., 1985. "A Comparative Analysis of Single- and ContinuouslyVariable-Capacity Heat Pump Concepts", Proceedings of the DOE/ORNL Heat Pump Conference: Research and Development on Heat Pumps for Space Conditioning Applications, CONF-841231, Washington, D. C., pp. 57-65.

Rice, C. K., Fischer, S. K., and Emerson, C. J., 1985. The Oak Ridge Heat Pump Models: II. An Annual Performance Factor / Loads Model for Residential Air-Source Heat Pumps, ORNLCON-160.

Rice, C. K. 1987. "The Effect Of Void Fraction Correlation and Heat Flux Assumption On Refrigerant Charge Inventory Predictions", ASHRAE Transactions, 93, Pt. 1, pp. 341-367.

Rice, C. K. 1988a. "Efficiency Characteristics of Speed-Modulated Drives at Predicted Torque Conditions for Air-To Air Heat Pumps", ASHRAE Transactions, 93, Pt. 1, pp. 341-367.

Rice, C.K. 1988b. "Capacity Modulation Component Characterization and Design Tool Development", Proceedings of the 2nd DOE/ORNL Heat Pump Conference: Research and Development on Heat Pumps for Space Conditioning Applications, CONF-8804100, Washington, D.C., April, pp. 23-33.

Rice, C.K., 1992. "Benchmark Performance Analysis Of An ECM-Modulated Air-To-Air-Heat Pump With Reciprocating Compressor", ASHRAE Transactions, 97, Pt.1.

Rusk, R. P., Van Gerpen, J. H., Nelson, R. M., Pate, M. B., 1990. "Development And Use Of a Mathematical Model Of An Engine-Driven Heat Pump", ASHRAE Transactions, 96, Pt. 2

Spatz, M., 1990. Personal communication, Allied-Signal Corporation, Buffalo, New York, April.

Young, G. 1990. Personal communication, General Electric, Motor Technology Department, Fort Wayne, Indiana, October.

Zigler, R. V. 1987. Personal communication, General Electric, Motor Technology Department, Fort Wayne, Indiana, May 


\section{APPENDIX A \\ CONTOUR SELECTION DATA FILE 'CONCHZ'}

\section{Input Data Definitions and Format}

Tables A.1 to A.4 describe the input data options for the parametric front-end to the ORNL Modulating Heat Pump Model. The input format for the choice of independent and dependent variables for parametric analysis is first given. This is supplemented by Tables A.2 through A.4 which describe the choices of independent and dependent variables which are built into the program. Table A.5 describes the format of the output contour-data-generation file generated by the model for the parameters selected by the user.

The 'CONCHZ' data file must always be the first input file to be read by Unit 5 - the default input unit number. $\mathrm{CONCHZ}$ is followed by the heat pump specification file 'HPDATA' - also read by Unit 5 as default. The remaining (optional) input data file 'CONTRL', which is described in Appendix $\mathrm{H}$, has a default unit number of 24 . The printed output is sent to unit 6 and the contourdata -generation file as described by Table A.5 is sent to unit 8 by default. All of the default input and output unit number settings are specified in the BLOCK DATA routine and are described further at the beginning of Appendix D and at the end of Appendix E.

\section{Sample Input File (Regular and Annotated)}

This section contains regular and annotated listings, Listings A.1 and A.2, respectively, of a sample 'CONCHZ' data file. The selected example is for a heat pump operating in the heating mode with a compressor frequency range from $180 \mathrm{~Hz}$ down to $50 \mathrm{~Hz}$ and for an ambient range from $17^{\circ} \mathrm{F}$ to $47^{\circ} \mathrm{F}$. All the available dependent variables were selected for this example.

The regular listing represents the data set as directly used by the model while the annotated version of the same data set is labeled with the variable names as described in Table A.1. The annotated listing is provided as a visual reference to users modifying existing data sets. 



\section{Table A.1. Description of CONCHZ Input Data to MODCON Program}

Variable Variable Description

Sample Value

Name

Selection of Operating Mode(s)

LINE $1 \quad$ FORMAT(I3)

MODEGN operating mode selector 1

$=0$, bypass contour data generation front-end (omit remainder of data set)

$=1$, steady-state heating mode

$=2$, steady-state cooling mode

$=3$, annual, with seasonal breakdowns (not yet operational)

$=4$, steady-state heating and cooling modes (for use with CONTRL.DAT)

$=5$, steady-state heating, cooling, and annual modes, with seasonal breakdowns (not yet operational)

\section{Heading Identifiers For Selected Operating Mode(s)}

LINE 2 FORMAT(10A8)

MTITLE(J) title heading(s) identifying contour data sets generated for HEATING MODE heating, cooling, and/or annual modes as appropriate

$\mathrm{J}=1 \quad$ if MODEGN $=1$ or 2 ,

$\mathrm{J}=1,2 \quad$ if MODEGN $=4$, or

$\mathrm{J}=1,2,3$ if $\mathrm{MODEGN}=3$ or 5

Selection of $X$ and $Y$ Independent Variables

LINE $3 \quad$ FORMAT(2I3, 5F10.0)

IDVARX ID number of X independent variable (refer to Table A.2) 18

$\begin{array}{lll}\text { NX } & \text { number of } X \text { values to be evaluated }\end{array}$

$\begin{array}{lll}\text { XLO minimum value of } \mathrm{X} \text { variable } & 7.0\end{array}$

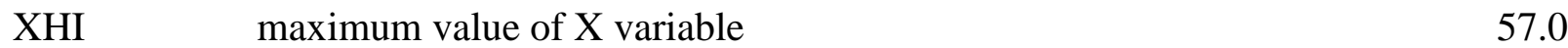

$\begin{array}{lll}\mathrm{XREF}(\mathrm{J}) & \mathrm{X} \text { reference point to mark on contour plots where } & 47.0\end{array}$

$\mathrm{J}=1 \quad$ if MODEGN $=1$ or 2 ,

$\mathrm{J}=1,2$ if MODEGN $=4$, or

$\mathrm{J}=1,2,3$ if MODEGN $=3$ or 5

LINE $4 \quad$ FORMAT(2I3, 5F10.0)

IDVARY ID number of Y independent variable (refer to Table A.2) 21

NY number of Y values to be evaluated (set to 0 for 1-D parameters) 
$\begin{array}{llr}\text { YLO } & \text { minimum value of Y variable } & 60.0\end{array}$

$\begin{array}{lll}\text { YHI } & \text { maximum value of Y variable } & 240.0\end{array}$

$\begin{array}{lll}\text { YREF }(J) & \text { Y reference point to mark on contour plots where } & 120.0\end{array}$

$\mathrm{J}=1 \quad$ if MODEGN $=1$ or 2 ,

$\mathrm{J}=1,2 \quad$ if MODEGN $=4$, or

$\mathrm{J}=1,2,3$ if MODEGN $=3$ or 5

\section{Operational Data (Included Only If MODEGN <3)}

LINE 5 FORMAT(I3)

NVALS number of control variables to be user-specified $\quad 1$

LINES FORMAT(2I3,6F10.0)

$\mathrm{J}=1, \mathrm{NVALS}$

$\mathrm{NFUN}(\mathrm{J}) \quad$ integer value selecting controlled parameter " $\mathrm{y}$ " where $\mathrm{y}=\mathrm{f}(\mathrm{x}) \quad 1$

$=1$, for compressor inlet superheat $\left(\mathrm{F}^{\circ}\right)$

$=2$, for condenser exit subcooling $\left(\mathrm{F}^{\circ}\right)$

$=3$, for indoor blower frequency $(\mathrm{Hz})$

$=4$, for outdoor fan frequency $(\mathrm{Hz})$

$=5$, for building load $(\mathrm{kBtuh} / \mathrm{h})$ - not fully operational, only used to determine supplemental heating needs

$\mathrm{NIND}(\mathrm{J}) \quad$ integer value selecting controlling parameter " $\mathrm{X}$ " 1

$=1$, for ambient temperature $\left({ }^{\circ} \mathrm{F}\right)$

$=2$, for compressor frequency $(\mathrm{Hz})$

Coefficients of linear control algorithm of the form $y=\left(y_{2}-y_{1}\right) /\left(x_{2}-x_{1}\right) \cdot\left(x-x_{1}\right)+y_{1}$

$\operatorname{VINDEP}(\mathrm{J}, 1)$ selected value of $\mathrm{x}_{1}$

$\operatorname{VINDEP}(\mathrm{J}, 2)$ selected value of $\mathrm{x}_{2}$

$\operatorname{VDEPEN}(\mathrm{J}, 1)$ prescribed value of $\mathrm{y}_{1}$

$\operatorname{VDEPEN}(\mathrm{J}, 2)$ prescribed value of $\mathrm{y}_{2}$

$\begin{array}{lll}\operatorname{VDEPLO}(\mathrm{J}) & \text { minimum-allowable value of } \mathrm{y}_{1} & 0.0\end{array}$

VDEPHI $(J)$ maximum-allowable value of $y_{2}$ 


\section{Dependent Variable Selections}

LINE $6 \quad$ FORMAT(I3)

NDVSS number of steady-state dependent variables

LINES FORMAT(I3,2X,8A8)

$\mathrm{J}=1$,NDVSS

IDVSS(J) ID number of dependent steady-state performance variable (see Table A.3)

NAMSS(J) user-selected descriptive label for variable IDVSS(J)

(The following lines are omitted if MODEGN is equal to 1,2 , or 4.)

LINE $7 \quad$ FORMAT(I3)

NDVAPF number of seasonal performance variables

LINES FORMAT(I3,2X,8A8)

$\mathrm{J}=1, \mathrm{NDVAPF}$

IDVAPF(J) ID number of dependent seasonal performance variable (see Table A.4)

NAMAPF(J) user-selected descriptive label for variable IDVAPF(J) 

Table A.2. Key to Independent Contour Variables Available for Selection in Input Data File CONCHZ

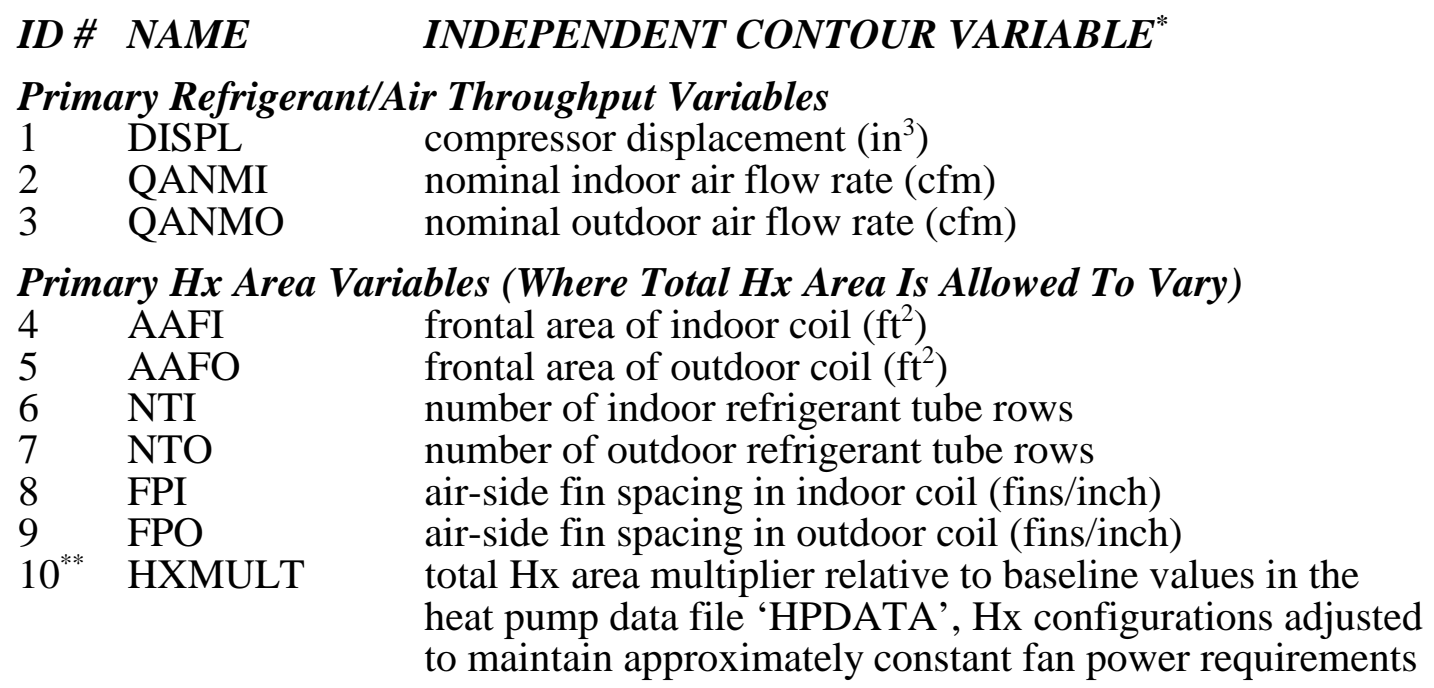

\section{Flow Control Variables}

11 DTROC refrigerant subcooling at condenser exit $\left(\mathrm{F}^{\circ}\right)$

12 TXVRAT capacity of the TXV (tons)

13 CAPFLO capillary tube flow factor

14 ORIFD diameter of short-tube orifice (in.)

\section{Charge Control Variables}

15 SUPER compressor inlet superheat $\left(\mathrm{F}^{\circ}\right)$

16 REFCHG system refrigerant charge (lbm)

\section{Air-Side-Condition Variables}

17 TAIII temperature of air entering indoor unit $\left({ }^{\circ} \mathrm{F}\right)$

18 TAIIO temperature of air entering outdoor unit $\left({ }^{\circ} \mathrm{F}\right)$

19 RHII indoor relative humidity

20 RHIO outdoor relative humidity

\section{Modulation Variables}

21 CMPFRQ operating compressor drive frequency $(\mathrm{Hz})$

22 FRQIDF operating indoor blower frequency $(\mathrm{Hz})$

23 FRQODF operating outdoor blower frequency $(\mathrm{Hz})$

24 CFRQRT operating compressor drive frequency ratio (relative to nominal)

25 FRQRTI operating indoor fan drive frequency ratio (relative to nominal)

26 FRQRTO operating outdoor fan drive frequency ratio (relative to nominal)

Motor Sizing Variables

27 CSIZMT nominal motor size for selected compressor (hp)

28 SIZMTI nominal indoor blower motor size (hp)

29 SIZMTO nominal outdoor fan motor size (hp)

\footnotetext{
"See the HPDATA input description and the text description accompanying Table 1 for further definitions of the independent variables.

** Refrigerant circuiting adjusted to hold refrigerant-side pressure drop constant.
} 


\title{
Table A.2. Key to Independent Contour Variables Available for Selection in Input Data File CONCHZ (continued)
}

\author{
ID \# NAME INDEPENDENT CONTOUR VARIABLE
}

\section{Hx Design Variables (Where Total Hx Area For Both Coils Is Held Constant)}

Independent of Total Hx Area

30 NSECTI number of equivalent indoor circuits

31 NSECTO number of equivalent outdoor circuits

32 DDUCT indoor duct size (+in.) or external pressure drop $\left(-\mathrm{in} . \mathrm{H}_{2} \mathrm{O}\right)$

Fixed Area Ratio, Tradeoff Variables For Single Hx's Holding Individual Hx Area Constant

33 NTI (vs AAFI) \# of indoor refrigerant tube rows vs frontal area - FPI held constant

34 NTO (vs AAFO) \# of outdoor refrigerant tube rows vs frontal area - FPO held constant

$35^{* *} \quad$ FPI (vs AAFI) indoor fin pitch (fins/in) vs frontal area - NTI held constant

$36^{* *}$ FPO (vs AAFO) outdoor fin pitch (fins/in) vs frontal area - NTO held constant

$37^{* *} \quad$ FPI (vs NTI) indoor fin pitch (fins/in) vs \# of tube rows - AAFI held constant

$38^{* *}$ FPO (vs NTO) outdoor fin pitch (fins/in) vs \# of tube rows - AAFO held constant

Adjustable Area Ratio, Tradeoff Variables Across Hx's Holding Total Hx Area Constant

One-Variable-Adjustment

$39^{* *}$ FRACI fraction of total area in indoor coil, frontal area AAFI adjusted and

$40^{* *} \quad$ with AAFI offset by AAFO to maintain fixed total hx area - fixed NT and FP

$40^{* * *}$ FRACO fraction of total area in outdoor coil, frontal area AAFO adjusted and

with AAFO offset by AAFI to maintain fixed total hx area - fixed NT and FP

$41^{* *}$ FRACI fraction of total area in indoor coil, \# of tube rows NTI adjusted and with NTI offset by NTO to maintain fixed total hx area - fixed AAF and FP

$42^{* *} \quad$ FRACO fraction of total area in outdoor coil, \# of tube rows NTO adjusted and with NTO offset by NTI to maintain fixed total hx area - fixed AAF and FP

43 FRACI fraction of total area in indoor coil, fin spacing FPI adjusted and with FPI offset by FPO to maintain fixed total hx area - fixed AAF and NT

44 FRACO fraction of total area in outdoor coil, fin spacing FPO adjusted and with FPO offset by FPI to maintain fixed total hx area - fixed $A A F$ and NT

Two-Variable-Adjustment

$45^{* *}$ FRACI with fraction of total area in indoor coil, AAFI and NTI adjusted and offset AAFI and NTI by AAFO and NTO to maintain fixed total hx area - fixed FP

$46^{* *} \quad$ FRACO with fraction of total area in outdoor coil, AAFO and NTO adjusted and offset AAFO and NTO by AAFI and NTI to maintain fixed total hx area - fixed FP

$47^{* *} \quad$ FRACI with fraction of total area in indoor coil, AAFI and FPI adjusted and offset AAFI and FPI by AAFO and FPO to maintain fixed total hx area - fixed NT

$48^{* *} \quad$ FRACO with fraction of total area in outdoor coil, AAFO and FPO adjusted and offset AAFO and FPO by AAFI and FPI to maintain fixed total hx area - fixed NT

$49^{* *} \quad$ FRACI with fraction of total area in indoor coil, NTI and FPI adjusted and offset NTI and FPI by AAFO and FPO to maintain fixed total hx area - fixed AAF

$50^{* *} \quad$ FRACO with fraction of total area in outdoor coil, NTO and FPO adjusted and offset NTO and FPO by AAFI and FPI to maintain fixed total hx area - fixed AAF

Three-Variable-Adjustment (Maintains Approx. Constant Fan Powers)

$51^{* *} \quad$ FRACI w/NTI, fraction of total area in indoor coil, NTI, AAFI, and FPI adjusted AAFI and FPI and offset by NTO, AAFO, and FPO to maintain fixed total hx area

$52^{* *} \quad$ FRACO w/NTO fraction of total area in outdoor coil, NTO, AAFO, and FPO adjusted AAFO, and FPO and offset by NTI, AAFI, and FPI to maintain fixed total hx area 


\title{
Table A.3. Key to Steady-State Dependent Contour Variables Available for Selection in Input Data File CONCHZ
}

\section{ID \# STEADY-STATE DEPENDENT VARIABLE}

\author{
Heat Pump Performance \\ 1 heat pump COP \\ 2 heat pump capacity $(\mathrm{kBtu} / \mathrm{h})$ \\ 3 heat pump EER (BTU/w-h) \\ 4 evaporator sensible-to-total capacity ratio (sensible heat ratio - SHR) \\ $5 \quad$ supply air temperature $\left({ }^{\circ} \mathrm{F}\right)$ \\ 6 heat pump system COP including $I^{2} R$ heat to meet specified heating load \\ 7 heat pump system capacity including $\mathrm{I}^{2} \mathrm{R}$ heat $(\mathrm{kBtu} / \mathrm{h})$ \\ 8 required $\mathrm{I}^{2} \mathrm{R}$ heat $(\mathrm{kBtu} / \mathrm{h})$
}

\section{Heat Pump Power Requirements}

9 total heat pump / $\mathrm{I}^{2} \mathrm{R}$ input power $(\mathrm{kw})$

10 average resistance heater power draw (kw)

11 compressor input power (kw)

12 total heat pump fan power (watts)

13 indoor blower power (watts)

14 outdoor fan power (watts)

\section{Refrigerant-Side Conditions}

15 evaporator average refrigerant saturation temperature $\left({ }^{\circ} \mathrm{F}\right)$

16 condenser average refrigerant saturation temperature $\left({ }^{\circ} \mathrm{F}\right)$

17 evaporator exit refrigerant temperature $\left({ }^{\circ} \mathrm{F}\right)$

18 condenser exit refrigerant temperature $\left({ }^{\circ} \mathrm{F}\right)$

19 refrigerant saturation temperature entering compressor $\left({ }^{\circ} \mathrm{F}\right)$

20 refrigerant saturation temperature leaving compressor $\left({ }^{\circ} \mathrm{F}\right)$

21 compressor pressure ratio

22 refrigerant mass flow rate $(\mathrm{lbm} / \mathrm{h})$

23 evaporator refrigerant pressure drop (psi)

24 condenser refrigerant pressure drop (psi)

25 evaporator average refrigerant two-phase heat transfer coefficient $\left(\mathrm{Btu} / \mathrm{h} / \mathrm{ft}^{2} /{ }^{\circ} \mathrm{F}\right)$

26 condenser average refrigerant two-phase heat transfer coefficient $\left(\mathrm{Btu} / \mathrm{h} / \mathrm{ft}^{2} /{ }^{\circ} \mathrm{F}\right)$

\section{Compressor Values - Selected Compressor}

percentage of nominal drive frequency of selected compressor (\%) selected compressor motor/drive efficiency (\%) estimated compressor superheat efficiency of selected compressor $(\%)$ selected compressor can isentropic efficiency $(\%)$ selected compressor can volumetric efficiency $(\%)$ 
Table A.3. Key to Steady-State Dependent Contour Variables Available for Selection in Input Data File CONCHZ (continued)

\author{
Compressor Values - Base Compressor \\ 38 base compressor operating speed (rpm) \\ 39 base compressor operating torque (lb- $\mathrm{ft})$ \\ 40 base compressor nominal torque (lb- $\mathrm{ft}$ ) \\ 41 percentage of base compressor nominal torque (\%) \\ 42 base compressor motor/drive efficiency (\%) \\ 43 base compressor can isentropic efficiency $(\%)$ \\ 44 base compressor can volumetric efficiency (\%)

\section{Compressor Motor Conversion Multipliers} \\ 45 ratio of selected (converted) to base compressor speed \\ 46 ratio of selected (converted) to base motor/drive efficiency w/o suction gas heating \\ effects \\ $47 \quad$ estimated suction gas superheating from base compressor motor $\left(\mathrm{F}^{\circ}\right)$ \\ $48 \quad$ estimated suction gas superheating from selected compressor motor $\left(\mathrm{F}^{\circ}\right)$ \\ 49 efficiency multiplier due to differential suction gas heating effects \\ 50 mass flow rate multiplier due to differential suction gas heating effects \\ 51 ratio of selected (converted) to base motor/drive efficiency with suction gas heating \\ effects \\ 52 ratio of selected (converted) to base refrigerant mass flow rate with suction gas \\ heating effects \\ 53 ratio of selected (converted) to base compressor power with suction gas heating \\ effects
}

\title{
Indoor Coil / Blower Values
}

54 indoor air flow rate $(\mathrm{cfm})$

55 indoor blower speed (rpm)

56 percentage of nominal indoor blower frequency $(\%)$

57 indoor air face velocity ( $\mathrm{ft} / \mathrm{min})$

58 indoor air surface velocity ( $\mathrm{ft} / \mathrm{min})$

59 indoor air-side heat transfer coefficient $\left(\mathrm{Btu} / \mathrm{h} / \mathrm{ft}^{2} /{ }^{\circ} \mathrm{F}\right)$

60 indoor air-side total pressure drop (in. of $\mathrm{H}_{2} \mathrm{O}$ )

61 indoor coil fin augmentation heat transfer multiplier

62 indoor coil fin augmentation pressure drop multiplier

63 indoor blower operating torque (oz-ft)

64 percentage of selected indoor motor nominal torque (\%)

65 required nominal size of selected indoor motor (hp)

66 motor/drive efficiency of selected indoor drive (\%)

67 motor/drive efficiency of base indoor drive (\%)

68 combined blower/motor/drive efficiency of selected indoor blower (\%)

\section{Outdoor Coil / Fan Values}

69 outdoor air flow rate (cfm)

70 outdoor fan speed (rpm)

71 percentage of nominal outdoor fan frequency (\%)

72 outdoor air face velocity ( $\mathrm{ft} / \mathrm{min})$

73 outdoor air surface velocity $(\mathrm{ft} / \mathrm{min})$

74 outdoor air-side heat transfer coefficient $\left(\mathrm{Btu} / \mathrm{h} / \mathrm{ft}^{2} /{ }^{\circ} \mathrm{F}\right)$

75 outdoor air-side total pressure drop (in. of $\mathrm{H}_{2} \mathrm{O}$ ) 
Table A.3. Key to Steady-State Dependent Contour Variables Available for Selection in Input Data File CONCHZ (continued)

\author{
Outdoor Coil / Fan Values (continued) \\ 76 outdoor coil fin augmentation heat transfer multiplier \\ 77 outdoor coil fin augmentation pressure drop multiplier \\ 78 outdoor fan operating torque (oz-ft) \\ 79 percentage of selected outdoor motor nominal torque (\%) \\ 80 required nominal size of selected outdoor motor (hp) \\ 81 motor/drive efficiency of selected outdoor drive (\%) \\ 82 motor/drive efficiency of base outdoor drive (\%) \\ 83 combined fan/motor/drive efficiency of selected outdoor fan (\%) \\ 84 outdoor fan-only efficiency (\%) \\ 85 outdoor fan specific speed
}

\title{
Charge And Flow Control Requirements
}

86 required refrigerant charge (lbm)

87 required capillary flow factor

88 required TXV capacity rating (tons)

89 fraction of rated TXV opening

90 required short tube orifice diameter (in)

91 required simple orifice effective $\mathrm{kA}$ product $\left(\mathrm{in}^{2}\right)$

Flow Control Parameters

92 evaporator exit refrigerant superheat $\left(\mathrm{F}^{\circ}\right)$ or quality (negative of)

93 compressor inlet refrigerant superheat $\left(\mathrm{F}^{\circ}\right)$ or quality (negative of)

94 compressor exit refrigerant superheat $\left(\mathrm{F}^{\circ}\right)$ or quality (negative of)

95 condenser exit refrigerant subcooling $\left(\mathrm{F}^{\circ}\right)$ or quality (negative of)

96 flow control inlet refrigerant subcooling $\left(\mathrm{F}^{\circ}\right)$ or quality (negative of)

97 refrigerant temperature at flow control inlet $\left({ }^{\circ} \mathrm{F}\right)$

98 refrigerant suction temperature at compressor inlet $\left({ }^{\circ} \mathrm{F}\right)$

99 refrigerant discharge temperature at compressor exit $\left({ }^{\circ} \mathrm{F}\right)$

100 refrigerant suction pressure at compressor inlet (psia)

101 refrigerant discharge pressure at compressor exit (psia)

Indoor Air-Side Pressure-Drop-Related Values

102 required indoor duct size (in.)

103 indoor duct pressure drop (in. of $\mathrm{H}_{2} \mathrm{O}$ )

104 indoor filter pressure drop (in. of $\mathrm{H}_{2} \mathrm{O}$ )

105 indoor heater pressure drop (in. of $\mathrm{H}_{2} \mathrm{O}$ )

106 indoor coil pressure drop (in. of $\mathrm{H}_{2} \mathrm{O}$ )

Additional Derived Compressor Efficiency Values

107 selected compressor-only isentropic efficiency - excluding motor (\%)

108 baseline compressor-only isentropic efficiency - excluding motor (\%)

\section{Additional Dehumidification Parameters}

109 wetted fraction of evaporator coil

110 moisture removal rate $(\mathrm{lbm} / \mathrm{h})$ 

Table A.4. Key to Seasonal Dependent Contour Variables Available for Selection in Input Data File CONCHZ (Not Yet Available)

$\begin{array}{ll}\text { ID \# } & \text { SEASONAL DEPENDENT VARIABLE} \\ 1 & \text { heating seasonal performance factor } \\ 2 & \text { cooling seasonal performance factor } \\ 3 & \text { annual performance factor } \\ 4 & \text { heating seasonal energy load (kBtuh) } \\ 5 & \text { cooling seasonal energy load (kBtuh) } \\ 6 & \text { annual energy load (kBtuh) } \\ 7 & \text { heating seasonal energy use (kWh or kBtuh) } \\ 8 & \text { cooling seasonal energy use (kWh or kBtuh) } \\ 9 & \text { annual energy use (kWh or kBtuh) } \\ 10 & \text { heating seasonal parasitic energy use (kWh) } \\ 11 & \text { cooling seasonal parasitic energy use (kWh) } \\ 12 & \text { annual parasitic energy use (kWh) } \\ 13 & \text { heating operating time (h) } \\ 14 & \text { cooling operating time (h) } \\ 15 & \text { annual operating time (h) } \\ 16 & \text { supplemental heating energy use }(\mathrm{kWh} \text { or kBtuh) } \\ 17 & \text { defrost tempering energy use (kWh or kBtuh) } \\ 18 & \text { defrost heat pump energy use (kWh or kBtuh) } \\ 19 & \text { total defrost time (h) } \\ 20 & \text { total number of defrosts }\end{array}$



Table A.5. Description of Output Contour Data File From MODCON

\author{
Identifying Name for Data Set: \\ RECORD $1 \quad$ FORMAT (80A) \\ MTITLE data set identifier from line 2 of CONCHZ input data \\ Independent Variable (Parametric) Data: \\ Identification of $X$ and $Y$ Independent Variables \\ $X$-Data \\ RECORD $2 \quad$ FORMAT $(2 \mathrm{I} 3,3 \mathrm{~F} 10.2)$ \\ IDVARX identifying ID number of $X$ independent variable (refer to Table A.2) \\ $\mathrm{NX} \quad$ number of $X$ values to be evaluated \\ XLO minimum value of $X$ variable \\ XHI maximum value of $X$ variable \\ $\mathrm{XREF} \quad \mathrm{X}$ coordinate of any specified reference point (to mark on contour plot) \\ Y-Data \\ RECORD $3 \quad$ FORMAT $(2 \mathrm{I} 3,3 \mathrm{~F} 10.2)$ \\ IDVARY identifying ID number of Y independent variable (refer to Table A.2) \\ NY number of Y values to be evaluated \\ YLO minimum value of Y variable \\ YHI maximum value of $Y$ variable \\ YREF Y coordinate of any specified reference point (to mark on contour plot) \\ Dependent Variable (Performance) Data: \\ Number of Data Sets \\ RECORD $4 \quad$ FORMAT (I3) \\ NDVAR number of dependent variables for which data are generated \\ Records 5 and 6 are generated for each dependent variable ( $J=1$, NDVAR). \\ Identification of Dependent Variable \\ RECORD $5 \quad$ FORMAT (I3, 2X, 75A) \\ $\operatorname{IDVARD}(\mathrm{J}) \quad$ identifier number for dependent variable \\ NAMDEP $(J) \quad$ descriptive label for dependent variable \\ Values of Dependent Variable \\ RECORD $6 \quad$ FORMAT (1P, 6E13.5) \\ VALDEP $\longrightarrow \quad$ (IX, IY, IDVARD $(\mathrm{J})$ ) array of function values stored as vectors \\ with the $\mathrm{X}$ subscript increasing most rapidly \\ and the $\mathrm{Y}$ subscript increasing least rapidly \\ going from left to right and top to bottom, respectively. \\ A new line starts each time the Y subscript changes.
}





\section{Listing A.1. Sample Contour Selection Data File 'CONCHZ' -}

\section{File: H2118V.CHZ}

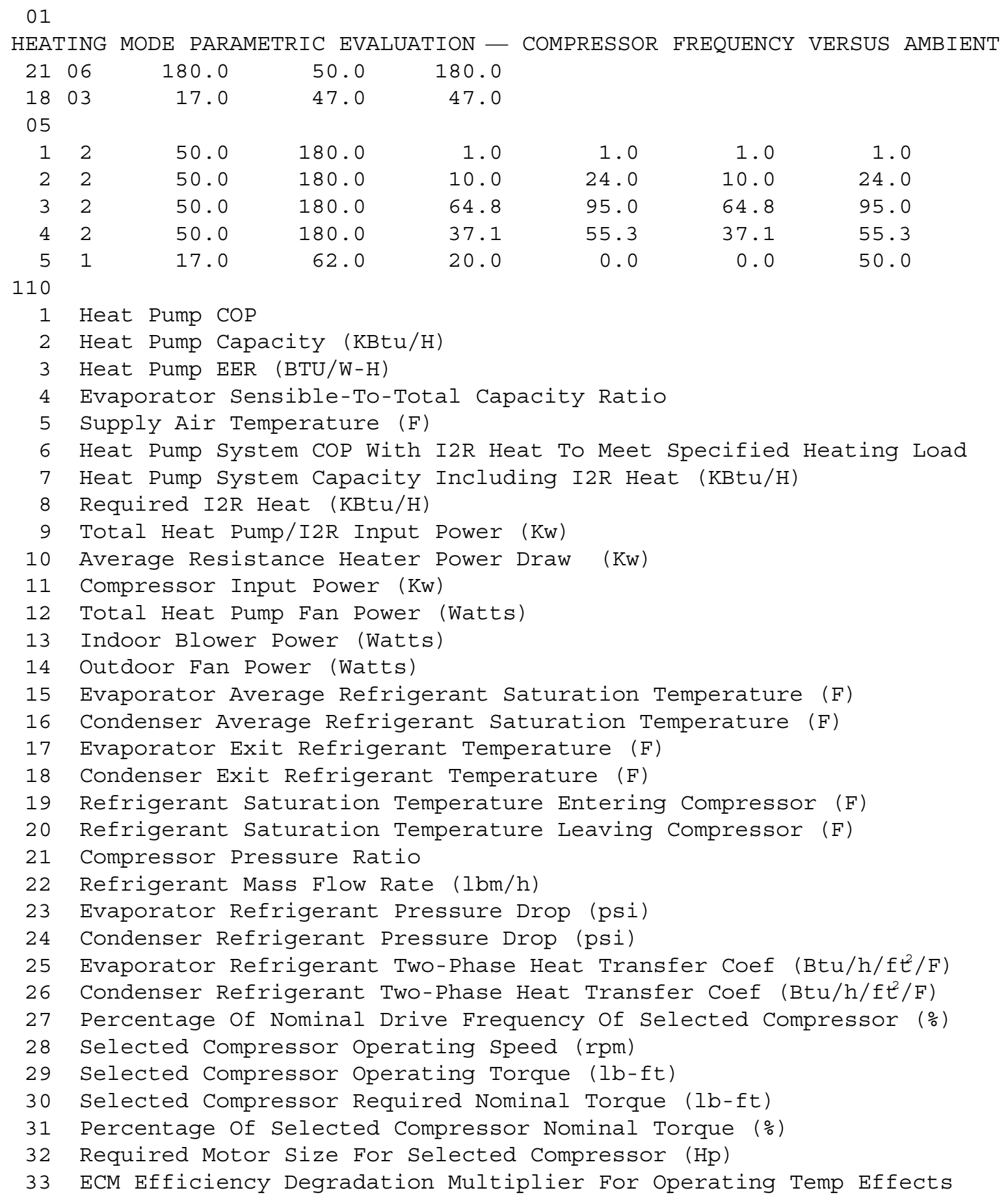




\section{Listing A.1. Sample Contour Selection Data File 'CONCHZ' - (continued)}

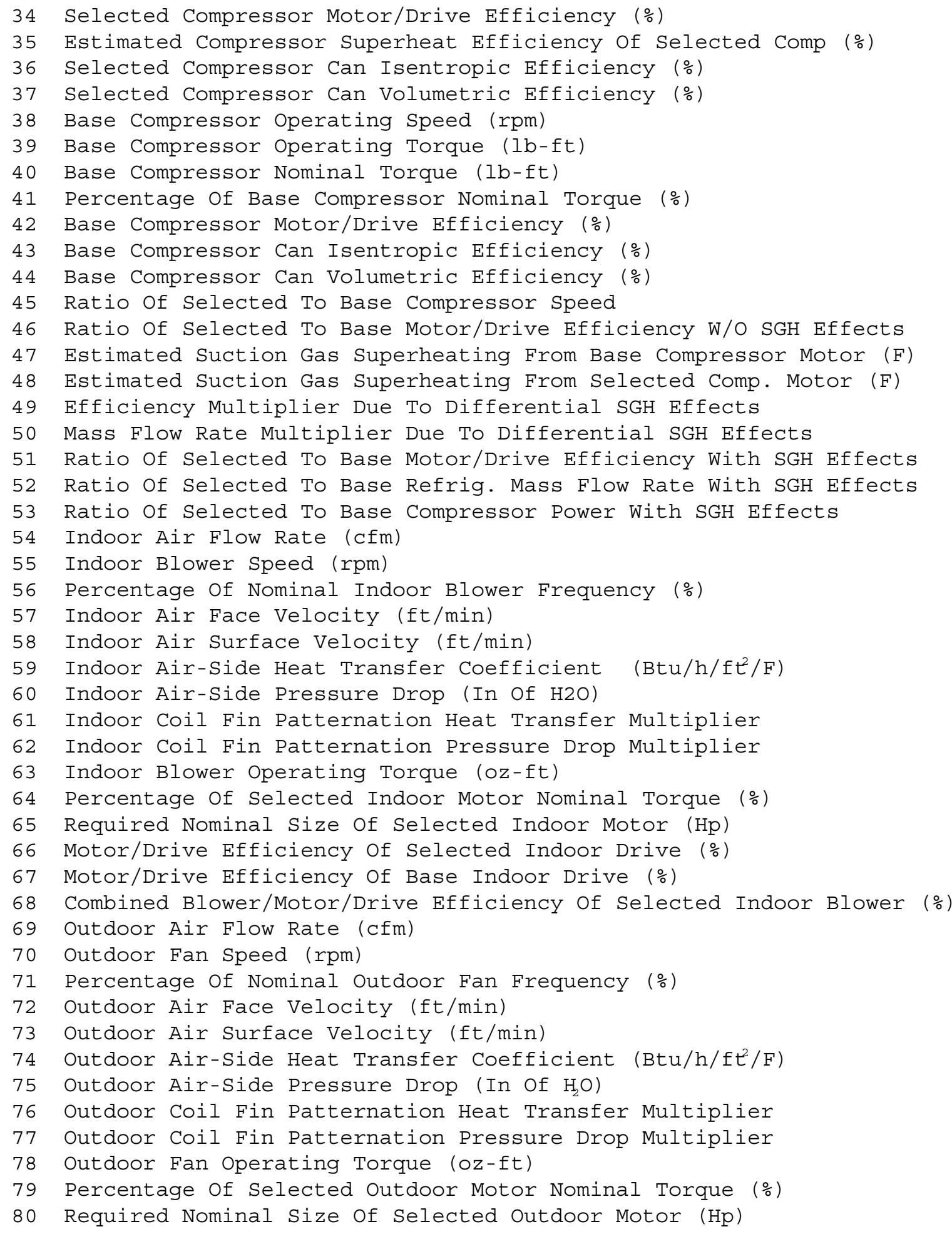




\section{Listing A.1. Sample Contour Selection Data File 'CONCHZ' - (continued)}

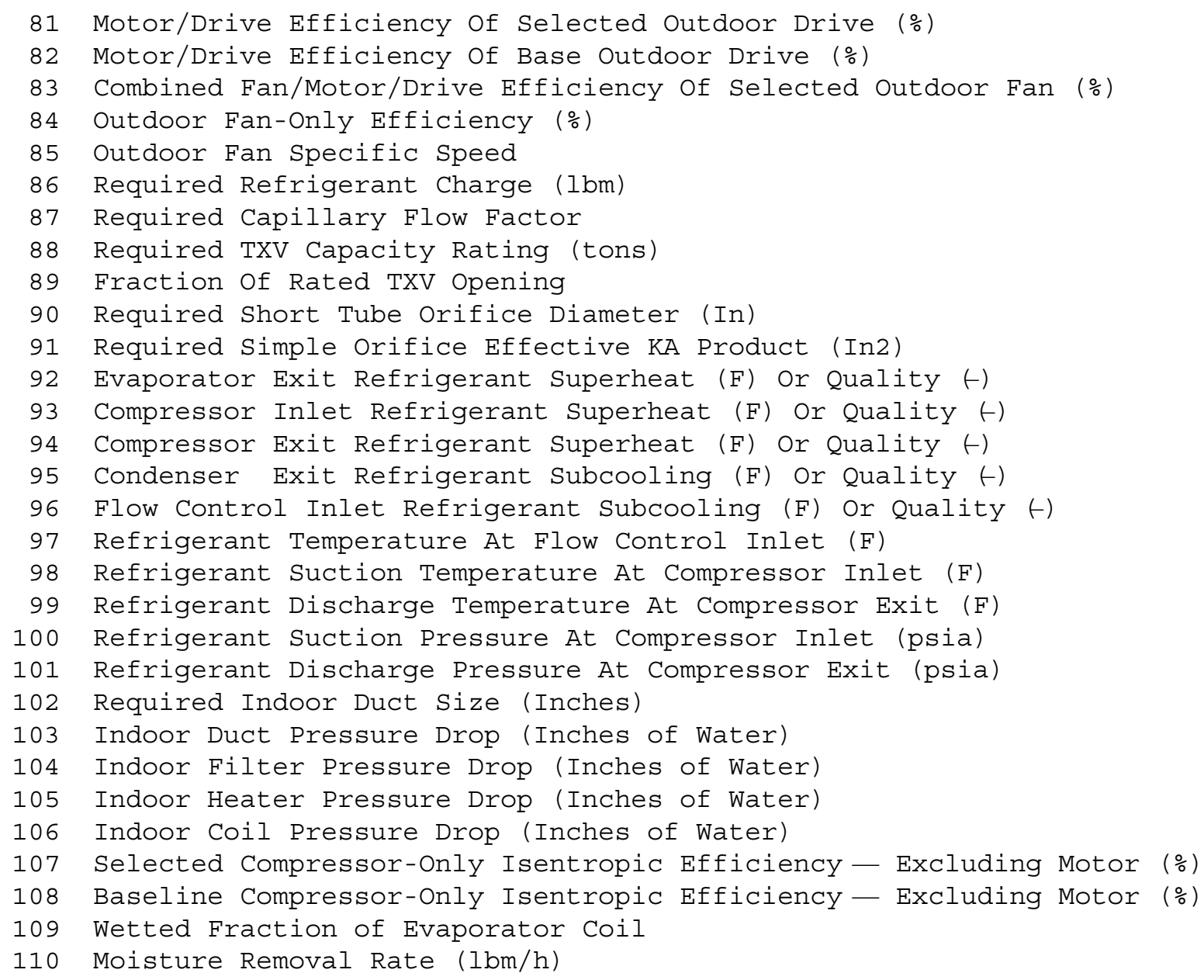





\section{Listing A.2. Annotated Sample Contour Selection Data File 'CONCHZ'}

\section{File: H2118V.CHZ}

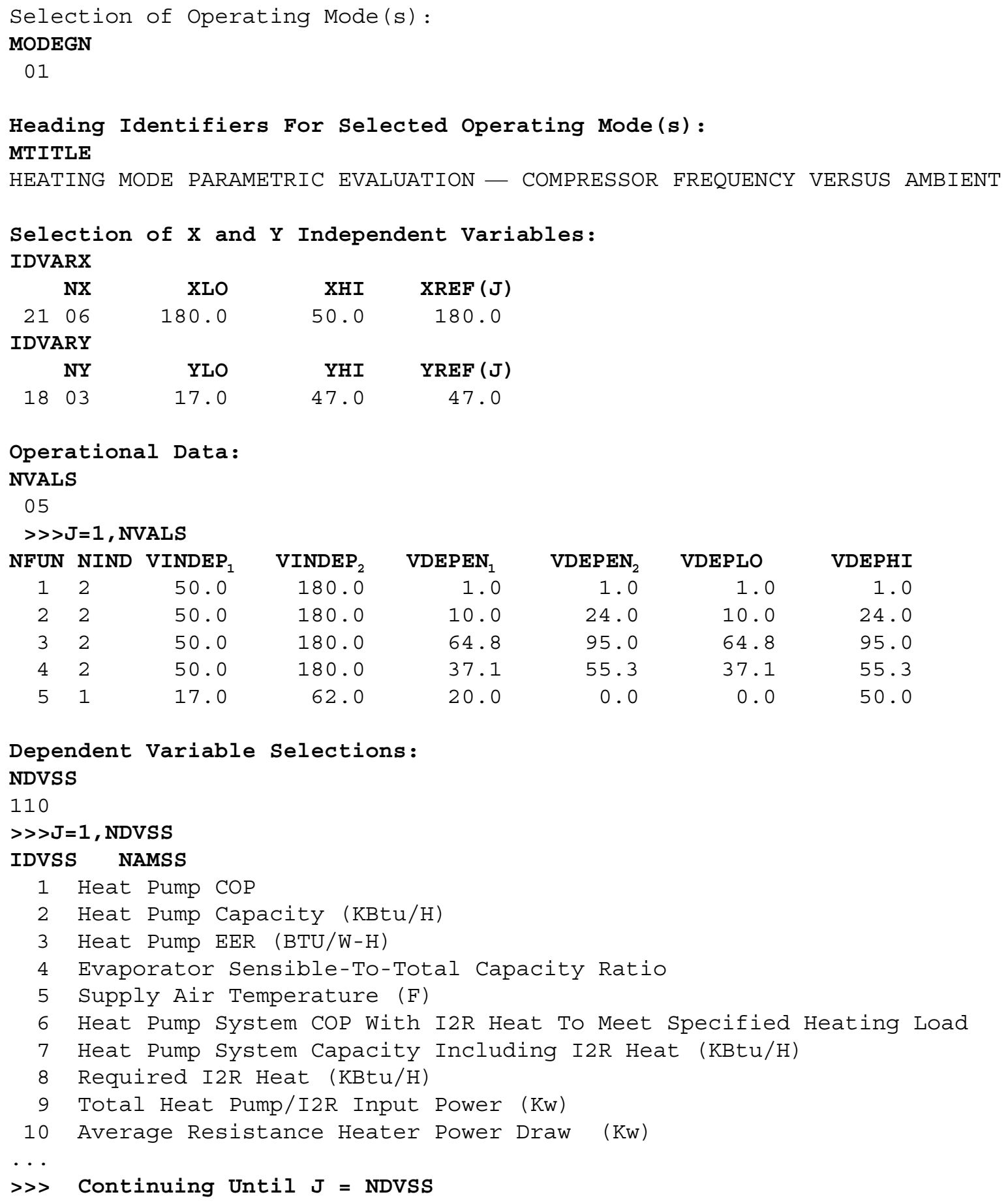





\section{APPENDIX B}

\section{HEAT PUMP SPECIFICATION DATA FILE 'HPDATA'}

\section{Input Data Definitions and Format}

In Table B.1, the input parameters and format requirements for the heat pump specification data file are described. Changes from the ORNL Mark III Single-Speed Version are denoted by vertical change bars in the extreme leftmost column.

The new data file format was designed to minimize changes required to update existing Mark III data sets. Most of the new input requirements are additive (either by appending to existing lines or by adding new lines). Extra lines for variable-speed compressors, specific augmented heat exchanger surfaces, charge inventory aspects, and convengence tolerances were the main additions. The options available to some previous entries have also been expanded.

\section{Sample Input Files (Regular and Annotated)}

This section contains regular Listings B.1 and B.2 and an annotated Listing B.3 of sample 'HPDATA' files. The regular listings B.1 and B.2 are for the same heat pump but for different ambient conditions and analysis purposes.

Listing B.1 is a data set appropriate for use in initial design calculations where the compressor and fan motors sizes have not yet been selected. This example data set is for the $95^{\circ} \mathrm{F}$ design cooling condition and the motors are to be sized by the model to meet user-specified percentages of nominal loading. The external pressure drop of the indoor duct system has also been specified by the user to impose a constant value at the design condition.

Listing B.2 is a data set appropriate for use in off-design calculations once the compressor and fan motors sizes and the indoor duct size have been selected. This example data set is for the $47^{\circ} \mathrm{F}$ offdesign heating condition and the motors and indoor duct system were sized previously by the design calculation at the $95^{\circ} \mathrm{F}$ condition.

\section{The changes required to the data sets to switch from a design to an off-design calculation are} highlighted in bold type in Listings B.1 and B.2.

The regular listings represent the data set as directly used by the model while the annotated version of the first data set is sectioned and labeled with the header types and variable names as described in Table B.1. The annotated listing is provided as a visual reference to users modifying existing data sets.

The compressor curve-fit coefficients required for the 'HPDATA' file can be generated as an output file from the compressor map-fitting program described in Appendix G. This output file can be imported into an existing heat pump model data set with minimal editing when a different compressor needs to be modeled. 
The example data set is for a fairly-representative modulating heat pump with total heat exchanger surface area approximately equivalent to that of a present-day commercially-available variable speed unit. The heat exchanger geometry details and compressor are that of a first-generation modulating heat pump described by Miller (1987, 1988a, 1988b). However, the compressor curve-fits provided are for sine-wave-driven tests of the first-generation-modulating compressor rather than for the inverter-driven case. The sine-wave-driven modulating induction motor data built into the model is for the same model motor used in the tested compressor. As such, the provided sample-compressordata is the most consistent baseline for use in assessing the effect of the benefits of advanced drives. 
Table B.1. Description of HPDATA Input to the MODCON Program 


\section{TITLE and OUTPUT DATA:}

LINE \#1 FORMAT $(A 80)$

| HTITLE Descriptive title for heat pump system defined by this data set $\quad$ SAMPLE

LINE \#2 FORMAT(8I10)

LPRINT Output switch to control the type and amount of printed results 1

$=-2$, for minimum output from contour data generation front end, no heat pump model output

$=-1$, for diagnostic output from contour data generation front end, no heat pump model output

$=0$, for minimum heat pump model output with only an energy input and output summary

$=1, \quad$ for a summary of the system operating conditions and component performance calculations as well as the energy summary

$=2$, for output after each intermediate iteration converges

$=3$, for continuous output during intermediate iterations

\section{MODE and REFRIGERANT DATA:}

\section{LINE \#3 FORMAT(8I10)}

NCORH Switch to specify cooling or heating mode

$=1$, for cooling mode

$=2$, for heating mode

$=3$, for dual mode (used in conjunction with contour data generation)

NR Refrigerant number - 12, 22, 114, 502, or 134(a)

(If NR is omitted, the default is R22)

\section{CHARGE INVENTORY / SUPERHEAT DATA:}

\section{LINE \#4 FORMAT(I10, 2F10.4, I10)}

ICHRGE Indicator for specifying charge inventory balance choice

$=0, \quad$ no charge balance - charge to be determined; specify compressor inlet superheat, specify condenser exit subcooling or flow control requirements.

$=1$, charge balance - high-side determined; specify refrigerant charge, estimate compressor inlet superheat, specify condenser exit subcooling or flow control requirements.

$=2$, charge balance - low-side determined; specify refrigerant charge, specify compressor inlet superheat, estimate condenser exit subcooling, determine flow control requirements.

\footnotetext{
*Bars in left-hand margins indicate changes in input or definitions from Mark III single-speed version.
} 
SUPER Specified (if ICHRGE=0,2) or estimated (if ICHRGE=1)

refrigerant superheat (or quality) at the compressor shell inlet

$\left(\mathrm{F}^{\circ}\right.$ or negative of the desired quality fraction)

REFCHG Specified system refrigerant charge (lbm)

(not needed if ICHRGE=0)

MVOID Switch to specify heat exchanger void fraction (slip) method

for charge inventory calculations

$=0$, default method - Zivi void fraction model

with analytical solution

for a constant heat flux approximation

$>0$, various user-selected void fraction models

with variable heat flux effects

(which require slower numerical solutions)

- mass-flow independent methods

$=1$, Homogeneous (no slip)

$=2$, Zivi

$=3$, Lockhart-Martinelli

$=4$, Thom

$=5$, Baroczy

- mass-flow dependent methods

$=6$, Hughmark

=7, Premoli ${ }^{*}$

$=8$, Tandon

\section{CHARGE INVENTORY CALCULATIONAL DATA:}

LINE \#5 FORMAT(I10, 7F10.4)

IMASS Switch for option to omit refrigerant charge calculations,

only active for ICHRGE $=0$ case

$=0$, if charge calculations are to be omitted

$=1$, if charge calculations are to be made

Compressor and Accumulator Geometry Values for Refrigerant Charge Calculations: (not required if IMASS $=0$ and $\mathrm{ICHRGE}=0$ )

(if an accumulator is not used, set accumulator height ACCHGT to 0.0)

VOLCMP Internal void space volume of compressor (cu. in.) 395.0

$\begin{array}{lll}\text { ACCHGT } & \text { Height of accumulator (in.) } & 10.0\end{array}$

$\begin{array}{lll}\text { ACCDIA } & \text { Internal diameter of accumulator (in.) } & 4.834\end{array}$

OILDIA Inner diameter of oil return hole J-tube (in.) 0.035

*Presently configured only with R-22 surface tension properties. 
UPPDIA Inner diameter of upper hole in J-tube (in.)

HOLDIS Vertical distance between holes (in.)

ATBDIA Inner diameter of J-tube (in.)

FLOW CONTROL DEVICE DATA: (the variables on this line depend on the type of flow control device selected)

LINE \#6 FORMAT(I10, 7F10.4)

\section{Specified or Estimated Condenser Subcooling:}

IREFC $\quad=0$, for specified or estimated refrigerant subcooling

at the condenser exit

DTROC Specified (if ICHRGE=0,1) or estimated (if ICHRGE=2) refrigerant subcooling (or quality) at the condenser exit ( $\mathrm{F}^{\circ}$ or negative of the desired quality fraction)

Thermostatic Expansion Valve:

IREFC $\quad=1$, for a thermostatic expansion valve (TXV)

TXVRAT Rated capacity of the TXV (tons)

STATIC Static superheat setting for the TXV $\left(\mathrm{F}^{\circ}\right)$

SUPRAT TXV superheat at rating conditions $\left(\mathrm{F}^{\circ}\right)$

SUPMAX Maximum effective operating superheat $\left(\mathrm{F}^{\circ}\right)$

BLEEDF TXV bypass or bleed factor

NZTBOP Switch to omit TXV nozzle and tube pressure drop calculations

=1.0, to include tube and nozzle pressure drop calculations

\section{Capillary Tube:}

IREFC $\quad=2$, for a capillary tube(s)

CAPFLO Capillary tube flow factor, see ASHRAE Handbook,

NCAP Number of capillary tubes in parallel

Short Tube Orifice:

IREFC $\quad=3$, for a short tube orifice

ORIFD Diameter of the short-tube orifice (in.) 
ESTIMATES of the LOW- and HIGH-SIDE REFRIGERANT SATURATION TEMPERATURES:

LINE \#7 FORMAT(8F10.4)

TSICMP $\quad$ Estimate of the refrigerant saturation temperature 48.0

$\begin{array}{lll}\text { TSOCMP } & \text { Estimate of the refrigerant saturation temperature } & 120.0\end{array}$ at the compressor shell outlet $\left({ }^{\circ} \mathrm{F}\right)$

\section{GENERAL COMPRESSOR DATA:}

LINE \#8 FORMAT $($ I10, 7F 10.4)

ICOMP Switch to specify which compressor submodel is to be used,

$=1, \quad$ for the efficiency-and-loss model (single-speed only)

$=2$, for the map-based model (single-or variable-speed)

DISPL Total piston displacement for selected compressor (cu. in.)

CMPSPD Speed/frequency-determining-parameter for selected compressor -

Operating frequency ratio (relative to nominal frequency on Line 9.1), if value $\leq 5$ and $\mathrm{ICOMP}=2$;

Operating drive frequency $(\mathrm{Hz})$, if value $>5$ and $\mathrm{ICOMP}=2$,

Synchronous compressor motor speed (rpm)

if ICOMP=1 and FLMOT is specified on LINE \#9;

Rated compressor motor speed (rpm)

if $\mathrm{ICOMP}=1$ and FLMOT is to be calculated

QCAN Compressor shell heat loss rate $(\mathrm{Btu} / \mathrm{h})$, used if CANFAC is 0.0

CANFAC Switch to control the method of specifying compressor shell heat loss rate, QCAN

$=0.0, \quad$ to specify QCAN explicitly

$<1.0, \quad$ to calculate QCAN as a fraction of compressor input power, POW, (i.e., QCAN $=$ CANFAC $*$ POW)

$=1.0, \quad \mathrm{QCAN}$ is based on map submodel of CANFAC (Map-based model only, Line 9.8)

$>1.0, \quad$ to calculate QCAN from the relationship : QCAN $=0.90 *[1-\{$ motor $\eta *$ mechanical $\eta\}] *$ POW, (only if ICOMP = 1) 
COMPRESSOR DATA FOR EFFICIENCY-AND-LOSS MODEL:

(Lines 9.0 and 9.1)

LINE \#9.0 FORMAT(8F10.4)

$\begin{array}{lll}\text { VR } & \text { Compressor actual clearance volume ratio } & 0.06\end{array}$

$\begin{array}{lll}\text { EFFMMX } & \text { Maximum efficiency of the compressor motor } & 0.82\end{array}$

$\begin{array}{lll}\text { ETAISN } & \text { Isentropic efficiency of the compressor } & 0.70\end{array}$

$\begin{array}{lll}\text { ETAMEC } & \text { Mechanical efficiency of the compressor } & 0.80\end{array}$

LINE \#9.1 FORMAT(I10, 7F10.4)

MTRCLC Switch to determine whether to calculate the 0

full load motor power (FLMOT) or to use the input value

$=0, \quad$ to calculate FLMOT

$=1$, to use the input value of FLMOT

FLMOT Compressor motor output at full load $(\mathrm{kW})$

(not used if MTRCLC $=0$ )

QHILO Heat transfer rate from the compressor inlet 300.0

line to the inlet gas $(\mathrm{Btu} / \mathrm{h})$, used if $\mathrm{HILOFC}=0.0$

0.0

HILOFC Switch to determine internal heat transfer

from the high side to the low side, QHILO

$=0.0, \quad$ to specify QHILO explicitly

$<1.0, \quad$ to calculate $\mathrm{QHILO}=\mathrm{HILOFC} * \mathrm{POW}$

$\geq 1.0, \quad$ to calculate $\mathrm{QHILO}=0.03 * \mathrm{POW}$

OR

MAP-BASED COMPRESSOR MODEL INPUT DATA:

(Alternative Lines 9.0 through 9.6)

LINE \#9.0 FORMAT(A80)

CTITLE Descriptive title for map-based compressor data $\quad$ MAP DATA

LINE \#9.1 FORMAT(3I10, 5F 10.4)

MODEDT Switch indicating type of compressor data representation 2

$=1$, curve fits to compressor input power and refrigerant mass flow rate

$=2$, curve fits to compressor shell isentropic and volumetric efficiencies 
ICMPDT Switch identifying drive efficiency level of base compressor data

$=0$, first-generation inverter-driven induction-motor (IDIM) efficiency

$=1$, state-of-the-art IDIM efficiency

$=2$, ideal sine-wave-driven, induction motor (SWDIM) efficiency

$=3$, electronically-commutated motor (ECM) efficiency

ICDVCH Switch choosing selected drive efficiency level

(to convert base compressor data)

$=0$, first-generation IDIM efficiency

$=1$, state-of-the-art IDIM efficiency

$=2$, ideal SWDIM efficiency

$=3$, ECM efficiency

CSIZMT If $>0.0$, nominal motor size for selected compressor (hp), used to determine relative motor loading and resultant motor efficiency

If $<0.0, \quad$ (negative of) specified percentage of nominal loading at which the motor efficiency of the selected compressor is to be evaluated, also (if CMPFRQ = CFRQNM) the required motor size will be calculated (auto-sizing)

CFRQNM Nominal frequency for selected motor rating $(\mathrm{Hz})$

CVLTNM Nominal voltage for selected motor rating (Volts)

— induction motors only

CVLHZM Selected operating volts/Hertz ratio multiplier (range of 0.85 to 1.15) — induction motors only

LINE \#9.2 FORMAT (I10, 7F10.4)

NHZ Number of frequencies for which compressor-data curve-fits are available,

DISPLB Base compressor displacement for compressor map (cubic inches)

SUPERB Base 'superheat' value for compressor map,

If $\geq 0, \quad$ base superheat entering compressor $\left(\mathrm{F}^{\circ}\right)$,

If $<0, \quad$ negative of return gas temperature into compressor $\left({ }^{\circ} \mathrm{F}\right)$

CSIZMB Motor size for base compressor (hp)

CFRQNB Nominal frequency for base motor rating $(\mathrm{Hz})$

60.0

CVLTNB Nominal voltage for base motor rating (volts)

210.0

- induction motors only 
MAP DATA AT SPECIFIED COMPRESSOR FREQUENCY (HZVAL):

LINE \#9.3 FORMAT $(8 F 10.4)$

HZVAL Compressor frequency value (Hz) for which map data follow

RPMVAL Nominal compressor speed at given frequency (rpm)

750.0

(to be used in volumetric efficiency calculations)

VLTVAL Compressor motor voltage (volts) at given frequency

for which map data apply — induction motors only

(If MODEDT = 1 on LINE 9.1)

POWADJ Adjustment factor to curve-fit for power at given frequency (set to 1.0 if value is omitted)

XMRADJ Adjustment factor to curve-fit for mass flow rate at given frequency (set to 1.0 if value is omitted)

(If MODEDT = 2 on LINE 9.1)

ETIADJ Adjustment factor to curve-fit for isentropic efficiency at given frequency (set to 1.0 if value is omitted)

ETVADJ Adjustment factor to curve-fit for volumetric efficiency at given frequency (set to 1.0 if value is omitted)

( If MODEDT = 1 on Line 9.1, Read Lines 9.4 and 9.5 )

\section{LINE \#9.4 FORMAT (6E10.3)}

CPOWER Coefficients for bi-quadratic fit to compressor power $(\mathrm{kW})$ as a function of compressor suction and discharge saturation temperatures $\left({ }^{\circ} \mathrm{F}\right)$, TSICMP and TSOCMP, of the form -

POWER $($ IHZ $)=$

$\begin{array}{llll}\text { CPOWER (1,IHZ) } & * & \text { TSOCMP } & + \\ \text { CPOWER (2,IHZ) } & * & \text { TSOCMP } & + \\ \text { CPOWER (3,IHZ) } & * & \text { TSICMP } & + \\ \text { CPOWER (4,IHZ) } & * & \text { TSICMP } & + \\ \text { CPOWER (5,IHZ) } & * & \text { TSOCMP } * \text { TSICMP } & + \\ \text { CPOWER }(6, \mathrm{IHZ}) & & & +\end{array}$

1.0

LINE \#9.5 FORMAT(6E10.3)

CMASSF Coefficients for bi-quadratic fit to compressor mass flow rate $(\mathrm{lbm} / \mathrm{h})$

as a function of compressor suction and discharge saturation temperatures $\left({ }^{\circ} \mathrm{F}\right), \mathrm{TSICMP}$ and TSOCMP, of the form - 
$\mathrm{XMR}(\mathrm{IHZ})=$

$\begin{array}{llll}\text { CMASSF (1,IHZ) } & * & \text { TSOCMP }^{2} & + \\ \text { CMASSF (2,IHZ) } & * & \text { TSOCMP }^{2} & + \\ \text { CMASSF (3,IHZ) } & * & \text { TSICMP }^{2} & + \\ \text { CMASSF (4,IHZ) } & * & \text { TSICMP } & + \\ \text { CMASSF (5,IHZ) } & * & \text { TSOCMP * TSICMP } & + \\ \text { CMASSF (6,IHZ) } & & & \end{array}$

(If MODEDT = 2 on Line 9.1, Read Lines 9.6 and 9.7)

LINE \#9.6 FORMAT (6E10.3)

CETAIS Coefficients for bi-quadratic fit

to compressor shell isentropic efficiency

as a function of compressor suction and discharge

saturation temperatures $\left({ }^{\circ} \mathrm{F}\right)$, TSICMP and TSOCMP,

$\operatorname{ETAISN}(\mathrm{IHZ})=$ of the form -

\begin{tabular}{|c|c|c|}
\hline CETAIS $(1, \mathrm{IHZ}) *$ TSOCMP $^{2}$ & + & $-2.324 \mathrm{E}-04$ \\
\hline CETAIS $(2$, IHZ) $*$ TSOCMP & + & $-5.143 \mathrm{E}-02$ \\
\hline CETAIS $\left(3\right.$, IHZ) $*$ TSICMP ${ }^{2}$ & + & $-2.726 \mathrm{E}-04$ \\
\hline CETAIS $(4$, IHZ2) $*$ TSICMP & + & $-9.975 \mathrm{E}-02$ \\
\hline $\begin{array}{l}\text { CETAIS }(5, \mathrm{IHZ}) * \text { TSOCMP } * \text { TSICMP } \\
\text { CETAIS }(6, \mathrm{IHZ})\end{array}$ & + & $\begin{array}{l}1.515 \mathrm{E}-03 \\
5.760 \mathrm{E}+00\end{array}$ \\
\hline
\end{tabular}

LINE \#9.7 FORMAT (6E10.3)

CETAVL Coefficients for curve fit

to compressor shell volumetric efficiency

as a function of pressure ratio $P_{R}$ and discharge pressure $P_{D}$ (psia)

$\operatorname{ETAVOL}(\mathrm{IHZ})=$ of the form -

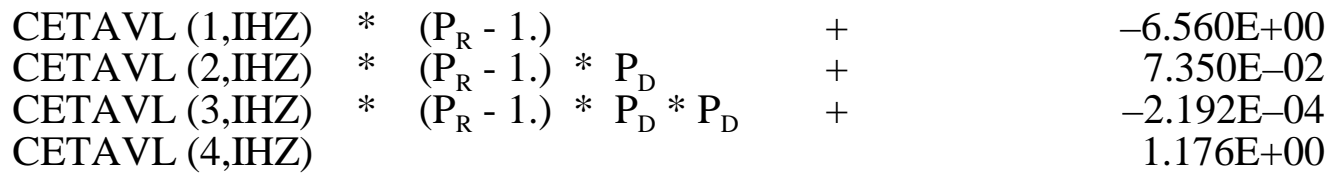

(Repeat Lines 9.3 - 9.7 For Each Compressor Frequency, IHZ=1, NHZ)

Compressor Shell Heat Loss Correlation :

LINE \#9.8 FORMAT (6E10.3)

CQCAN Coefficients of quadratic fit to compressor shell heat loss as a function of compressor dischargesaturation temperature $\left({ }^{\circ} \mathrm{F}\right)$

CANFAC $=$ of the form -

$\begin{array}{llllr}\text { CQCAN (1) } & * & \text { TSOCMP } & + & -1.704 \mathrm{E}-02 \\ \text { CQCAN (2) } & * & \text { TSOCMP }^{2} & + & 5.610 \mathrm{E}-05 \\ \text { CQCAN (3) } & & & & 1.314 \mathrm{E}+00\end{array}$

(If CANFAC $\neq 1$ on Line \#8, Line \#9.8 must be omitted) 
INDOOR UNIT DATA:

LINE \#10 FORMAT(8F10.4)

Indoor Operating Conditions:

TAIII

Air temperature entering the indoor unit $\left({ }^{\circ} \mathrm{F}\right)$

80.0

RHII Relative humidity of the air entering the indoor unit

0.52

LINE \#11 FORMAT $(5 F 10.4,2 I 5,2 F 10.4)$

Indoor Blower:

FRQIDF Operating frequency parameter for indoor blower -

if $\leq 5$, operating frequency ratio relative to nominal given by FRQNMI 1.0 if $>5$, operating frequency $(\mathrm{Hz})$

$\begin{array}{lll}\text { FRQNMI Nominal indoor blower frequency }(\mathrm{Hz}) & 108.0\end{array}$

$\begin{array}{lll}\text { QANMI } & \text { Nominal air flow rate (cfm) }\end{array}$

SIZMTI ECM blower motor sizing parameter -

(SIZMTI is only used if ICHIDF=3)

$>0.0$, nominal blower motor size (hp), used to determine relative motor loading and resultant ECM efficiency

$<0.0$, (negative of) percentage of nominal loading at which the ECM efficiency is to be evaluated, also - if FRQIDF $=$ FRQNMI the required motor size will be calculated (auto-sizing)

FANEFI Fan / fan-motor efficiency parameter -

$\leq 1.0$, specified fixed value of separate or combined efficiencies of fan and/or drive: (those values not explicitly specified by FANEFI will be calculated based on ICHIDF selection)

If ICHIDF $<0$, specified value of combined fan / fan-motor efficiency

If ICHIDF $\geq 0$, specified fan-only efficiency; 
FANEFI... $\quad>1.0, \quad$ directly-specified power (watts) of reference drive

at nominal air flow rate (if available measured

power is not at selected nominal cfm, then ratio

the measured power by cube of (fim ratio),

at reference inlet air temperatures

of $70^{\circ} \mathrm{F}$ heating and $80^{\circ} \mathrm{F}$ cooling

IRFIDF Integer switch to identify reference drive type

if FANEFI is used to specify nominal fan power

(only used if FANEFI > 1.0)

$<0, \quad$ No reference drive type to be used, gives a constant implicit drive efficiency with speed

$\geq 0, \quad$ Nominal input power is referenced to choice of following drives (drive efficiency will vary with speed)

$=0, \quad$ specifies a first-generation IDIM drive

$=1$, specifies a state-of-the-art IDIM drive

$=2$, specifies an ideal SWDIM drive

$=3$, specifies an ECM drive

ICHIDF Integer switch for choosing selected drive type:

For use in combination with given FANEFI values

(If FANEFI $\leq 1.0$ )

or

For conversion from reference IRFIDF values

to selected ICHIDF drive type

(If FANEFI > 1.0)

$<0, \quad$ drive efficiency assumed constant as explicitly

or implicitly given by FANEFI

(If IRFIDF $<0$ and FANEFI $>1.0$,

ICHIDF will be automatically set to -1 )

$\geq 0, \quad$ drive efficiency computed using choice of following drives (drive efficiency will vary with speed)

$=0, \quad$ specifies a first-generation IDIM drive

$=1$, specifies a state-of-the-art IDIM drive

$=2$, specifies an ideal SWDIM drive

$=3$, specifies an ECM drive

DDUCT

Indoor duct sizing parameter -

If $>0$, equivalent diameter of each of 6 identical air ducts (in.)

If $\leq 0$, (negative of) specified external pressure drop of duct system $\quad-0.15$

- independent of specified air flow rate or fan speed

(Note: DDUCT is not used in fan power calculations if FANEFI > 1.0)

FIXCAP House heating load (Btu/h), optional, used to calculate the necessary backup resistance heat in the heating mode 
LINE \#12 FORMAT (8F 10.4)

\section{Indoor Heat Exchanger Configuration:}

$\begin{array}{lll}\text { AAFI } & \text { Frontal (face) area of the coil (sq. ft.) } & 3.90\end{array}$

NTI Number of refrigerant tube rows in the direction of air flow $\quad 4.0$

NSECTI Number of equivalent, parallel refrigerant circuits in heat exchanger $\quad 3.0$

WTI Spacing of the refrigerant tubes in the direction of air flow (in.) $\quad 0.866$

$\begin{array}{lll}\text { STI } & \text { Spacing of the refrigerant tube passes } & 1.00\end{array}$

$\begin{array}{lll}\text { RTBI } & \text { Total number of return bends in heat exchanger (all circuits) } & 128.0\end{array}$

\section{LINE \#13.0 FORMAT $(8 F 10.4)$}

Indoor Heat Exchanger Configuration (continued):

FINTYI Switch to specify the type of fin surface,

$=1.0$, for smooth fins

$=2.0$, for general wavy (sinusoidal) or zig-zag (corrugated) fins

- using multipliers to smooth fin equations

=3.0, for general louvered (simple-strip) fins

- using multipliers to smooth fin equations

$=4.0$, for specific zig-zag fin designs

$=5.0$, for specific louvered ( simple-strip) fin designs

FPI Fin pitch (fins/in.)

DELTAI Fin thickness (in.)

DEAI Outside diameter of the refrigerant tubes (in.)

DERI Inside diameter of the refrigerant tubes (in.)

XKFI Thermal conductivity of the fins (Btu/h-ft- F)

XKTI Thermal conductivity of the tubes (Btu/h-ft- F)

225.0

HCONTI Fraction of the default computed contact conductance between the fins and tubes

999.999

\section{LINE \#14 FORMAT(I10, 7F10.4)}

Fin Patternation Data for Indoor Coil:

If FINTYI $<4.0$, leave a blank line 
If FINTYI = 4.0,

NFPZGI Number of fin patterns per row of tubes in flow direction (integer) 2

$\begin{array}{lll}\text { FPDZGI } & \text { Fin pattern depth (in) } & 0.045\end{array}$

If FINTYI = 5.0,

NSLVI Number of strips in an enhanced zone (integer)

XLSLVI Length of enhanced louvered zone $(\mathrm{mm})$

XWSLVI Width of single strip in flow direction ( $\mathrm{mm}$ )

LINE \#15 FORMAT(8F10.4)

Heat Transfer and Pressure Drop Multipliers for Indoor Coil :

$\begin{array}{lll}\text { HTRMLI } & \text { Refrigerant-side heat transfer multiplier } & 1.0\end{array}$

$\begin{array}{lll}\text { PDRMLI } & \text { Refrigerant-side pressure-drop multiplier } & 1.0\end{array}$

$\begin{array}{lll}\text { HTAMLI } & \text { Air-side heat transfer multiplier } & 1.0\end{array}$

PDAMLI Air-side coil pressure-drop multiplier $\quad 1.0$

$\begin{array}{lll}\text { CABMLI } & \text { Air-side system pressure-drop multiplier } & 1.0\end{array}$

\section{OUTDOOR UNIT DATA:}

LINE \#16 FORMAT(8F10.4)

Outdoor Operating Conditions:

TAIIO Air temperature entering the heat exchanger $(\mathrm{F}) \quad 95.0$

$\begin{array}{lll}\text { RHIO Relative humidity of the air entering the heat exchanger } & 0.40\end{array}$

LINE \#17 FORMAT(5F10.4,2I5,I10)

Outdoor Fan:

FRQODF Operating frequency parameter for outdoor fan -

if $\leq 5$, operating frequency ratio relative to nominal given by FRQNMO 1.0

if $>5$, operating frequency $(\mathrm{Hz})$

FRQNMO Nominal outdoor fan frequency $(\mathrm{Hz})$ 
QANMO Nominal air flow rate (cfm)

SIZMTO ECM blower motor sizing parameter -

(SIZMTO is only used if ICHODF=3)

$>0.0$, nominal blower motor size (hp), used to determine relative motor loading and resultant ECM efficiency

$<0.0$, (negative of) percentage of nominal loading at which the ECM efficiency is to be evaluated, also - if FRQODF = FRQNMO the required motor size will be calculated (auto-sizing)

FANEFO Fan / fan motor efficiency parameter -

$\leq 1.0$, specified fixed value of separate or combined efficiencies of fan and/or drive: (those values not explicitly specified by FANEFO will be calculated based on MFANFT / ICHODF selections)

If MFANFT $=0$ and ICHODF < 0 , specified value of combined fan / fan motor efficiency

If $\mathrm{MFANFT}=0$ and $\mathrm{ICHODF} \geq 0$, specified fan-only efficiency

If $\mathrm{MFANFT}=1$ and $\mathrm{ICHODF}<0$, specified drive efficiency

If $\mathrm{MFANFT}=1$ and $\mathrm{ICHODF}=>0$, specified value is ignored, model calculates both fan and drive efficiencies

>1.0, directly-specified power (watts) of reference drive at nominal air flow rate (if available measured power is not at selected nominal cfm, then ratio the measured power by cube of (fm ratio), at reference inlet air temperatures of $47^{\circ} \mathrm{F}$ heating or $95^{\circ} \mathrm{F}$ cooling

IRFODF Integer switch to identify reference drive type if FANEFO is used to specify nominal fan power (only used if FANEFO > 1.0)

$<0$, No reference drive type to be used, gives a constant implicit drive efficiency with speed 
IRFODF... $\quad \geq 0, \quad$ Nominal input power is referenced to choice of following drives (drive efficiency will vary with speed)

$=0$, specifies a first-generation IDIM drive

$=1$, specifies a state-of-the-art IDIM drive

$=2$, specifies an ideal SWDIM drive

$=3$, specifies an ECM drive

ICHODF Integer switch for choosing selected drive type:

For use in combination with given FANEFO values

(If FANEFO $\leq 1.0$ )

or

For conversion from reference IRFODF values

to selected ICHODF drive type

(If FANEFO > 1.0)

$<0, \quad$ drive efficiency assumed constant as explicitly

or implicitly given by FANEFO

(If IRFODF $<0$ and FANEFO $>1.0$,

ICHODF will be automatically set to -1 )

$\geq 0, \quad$ drive efficiency computed using choice of following drives -

(drive efficiency will vary with speed)

$=0$, specifies a first-generation IDIM drive

$=1$, specifies a state-of-the-art IDIM drive

$=2$, specifies an ideal SWDIM drive

$=3$, specifies an ECM drive

MFANFT Switch for using static efficiency vs specific speed

for the efficiency of the outdoor fan -

$=0, \quad$ specified value of FANEFO is used

$=1$, curve fit for fan static efficiency is used - with fan motor efficiency either specified by FANEFO or calculated internally (should not be chosen if FANEFO > 1.0)

LINE \#18 FORMAT $(8 F 10.4)$

Outdoor Heat Exchanger Configuration:

$\begin{array}{lll}\text { AAFO } & \text { Frontal (face) area of the coil (sq. ft.) } & 9.05\end{array}$

NTO Number of refrigerant tube rows in the direction of air flow 3.0

NSECTO Number of equivalent, parallel refrigerant circuits in heat exchanger $\quad 3.0$

WTO Spacing of the refrigerant tubes in the direction of air flow (in.) $\quad 1.08$

$\begin{array}{lll}\text { STO Spacing of the refrigerant tube passes } & 1.25\end{array}$

$\begin{array}{lll}\text { RTBO } & \text { Total number of return bends in heat exchanger (all circuits) }\end{array}$ 
LINE \#19.0 FORMAT (8F 10.4)

Outdoor Heat Exchanger Configuration (continued):

FINTYO Switch to specify the type of fin surface,

$=1.0$, for smooth fins

$=2.0$, for general wavy (sinusoidal) or zig-zag (corrugated) fins

- using multipliers to smooth fin equations

$=3.0$, for general louvered (simple-strip) fins

- using multipliers to smooth fin equations

$=4.0$, for specific zig-zag fin designs

$=5.0$, for specific louvered (simple-strip) fin designs

FPO Fin pitch (fins/in.)

DELTAO Fin thickness (in.)

DEAO Outside diameter of the refrigerant tubes (in.)

DERO Inside diameter of the refrigerant tubes (in.)

XKFO Thermal conductivity of the fins (Btu/h-ft- ${ }^{\circ} \mathrm{F}$ )

XKTO

Thermal conductivity of the tubes $\left(\mathrm{Btu} / \mathrm{h}-\mathrm{ft}-{ }^{\circ} \mathrm{F}\right)$

HCONTO Fraction of the default computed contact conductance between the fins and tubes

Fin Patternation Data for Outdoor Coil:

LINE \# $20 \quad$ FORMAT(I10, 7F10.4)

If FINTYO $<4.0$, leave a blank line

If FINTYO = 4.0,

NFPZGO Number of fin patterns per row of tubes in flow direction (integer)

FPDZGO Fin pattern depth (in.)

If FINTYO = 5.0,

NSLVO Number of strips in an enhanced zone (integer)

XLSLVO Length of enhanced louvered zone (mm)

XWSLVO Width of single strip in flow direction $(\mathrm{mm})$ 
Heat Transfer and Pressure Drop Multipliers for Outdoor Coil :

$\begin{array}{lll}\text { HTRMLO Refrigerant-side heat transfer multiplier } & 1.0\end{array}$

$\begin{array}{lll}\text { PDRMLO Refrigerant-side pressure-drop multiplier } & 1.0\end{array}$

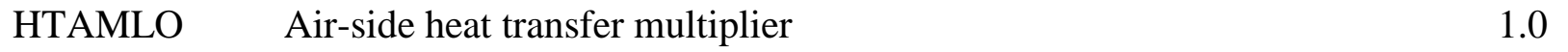
$\begin{array}{lll}\text { PDAMLO } & \text { Air — side coil pressure-drop multiplier } & 1.0\end{array}$ $\begin{array}{lll}\text { CABMLO } & \text { Air }- \text { side system pressure-drop multiplier } & 1.0\end{array}$

CONFIGURATION OPTIONS DATA:

LINE \#22 FORMAT (8I10)

MCMPOP Switch for adding compressor can heat loss to air in the outdoor coil $=0$, heat loss not added to outdoor air

$=1$, heat loss added to air before crossing the outdoor coil

$=2$, heat loss added to air after crossing the outdoor coil

MFANIN Switch for adding heat loss from the indoor fan to air stream, settings are similar to those for MCMPOP

MFANOU Switch for adding heat loss from the outdoor fan to air stream, settings are similar to those for MCMPOP

\section{0} 0

\section{REFRIGERANT LINES DATA:}

\section{LINE \#23 FORMAT(8F10.4)}

\section{Heat Transfer in Refrigerant Lines :}

QSUCLN If $>0$, rate of heat gain in the compressor suction line $(\mathrm{Btu} / \mathrm{h}) ; \quad 100$.

If $<0$, the negative of the desired temperature rise

QDISLN $\quad$ Rate of heat loss in the compressor discharge line (Btu/h) 700.

QLIQLN $\quad$ Rate of heat loss in the liquid line (Btu/h) 700. 
LINE \#24 FORMAT (8F 10.4)

Lines Between Coils and from Reversing Valve to Coils:

$\begin{array}{lll}\text { DLL Inside diameter of the liquid line (in.) } & 0.2555\end{array}$

XLEQLL Equivalent length of the liquid line (ft.) 39.8

DLRVIC Inside diameter of the vapor line between the reversing valve 0.686 and the indoor coil (in.)

XLRVIC Equivalent length of the vapor line between the reversing valve 31.0 and the indoor coil (ft.)

DLRVOC Inside diameter of the vapor line between the reversing valve 0.686 and the outdoor coil (in.)

XLRVOC Equivalent length of the vapor line between the reversing valve 2.0

LINE \#25 FORMAT(8F10.4)

Lines from the Reversing Valve to the Compressor:

DSLRV Inside diameter of the suction line from the reversing valve to the compressor inlet (in.)

0.793

XLEQLP Equivalent length of the low-pressure line from the reversing valve to the compressor inlet (ft.)

DDLRV Inside diameter of the discharge line from the compressor outlet 0.561 to the reversing valve (in.)

XLEQHP Equivalent length of the high-pressure line from the compressor outlet 2.0 to the reversing valve (ft.) 


\section{SOLUTION CONVERGENCE CRITERIA :}

LINE \#26 FORMAT (8F10.4)

\section{Iteration Convergence Parameters :}

AMBCON Convergence parameter for the iteration on evaporator inlet air $\quad 0.20$

CNDCON Convergence parameter for the iteration on condenser exit subcooling (or on exit quality $* 200)$ - used when IREFC $=0$ on Line $6\left(\mathrm{~F}^{\circ}\right)$; also the quantity $\{2 * \mathrm{CNDCON}\}$ is used as the convergence parameter for the charge balancing iteration when ICHRGE $=2$

FLOCON Convergence parameter for iteration on refrigerant mass flow rate - used when IREFC $>0$ on Line 6 (equivalent $\mathrm{F}^{\circ}$ ), value is specified as if it were in degrees $\mathrm{F}$ and is scaled internally (by $1 / 20^{\text {th }}$ ) to give a mass flow convergence factor

EVPCON Convergence parameter for iteration on evaporator exit superheat $\left(\mathrm{F}^{\circ}\right), \quad 0.50$ (or on exit quality * 500);

Also the quantity $\{2 *$ EVPCON $\}$ is used as the convergence parameter for the charge balancing iteration when ICHRGE $=1$

CONMST Convergence parameter for iterations on evaporator tube wall temperatures in subroutine EVAP and dew-point temperature in subroutine XMOIST $\left(\mathrm{F}^{\circ}\right)$

CMPCON Convergence parameter for iteration on suction gas enthalpy in the efficiency-and-loss compressor model (Btu/lbm) only used when ICOMP $=1$ on Line 8

TOLH Tolerance parameter used by refrigerant routines in calculating properties of superheated vapor when converging on a known enthalpy value (Btu/lbm)

TOLS Tolerance parameter used by refrigerant routines in calculating properties of superheated vapor when converging on a known entropy value $\left(\mathrm{Btu} / \mathrm{lbm} /{ }^{\circ} \mathrm{R}\right)$ 



\section{Listing B.1. Sample Heat Pump Specification File 'HPDATA' $-95^{\circ}$ F Design Cooling Condition -}

\section{File: DESIGN.HPS}

SAMPLE ECM HEAT PUMP, 95 F DESIGN PT: AUTO-MOTOR + DUCT SIZING, FILE:DESIGN.HPS

$\begin{array}{rrr}1 & & \\ 1 & 22 & \\ 0 & 10.0 & 0.0 \\ 1 & 395.0 & 10.0 \\ 0 & 16.0 & 0.0 \\ 48.0 & 120.0 & \\ 2 & 1.700 & 1.0\end{array}$

SWDIM RECIPROCATING COMPRESSOR

$\begin{array}{rrrrr}0 & & & & \\ 4.834 & 0.035 & 0.040 & 2.5 & 0.68 \\ 0.0 & 0.0 & 0.0 & 0.0 & \end{array}$

$0.0 \quad 1.0$

CURVE FITS FROM ORNL AND MANUF'S DATA

\begin{tabular}{|c|c|c|c|c|c|c|c|}
\hline 2 & 2 & 3 & -130.0 & 180.0 & 210.0 & 1.0 & \\
\hline 7 & 3.64 & 20.0 & 2.75 & 60.0 & 210.0 & & \\
\hline 15.0000 & 750.0000 & 53.0000 & 1.0 & 1.0 & & & \\
\hline$-2.324 \mathrm{E}-04$ & $-5.143 E-02-$ & $2.726 \mathrm{E}-04-$ & $-9.975 E-02$ & $1.515 \mathrm{E}-03$ & $5.760 \mathrm{E}+00$ & & \\
\hline$-6.560 E+00$ & $7.350 E-02-$ & $2.192 \mathrm{E}-04$ & $1.176 \mathrm{E}+00$ & & & & \\
\hline 20.0000 & 1050.0000 & 70.0000 & 1.0 & 1.0 & & & \\
\hline$-5.414 \mathrm{E}-05$ & $-7.267 \mathrm{E}-04-$ & 1.181E-04- & $-3.888 E-04$ & $1.387 \mathrm{E}-04$ & $7.244 E-01$ & & \\
\hline$-5.320 \mathrm{E}-01$ & $4.385 E-03-$ & $1.290 \mathrm{E}-05$ & $9.773 E-01$ & & & & \\
\hline 30.0000 & 1650.0000 & 107.0000 & 1.0 & 1.0 & & & \\
\hline$-1.209 \mathrm{E}-04$ & $1.976 \mathrm{E}-02-$ & $6.166 \mathrm{E}-05-$ & $-8.747 E-04$ & $7.018 \mathrm{E}-05-$ & $-3.318 E-01$ & & \\
\hline$-2.101 E-01$ & $1.104 \mathrm{E}-03-$ & $3.066 E-06$ & $9.595 \mathrm{E}-01$ & & & & \\
\hline 45.0000 & 2550.0000 & 156.0000 & 1.0 & 1.0 & & & \\
\hline$-1.861 \mathrm{E}-05$ & $-3.855 E-03-$ & $1.039 \mathrm{E}-04-$ & $-6.916 E-03$ & $1.498 \mathrm{E}-04$ & $1.004 \mathrm{E}+00$ & & \\
\hline$-1.106 \mathrm{E}-01$ & $3.117 \mathrm{E}-04-$ & $8.162 \mathrm{E}-07$ & $8.922 \mathrm{E}-01$ & & & & \\
\hline 60.0000 & 3450.0000 & 208.0000 & 1.0 & 1.0 & & & \\
\hline$-7.977 E-05$ & $1.039 \mathrm{E}-02-$ & 1. $293 E-04-$ & $-9.867 E-03$ & $1.840 \mathrm{E}-04$ & $1.825 E-01$ & & \\
\hline$-1.789 \mathrm{E}-01$ & $4.585 E-04-$ & $6.751 E-07$ & $9.523 E-01$ & & & & \\
\hline 75.0000 & 4350.0000 & 208.0000 & 1.0 & 1.0 & & & \\
\hline$-6.626 \mathrm{E}-06$ & $1.071 E-04-$ & $4.978 E-05-$ & $-1.304 E-03$ & $3.893 E-05$ & $5.454 \mathrm{E}-01$ & & \\
\hline$-1.445 E-01$ & $4.353 E-04-$ & $7.215 E-07$ & $8.580 \mathrm{E}-01$ & & & & \\
\hline 90.0000 & 5250.0000 & 208.0000 & 1.0 & 1.0 & & & \\
\hline$-4.169 \mathrm{E}-05$ & $7.656 E-03-$ & $7.209 E-05-$ & $-4.765 E-03$ & $7.275 E-05$ & $1.228 E-01$ & & \\
\hline$-8.835 E-02$ & $1.966 \mathrm{E}-04-$ & $4.783 E-07$ & $7.990 \mathrm{E}-01$ & & & & \\
\hline$-1.704 \mathrm{E}-02$ & $5.610 E-05$ & $1.314 E+00$ & & & & & \\
\hline 80.0 & 0.52 & & & & & & \\
\hline 1.0 & 108.0 & 900. & -75.0 & 0.45 & 3 & -0.15 & 0.0 \\
\hline 3.900 & 4.0 & 3.00 & 0.866 & 1.00 & 128.0 & 1.0 & \\
\hline 2.0 & 14.0 & 0.0050 & 0.3950 & 0.3710 & 128.3 & 225.0 & 999.999 \\
\hline 2 & 0.045 & & & & & & \\
\hline 1.0 & 1.0 & 1.0 & 1.0 & 1.0 & & & \\
\hline 95.0 & 0.40 & & & & & & \\
\hline 1.0 & 82.5 & 2700.0 & -75.0 & 0.00 & 3 & 1 & \\
\hline 9.050 & 3.0 & 3.00 & 1.08 & 1.25 & 72.0 & 1.0 & \\
\hline 2.0 & 13.0 & 0.0060 & 0.3950 & 0.3710 & 128.3 & 225.0 & 999.999 \\
\hline 3 & 0.092 & & & & & & \\
\hline 1.0 & 1.0 & 1.0 & 1.0 & 1.0 & & & \\
\hline 0 & 2 & 2 & & & & & \\
\hline 100. & 700. & 700 & & & & & \\
\hline 0.2555 & 39.8 & 0.6860 & 31.00 & 0.6860 & 2.00 & & \\
\hline 0.7930 & 5.00 & 0.5610 & 2.00 & & & & \\
\hline 0.05 & 0.05 & 0.40 & 0.10 & 0.0015 & 0.05 & 0.0005 & 0.00003 \\
\hline
\end{tabular}





\section{Listing B.2. Sample Heat Pump Specification File 'HPDATA' $-47^{\circ}$ F Off-Design Heating Condition}

\section{File : OFFDES.HPS}

SAMPLE ECM HEAT PUMP, OFF-DESIGN PT: SPECIFIED MOTORS AND DUCTS, FILE:OFFDES.HPS

$\begin{array}{rrr}1 & & \\ 2 & 22 & \\ 0 & 1.0 & 0.0 \\ 1 & 395.0 & 10.0 \\ 0 & 10.0 & 0.0 \\ 40.0 & 100.0 & \\ 2 & 1.700 & 50.0\end{array}$

SWDIM RECIPROCATING COMPRESSOR
4.834
0.035
0.040
2.5
0.0
0.0

$0.0 \quad 1.0$

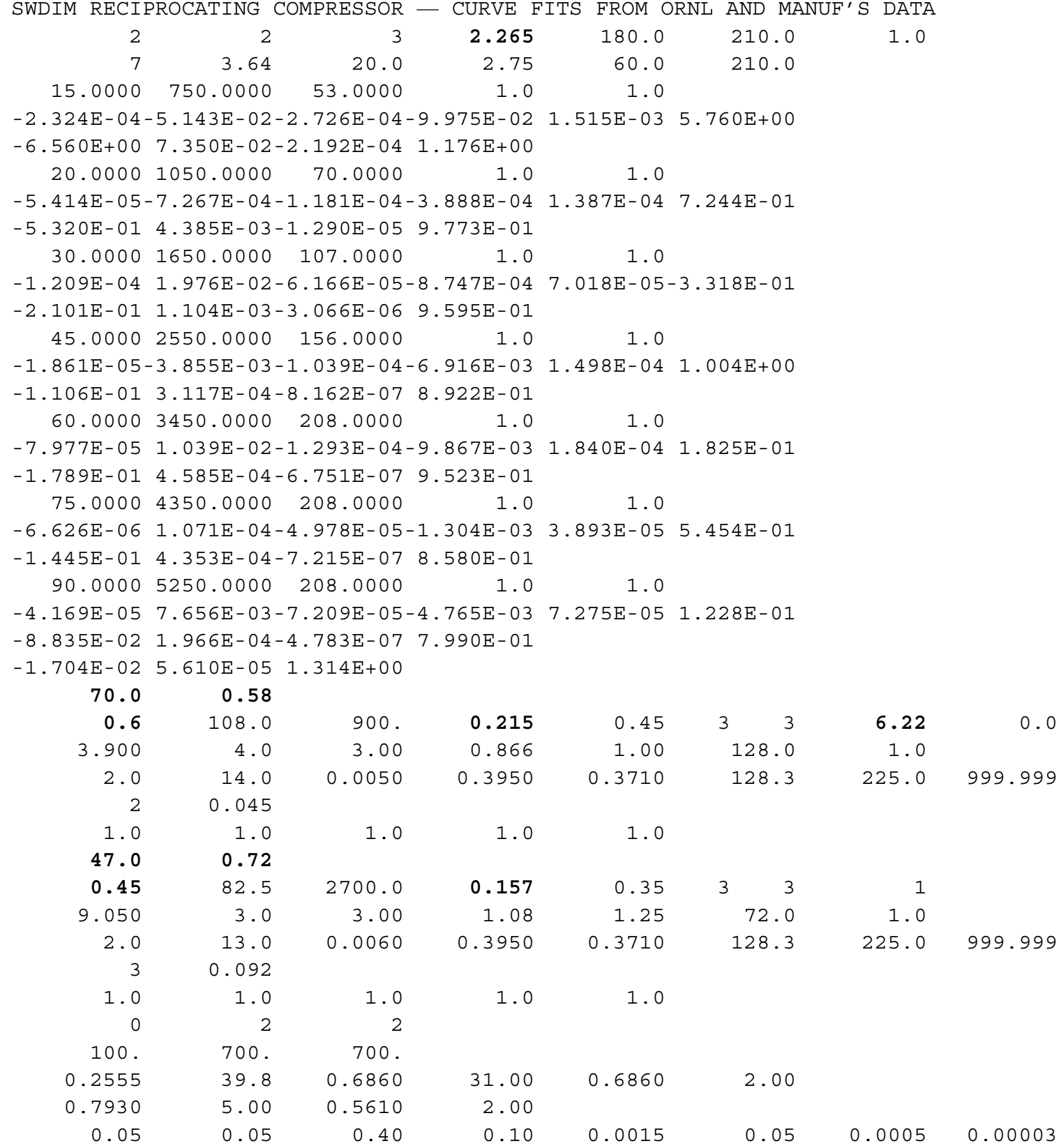





\section{Listing B.3. Annotated Sample Heat Pump Specification File 'HPDATA' $-95{ }^{\circ} \mathrm{F}$ Design Cooling Condition -}

File: DESIGN.HPS

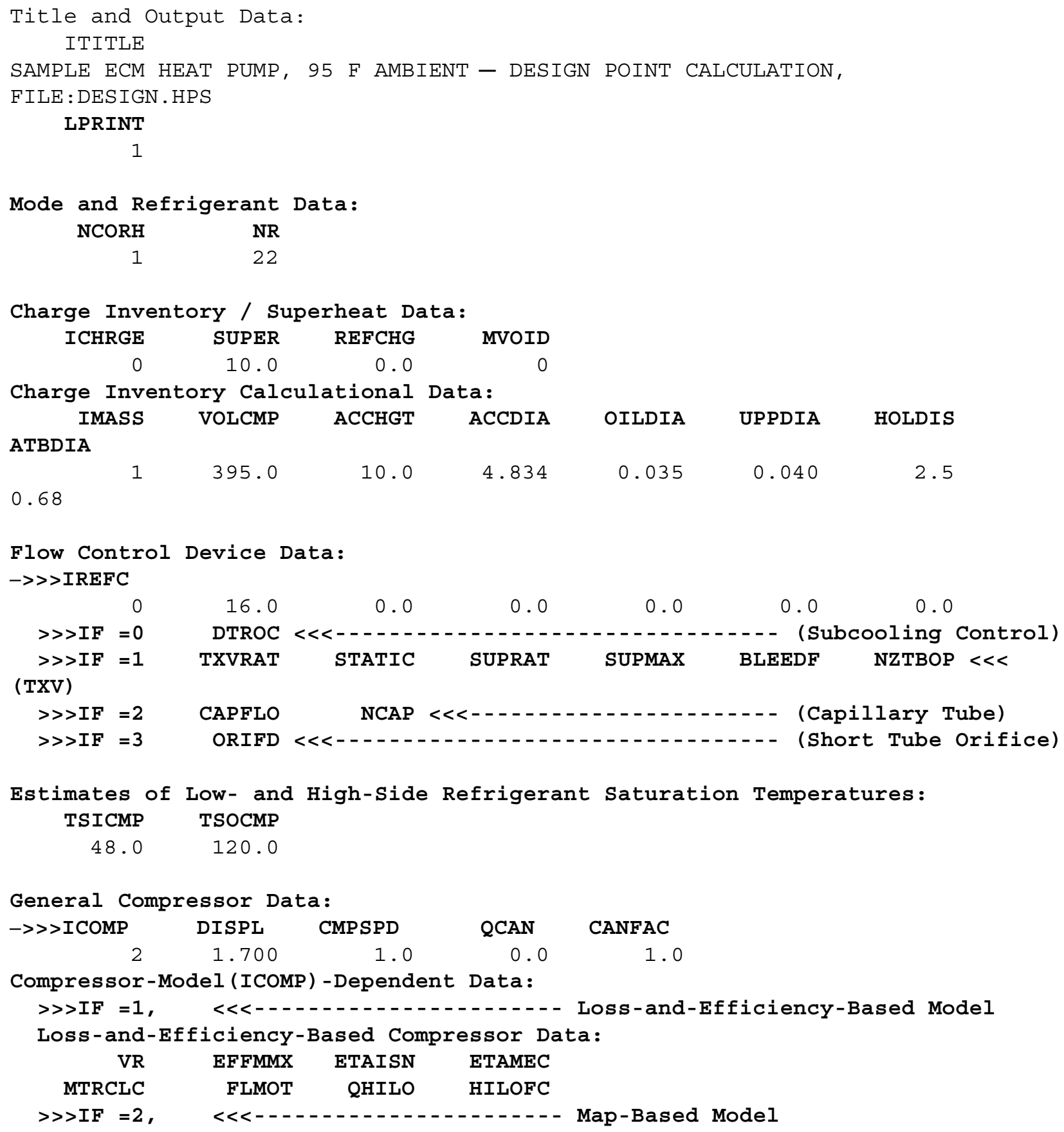




\section{Listing B.3. Annotated Sample Heat Pump Specification File 'HPDATA' $-95{ }^{\circ} \mathrm{F}$ Design Cooling Condition - (continued)}

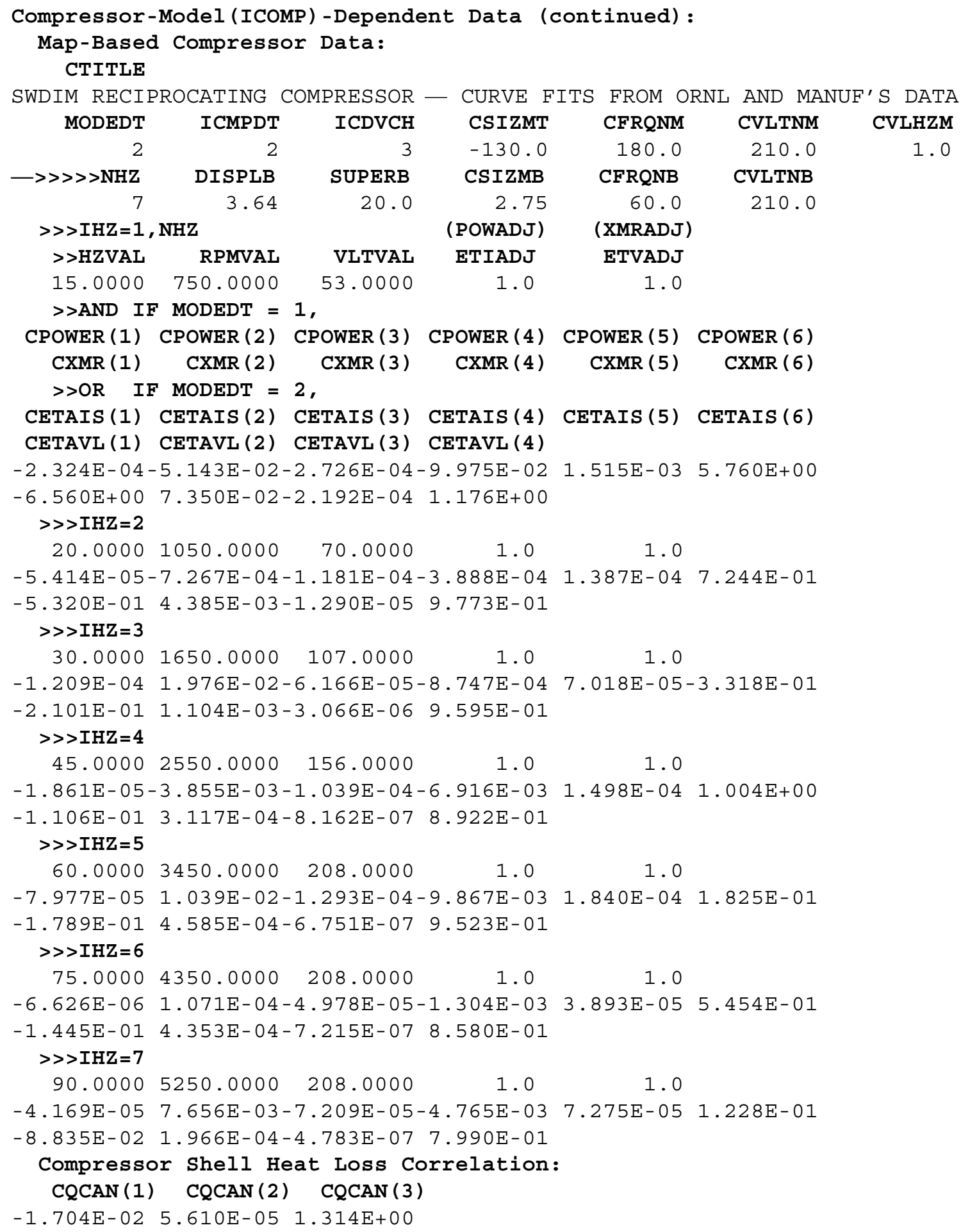




\section{Listing B.3. Annotated Sample Heat Pump Specification File 'HPDATA' - $95^{\circ}$ F Design Cooling Condition - (continued)}

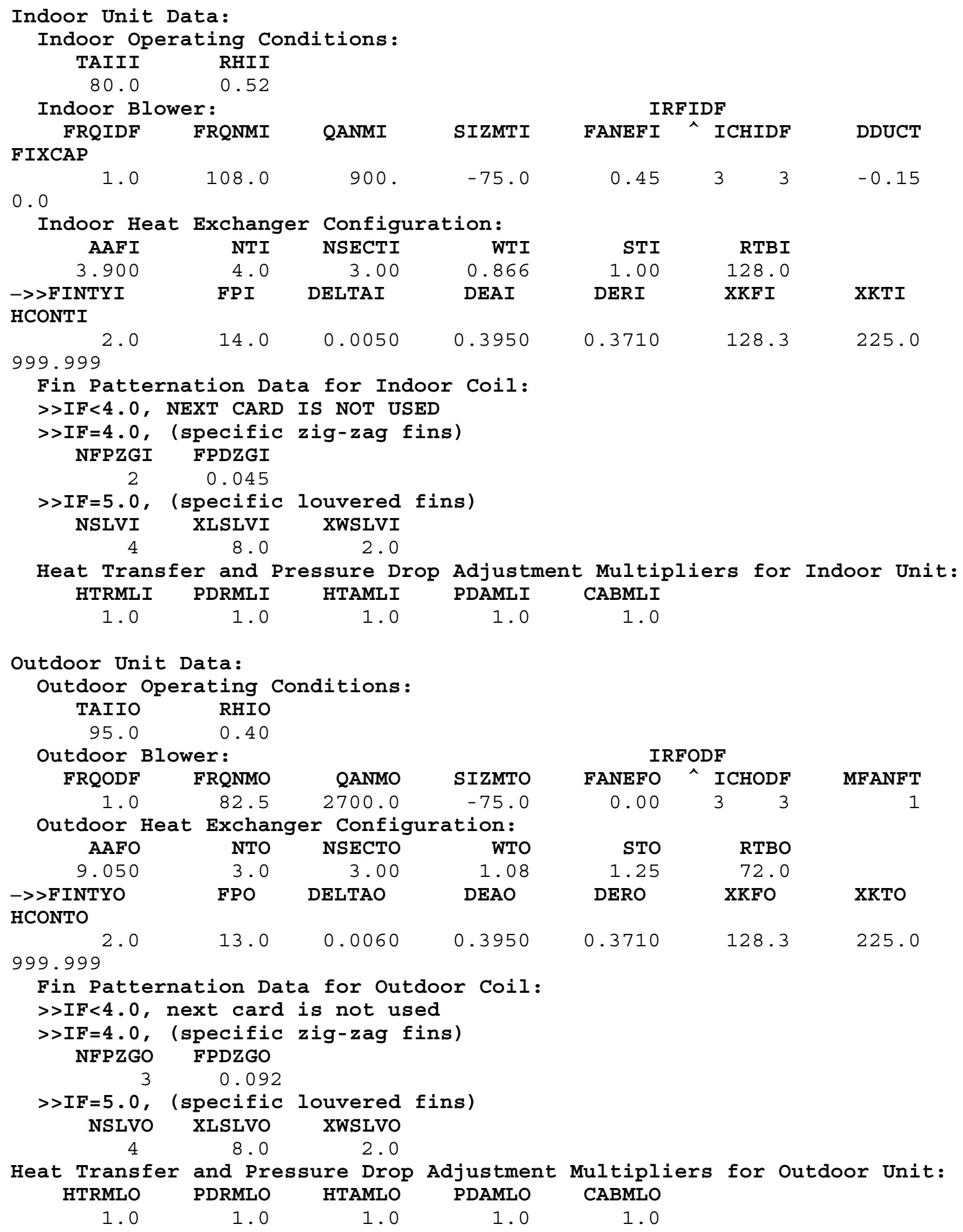


Listing B.3. Annotated Sample Heat Pump Specification File 'HPDATA' - $95^{\circ} \mathrm{F}$ Design Cooling Condition (continued)

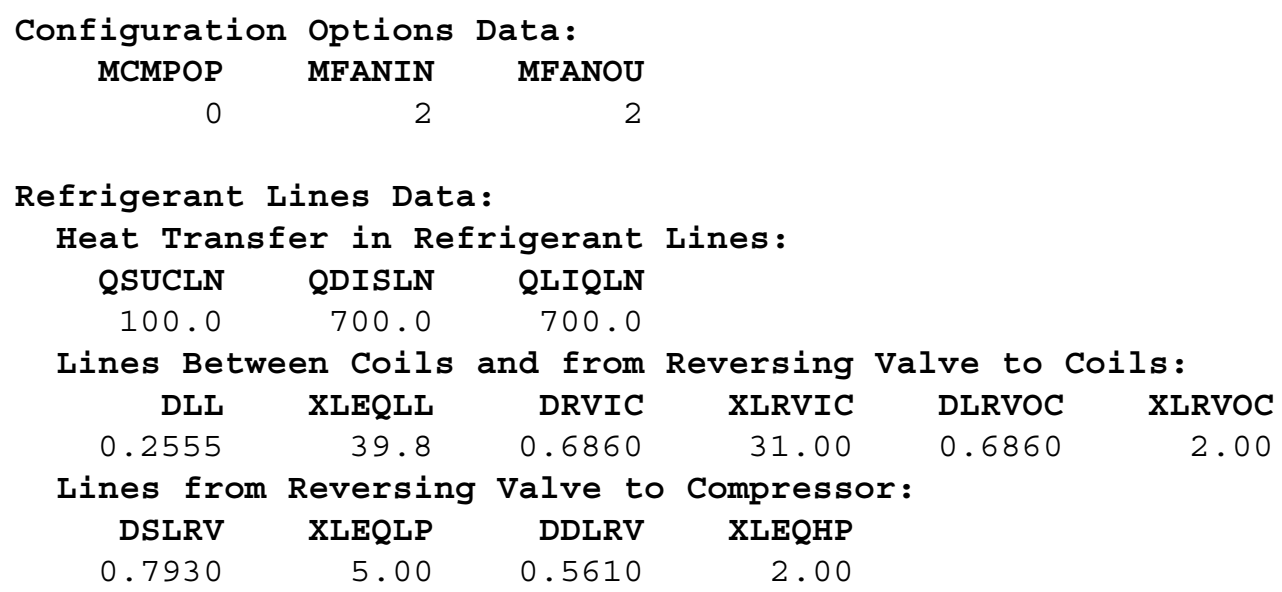




\section{APPENDIX C}

\section{SAMPLE PROGRAM RESULTS}

\section{Single-Point Cases}

Sample program output for single-case runs of the ORNL Modulating Design Tool are shown in Listings C.1 and C. 2 for the LPRINT $=3$ summary output option. These cases are the results of executing the model with the data files DESIGN.HPS and OFFDES.HPS as given in Listings B.1 and B.2, respectively, with each file preceded by a null 'CONCHZ' data set (a single line with a zero in column 3) indicating that no parametric analysis was desired. In these cases, no contour data generation output file is created.

The two cases show, respectively, results for a maximum-speed, cooling-mode, design point case with auto-motor sizing and a minimum-speed, heating-mode, off-design case with specified motor sizes and indoor duct system. For each run, the new output added since the Mark III single-speed model is indicated in bold type. New sections of printed output include a fan/blower performance section and a tabulation of charge inventory computations by component (the latter as described earlier in the report in Table CHG1).

\section{Parametric Case}

The outputs from an sample parametric analysis case are shown in Listings C.3 and C.4. For this run, the 'CONCHZ' data set H2118V.CHZ as given in Listing A.1 and the 'HPDATA' file OFFDES.HPS as given in Listing B.2 were used. The selected example is for a heat pump operating in the heating mode with a compressor frequency range from $180 \mathrm{~Hz}$ down to $50 \mathrm{~Hz}$ and for an ambient range from $17^{\circ} \mathrm{F}$ to $47^{\circ} \mathrm{F}$. All the available dependent variables were selected to be generated for this example.

Listing C.3 gives the sample print output which includes a summary of the operational control parameters specified by the user as a function of compressor frequency and ambient temperature. In this example, compressor inlet superheat, condenser outlet subcooling, and indoor and outdoor air flow rates are controlled as functions of compressor frequency and a building heating load line is given as a function of ambient temperature. The latter allows effects of resistance heat requirements to be included in the system power and COP calculations.

Listing C.4 shows an example of the type of parametric sensitivity data sets that can be generated by the ORNL Modulating Heat Pump Design Tool when the full available parameter list of dependent variables is chosen. These data sets can be readily exported to PC's for graphical analysis of selected parameters of interest. The output format of this data file is described in Table A.5. 

Listing C.1. Sample Single-Point Heat Pump Model Run

$-95^{\circ}$ F Design Cooling Condition -

Summary Output 

***** CONTOUR DATA GENERATION INFORMATION $* * * * *$

*** CONTOUR DATA GENERATOR FRONT-END IS BYPASSED

$\star * * * *$ INPUT DATA $* * * * *$

SAMPLE ECM HEAT PUMP, 95 F DESIGN PT: AUTO-MOTOR + DUCT SIZING, FILE:DESIGN.HPS

SUMMARY OUTPUT

COOLING MODE OF OPERATION

THE REFRIGERANT IS $R 22$

REFRIGERANT CHARGE IS NOT SPECIFIED

COMPRESSOR INLET SUPERHEAT IS SPECIFIED AT $10.00 \mathrm{~F}$

CONDENSER EXIT SUBCOOLING IS SPECIFIED AT $16.00 \mathrm{~F}$

ESTIMATE OF:

SATURATION TEMPERATURE INTO COMPRESSOR $48.00 \mathrm{~F}$

SATURATION TEMPERATURE OUT OF COMPRESSOR $120.00 \mathrm{~F}$

COMPRESSOR CHARACTERISTICS :

OPERATING FREQUENCY RATIO 1.000

TOTAL DISPLACEMENT

1.000
1.700 CUBIC INCHES

SWDIM RECIPROCATING COMPRESSOR - CURVE FITS FROM ORNL AND MANUF'S DATA

DRIVE TYPE OF INPUT COMPRESSOR DATA IS SINE-WAVE-DRIVEN

DRIVE TYPE IS TO BE CONVERTED TO PM-ECM-DRIVEN

SELECTED PERCENTAGE OF NOMINAL LOADING IS $130.0 \%$ NOMINAL FREQUENCY FOR MOTOR RATING AT $180.0 \mathrm{HZ}$

BASE SUPERHEAT FOR COMPRESSOR MAP $20.000 \mathrm{~F}$

BASE DISPLACEMENT FOR COMPRESSOR MAP $\quad 3.640$ CU IN

BASE MOTOR SIZE IS $2.75 \mathrm{HP}$

NOMINAL VOLTAGE FOR BASE MOTOR RATING AT 210.0 VOLTS

$* * * * *$ INPUT DATA $* * * * *$

- USER PROVIDED COEFFICIENTS FOR COMPRESSOR SHELL ISENTROPIC AND VOLUMETRIC EFFICIENCY -

CURVE FIT REPRESENTATIONS AT 7 DISCRETE FREQUENCIES

CURVE FIT COEFFICIENTS AT $15.0 \mathrm{HZ}$ FREQUENCY NOMINAL SPEED OF 750.0 RPM DRIVE VOLTAGE OF

ISENTROPIC EFF $=-2.324 \mathrm{E}-04 *$ CONDENSING TEMPERATURE**2+-5.143E-02*CONDENSING TEMPERATURE

$+-2.726 \mathrm{E}-04 *$ EVAPORATING TEMPERATURE $* 2+-9.975 \mathrm{E}-02 *$ EVAPORATING TEMPERAT

VOLUMETRIC EFF $=-6.560 \mathrm{E}+00 *($ PRESSURE RATIO -1.$)+7.350 \mathrm{E}-02 *($ PRESSURE RATIO -1.$) *$ CONDENSING PRESSURE

$+-2.192 \mathrm{E}-04 *($ PRESSURE RATIO -1.$) *$ CONDENSING PRESSURE**2 $+1.176 \mathrm{E}+00$ 

CURVE FIT COEFFICIENTS AT 20.0 HZ FREQUENCY NOMINAL SPEED OF 1050.0 RPM DRIVE VOLTAGE OF

ISENTROPIC EFF

MPERATURE **2 +-7.267 - $04 *$ CONDENSING

$+1.387 \mathrm{E}-04 *$ CONDENSING TEMPERATURE*EVAPORATING TEMPERATURE $+7.244 \mathrm{E}-01$

-5.320E-01*(PRESSURE RATIO - 1.) + 4.385E-03*(PRESSURE RATIO - 1.)*CONDENSING PRESSURE

$+-1.290 \mathrm{E}-05 *$ (PRESSURE RATIO - 1.)*CONDENSING PRESSURE**2 + 9.773E-01

CURVE FIT COEFFICIENTS AT $30.0 \mathrm{HZ} \mathrm{FREQUENCY} \mathrm{NOMINAL} \mathrm{SPEED} \mathrm{OF} 1650.0$ RPM DRIVE VOLTAGE OF

ISENTROPIC EFF $=-1.209 \mathrm{E}-04 *$ CONDENSING TEMPERATURE $* 2+1.976 \mathrm{E}-02 *$ CONDENSING TEMPERATURE

$+-6.166 \mathrm{E}-05 *$ EVAPORATING TEMPERATURE $* * 2+-8.747 \mathrm{E}-04 *$ EVAPORATING TEMPERATURE

$+7.018 \mathrm{E}-05 *$ CONDENSING TEMPERATURE*EVAPORATING TEMPERATURE $+-3.318 \mathrm{E}-01$

VOLUMETRIC EFF $=-2.101 \mathrm{E}-01 *($ PRESSURE RATIO - 1.) $+1.104 \mathrm{E}-03 *$ (PRESSURE RATIO - 1.$) *$ CONDENSING PRESSURE

$+-3.066 \mathrm{E}-06$ * (PRESSURE RATIO - 1.)*CONDENSING PRESSURE**2 + 9.595E-01

CURVE FIT COEFFICIENTS AT 45.0 HZ FREQUENCY NOMINAL SPEED OF 2550.0 RPM DRIVE VOLTAGE OF 156.0 VOLTS ISENTROPIC EFF $=-1.861 \mathrm{E}-05 *$ CONDENSING TEMPERATURE**2 $+-3.855 \mathrm{E}-03 *$ CONDENSING TEMPERATURE

$+-1.039 \mathrm{E}-04 *$ EVAPORATING TEMPERATURE**2 $+-6.916 \mathrm{E}-03 *$ EVAPORATING TEMPERATURE

VOLUMETRIC EFF $=+1.498 E-04 *$ CONDENSING TEMPERATURE*EVAPORATING TEMPERATURE $+1.004 E+00$ -1.106E-01*(PRESSURE RATIO - 1.) + 3.117E-04*(PRESSURE RATIO - 1.)*CONDENSING PRESSURE $+-8.162 \mathrm{E}-07$ * (PRESSURE RATIO - 1.)*CONDENSING PRESSURE**2 + 8.922E-01

CURVE FIT COEFFICIENTS AT $60.0 \mathrm{HZ}$ FREQUENCY NOMINAL SPEED OF $3450.0 \mathrm{RPM}$ DRIVE VOLTAGE OF 208.0 VOLTS ISENTROPIC EFF $=-7.977 \mathrm{E}-05 *$ CONDENSING TEMPERATURE $* 2+1.039 \mathrm{E}-02 *$ CONDENSING TEMPERATURE $+-1.293 \mathrm{E}-04 *$ EVAPORATING TEMPERATURE $* 2+-9.867 \mathrm{E}-03 *$ EVAPORATING TEMPERATUR

$+1.840 \mathrm{E}-04$ * CONDENSING TEMPERATURE*EVAPORATING TEMPERATURE $+1.825 \mathrm{E}-01$

VOLUMETRIC EFF = $-1.789 \mathrm{E}-01 *$ (PRESSURE RATIO - 1.) +4.585E-04*(PRESSURE RATIO - 1.)*CONDENSING PRESSURE $+-6.751 \mathrm{E}-07$ (PRESSURE RATIO - 1.)*CONDENSING PRESSURE**2 + $9.523 \mathrm{E}-01$

CURVE FIT COEFFICIENTS AT $75.0 \mathrm{HZ}$ FREQUENCY NOMINAL SPEED OF $4350.0 \mathrm{RPM}$ DRIVE VOLTAGE OF ISENTROPIC EFF $=-6.626 \mathrm{E}-06 *$ CONDENSING TEMPERATURE $* * 2+1.071 \mathrm{E}-04 *$ CONDENSING TEMPERATURE $+-4.978 \mathrm{E}-05 *$ EVAPORATING TEMPERATURE $* * 2+-1.304 \mathrm{E}-03 *$ EVAPORATING TEMPERAT

VOLUMETRIC EFF = $-1.445 \mathrm{E}-01 *($ PRESSURE RATIO -1.$)+4.353 \mathrm{E}-04 *($ PRESSURE RATIO -1.$) *$ CONDENSING PRESSURE

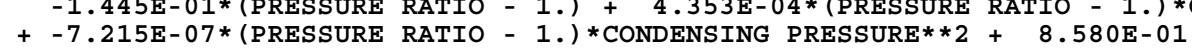

CURVE FIT COEFFICIENTS AT $90.0 \mathrm{HZ} \mathrm{FREQUENCY} \mathrm{NOMINAL} \mathrm{SPEED} \mathrm{OF} 5250.0 \mathrm{RPM}$ DRIVE VOLTAGE OF ISENTROPIC EFF $=-4.169 \mathrm{E}-05$ * CONDENSING TEMPERATURE**2 $+7.656 \mathrm{E}-03$ *CONDENSING TEMPERATURE $+-7.209 \mathrm{E}-05 *$ EVAPORATING TEMPERATURE $* * 2+-4.765 \mathrm{E}-03 *$ EVAPORATING TEMPERATURE

VOLUMETRIC EFF $=+-8.835 \mathrm{E}-02 *($ PRESSURE RATIO -1.$)+1.966 \mathrm{E}-04 *($ PRESSURE RATIO -1.$) * \mathrm{CO}$ $+-4.783 \mathrm{E}-07 *$ (PRESSURE RATIO - 1.)*CONDENSING PRESSURE**2 + 7.990E-01

GENERAL SHELL HEAT LOSS CORRELATION IS SELECTED

CANFAC $=-1.70400 \mathrm{E}-02 *$ CONDENS ING TEMPERATURE $+5.61000 \mathrm{E}-05 *$ CONDENSING TEMPERATURE**2 $+1.31400 \mathrm{E}+00$

SUPERHEAT CORRECTION TERMS (SET IN BLOCK DATA):

SUCTION GAS HEATING FACTOR 0.330

VOLUMETRIC EFFICIENCY CORRECTION FACTOR 0.750

SUCTION GAS HEAT PICKUP FRACTION 
INDOOR UNIT:

$\begin{array}{lrl}\text { INLET AIR TEMPERATURE } & 80.000 \mathrm{~F} \\ \text { FAN OPERATING FREQUENCY RATIO } & 1.00 \\ \text { FAN NOMINAL FREQUENCY } & 108.00 \mathrm{HZ} \\ \text { FAN NOMINAL SPEED } & 1080.00 \mathrm{RPM} \\ \text { PERCENT OF NOMINAL LOADING } & 75.0 \% \\ \text { CONSTANT FAN-ONLY EFFICIENCY } & 0.45 \\ \text { SELECTED FAN DRIVE } & \text { PM-ECM-DRIVEN } \\ \text { SPECIFIED EXTERNAL (DUCT) PRESSURE DROP } & 0.15 \text { IN H20 } \\ \text { FRONTAL AREA OF HX } & 3.900 \text { SQ FT } \\ \text { NUMBER OF TUBES IN DIRECTION OF AIR FLOW } & 4.00 \\ \text { NUMBER OF PARALLEL CIRCUITS } & 3.00 \\ \text { OD OF TUBE IN HX } & 0.3900 \mathrm{IN} \\ \text { ID OF TUBES IN HX } & 0.37100 \mathrm{IN} \\ \text { HORIZONTAL TUBE SPACING } & 0.866 \text { IN } \\ \text { VERTICAL TUBE SPACING } & 1.000 \text { IN } \\ \text { REF-SIDE HEAT-TRANSFER MULTIPLIER } & 1.000 \\ \text { REF-SIDE PRESSURE-DROP MULTIPLIER } & 1.000\end{array}$

GENERAL WAVY OR ZIG-ZAG FINS FIN PITCH

FIN THICKNESS

THERMAL CONDUCTIVITY: FINS

THERMAL CONDUCTIVITY: TUBES

FRACTION OF COMPUTED CONTACT CONDUCTANCE 999.999

NUMBER OF RETURN BENDS

128.00

AIR-SIDE PRESSURE-DROP MULTIPLIER - UNIT 1.000

AIR-SIDE PRESSURE-DROP MULTIPLIER - SYSTEM 1.000

OUTDOOR UNIT:

INLET AIR TEMPERATURE

FAN OPERATING FREQUENCY RATIO

FAN NOMINAL FREQUENCY

FAN NOMINAL SPEED

PERCENT OF NOMINAL LOADING

FAN AND DRIVE EFFICIENCY

$\begin{array}{lr}\text { SELECTED FAN DRIVE } & \text { PM-ECM-DRIVEN } \\ \text { FRONTAL AREA OF HX } & 9.050 \text { SQ FT }\end{array}$

NUMBER OF TUBES IN DIRECTION OF AIR FLOW 3.00

NUMBER OF PARALLEL CIRCUITS

OD OF TUBES IN HX

39500 IN

ID OF TUBES IN HX

HORIZONTAL TUBE SPACING
VERTICAL TUBE SPACING

VERTICAL TUBE SPACING

$95.000 \mathrm{~F}$

1.00

$82.50 \mathrm{HZ}$

RELATIVE HUMIDITY

0.40000

NOMINAL AIRFLOW RATE

$2700.00 \mathrm{CFM}$

NUMBER OF MOTOR POLES

12

GENERAL WAVY OR ZIG-ZAG FINS

FIN PITCH

$13.00 \mathrm{FINS} / \mathrm{IN}$

FIN THICKNESS

$0.00600 \mathrm{IN}$

THERMAL CONDUCTIVITY: FINS

THERMAL CONDUCTIVITY: TUBES $225.00 \mathrm{BTU} / \mathrm{H}-\mathrm{FT}-\mathrm{F}$

FRACTION OF COMPUTED CONTACT CONDUCTANCE 999.999

NUMBER OF RETURN BENDS

99.999
72.00

1.080 IN

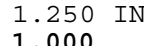

AIR-SIDE HEAT-TRANSFER MULTIPLIER

1.000

1.000

AIR-SIDE PRESSURE-DROP MULTIPLIER - UNIT 1.000

REF-SIDE PRESSURE-DROP MULTIPIITRR

OUTDOOR UNIT: FAN

FAN STATIC EFFICIENCY $=-3.993 \mathrm{E}+00+4.266 \mathrm{E}+00 *$ LOG10 $(\mathrm{S} / 1000)+.-1.024 \mathrm{E}+00 *(\mathrm{LOG} 10(\mathrm{~S} / 1000)) * *$.

WHERE

SPECIFIC SPEED $(\mathrm{S})=$ FAN RPM * (AIR FLOW CFM**0.5) / (COIL STATIC PRESSURE DROP**0.75)

POWER TO THE INDOOR FAN ADDED TO AIR AFTER CROSSING THE INDOOR COIL.

POWER TO THE OUTDOOR FAN ADDED TO AIR AFTER CROSSING THE OUTDOOR COIL. 
$\star * * * *$ INPUT DATA $* * * * *$

LINE HEAT TRANSFER:

HEAT GAIN IN SUCTION LINE $\quad 100.0 \mathrm{BTU} / \mathrm{H}$

$\begin{array}{llll}\text { HEAT LOSS IN DISCHARGE LINE } & 700.0 \mathrm{BTU} / \mathrm{H} \\ \text { HEAT LOSS IN LIQUID LINE } & 700.0 \mathrm{BTU} / \mathrm{H}\end{array}$

ESCRIPTION OF CONNECTING TUBING:

LIQUID LINE FROM INDOOR TO OUTDOOR HEAT EXCHANGER
.25550 IN

FROM INDOOR COIL TO REVERSING VALVE

$\begin{array}{lr}\text { ID } & 0.68600 \text { IN } \\ \text { EQUIVALENT LENGTH } & 31.00 \text { FT }\end{array}$

FROM REVERSING VALVE TO COMPRESSOR INLET

$\begin{array}{lr}\text { ID } & 0.79300 \text { IN } \\ \text { EQUIVALENT LENGTH } & 5.00 \text { FT }\end{array}$

FROM OUTDOOR COIL TO REVERSING VALVE ID $\quad 0.68600$ IN FROM REVERSING VALVE TO COMPRESSOR OUTLET $\begin{array}{lr}\text { ID } & 0.56100 \text { IN } \\ \text { EQUIVALENT LENGTH } & 2.00 \mathrm{FT}\end{array}$

COMPRESSOR AND ACCUMULATOR GEOMETRY DATA: VOLCMP $=395.00 \mathrm{CU}$ IN

ACCHGT $=10.00 \mathrm{IN}$ ACCDIA $=4.83 \mathrm{IN} \quad$ ATBDIA $=0.6800 \mathrm{IN}$

OILDIA $=0.035$ IN UPPDIA $=0.040$ IN HOLDIS $=2.50$ IN

$\begin{array}{ccllllll}\text { ITERATION } & \text { TOLERANCES } & \text { AMPCON } & 0.050 & \text { BTU/LBM } & \text { TOLH } & 0.00050 & \text { BTU/LBM } \\ \text { AMBCON } & 0.050 \mathrm{~F} & \text { CMPCON } & 0.400 \mathrm{~F} & \text { TOLS } & 0.00003 & \text { BTU/LBM-R }\end{array}$

CONMST $\quad 0.002 \mathrm{~F}$

\section{$\star * * * *$ CALCULATED HEAT PUMP PERFORMANCE $* * * * *$}

SYSTEM SUMMARY

COMPRESSOR SUCTION LINE INLET SHELL INLET (1) $\begin{array}{ll}\text { CONDENSER INLET } & \text { INT } \\ \text { OUTLET }\end{array}$

EXPANSION DEVICE

EVAPORATOR INLET OUTLET
REFRIGERANT

TEMPERATURE $58.980 \mathrm{~F}$ 187.181

$179.280 \mathrm{~F}$ 98.865

$93.553 \mathrm{~F}$

$54.386 \mathrm{~F}$ 58.980
SATURATION

EMPERATURE $50.583 \mathrm{~F}$ 49.876

$115.373 \mathrm{~F}$ 114.871

$112.896 \mathrm{~F}$ $54.386 \mathrm{~F}$ 50.583
REFRIGERANT

ENTHALPY

$110.529 \mathrm{BTU} / \mathrm{LBM}$

110.764

$126.869 \mathrm{BTU} / \mathrm{LBM}$

38.911

$37.263 \mathrm{BTU} / \mathrm{LBM}$

$37.263 \mathrm{BTU} / \mathrm{LBM}$

110.529

REFRIGERANT
QUALITY
1.0000
1.0000
1.0000
1.0000
0.0000
0.0000
0.1400
1.0000

REFRIGERANT

PRESSURE

99.696 PSIA

98.524
258.800

258.675 PSIA

250.436 PSIA

106.176 PSIA

99.696
AIR

TEMPERATURE

$95.000 \mathrm{~F}$ 07.948

$80.000 \mathrm{~F}$ 
$* * * *$ CALCULATED HEAT PUMP PERFORMANCE $* * * * *$

DRIVE FREQUENCIES

COMPRESSOR $\quad \begin{aligned} 180.0 \mathrm{~Hz} \\ \text { CONDENSER FAN }\end{aligned}$

EVAPORATOR FAN $108.0 \mathrm{HZ}$

COMPRESSOR PERFORMANCE $\begin{array}{llrl}\text { COMPRESSOR } & \text { DRIVE POWER } & 2.441 & \mathrm{KW} \\ \text { REFRIGERANT MASS FLOW RATE } & 424.806 \mathrm{LBM} / \mathrm{H} \\ \text { MOTOR OPERATING SPEED } & 5400.000 & \text { RPM }\end{array}$ $\begin{array}{lr}\text { MOTOR OPERATING SPEED } & 5400.000 \mathrm{RPM} \\ & 100.00 \%\end{array}$

MOTOR NOMINAL SIZE REQUIRED $2.265 \mathrm{HP}$ MOTOR OPERATING TORQUE 45.818 OZ-FT $\%$ OF BASE NOMINAL TORQUE $146.459 \%$

FLOW MULTIPLIER

MOTOR HEAT

OVERALL DRIVE CHANGE

1.043
1.161

COMPRESSOR SHELL HEAT LOSS

$788.339 \mathrm{BTU} / \mathrm{H}$

FAN/BLOWER PERFORMANCE
AIR FLOW RATE

FACE VELOCITY

\section{CONDENSER \\ $2700.00 \mathrm{CFM}$ \\ 298.34 FT/MIN \\ $49.81 \mathrm{FT} / \mathrm{MIN}$ \\ 0.098 IN H2O}

DUCT PRESSURE DROP

DUCT PRESSURE DROP

FILTER PRESSURE DROP

TOTAL PRESSURE DROP

\section{MOTOR SPEED}

OF NOMINAL FREQUENCY DRIVE EFFICIENCY

AT OPERATING SPEED

FAN MOTOR TORQUE

O OF NOMINAL TORQUE

COMBINED DRIVE \& FAN

OUTDOOR FAN PERFORMANCE: SPECIFIC SPEED

FAN-ONLY EFFICIENCY

0.098 IN H2O

$825.00 \mathrm{RPM}$

$100.00 \%$

0.788

12.01 OZ-FT

$75.00 \%$

0.280

$243.88 \quad \mathrm{E}+03$
0.355

$\begin{array}{lr}\text { COMPRESSOR EFFICIENCY } & \\ \text { OVERALL ISENTROPIC } & 0.5406 \\ \text { VOLUMETRIC } & 0.7658 \\ \text { AT A PRESSURE RATIO OF } & 2.627\end{array}$

DRIVE EFFICIENCY SELECTED MOTOR/DRIVE 0.8982 $\begin{array}{lll}\text { BASE } & \text { MOTOR/DRIVE } & 0.7810\end{array}$

EFFICIENCY MULTIPLIER

1.044 $\begin{array}{ll}\text { MOTOR HEAT } & 1.044 \\ \text { OVERALL DRIVE CHANGE } & 1.201\end{array}$

SUPERHEAT CORRECTION TERMS POWER

0.9936 MASS FLOW RATE 1.0183

EVAPORATOR

900.00 CFM

230.77 FT/MIN

$417.04 \mathrm{FT} / \mathrm{MIN}$

0.187 IN H20

0.150 IN H2O

0.072 IN H2O

0.103 IN H2O
0.512 IN $\mathrm{H} 20$

$1080.00 \mathrm{RPM}$

$100.00 \%$

0.814

12.55 OZ-FT

$75.00 \%$

0.366 
$\star * * *$ CALCULATED HEAT PUMP PERFORMANCE $* * * * *$

CONDENSER - HEAT TRANSFER PERFORMANCE OF EACH CIRCUIT

$\begin{array}{lrl}\text { INLET AIR TEMPERATURE } & 95.000 & \mathrm{~F} \\ \text { AIR TEMPERATURE LEAVING COIL } & 107.815 & \mathrm{~F} \\ \text { HEAT GENERATED FROM FAN } & 380.8 & \text { BTU/H } \\ \text { OUTLET AIR TEMPERATURE } & 107.948 & \mathrm{~F}\end{array}$

TOTAL HEAT EXCHANGER EFFECTIVENESS 0.7199

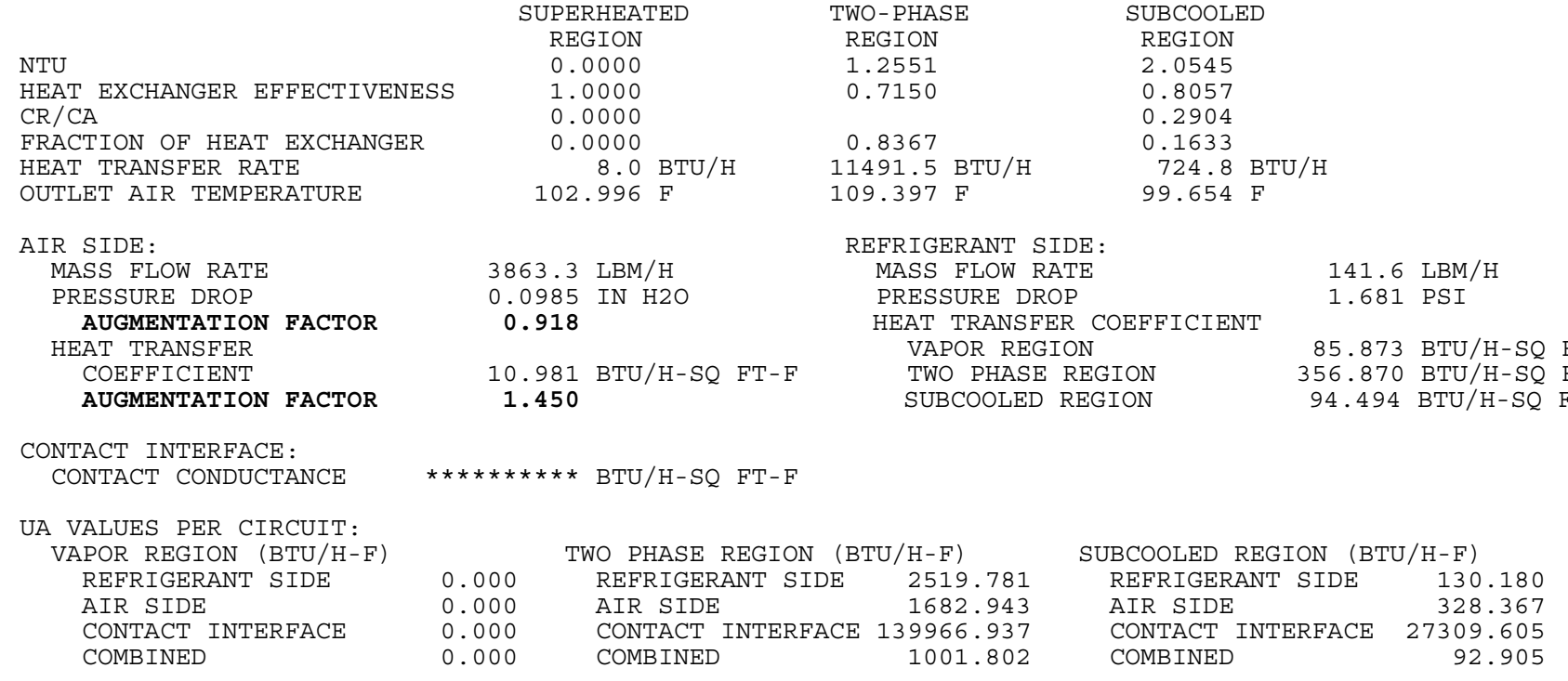

FLOW CONTROL DEVICE - CONDENSER EXIT SUBCOOLING IS SPECIFIED AS $16.000 \mathrm{~F}$

CORRESPONDING TXV RATING PARAMETERS: RATED OPERATING SUPERHEAT $11.000 \mathrm{~F}$ STATIC SUPERHEAT RATING $\quad 6.000$ FRACTION OF RATED OPENING $\quad 0.476$

$\begin{array}{lll}\text { FRACTION OF RATED OPENING } & 0.476 & \\ \text { TXV CAPACITY RATING: } & 3.537 \text { TONS }\end{array}$

CORRESPONDING CAPILLARY TUBE PARAMETERS: NUMBER OF CAPILLARY TUBES CABIE FLOW FACTOR

3. 458
CORRESPONDING ORIFICE PARAMETER: ORIFICE DIAMETER 0.0651 IN 
$\star * * * *$ CALCULATED HEAT PUMP PERFORMANCE $* * * * *$

EVAPORATOR - HEAT TRANSFER PERFORMANCE OF EACH CIRCUIT

$\begin{array}{lrl}\text { INLET AIR TEMPERATURE } & 80.000 & \mathrm{~F} \\ \text { AIR TEMPERATURE LEAVING COIL } & 56.344 \mathrm{~F} \\ \text { HEAT GENERATED FROM FAN } & 504.4 \mathrm{BTU} / \mathrm{H} \\ \text { OUTLET AIR TEMPERATURE } & 56.861 \mathrm{~F}\end{array}$

MOISTURE REMOVAL OCCURS

SUMMARY OF DEHUMIDIFICATION PERFORMANCE (TWO-PHASE REGION)

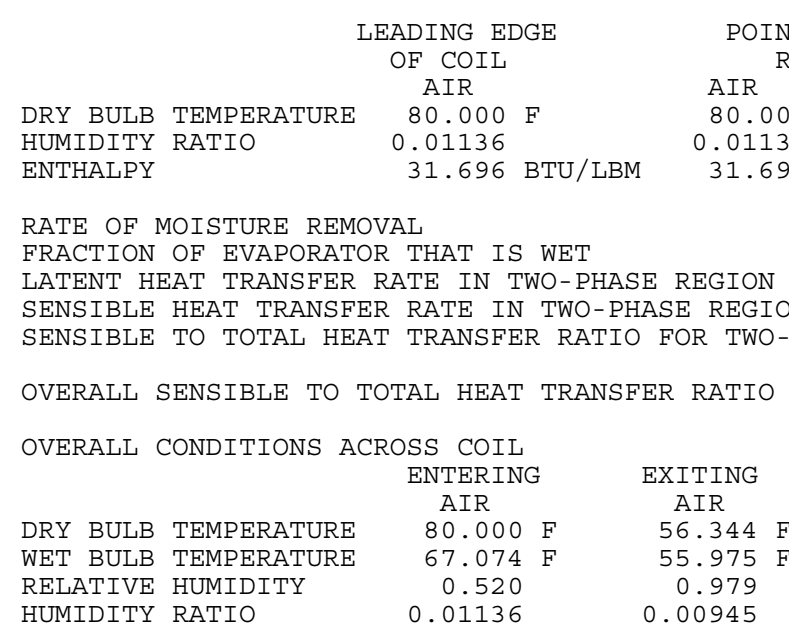

TOTAL HEAT EXCHANGER EFFECTIVENESS (SENSIBLE)

$\mathrm{NTU}$

HEAT EXCHANGER EFFECTIVENESS $\quad 0.5164$ REGION REMOVAL MOISTURE REMOVAL BEGINS

BTU/LBM 0.01136

$26.975 \mathrm{BTU} / \mathrm{LBM}$

LEAVING EDGE OF COIL

WALL

$0.00936-10$

0.00936

$23.617 \mathrm{BTU} / \mathrm{LBM} \quad 22.696 \mathrm{BTU} / \mathrm{LBM}$

$2.5355 \mathrm{LBM} / \mathrm{H}$

1.0000

2689. BTU/

7471. BTU/H

0.7353

0.7408

\subsection{9}

0.5164

1.8442

$214.7 \mathrm{BTU} / \mathrm{H}$

FRACTION OF HEAT EXCHANGE

HEAT TRANSFER RATE

$58.02 \mathrm{LBM} / \mathrm{H}$

OUTLTT ATR TEMPERATURE

$64.923 \mathrm{~F}$

TWO-PHASE
REGION
2.3051
0.9002

0.9562
$10160.3 \mathrm{BTU} / \mathrm{H}$
$1265.55 \mathrm{LBM} / \mathrm{H}$
$55.951 \mathrm{~F}$


EVAPORATOR - HEAT TRANSFER PERFORMANCE OF EACH CIRCUIT

AIR SIDE:

MASS FLOW RATE

AUGMENTATION FACTOR

HEAT TRANSFER COEFFICIENT

DRY COIL
WET COIL

AUGMENTATION FACTOR

CONTACT INTERFACE:

CONTACT CONDUCTANCE

983204.125 BTU/H-SQ FT-F

DRY FIN EFFICIENCY

WET FIN EFFICIENCY (AVERAGE) 0.87

WET CONTACT FACTOR (AVERAGE) 1.330

UA VALUES PER CIRCUIT:VAPOR $\begin{array}{ll} & \text { REGION } \\ \text { REFRIGERANT SIDE } & 19.051\end{array}$

AIR SIDE

DRY COIL
WET COII

WET COIL
CONTACT INTERFACE

DRY COIL

WET COII

COMBINED

DRY COIL

5659.703

40.119

TWO PHAS

REGION

$4071.052 \mathrm{BTU} / \mathrm{H}-\mathrm{F}$

$0.000 \mathrm{BTU} / \mathrm{H}-\mathrm{F}$ $880.400 \mathrm{BTU} / \mathrm{H}-\mathrm{F}$

$0.000 \mathrm{BTU} / \mathrm{H}-\mathrm{F}$ $124081.250 \mathrm{BTU} / \mathrm{H}-\mathrm{F}$

$0.000 \mathrm{BTU} / \mathrm{H}-\mathrm{F}$

$719.661 \mathrm{BTU} / \mathrm{H}-\mathrm{F}$

12.888

$9.196 \mathrm{BTU} / \mathrm{H}-\mathrm{SQ}$ FT-F
REFRIGERANT SIDE

MASS FLOW RATE

PRESSURE DROP

$141.6 \mathrm{LBM} / \mathrm{H}$

HEAT TRANSFER COEFFICIENT VAPOR REGION

TWO PHASE REGION

71.709
$702.501 \mathrm{BTU} / \mathrm{BT}-\mathrm{SQ}$-SQ FT-F
0.512 IN $\mathrm{H} 2 \mathrm{O}$ 
$* * * *$ SUMMARY OF ENERGY INPUT AND OUTPUT $* * * * *$

SAMPLE ECM HEAT PUMP, 95 F DESIGN PT: AUTO-MOTOR + DUCT SIZING, FILE:DESIGN.HPS

OPERATING CONDITIONS :

AIR TEMPERATURE INTO EVAPORATOR

AIR TEMPERATURE INTO CONDENSER

SATURATION TEMP INTO COMPRESSOR

\section{DRIVE FREQUENCIES:}

\section{COMPRESSOR}

INDOOR FAN

OUTDOOR FAN

DRIVE FREQUENCY RATIOS:

COMPRESSOR

INDOOR FAN

OUTDOOR FAN

$80.00 \mathrm{~F}$
$95.00 \mathrm{~F}$
$49.88 \mathrm{~F}$
$115.41 \mathrm{~F}$

NERGY INPUT SUMMARY:

HEAT PUMPED FROM AIR SOURCE

$180.00 \mathrm{HZ}$

$108.00 \mathrm{HZ}$

$82.50 \mathrm{HZ}$

POWER TO INDOOR FAN MOTOR

POWER TO OUTDOOR FAN MOTOR

TOTAL PARASITIC POWER

$\begin{array}{lll}\text { POWER TO } & \text { COMPRESSOR } & \text { MOTOR } \\ \text { TOTAL } & \text { INPUT } & \text { POWER }\end{array}$

\subsection{0}

1.00
1.00

REFRIGERANT-SIDE SUMMARY:

HEAT GAIN TO EVAPORATOR FROM AIR $31125.1 \mathrm{BTU} / \mathrm{H}$ DUAPORATOR

HEAT GAIN TO SUCTION LINE

ENERGY INPUT TO COMPRESSOR

HEAT LOSS FROM COMPRESSOR SHELL

HEAT LOSS FROM DISCHARGE LIN

HEAT LOSS

FROM LIQUID LINE

$31125.1 \mathrm{BTU} / \mathrm{H}$

147.8 WATTS

111.6 WATTS

259.4 WATTS

2440.7 WATTS

2700.0 WATTS $100.0 \mathrm{BTU} / \mathrm{H}$ $8330.0 \mathrm{BTU} / \mathrm{H}$ $788.3 \mathrm{BTU} / \mathrm{H}$ 6672.8 BTU/H $36672.8 \mathrm{BTU} / \mathrm{H}$ ENERGY OUTPUT SUMMARY :

HEAT RATE FROM REFRIGERANT TO INDOOR AIR $31125.1 \mathrm{BTU} / \mathrm{H}$ HEAT RATE FROM FAN TO INDOOR AIR $504.4 \mathrm{BTU} / \mathrm{H}$ TO/FROM INDOOR AIR $30620.8 \mathrm{BTU} / \mathrm{H}$

COOLING PERFORMANCE:
COP
3.323
CAPACITY
$11.341 \mathrm{BTU} / \mathrm{H}-\mathrm{W}$ 
$* * * *$ CHARGE INVENTORY RESULTS $* * * * *$

ANALYTICAL SOLUTION OF ZIVI'S METHOD

FOR A CONSTANT HEAT FLUX APPROXIMATION

STEADY-STATE REFRIGERANT MASS DISTRIBUTION (LBM)

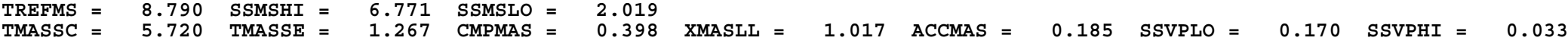

EQUILIBRIUM REFRIGERANT MASS DISTRIBUTION (LBM)

EQMSHI $=0.623$ EQMSLO $=8.166$ XMSLQ $=6.740$ XEQUIL $=0.1746$

HI/LO AND COMPONENT INTERNAL VOLUMES (CU FT), ACCUMULATOR LIQUID LEVEL (INCHES)

VOLHI $=0.227$ VOLLOW $=0.585$ VOLCND $=0.205$ VOLEVP $=0.153$ VOLCMP $=0.229$ VOLACC $=0.106 \quad$ XLEVEL $=0.000$ IN 


\title{
Listing C.2. Sample Single-Point Heat Pump Model Run
}

$-47^{\circ}$ F Off-Design Heating Condition -

\author{
Summary Output
}



$* * * *$ CONTOUR DATA GENERATION INFORMATION $* * * * *$

*** CONTOUR DATA GENERATOR FRONT-END IS BYPASSED

$\star * * * *$ INPUT DATA $* * * * *$

SAMPLE ECM HEAT PUMP, OFF-DESIGN PT: SPECIFIED MOTORS AND DUCTS, FILE:OFFDES.HPS

SUMMARY OUTPUT

HEATING MODE OF OPERATION

THE REFRIGERANT IS $R 22$

REFRIGERANT CHARGE IS NOT SPECIFIED

COMPRESSOR INLET SUPERHEAT IS SPECIFIED AT $1.00 \mathrm{~F}$

CONDENSER EXIT SUBCOOLING IS SPECIFIED AT $10.00 \mathrm{~F}$

ESTIMATE OF:

SATURATION TEMPERATURE INTO COMPRESSOR $40.00 \mathrm{~F}$

SATURATION TEMPERATURE OUT OF COMPRESSOR $100.00 \mathrm{~F}$

COMPRESSOR CHARACTERISTICS :

OPERATING FREQUENCY $\quad 50.000 \mathrm{~Hz}$

TOTAL DISPLACEMENT

1.700 CUBIC INCHES

SWDIM RECIPROCATING COMPRESSOR - CURVE FITS FROM ORNL AND MANUF'S DATA

DRIVE TYPE OF INPUT COMPRESSOR DATA IS SINE-WAVE-DRIVEN

DRIVE TYPE IS TO BE CONVERTED TO TO PM-ECM-DRIVEN

SELECTED MOTOR SIZE IS
NOMINAL FREQUENCY FOR

$2.27 \mathrm{HP}$

BASE SUPERHEAT FOR COMPRESSOR MAP $20.000 \mathrm{~F}$

BASE DISPLACEMENT FOR COMPRESSOR MAP $\quad 3.640$ CU IN

BASE MOTOR SIZE IS $2.75 \mathrm{HP}$

NOMINAL VOLTAGE FOR BASE MOTOR RATING AT 210.0 VOLTS

$\star * * * *$ INPUT DATA $* * * * *$

- USER PROVIDED COEFFICIENTS FOR COMPRESSOR SHELL ISENTROPIC AND VOLUMETRIC EFFICIENCY -

CURVE FIT REPRESENTATIONS AT 7 DISCRETE FREQUENCIES

CURVE FIT COEFFICIENTS AT $15.0 \mathrm{HZ}$ FREQUENCY POMINAL SPEED OF 750.0 RPM DRIVE VOLTAGE OF
ISENTROPIC EFF $=-2.324 \mathrm{E}-04 *$ CONDENSING TEMPERATURE**2 $+-5.143 \mathrm{E}-02 *$ CONDENSING TEMPERATURE

ISENTROPIC EFF $=-2.324 \mathrm{E}-04 *$ CONDENSING TEMPERATURE $* * 2+-5.143 \mathrm{E}-02 *$ CONDENSING TEMPERATURE

$+1.515 \mathrm{E}-03 *$ CONDENSING TEMPERATURE* $2+-9.975 \mathrm{E}-02 *$ EVAPORATING TEMPERAT

VOLUMETRIC EFF = $\begin{aligned} & +6.560 \mathrm{E}+00 * \text { (PRESSURE RATIO }-1 .)+7.350 \mathrm{E}-02 *(\text { PRESSURE RATIO }-1 . \text { ) * CONDENSING PRESSURE } \\ & +-2.192 \mathrm{E}-04 \text { * (PRESSURE RATIO }-1 .) * \text { CONDENSING PRESSURE**2 }+1.176 \mathrm{E}+00\end{aligned}$ 

CURVE FIT COEFFICIENTS AT 20.0 HZ FREQUENCY NOMINAL SPEED OF 1050.0 RPM DRIVE VOLTAGE OF

ISENTROPIC EFF

MPERATURE **2 +-7.267 - $04 *$ CONDENSING

$+1.387 \mathrm{E}-04 *$ CONDENSING TEMPERATURE*EVAPORATING TEMPERATURE $+7.244 \mathrm{E}-01$

$-5.320 \mathrm{E}-01$ * (PRESSURE RATIO - 1.) + 4.385E-03*(PRESSURE RATIO - 1.)*CONDENSING PRESSURE

$+-1.290 \mathrm{E}-05 *$ (PRESSURE RATIO - 1.)*CONDENSING PRESSURE**2 + 9.773E-01

CURVE FIT COEFFICIENTS AT $30.0 \mathrm{HZ}$ FREQUENCY NOMINAL SPEED OF $1650.0 \mathrm{RPM}$ DRIVE VOLTAGE OF

ISENTROPIC EFF $=-1.209 \mathrm{E}-04 *$ CONDENSING TEMPERATURE $* 2+1.976 \mathrm{E}-02 *$ CONDENSING TEMPERATURE

$+-6.166 \mathrm{E}-05 *$ EVAPORATING TEMPERATURE $* * 2+-8.747 \mathrm{E}-04 *$ EVAPORATING TEMPERATURE

$+7.018 \mathrm{E}-05 *$ CONDENSING TEMPERATURE*EVAPORATING TEMPERATURE $+-3.318 \mathrm{E}-01$

VOLUMETRIC EFF $=-2.101 \mathrm{E}-01 *($ PRESSURE RATIO - 1.) $+1.104 \mathrm{E}-03 *$ (PRESSURE RATIO - 1.$) *$ CONDENSING PRESSURE

$+-3.066 \mathrm{E}-06$ * (PRESSURE RATIO - 1.)*CONDENSING PRESSURE**2 + 9.595E-01

CURVE FIT COEFFICIENTS AT $45.0 \mathrm{HZ}$ FREQUENCY NOMINAL SPEED OF 2550.0 RPM DRIVE VOLTAGE OF

ISENTROPIC EFF $=-1.861 \mathrm{E}-05 *$ CONDENSING TEMPERATURE $* 2+-3.855 \mathrm{E}-03 *$ CONDENSING TEMPERATURE

$+1.498 \mathrm{E}-04$ * CONDENSING TEMPERATURE*EVAPORATING TEMPERATURE $+1.004 \mathrm{E}+00$

VOLUMETRIC EFF $=-1.106 \mathrm{E}-01 *($ PRESSURE RATIO -1.$)+3.117 \mathrm{E}-04$ * (PRESSURE RATIO - 1.$)$ *CONDENSING PRESSURE $+-8.162 \mathrm{E}-07 *$ (PRESSURE RATIO - 1.)*CONDENSING PRESSURE**2+8.922E-01

CURVE FIT COEFFICIENTS AT $60.0 \mathrm{HZ}$ FREQUENCY NOMINAL SPEED OF $3450.0 \mathrm{RPM}$ DRIVE VOLTAGE OF 208.0 VOLTS ISENTROPIC EFF $=-7.977 \mathrm{E}-05 *$ CONDENSING TEMPERATURE**2 $+1.039 \mathrm{E}-02 *$ CONDENSING TEMPERATUR $+-1.293 \mathrm{E}-04 *$ EVAPORATING TEMPERATURE $* 2+-9.867 \mathrm{E}-03 *$ EVAPORATING TEMPERATUR

$+1.840 \mathrm{E}-04 *$ CONDENSING TEMPERATURE*EVAPORATING TEMPERATURE $+1.825 \mathrm{E}-01$

VOLUMETRIC EFF $=-1.789 \mathrm{E}-01 *$ (PRESSURE RATIO - 1.$)+4.585 \mathrm{E}-04 *$ (PRESSURE RATIO -1.$) *$ CONDENSING PRESSURE $+-6.751 \mathrm{E}-07$ (PRESSURE RATIO - 1.)*CONDENSING PRESSURE**2 + $9.523 \mathrm{E}-01$

CURVE FIT COEFFICIENTS AT $75.0 \mathrm{HZ}$ FREQUENCY NOMINAL SPEED OF $4350.0 \mathrm{RPM}$ DRIVE VOLTAGE OF

ISENTROPIC EFF $=-6.626 \mathrm{E}-06 *$ CONDENSING TEMPERATURE $* * 2+1.071 \mathrm{E}-04 *$ CONDENSING TEMPERATURE

$+-4.978 \mathrm{E}-05 *$ EVAPORATING TEMPERATURE $* * 2+-1.304 \mathrm{E}-03 *$ EVAPORATING TEMPERATU
$+\quad 3.893 \mathrm{E}-05 *$ CONDENSING TEMPERATURE $*$ EVAPORATING TEMPERATURE $+5.454 \mathrm{E}-01$

VOLUMETRIC EFF $=-1.445 E-01 *($ PRESSURE RATIO - 1.) + 4.353E-04*(PRESSURE RATIO - 1.)*CONDENSING PRESSURE $+-7.215 \mathrm{E}-07$ * (PRESSURE RATIO - 1.)*CONDENSING PRESSURE**2 + 8.580E-01

CURVE FIT COEFFICIENTS AT $90.0 \mathrm{HZ} \mathrm{FREQUENCY} \mathrm{NOMINAL} \mathrm{SPEED} \mathrm{OF} 5250.0 \mathrm{RPM}$ DRIVE VOLTAGE OF

ISENTROPIC EFF $=-4.169 \mathrm{E}-05$ *CONDENSING TEMPERATURE**2 $+7.656 \mathrm{E}-03 *$ CONDENSING TEMPERATURE

$+-7.209 \mathrm{E}-05 *$ EVAPORATING TEMPERATURE $* 2+2+-4.765 \mathrm{E}-03 *$ EVAPORATING TEMPERATURE

VOLUMETRIC EFF $=+-8.835 \mathrm{E}-02 *($ PRESSURE RATIO -1.$)+1.966 \mathrm{E}-04 *$ (PRESSURE RATIO -1.$) *$ COMD

$+-4.783 \mathrm{E}-07 *$ (PRESSURE RATIO -1.$) *$ CONDENSING PRESSURE**2 $+7.990 \mathrm{E}-01$

GENERAL SHELL HEAT LOSS CORRELATION IS SELECTED

CANFAC $=-1.70400 \mathrm{E}-02 *$ CONDENSING TEMPERATURE $+5.61000 \mathrm{E}-05 *$ CONDENSING TEMPERATURE**2 $+1.31400 \mathrm{E}+00$

SUPERHEAT CORRECTION TERMS (SET IN BLOCK DATA):

SUCTION GAS HEATING FACTOR 0.330

VOLUMETRIC EFFICIENCY CORRECTION FACTOR 0.750

SUCTTON GAS HEAT PTCKUP FRACTION 
INDOOR UNIT:

$\begin{array}{lrl}\text { INLET AIR TEMPERATURE } & 70.000 \mathrm{~F} \\ \text { FAN OPERATING FREQUENCY RATIO } & 0.60 \\ \text { FAN NOMINAL FREQUENCY } & 108.00 \mathrm{~Hz} \\ \text { FAN NOMINAL SPEED } & 1080.00 \mathrm{RPM} \\ \text { NOMINAL MOTOR SIZE } & 0.21 \mathrm{HP} \\ \text { CONSTANT FAN-ONLY EFFICIENCY } & 0.45 \\ \text { SELECTED FAN DRIVE } & \text { PM-ECM-DRIVEN } \\ \text { ID OF EACH OF 6 EQUIVALENT DUCTS } & 6.22 \mathrm{IN} \\ \text { FRONTAL AREA OF HX } & 3.900 \mathrm{SQ} \\ \text { NUMBER OF TUBES IN DIRECTION OF AIR FLOW } & 4.00 \\ \text { NUMBER OF PARALLEL CIRCUITS } & 3.00 \\ \text { OD OF TUBES IN HX } & 0.39500 \mathrm{IN} \\ \text { ID OF TUBES IN HX } & 0.37100 \mathrm{IN} \\ \text { HORIZONTAL TUBE SPACING } & 0.866 \mathrm{IN} \\ \text { VERTICAL TUBE SPACING } & 1.000 \mathrm{IN} \\ \text { REF-SIDE HEAT-TRANSFER MULTIPLIER } & 1.000 \\ \text { REF-SIDE PRESSURE-DROP MULTIPLIER } & 1.000\end{array}$

RELATIVE HUMIDITY

NOMINAL AIRFLOW RATE

NUMBER OF MOTOR POLES
0.58000

$900.00 \mathrm{CFM}$

12

GENERAL WAVY OR ZIG-ZAG FINS

FIN PITCH

FIN THICKNESS

THERMAL CONDUCTIVITY: FINS

THERMAL CONDUCTIVITY: TUBES

NUMBER OF RETURN BEND

1.000

AIR-SIDE PRESSURE-DROP MULTIPLIER - UNIT 1.000

AIR-SIDE PRESSURE-DROP MULTIPLIER - SYSTEM 1.000

RELATIVE HUMIDITY

0.72000

NOMINAL AIRFLOW RATE

NUMBER OF MOTOR POLES

$2700.00 \mathrm{CFM}$

12

$\begin{array}{rl}82.50 & \mathrm{HZ} \\ 825.00 & \mathrm{RP} \\ 0.16 \mathrm{HP}\end{array}$

FAN NOMINAL SPEED

NOMINAL MOTOR SIZE
FAN AND DRIVE EFICIENCY

FAN AND DRIVE EFFICI
SELECTED FAN DRIVE

CALCULATED
PM-ECM-DRIVEN

FRONTAL AREA OF HX $\quad 9.050$ SQ FT

NUMBER OF TUBES IN DIRECTION OF AIR FLOW 3.00

NUMBER OF PARALLEL CIRCUITS

OD OF TUBES IN HX

3.00

0.39500 IN

0.37100 IN

$\begin{array}{ll}1.080 & \text { IN } \\ 1.250 & \text { IN }\end{array}$

HORIZONTAL TUBE SPACIN

VERTICAL TUBE SPACIN

1.000

1.000
GENERAL WAVY OR ZIG-ZAG FINS

FIN PITCH

FIN THICKNESS

THERMAL CONDUCTIVITY: FINS

THERMAL CONDUCTIVITY: TUBES

FRACTION OF COMPUTED CON
NUMBER OF RETURN BENDS

NUMBER OF RETURN BENDS

AIR-SIDE PRESSURE-DROP MULTIPLIER - SYSTEM 1.000
AIR-SIDE HEAT-TRANSFER MULTIPLIER

1.000
$13.00 \mathrm{FINS} / \mathrm{IN}$

$0.00600 \mathrm{IN}$

$128.30 \mathrm{BTU} / \mathrm{H}-\mathrm{FT}-\mathrm{F}$

$225.00 \mathrm{BTU} / \mathrm{H}-\mathrm{FT}-\mathrm{F}$

OUTDOOR UNIT: FAN

FAN STATIC EFFICIENCY $=-3.993 \mathrm{E}+00+4.266 \mathrm{E}+00 * \operatorname{LOG10}(\mathrm{S} / 1000)+.-1.024 \mathrm{E}+00 *(\mathrm{LOG} 10(\mathrm{~S} / 1000)) * *$.

NHERE

SPECIFIC SPEED $(S)=$ FAN RPM * (AIR FLOW CFM**0.5) / (COIL STATIC PRESSURE DROP**0.75)

POWER TO THE INDOOR FAN ADDED TO AIR AFTER CROSSING THE INDOOR COIL.

POWER TO THE OUTDOOR FAN ADDED TO AIR AFTER CROSSING THE OUTDOOR COIL. 
$\star * * * *$ INPUT DATA $* * * * *$

LINE HEAT TRANSFER:

HEAT GAIN IN SUCTION LINE $\quad 100.0 \mathrm{BTU} / \mathrm{H}$

$\begin{array}{llll}\text { HEAT LOSS IN DISCHARGE LINE } & 700.0 \mathrm{BTU} / \mathrm{H} \\ \text { HEAT LOSS IN LIQUID LINE } & 700.0 \mathrm{BTU} / \mathrm{H}\end{array}$

ESCRIPTION OF CONNECTING TUBING:

LIQUID LINE FROM INDOOR TO OUTDOOR HEAT EXCHANGER

$$
\begin{array}{lr}
\text { ID } & 0.25550 \text { IN } \\
\text { EQUIVALENT LENGTH } & 39.80 \text { FT }
\end{array}
$$

FROM INDOOR COIL TO REVERSING VALVE

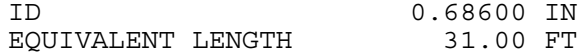
FROM REVERSING VALVE TO COMPRESSOR INLET

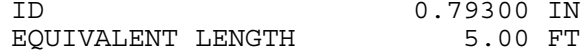 $\begin{array}{lr}\text { ID } & 0.79300 \text { IN } \\ \text { EQUIVALENT LENGTH } & 5.00 \text { FT }\end{array}$

FROM ID $0.68600 \mathrm{IN}$ FROM REVERSING VALVE TO COMPRESSOR $2.00 \mathrm{FT}$ 0.56100 IN

COMPRESSOR AND ACCUMULATOR GEOMETRY DATA: VOLCMP $=395.00 \mathrm{CU}$ IN

ACCHGT $=10.00 \mathrm{IN}$ ACCDIA $=4.83 \mathrm{IN}$ ATBDIA $=0.6800 \mathrm{IN}$

OILDIA $=0.035$ IN UPPDIA $=0.040$ IN HOLDIS $=2.50$ IN

$\begin{array}{ccllllll}\text { ITERATION } & \text { TOLERANCES } & \text { MMCON } & 0.050 & \text { BTU/LBM } & \text { TOLH } & 0.00050 & \text { BTU/LBM } \\ \text { AMBCON } & 0.050 \mathrm{~F} & \text { CMPCON } & 0.0500 \mathrm{~F} & \text { TOLS } & 0.00003 \mathrm{BTU} / \mathrm{LBM}-\mathrm{R}\end{array}$

$0.050 \mathrm{~F}$

EVPCON $\quad 0.100 \mathrm{~F} \quad$ CONMST $0.002 \mathrm{~F}$

$* * * *$ CALCULATED HEAT PUMP PERFORMANCE $* * * * *$

SYSTEM SUMMARY

COMPRESSOR SUCTION LINE INLET SHELL INLET SHELL INLET

$\begin{array}{ll}\text { CONDENSER INLET } & \text { OUTLET }\end{array}$

EXPANSION DEVICE

EVAPORATOR INLET OUTIET

\begin{tabular}{|c|c|c|c|c|}
\hline \multirow{5}{*}{$\begin{array}{r}\text { REFRIGERANT } \\
\text { TEMPERATURE } \\
39.142 \\
40.132 \\
125.886\end{array}$} & SATURATION & REFRIGERAN & & REFRIGERAN \\
\hline & TEMPERATURE & ENTHALPY & & QUALITY \\
\hline & $39.142 \mathrm{~F}$ & 107.292 & $\mathrm{BTU} / \mathrm{LBM}$ & 0.9911 \\
\hline & 39.132 & 108.245 & & 1.0000 \\
\hline & 87.735 & 119.289 & & 1.0000 \\
\hline $93.042 \mathrm{~F}$ & $87.710 \mathrm{~F}$ & 112.616 & $\mathrm{BTU} / \mathrm{LBM}$ & 1.00 \\
\hline 77.639 & 87.645 & 32.398 & & 00 \\
\hline $54.886 \mathrm{~F}$ & $87.439 \mathrm{~F}$ & 25.725 & $\mathrm{BTU} / \mathrm{LBM}$ & 0.0000 \\
\hline $\begin{array}{l}39.491 \mathrm{~F} \\
39.142\end{array}$ & $\begin{array}{l}39.491 \mathrm{~F} \\
39.142\end{array}$ & $\begin{array}{r}25.725 \\
107.292\end{array}$ & $\mathrm{BTU} / \mathrm{LBM}$ & $\begin{array}{l}0.0512 \\
0.9911\end{array}$ \\
\hline
\end{tabular}

R

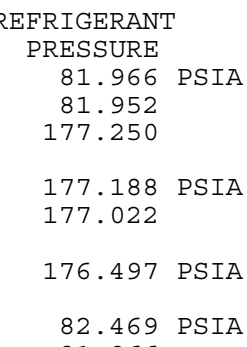

$47.002 \mathrm{~F}$ 
DRIVE FREQUENCIES

$\begin{array}{ll}\text { COMPRESSOR } & \\ \text { CONDENSER FAN } & 50.0 \mathrm{~Hz} \\ & 64.8 \mathrm{~Hz}\end{array}$

EVAPORATOR FAN $\quad 37.1 \mathrm{HZ}$

COMPRESSOR PERFORMANCE

COMPRESSOR DRIVE POWER

REFRIGERANT MASS FLOW RATE

MOTOR OPERATING SPEED

$0.453 \mathrm{KW}$

$104.908 \mathrm{LBM} / \mathrm{H}$

$1500.000 \mathrm{RPM}$

$27.78 \%$

TOTOR

OPERATING TORQU

26.636 OZ-FT

$75.569 \%$

\% OF BASE NOMINAL TORQUE $85.145 \%$

FLOW MULTIPLIER

MOTOR HEAT

OVERALL DRIVE CHANGE

1.008

1.107

COMPRESSOR SHELL HEAT LOSS

$387.865 \mathrm{BTU} / \mathrm{H}$

\section{FAN/BLOWER PERFORMANCE}

AIR FLOW RATE

$\begin{array}{ll}\text { FACE } & \text { VELOCITY } \\ \text { SURFACE } & \text { VELOCITY }\end{array}$

UNIT PRESSURE DROP

$\begin{array}{lll}\text { DUCT } & \text { PRESSURE } & \text { DROP } \\ \text { FILTER } & \text { PRESSURE } & \text { DROP }\end{array}$

FILTER PRESSURE DROP
HEATER PRESSURE DROP

HEATER PRESSURE DROP
TOTAL PRESSURE DROP

\section{MOTOR SPEED}

OF NOMINAL FREQUENCY DRIVE EFFICIENCY

AT OPERATING SPEED

AAN MOTOR TORQUE

OF NOMINAL TORQU

COMBINED DRIVE \& FAN DFFICI DRCY

$\begin{aligned} & \text { CONDENSER } \\ & 540.00 \text { CFM } \\ & 138.46 \text { FT/MIN } \\ & 250.22 \text { FT/MIN } \\ & \\ & 0.036 \text { IN H20 } \\ & 0.057 \text { IN H20 } \\ & 0.025 \text { IN H20 } \\ & 0.036 \text { IN H20 } \\ & 0.154 \text { IN H20 } \\ & 648.00 \text { RPM } \\ & 60.00 \% \\ & 0.637 \\ & 3.77 \text { OZ-FT } \\ & 22.53 \% \\ & 0.215 \text { HP }\end{aligned}$

0.287

OUTDOOR FAN PERFORMANCE SPECIFIC SPEED

FAN-ONLY EFFICIENCY

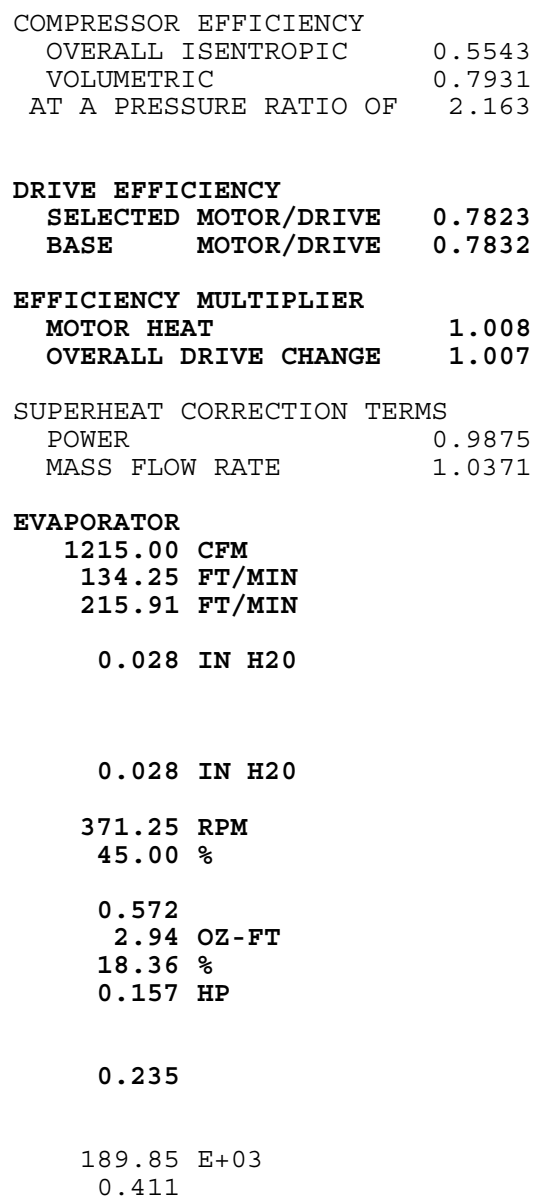

DRIVE EFFICIENCY

FFICIENCY MULTIPLIER

MOTOR HEAT
OVERALL DRIVE CHANG

9875 $\begin{array}{lr}\text { POWER } & 0.9875 \\ \text { MASS FLOW RATE } & 1.0371\end{array}$

0.411 
$\star * * *$ CALCULATED HEAT PUMP PERFORMANCE $* * * * *$

CONDENSER - HEAT TRANSFER PERFORMANCE OF EACH CIRCUIT

$\begin{array}{lrl}\text { INLET AIR TEMPERATURE } & 70.000 & \mathrm{~F} \\ \text { AIR TEMPERATURE LEAVING COIL } & 84.179 & \mathrm{~F} \\ \text { HEAT GENERATED FROM FAN } & 116.1 & \mathrm{BTU} / \mathrm{H} \\ \text { OUTLET AIR TEMPERATURE } & 84.374 & \mathrm{~F}\end{array}$

TOTAL HEAT EXCHANGER EFFECTIVENESS 0.8262

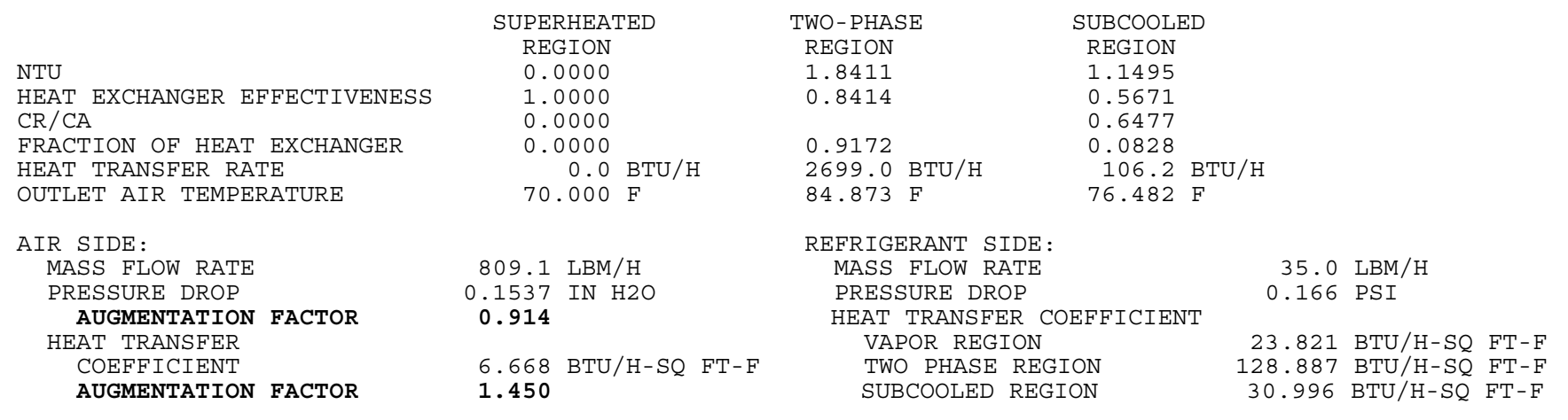

CONTACT INTERFACE :

CONTACT CONDUCTANCE

983204.125 BTU/H-SQ FT-F

UA VALUES PER CIRCUIT: VAPOR REGION (BTU/H-F) REFRIGERANT SIDE AIR SIDE CONTACT INTERFACE

TWO PHASE REGION (BTU/H-F) REFRIGERANT SIDE 716.460 AIR SIDE CONTACT INTERFACE 118421.875 $\begin{array}{lr}\text { COMBINED } & 334.101\end{array}$
SUBCOOLED REGION (BTU/H-F) REFRIGERANT SIDE 15.557 AIR SIDE CONTACT INTERFACE 10692.523 $\begin{array}{lr}\text { COMBINED } & 12.200\end{array}$

FLOW CONTROL DEVICE - CONDENSER EXIT SUBCOOLING IS SPECIFIED AS $10.000 \mathrm{~F}$

CORRESPONDING TXV RATING PARAMETERS RATED OPERATING SUPERHEAT $11.000 \mathrm{~F}$ STATIC SUPERHEAT RATING $\quad 6.000$ FRACTION OF RATED OPENING 1.000

$\begin{array}{ll}\text { FRACTION OF RATED OPENING } & 1.000 \\ \text { TXV CAPACITY RATING: } & 0.535 \text { TONS }\end{array}$ WITH NOZZL RAND TUB

CORRESPONDING CAPILLARY TUBE PARAMETERS: NUMBER OF CAPILLARY TUBES
0.891
CORRESPONDING ORIFICE PARAMETER : ORIFICE DIAMETER 0.0318 IN WITH NOZZLE AND TUBES

CALCULATED SUPERHEAT IS BELOW THE OPERATING RANGE:

TXV SIZE BASED ON RATED RATHER THAN ACTUAL 
$* * * *$ CALCULATED HEAT PUMP PERFORMANCE $* * * * *$

EVAPORATOR - HEAT TRANSFER PERFORMANCE OF EACH CIRCUIT

$\begin{array}{lrl}\text { INLET AIR TEMPERATURE } & 47.002 & \mathrm{~F} \\ \text { AIR TEMPERATURE LEAVING COIL } & 40.823 & \mathrm{~F} \\ \text { HEAT GENERATED FROM FAN } & 57.8 \mathrm{BTU} / \mathrm{H} \\ \text { OUTLET AIR TEMPERATURE } & 40.864 \mathrm{~F}\end{array}$

NO MOISTURE REMOVAL OCCURS

TOTAL HEAT EXCHANGER EFFECTIVENESS (SENSIBLE)

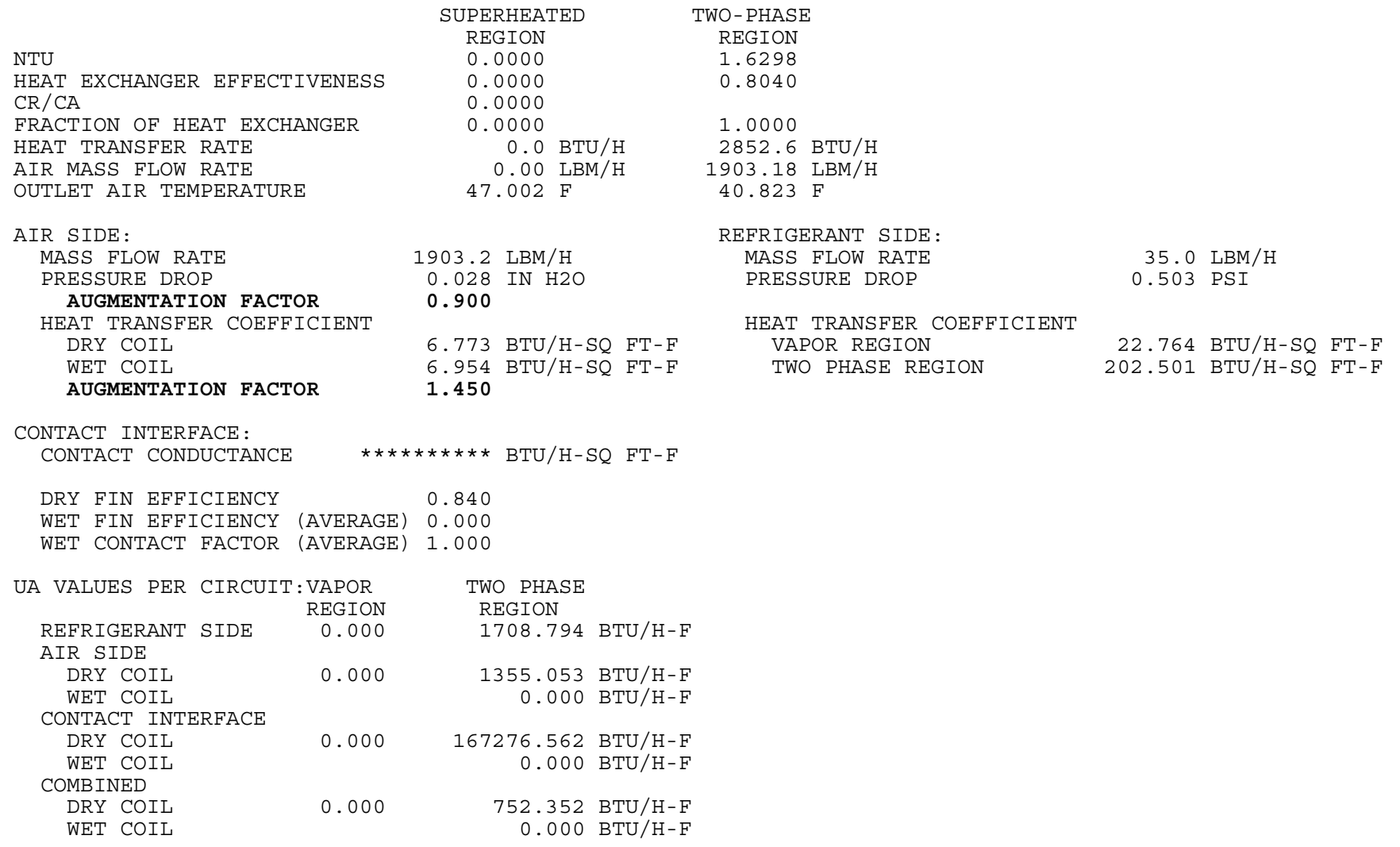


$* * * *$ SUMMARY OF ENERGY INPUT AND OUTPUT $* * * * *$

SAMPLE ECM HEAT PUMP, OFF-DESIGN PT: SPECIFIED MOTORS AND DUCTS, FILE:OFFDES.HPS

OPERATING CONDITIONS :

AIR TEMPERATURE INTO EVAPORATOR

AIR TEMPERATURE INTO CONDENSER

SATURATION TEMP INTO COMPRESSOR

SATURATION TEMP OUT OF COMPRESSOR

$47.00 \mathrm{~F}$

70.00
39.13
87.73

$87.73 \mathrm{~F}$

\section{DRIVE FREQUENCIES :}

COMPRESSOR

INDOOR FAN

$50.00 \mathrm{HZ}$

$64.80 \mathrm{HZ}$

$37.12 \mathrm{HZ}$

\section{DRIVE FREQUENCY RATIOS:}

COMPRESSOR

INDOOR FAN

OUTDOOR FAN

0.28

0.6

0.45

ENERGY INPUT SUMMARY

HEAT PUMPED FROM AIR SOURCE

$8557.9 \mathrm{BTU} / \mathrm{H}$

POWER TO INDOOR FAN MOTOR

POWER TO OUTDOOR FAN MOTOR

TOTAL PARASITIC POWER

34.0 WATTS

16.9 WATTS

51.0 WATTS

$\begin{array}{lll}\text { POWER TO } & \text { COMPRESSOR } & \text { MOTOR } \\ \text { TOTAL } & \text { INPUT } & \text { POWER }\end{array}$

453.1 WATTS

REFRIGERANT-SIDE SUMMARY:

HEAT GAIN TO EVAPORATOR FROM AIR $8557.9 \mathrm{BTU} / \mathrm{H}$ $\begin{array}{lll}\text { HEAT GAIN } & \text { TO SUCTION LINE } & 100.0 \mathrm{BTU} / \mathrm{H}\end{array}$ ENERGY INPUT TO COMPRESSOR 1546.4 BTU/H HEAT LOSS FROM COMPRESSOR SHELL $387.9 \mathrm{BTU} / \mathrm{H}$ HEAT LOSS FROM DISCHARGE LINE $\begin{array}{llllr}\text { HEAT LOSS } & \text { FROM CONDENSER TO AIR } & 8415.6 \mathrm{BTU} / \mathrm{H} \\ \text { HEAT LOSS } & \text { FROM LIQUID LINE } & & 700.0 \mathrm{BTU} / \mathrm{H}\end{array}$

ENERGY OUTPUT SUMMARY:

HEAT RATE FROM REFRIGERANT TO INDOOR AIR $8415.6 \mathrm{BTU} / \mathrm{H}$ HEAT RATE FROM FAN TO INDOOR AIR $116.1 \mathrm{BTU} / \mathrm{H}$

HEATING PERFORMANCE :

$\begin{array}{lll}\text { HEAT PUMP COP } & 4.960 \\ \text { HEAT PUMP CAPACITY } & 8531.7 \mathrm{BTU} / \mathrm{H}\end{array}$ 
$* * * *$ CHARGE INVENTORY RESULTS $* * * * *$

ANALYTICAL SOLUTION OF ZIVI'S METHOD

FOR A CONSTANT HEAT FLUX APPROXIMATION

STEADY-STATE REFRIGERANT MASS DISTRIBUTION (LBM)

TMASSC $=3.320$ TMASSE $=2.049$ CMPMAS $=0.342$ XMASLL $=1.076$ ACCMAS $=0.159$ SSVPLO $=0.033$ SSVPHI $=0.251$

EQUILIBRIUM REFRIGERANT MASS DISTRIBUTION (LBM)

EQMSHI $=0.400$ EQMSLO $=6.830$ XMSLQ $=5.999$ XEQUIL $=0.1215$

HI/LO AND COMPONENT INTERNAL VOLUMES (CU FT), ACCUMULATOR LIQUID LEVEL (INCHES)

VOLHI $=0.250$ VOLLOW $=0.562$ VOLCND $=0.153$ VOLEVP $=0.205$ VOLCMP $=0.229$ VOLACC $=0.106 \quad$ XLEVEL $=0.000$ IN 



\title{
Listing C.3. Sample Parametric Heat Pump Model Run
}

— Heating Mode, Compressor Frequency Vs Ambient -

\author{
Abbreviated Output Listing
}



$* * * * *$ CONTOUR DATA GENERATION INFORMATION *****

STEADY-STATE HEATING MODE DATA

CONTOUR DATA FILE TITLES -

HEATING MODE PARAMETRIC EVALUATION — COMPRESSOR FREQUENCY VERSUS AMBIENT

INDEPENDENT VARIABLE SPECIFICATION -

ID\# \# OF PTS. XLO XHI CONTOUR REFERENCE POINTS HEATING COOLING SEASONAL

$\begin{array}{llllll}X & 21 & 6 & 180.000 & 50.000 & 180.000\end{array}$

$\begin{array}{llllll}\mathrm{Y} & 18 & 3 & 17.000 & 47.000 & 47.000\end{array}$

DESIGN PARAMETERS, FUNCTIONS, AND RANGES:

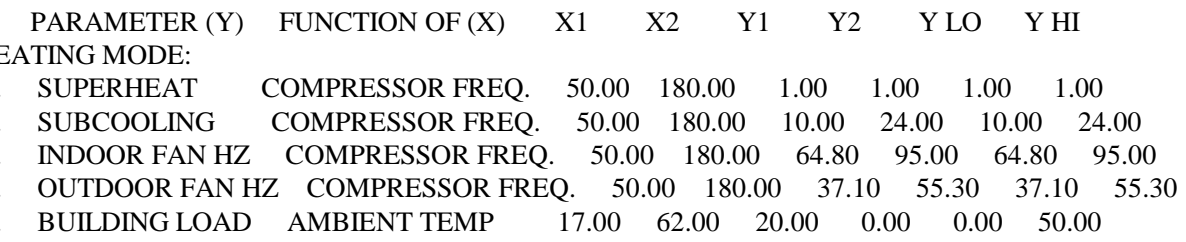

DEPENDENT VARIABLE ID\#'S AND LABELS -

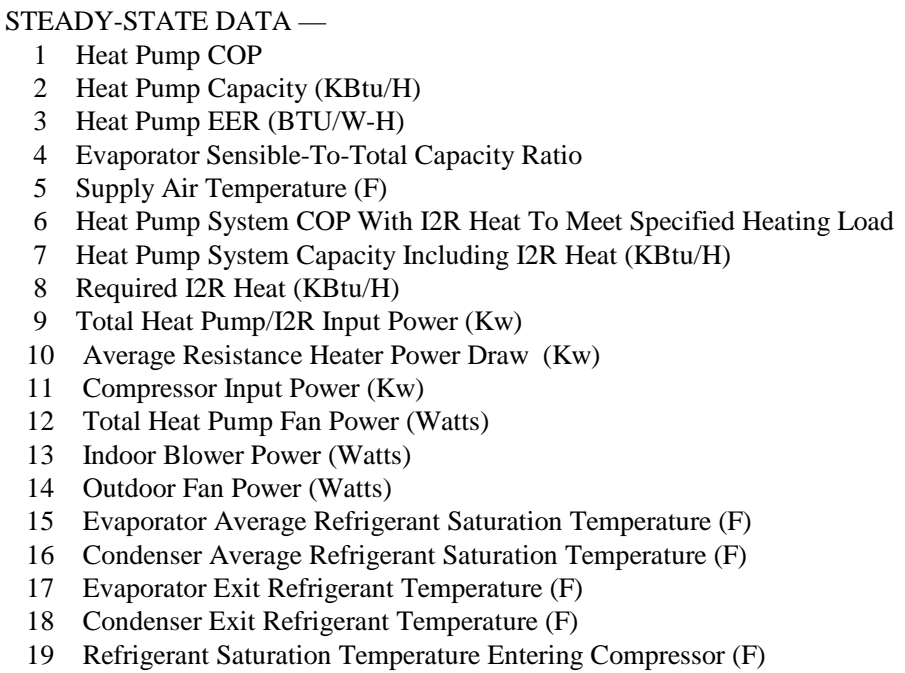


20 Refrigerant Saturation Temperature Leaving Compressor (F)

21 Compressor Pressure Ratio

22 Refrigerant Mass Flow Rate $(\mathrm{lbm} / \mathrm{h})$

23 Evaporator Refrigerant Pressure Drop (psi)

24 Condenser Refrigerant Pressure Drop (psi)

25 Evaporator Refrigerant Two-Phase Heat Transfer Coef $\left(\mathrm{Btu} / \mathrm{h} / \mathrm{ft}^{2} / \mathrm{F}\right)$

26 Condenser Refrigerant Two-Phase Heat Transfer Coef $\left(\mathrm{Btu} / \mathrm{h} / \mathrm{ft}^{2} / \mathrm{F}\right)$

27 Percentage Of Nominal Drive Frequency Of Selected Compressor (\%)

28 Selected Compressor Operating Speed (rpm)

29 Selected Compressor Operating Torque (lb-ft)

30 Selected Compressor Required Nominal Torque (lb-ft)

31 Percentage Of Selected Compressor Nominal Torque (\%)

32 Required Motor Size For Selected Compressor (Hp)

33 ECM Efficiency Degradation Multiplier For Operating Temp Effects

34 Selected Compressor Motor/Drive Efficiency (\%)

35 Estimated Compressor Superheat Efficiency Of Selected Comp (\%)

36 Selected Compressor Can Isentropic Efficiency (\%)

37 Selected Compressor Can Volumetric Efficiency (\%)

38 Base Compressor Operating Speed (rpm)

39 Base Compressor Operating Torque (lb-ft)

40 Base Compressor Nominal Torque (lb-ft)

41 Percentage Of Base Compressor Nominal Torque (\%)

42 Base Compressor Motor/Drive Efficiency (\%)

43 Base Compressor Can Isentropic Efficiency (\%)

44 Base Compressor Can Volumetric Efficiency (\%)

45 Ratio Of Selected To Base Compressor Speed

46 Ratio Of Selected To Base Motor/Drive Efficiency W/O SGH Effects

47 Estimated Suction Gas Superheating From Base Compressor Motor (F)

48 Estimated Suction Gas Superheating From Selected Comp. Motor $(\mathrm{F})$

49 Efficiency Multiplier Due To Differential SGH Effects

50 Mass Flow Rate Multiplier Due To Differential SGH Effects

51 Ratio Of Selected To Base Motor/Drive Efficiency With SGH Effects

52 Ratio Of Selected To Base Refrig. Mass Flow Rate With SGH Effects

53 Ratio Of Selected To Base Compressor Power With SGH Effects

54 Indoor Air Flow Rate (cfm)

55 Indoor Blower Speed (rpm)

56 Percentage Of Nominal Indoor Blower Frequency (\%)

57 Indoor Air Face Velocity (ft/min)

58 Indoor Air Surface Velocity (ft/min)

60 Indoor Air-Side Pressure Drop (In Of H2O)

61 Indoor Coil Fin Patternation Heat Transfer Multiplier

62 Indoor Coil Fin Patternation Pressure Drop Multiplie

63 Indoor Blower Operating Torque (oz-ft)

64 Percentage Of Selected Indoor Motor Nominal Torque (\%)

65 Required Nominal Size Of Selected Indoor Motor (Hp)

66 Motor/Drive Efficiency Of Selected Indoor Drive (\%)

67 Motor/Drive Efficiency Of Base Indoor Drive (\%) 
68 Combined Blower/Motor/Drive Efficiency Of Selected Indoor Blower (\%)

69 Outdoor Air Flow Rate (cfm)

70 Outdoor Fan Speed (rpm)

71 Percentage Of Nominal Outdoor Fan Frequency (\%)

72 Outdoor Air Face Velocity (ft/min)

73 Outdoor Air Surface Velocity (ft/min)

74 Outdoor Air-Side Heat Transfer Coefficient (Btu/h/ft $\left.{ }^{2} / \mathrm{F}\right)$

75 Outdoor Air-Side Pressure Drop (In Of H2O)

76 Outdoor Coil Fin Patternation Heat Transfer Multiplier

77 Outdoor Coil Fin Patternation Pressure Drop Multiplier

78 Outdoor Fan Operating Torque (oz-ft)

79 Percentage Of Selected Outdoor Motor Nominal Torque (\%)

80 Required Nominal Size Of Selected Outdoor Motor (Hp)

81 Motor/Drive Efficiency Of Selected Outdoor Drive (\%)

82 Motor/Drive Efficiency Of Base Outdoor Drive (\%)

83 Combined Fan/Motor/Drive Efficiency Of Selected Outdoor Fan (\%)

84 Outdoor Fan-Only Efficiency (\%)

85 Outdoor Fan Specific Speed

86 Required Refrigerant Charge (lbm)

87 Required Capillary Flow Factor

88 Required TXV Capacity Rating (Tons)

89 Fraction Of Rated TXV Opening

90 Required Short Tube Orifice Diameter (In)

91 Required Simple Orifice Effective KA Product (In2)

92 Evaporator Exit Refrigerant Superheat (F) Or Quality (-)

93 Compressor Inlet Refrigerant Superheat (F) Or Quality (-)

94 Compressor Exit Refrigerant Superheat (F) Or Quality (-)

95 Condenser Exit Refrigerant Subcooling (F) Or Quality (-)

96 Flow Control Inlet Refrigerant Subcooling (F) Or Quality (-)

97 Refrigerant Temperature At Flow Control Inlet (F)

98 Refrigerant Suction Temperature At Compressor Inlet (F)

99 Refrigerant Discharge Temperature At Compressor Exit (F)

100 Refrigerant Suction Pressure At Compressor Inlet (psia)

101 Refrigerant Discharge Pressure At Compressor Exit (psia)

102 Required Indoor Duct Size (Inches)

103 Indoor Duct Pressure Drop (Inches of Water)

104 Indoor Filter Pressure Drop (Inches of Water)

105 Indoor Heater Pressure Drop (Inches of Water)

106 Indoor Coil Pressure Drop (Inches of Water)

107 Selected Compressor-Only Isentropic Efficiency — Excluding Motor (\%)

108 Baseline Compressor-Only Isentropic Efficiency — Excluding Motor (\%)

109 Wetted Fraction of Evaporator Coil

110 Moisture Removal Rate $(\mathrm{lbm} / \mathrm{h})$ 
***** INPUT DATA *****

SAMPLE ECM HEAT PUMP, OFF-DESIGN PT: SPECIFIED MOTORS AND DUCTS, FILE:OFFDES.HPS

NO HEAT PUMP MODEL OUTPUT

HEATING MODE OF OPERATION

THE REFRIGERANT IS R 22

REFRIGERANT CHARGE IS NOT SPECIFIED

COMPRESSOR INLET SUPERHEAT IS SPECIFIED AT $1.00 \mathrm{~F}$

CONDENSER EXIT SUBCOOLING IS SPECIFIED AT $10.00 \mathrm{~F}$

ESTIMATE OF:

SATURATION TEMPERATURE INTO COMPRESSOR $40.00 \mathrm{~F}$

SATURATION TEMPERATURE OUT OF COMPRESSOR $100.00 \mathrm{~F}$

COMPRESSOR CHARACTERISTICS:

OPERATING FREQUENCY $\quad 50.000 \mathrm{HZ}$

TOTAL DISPLACEMENT

SWDIM RECIPROCATING COMPRESSOR — CURVE FITS FROM ORNL AND MANUF'S DATA

DRIVE TYPE OF INPUT COMPRESSOR DATA IS SINE-WAVE-DRIVEN

DRIVE TYPE IS TO BE CONVERTED TO PM-ECM-DRIVEN

SELECTED MOTOR SIZE IS

$227 \mathrm{HP}$

NOMINAL FREQUENCY FOR MOTOR RATING AT $180.0 \mathrm{HZ}$

BASE SUPERHEAT FOR COMPRESSOR MAP $20.000 \mathrm{~F}$

BASE DISPLACEMENT FOR COMPRESSOR MAP $3.640 \mathrm{CU}$ IN

BASE MOTOR SIZE IS $2.75 \mathrm{HP}$

NOMINAL FREQUENCY FOR BASE MOTOR RATING AT $60.0 \mathrm{HZ}$

NOMINAL VOLTAGE FOR BASE MOTOR RATING AT 210.0 VOLTS

REMAINING INPUT ECHO OMITTED FROM LISTING FOR SAKE OF BREVITY (SAME AS FOR THE OFF-DESIGN RUN SHOWN PREVIOUSLY) 
SELECTED OUTPUT FROM PARAMETRIC RUNS - LPRINT = -1, INTERMEDIATE-FREQUENCY RESULTS OMITTED

$\mathrm{IDX}=21 \quad \mathrm{XVAL}=180.000-$ MAXIMUM FREQUENCY CASE

$\mathrm{IDY}=18 \quad \mathrm{YVAL}=17.000$

STARTING GUESSES FOR - TSICMP $=40.00 \quad$ TSOCMP $=100.00$

COMPRESSOR INLET SUPERHEAT $1.000 \mathrm{~F}$ DEG

CONDENSER EXIT SUBCOOLING $24.000 \mathrm{~F}$ DEG

INDOOR FAN FREQUENCY $95.000 \mathrm{HZ}$

OUTDOOR FAN FREQUENCY $\quad 55.300 \mathrm{HZ}$

COMPRESSOR INLET SAT. TEMP. $\quad 8.49 \mathrm{~F}$

COMPRESSOR EXIT SAT. TEMP. $96.75 \mathrm{~F}$

COP 2.85

HEAT PUMP CAPACITY $\quad 15629.9$ BTU/H

SYSTEM COP 2.03

SYSTEM CAPACITY $\quad 20000.0 \mathrm{BTU} / \mathrm{H}$

$\mathrm{IDY}=18 \quad \mathrm{YVAL}=32.000$

STARTING GUESSES FOR - TSICMP $=8.49$ TSOCMP $=96.75$

COMPRESSOR INLET SUPERHEAT $1.000 \mathrm{~F}$ DEG

CONDENSER EXIT SUBCOOLING $24.000 \mathrm{~F}$ DEG

INDOOR FAN FREQUENCY $\quad 95.000 \mathrm{HZ}$ COMPRESSOR EXIT SAT. TEMP. $102.30 \mathrm{~F}$

COP 3.28

HEAT PUMP CAPACITY $\quad 21184.5$ BTU/H

SYSTEM COP 3.28

SYSTEM CAPACITY $\quad 21184.5 \mathrm{BTU} / \mathrm{H}$

$\mathrm{IDY}=18 \quad \mathrm{YVAL}=47.000$

STARTING GUESSES FOR - TSICMP $=21.18 \quad$ TSOCMP $=102.30$

COMPRESSOR INLET SUPERHEAT $1.000 \mathrm{~F}$ DEG

CONDENSER EXIT SUBCOOLING $24.000 \mathrm{~F}$ DEG

NDOOR FAN FREQUNCY

OUTDOOR FAN FREQUENCY $55.300 \mathrm{HZ}$

COMPRESSOR INLET SAT. TEMP. $\quad 33.58 \mathrm{~F}$ COMPRESSOR EXIT SAT. TEMP. $109.69 \mathrm{~F}$ 3.70

HEAT PUMP CAPACITY $\quad 27529.0$ BTU/H

SYSTEM COP $\quad 3.70$

SYSTEM CAPACITY $\quad 27529.0 \mathrm{BTU} / \mathrm{H}$

.... OMITTING INTERMEDIATE SPEED RESULTS 



\section{Listing C.4. Sample Parametric Heat Pump Model Run}

— Heating Mode, Compressor Frequency Vs Ambient -

Output Contour Data Generation File 



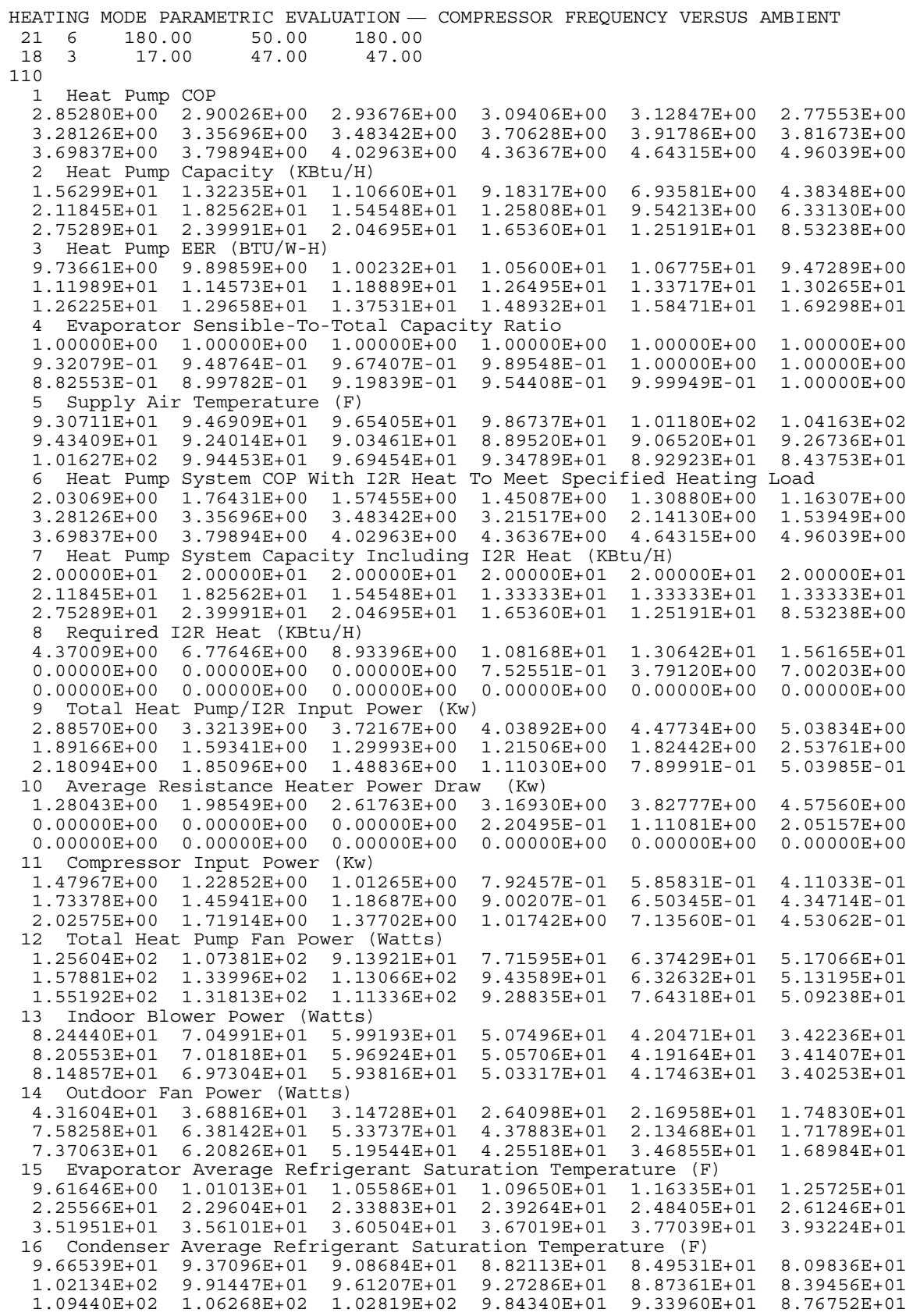




\begin{tabular}{|c|c|c|c|c|c|}
\hline $5 E+00$ & $E+00$ & $97437 \mathrm{E}+00$ & $6777 \mathrm{E}+01$ & $9 \mathrm{E}+01$ & $7 E+01$ \\
\hline $480 E+01$ & $2.19614 \mathrm{E}+01$ & $2.26416 \mathrm{E}+01$ & $2.34006 \mathrm{E}+01$ & $2.45217 \mathrm{E}+01$ & $2.60149 \mathrm{E}+01$ \\
\hline $3.36582 \mathrm{E}+01$ & $3.44246 \mathrm{E}+01$ & $3.51587 \mathrm{E}+01$ & $3.60945 \mathrm{E}+01$ & $3.73440 E+01$ & $3.91467 \mathrm{E}+01$ \\
\hline \multicolumn{6}{|l|}{18 Condenser } \\
\hline 7.258 & $\mathrm{E}+01$ & $7.24343 \mathrm{E}+01$ & $7.25811 \mathrm{E}+01$ & 7. $21320 \mathrm{E}+01$ & $7.09678 \mathrm{E}+01$ \\
\hline $7.80250 \mathrm{E}+01$ & $7.78655 \mathrm{E}+01$ & $7.76589 \mathrm{E}+01$ & $7.70749 \mathrm{E}+01$ & 7. $59065 \mathrm{E}+01$ & 7. $39243 E+01$ \\
\hline $8.53083 E+01$ & $8.49496 \mathrm{E}+01$ & $8.43157 \mathrm{E}+01$ & $8.27603 \mathrm{E}+01$ & $8.05282 \mathrm{E}+01$ & \\
\hline Refrigerar & nt saturatior & n Temperature & Entering Comp & ressor (F) & \\
\hline $8.48881 \mathrm{E}+00$ & $9.26110 \mathrm{E}+00$ & $9.94286 \mathrm{E}+00$ & $1.06559 \mathrm{E}+01$ & $1.14196 \mathrm{E}+01$ & $1 E+01$ \\
\hline $2.11796 \mathrm{E}+01$ & $2.19095 \mathrm{E}+01$ & $2.26031 \mathrm{E}+01$ & $2.33723 \mathrm{E}+01$ & $2.45040 \mathrm{E}+01$ & $4 \mathrm{E}+01$ \\
\hline $3.35797 \mathrm{E}+01$ & $3.43631 \mathrm{E}+01$ & $3.51113 E+01$ & $3.60616 \mathrm{E}+01$ & $3.73258 \mathrm{E}+01$ & $3.91378 E+01$ \\
\hline Refrigerar & nt saturatior & n Temperature & Leaving Compr & essor (F) & \\
\hline $9.67543 \mathrm{E}+01$ & $9.37920 \mathrm{E}+01$ & $9.09345 \mathrm{E}+01$ & $8.82650 \mathrm{E}+01$ & $8.49906 \mathrm{E}+01$ & $E+01$ \\
\hline $1.02302 \mathrm{E}+02$ & $9.92842 \mathrm{E}+01$ & $9.62369 \mathrm{E}+01$ & $9.28204 \mathrm{E}+01$ & $5 E+01$ & +01 \\
\hline $1.09689 \mathrm{E}+02$ & $1.06481 \mathrm{E}+02$ & $1.02994 \mathrm{E}+02$ & $9.85713 \mathrm{E}+01$ & +01 & $E+01$ \\
\hline \multicolumn{6}{|c|}{21 Compressor Pressure Ratio } \\
\hline $4.37329 \mathrm{E}+00$ & $4.13109 \mathrm{E}+00$ & $3.91360 \mathrm{E}+00$ & 3.7140 & $\mathrm{E}+00$ & $1 \mathrm{E}+00$ \\
\hline $3.68115 \mathrm{E}+00$ & $3.48355 \mathrm{E}+00$ & $3.29594 \mathrm{E}+00$ & $3.09654 \mathrm{E}+00$ & +00 & $\mathrm{E}+00$ \\
\hline $3.23271 \mathrm{E}+00$ & $389 E+00$ & $2.87469 \mathrm{E}+00$ & $015 \mathrm{E}+00$ & $\mathrm{E}+00$ & +00 \\
\hline \multicolumn{6}{|l|}{22 Refrigerant } \\
\hline $1.60387 \mathrm{E}+02$ & $1.38809 \mathrm{E}+02$ & $1.18978 \mathrm{E}+02$ & $1.02608 \mathrm{E}+02$ & $E+01$ & $\mathrm{E}+01$ \\
\hline $2.24178 \mathrm{E}+02$ & $1.96721 \mathrm{E}+02$ & $1.70530 \mathrm{E}+02$ & $1.43351 \mathrm{E}+02$ & $\mathrm{E}+02$ & +01 \\
\hline $2.99332 \mathrm{E}+02$ & $2.64791 \mathrm{E}+02$ & $2.31223 E+02$ & $1.91991 \mathrm{E}+02$ & $\mathrm{E}+02$ & $E+02$ \\
\hline \multicolumn{6}{|c|}{23 Evaporator Refrigerant } \\
\hline $2.02725 \mathrm{E}+00$ & $1.51884 \mathrm{E}+00$ & $1.12068 \mathrm{E}+00$ & $5.56054 \mathrm{E}-01$ & & -01 \\
\hline $2.99837 \mathrm{E}+00$ & $2.30301 \mathrm{E}+00$ & $1.72956 \mathrm{E}+00$ & $1.22753 \mathrm{E}+00$ & $7.53081 \mathrm{E}-01$ & $5 E-01$ \\
\hline $4.19297 \mathrm{E}+00$ & $3.25357 \mathrm{E}+00$ & $2.46372 \mathrm{E}+00$ & $1.69233 \mathrm{E}+00$ & $1.01569 \mathrm{E}+00$ & $2 E-01$ \\
\hline \multicolumn{6}{|l|}{24 Condenser } \\
\hline $2.73726 \mathrm{E}-01$ & $2.21252 \mathrm{E}-01$ & $1.76553 \mathrm{E}-01$ & $1.43476 \mathrm{E}-01$ & 9.703 & E-02 \\
\hline $5.24219 \mathrm{E}-01$ & $4.31084 \mathrm{E}-01$ & $3.47616 \mathrm{E}-01$ & $2.65944 \mathrm{E}-01$ & 1.793 & $E-02$ \\
\hline 8.73 & 7.24 & $5.89035 \mathrm{E}-01$ & 4.4034 & 2.9 & -01 \\
\hline \multicolumn{6}{|c|}{25 Evaporator Refrigerant } \\
\hline $4.01368 \mathrm{E}+02$ & $3.51625 \mathrm{E}+02$ & $3.04917 \mathrm{E}+02$ & $2.65340 \mathrm{E}+02$ & $2.08270 \mathrm{E}+02$ & $1.27868 \mathrm{E}+02$ \\
\hline $4.88006 \mathrm{E}+02$ & $4.34132 \mathrm{E}+02$ & $3.81412 \mathrm{E}+02$ & $3.24267 \mathrm{E}+02$ & $2.54626 \mathrm{E}+02$ & $4 E+02$ \\
\hline $5.74677 \mathrm{E}+02$ & 5. & $4 \mathrm{E}+02$ & $3.81247 \mathrm{E}+02$ & 2 & +02 \\
\hline \multicolumn{6}{|l|}{26 Condenser $R$} \\
\hline $1.74848 \mathrm{E}+02$ & $1.57507 \mathrm{E}+02$ & $1.40772 \mathrm{E}+02$ & $1.26381 \mathrm{E}+02$ & $1.05480 \mathrm{E}+02$ & $E+01$ \\
\hline 2.24 & $2.04599 \mathrm{E}+02$ & $1.84206 \mathrm{E}+02$ & $1.62341 \mathrm{E}+02$ & & +02 \\
\hline $2.74392 \mathrm{E}+02$ & $2.51827 \mathrm{E}+02$ & $2.29103 E+02$ & $2.00726 \mathrm{E}+02$ & 1.6 & +02 \\
\hline \multicolumn{6}{|c|}{27 Percentage of Nominal D } \\
\hline $1.00000 \mathrm{E}+02$ & $8.55555 \mathrm{E}+01$ & $7.11111 \mathrm{E}+01$ & $5.66667 \mathrm{E}+01$ & $E+01$ & $E+01$ \\
\hline 1.00 & $8.55555 \mathrm{E}+01$ & 7.11111E+01 & $5.66667 \mathrm{E}+01$ & & +01 \\
\hline $1.00000 \mathrm{E}+02$ & $8.55555 \mathrm{E}+01$ & 7.11111E+01 & $5.66667 \mathrm{E}+01$ & $E+01$ & $E+01$ \\
\hline \multicolumn{6}{|l|}{28 Selected $\mathrm{Cc}$} \\
\hline $5.40000 \mathrm{E}+03$ & $4.62000 \mathrm{E}+03$ & $3.84000 \mathrm{E}+03$ & 3.0600 & 03 & $\mathrm{E}+03$ \\
\hline 5.40 & 4 . & $000 \mathrm{E}+03$ & 03 & & 03 \\
\hline $5.40000 \mathrm{E}+03$ & $4.62000 \mathrm{E}+03$ & $3.84000 E+03$ & $3.06000 \mathrm{E}+03$ & $E+03$ & $E+03$ \\
\hline \multicolumn{6}{|l|}{29 Selected Co } \\
\hline $2.76560 \mathrm{E}+01$ & $2.64968 \mathrm{E}+01$ & $2.60417 \mathrm{E}+01$ & $E+01$ & +01 & +01 \\
\hline 3.23 & $3.14337 \mathrm{E}+01$ & $3.03634 \mathrm{E}+01$ & 2.8 & & \\
\hline $3.79672 \mathrm{E}+01$ & $3.70762 \mathrm{E}+01$ & $3.53536 \mathrm{E}+01$ & $3.21991 \mathrm{E}+01$ & $E+01$ & $2.66348 \mathrm{E}+01$ \\
\hline \multicolumn{6}{|l|}{30 Selected Co } \\
\hline $3.52475 \mathrm{E}+01$ & $3.52475 \mathrm{E}+01$ & $3.52475 \mathrm{E}+01$ & $3.52475 \mathrm{E}+01$ & $E+01$ & $75 E+01$ \\
\hline $3.52475 \mathrm{E}+01$ & $3.52475 \mathrm{E}+01$ & $3.52475 \mathrm{E}+01$ & $3.52475 \mathrm{E}+01$ & & \\
\hline $75 E+01$ & $3.52475 \mathrm{E}+01$ & $3.52475 \mathrm{E}+01$ & $3.52475 \mathrm{E}+0$ & 3. & $\Xi+01$ \\
\hline \multicolumn{6}{|c|}{31 Percentage of Selected C } \\
\hline $7.84622 \mathrm{E}+01$ & $7.51735 \mathrm{E}+01$ & $7.38823 \mathrm{E}+01$ & $7.09931 \mathrm{E}+01$ & 6.84 & +01 \\
\hline $9.19167 \mathrm{E}+01$ & $8.91799 \mathrm{E}+01$ & $8.61433 \mathrm{E}+01$ & $8.07866 \mathrm{E}+01$ & +01 & $E+01$ \\
\hline $1.07716 \mathrm{E}+02$ & $1.05188 \mathrm{E}+02$ & $1.00301 \mathrm{E}+02$ & $9.13514 \mathrm{E}+01$ & $4 E+01$ & $\mathrm{DE}+01$ \\
\hline \multicolumn{6}{|c|}{ 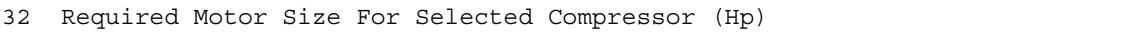 } \\
\hline $0.00000 \mathrm{E}+00$ & $0.00000 \mathrm{E}+00$ & $0.00000 \mathrm{E}+00$ & $0.00000 \mathrm{E}+00$ & & \\
\hline 0.00 & $0.00000 \mathrm{E}+00$ & $0.00000 \mathrm{E}+00$ & $0.00000 \mathrm{E}+00$ & 00 & +00 \\
\hline $0.00000 \mathrm{E}+00$ & $0.00000 \mathrm{E}+00$ & $0.00000 \mathrm{E}+00$ & $0.00000 \mathrm{E}+00$ & $0.00000 \mathrm{E}+00$ & $0.00000 \mathrm{E}+00$ \\
\hline $\mathrm{ECM}$ & & iplj & er & & \\
\hline $9.95791 \mathrm{E}-01$ & $9.95316 \mathrm{E}-01$ & $9.94497 \mathrm{E}-01$ & $9.93466 \mathrm{E}-01$ & $9.91728 \mathrm{E}-01$ & 9.8 \\
\hline 9.95 & $4585 E-01$ & $9.93757 \mathrm{E}-01$ & $9.92695 \mathrm{E}-01$ & $9.90983 E-01$ & $9.87580 \mathrm{E}-01$ \\
\hline & & & & & \\
\hline
\end{tabular}


34 Selected Compressor Motor/Drive Efficiency (\%)

$\begin{array}{lllllll}8.95347 \mathrm{E}+01 & 8.84005 \mathrm{E}+01 & 8.76109 \mathrm{E}+01 & 8.57273 \mathrm{E}+01 & 8.33369 \mathrm{E}+01 & 7.83589 \mathrm{E}+01\end{array}$

$\begin{array}{llllll}8.94826 \mathrm{E}+01 & 8.82643 \mathrm{E}+01 & 8.71501 \mathrm{E}+01 & 8.58840 \mathrm{E}+01 & 8.32646 \mathrm{E}+01 & 7.83146 \mathrm{E}+01\end{array}$

$\begin{array}{llllll}8.97150 \mathrm{E}+01 & 8.83654 \mathrm{E}+01 & 8.74543 \mathrm{E}+01 & 8.59080 \mathrm{E}+01 & 8.28573 \mathrm{E}+01 & 7.82292 \mathrm{E}+01\end{array}$

35 Estimated Compressor Superheat Efficiency of Selected Comp (\%)

$\begin{array}{lllllll}9.51716 \mathrm{E}+01 & 9.50292 \mathrm{E}+01 & 9.49821 \mathrm{E}+01 & 9.50380 \mathrm{E}+01 & 9.48605 \mathrm{E}+01 & 9.32442 \mathrm{E}+01\end{array}$

$\begin{array}{llllll}9.58791 \mathrm{E}+01 & 9.57345 \mathrm{E}+01 & 9.57177 \mathrm{E}+01 & 9.58784 \mathrm{E}+01 & 9.58407 \mathrm{E}+01 & 9.49875 \mathrm{E}+01\end{array}$

$\begin{array}{llllll}9.64016 \mathrm{E}+01 & 9.62428 \mathrm{E}+01 & 9.63593 \mathrm{E}+01 & 9.65454 \mathrm{E}+01 & 9.64497 \mathrm{E}+01 & 9.61843 \mathrm{E}+01\end{array}$

36 Selected Compressor Can Isentropic Efficiency (\%)

$\begin{array}{llllllll}5.09431 \mathrm{E}+01 & 5.09158 \mathrm{E}+01 & 5.07952 \mathrm{E}+01 & 5.36976 \mathrm{E}+01 & 5.40884 \mathrm{E}+01 & 4.72510 \mathrm{E}+01\end{array}$

$5.34288 \mathrm{E}+01 \quad 5.32070 \mathrm{E}+01 \quad 5.40603 \mathrm{E}+01 \quad 5.66160 \mathrm{E}+01 \quad 5.68402 \mathrm{E}+01 \quad 5.27842 \mathrm{E}+01$

$\begin{array}{llllll}5.47364 \mathrm{E}+01 & 5.41536 \mathrm{E}+01 & 5.56896 \mathrm{E}+01 & 5.77860 \mathrm{E}+01 & 5.76444 \mathrm{E}+01 & 5.54343 \mathrm{E}+01\end{array}$

37 Selected Compressor Can Volumetric Efficiency (\%)

$\begin{array}{cccccc}5.86451 \mathrm{E}+01 & 5.84508 \mathrm{E}+01 & 5.94960 \mathrm{E}+01 & 6.35216 \mathrm{E}+01 & 6.58961 \mathrm{E}+01 & 6.45083 \mathrm{E}+01\end{array}$

$\begin{array}{llllll}6.46291 \mathrm{E}+01 & 6.54146 \mathrm{E}+01 & 6.73674 \mathrm{E}+01 & 7.00827 \mathrm{E}+01 & 7.20846 \mathrm{E}+01 & 7.33221 \mathrm{E}+01\end{array}$

$\begin{array}{llllll}6.91780 \mathrm{E}+01 & 7.05587 \mathrm{E}+01 & 7.31720 \mathrm{E}+01 & 7.50034 \mathrm{E}+01 & 7.64872 \mathrm{E}+01 & 7.93124 \mathrm{E}+01\end{array}$

38 Base Compressor Operating speed (rpm)

$\begin{array}{lllllll}5.10541 \mathrm{E}+03 & 4.42087 \mathrm{E}+03 & 3.70692 \mathrm{E}+03 & 2.94909 \mathrm{E}+03 & 2.18307 \mathrm{E}+03 & 1.38034 \mathrm{E}+03\end{array}$

$\begin{array}{llllll}5.04538 \mathrm{E}+03 & 4.37942 \mathrm{E}+03 & 3.68341 \mathrm{E}+03 & 2.93277 \mathrm{E}+03 & 2.17198 \mathrm{E}+03 & 1.37203 \mathrm{E}+03\end{array}$

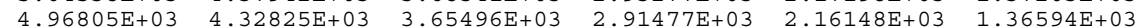

39 Base Compressor Operating Torque (lb-ft)

$\begin{array}{lllllll}2.76560 \mathrm{E}+01 & 2.64968 \mathrm{E}+01 & 2.60417 \mathrm{E}+01 & 2.50233 \mathrm{E}+01 & 2.41361 \mathrm{E}+01 & 2.42023 \mathrm{E}+01\end{array}$

$\begin{array}{llllll}3.23984 \mathrm{E}+01 & 3.14337 \mathrm{E}+01 & 3.03634 \mathrm{E}+01 & 2.84753 \mathrm{E}+01 & 2.67702 \mathrm{E}+01 & 2.56163 \mathrm{E}+01\end{array}$

$\begin{array}{llllll}3.79672 \mathrm{E}+01 & 3.70762 \mathrm{E}+01 & 3.53536 \mathrm{E}+01 & 3.21991 \mathrm{E}+01 & 2.92285 \mathrm{E}+01 & 2.66348 \mathrm{E}+01\end{array}$

40 Base Compressor Nominal Torque (lb-ft)

$\begin{array}{lllllll}3.12835 \mathrm{E}+01 & 3.12835 \mathrm{E}+01 & 3.12835 \mathrm{E}+01 & 3.12835 \mathrm{E}+01 & 3.12835 \mathrm{E}+01 & 3.12835 \mathrm{E}+01\end{array}$

$\begin{array}{llllll}3.12835 \mathrm{E}+01 & 3.12835 \mathrm{E}+01 & 3.12835 \mathrm{E}+01 & 3.12835 \mathrm{E}+01 & 3.12835 \mathrm{E}+01 & 3.12835 \mathrm{E}+01\end{array}$

$\begin{array}{llllll}3.12835 \mathrm{E}+01 & 3.12835 \mathrm{E}+01 & 3.12835 \mathrm{E}+01 & 3.12835 \mathrm{E}+01 & 3.12835 \mathrm{E}+01 & 3.12835 \mathrm{E}+01\end{array}$

41 Percentage of Base Compressor Nominal Torque (\%)

$\begin{array}{lllllll}8.84045 \mathrm{E}+01 & 8.46990 \mathrm{E}+01 & 8.32442 \mathrm{E}+01 & 7.99889 \mathrm{E}+01 & 7.71527 \mathrm{E}+01 & 7.73643 \mathrm{E}+01\end{array}$

$\begin{array}{llllll}1.03564 \mathrm{E}+02 & 1.00480 \mathrm{E}+02 & 9.70589 \mathrm{E}+01 & 9.10233 \mathrm{E}+01 & 8.55729 \mathrm{E}+01 & 8.18844 \mathrm{E}+01\end{array}$

$\begin{array}{llllll}1.21365 \mathrm{E}+02 & 1.18517 \mathrm{E}+02 & 1.13010 \mathrm{E}+02 & 1.02927 \mathrm{E}+02 & 9.34310 \mathrm{E}+01 & 8.51401 \mathrm{E}+01\end{array}$

42 Base Compressor Motor/Drive Efficiency (\%)

$\begin{array}{lllllll}8.66268 \mathrm{E}+01 & 8.85265 \mathrm{E}+01 & 8.92690 \mathrm{E}+01 & 8.81688 \mathrm{E}+01 & 8.59727 \mathrm{E}+01 & 7.90773 \mathrm{E}+01\end{array}$

$\begin{array}{lllllll}8.42405 \mathrm{E}+01 & 8.64345 \mathrm{E}+01 & 8.77669 \mathrm{E}+01 & 8.73952 \mathrm{E}+01 & 8.56310 \mathrm{E}+01 & 7.86714 \mathrm{E}+01\end{array}$

$\begin{array}{llllll}8.19207 \mathrm{E}+01 & 8.48757 \mathrm{E}+01 & 8.68669 \mathrm{E}+01 & 8.60083 \mathrm{E}+01 & 8.49297 \mathrm{E}+01 & 7.83188 \mathrm{E}+01\end{array}$

43 Base Compressor Can Isentropic Efficiency (\%)

$\begin{array}{lllllll}4.87382 \mathrm{E}+01 & 5.10943 \mathrm{E}+01 & 5.21693 \mathrm{E}+01 & 5.57029 \mathrm{E}+01 & 5.61939 \mathrm{E}+01 & 4.76488 \mathrm{E}+01\end{array}$

$\begin{array}{llllll}4.94079 \mathrm{E}+01 & 5.18706 \mathrm{E}+01 & 5.46596 \mathrm{E}+01 & 5.78477 \mathrm{E}+01 & 5.87916 \mathrm{E}+01 & 5.29165 \mathrm{E}+01\end{array}$

$\begin{array}{llllll}4.87645 \mathrm{E}+01 & 5.15482 \mathrm{E}+01 & 5.53651 \mathrm{E}+01 & 5.79361 \mathrm{E}+01 & 5.93505 \mathrm{E}+01 & 5.53786 \mathrm{E}+01\end{array}$

44 Base Compressor Can Volumetric Efficiency (\%)

$\begin{array}{lllllll}5.69091 \mathrm{E}+01 & 5.84668 \mathrm{E}+01 & 6.08202 \mathrm{E}+01 & 6.55704 \mathrm{E}+01 & 6.86914 \mathrm{E}+01 & 6.65601 \mathrm{E}+01\end{array}$

$\begin{array}{llllll}6.16107 \mathrm{E}+01 & 6.44396 \mathrm{E}+01 & 6.81999 \mathrm{E}+01 & 7.17233 \mathrm{E}+01 & 7.46926 \mathrm{E}+01 & 7.52438 \mathrm{E}+01\end{array}$

$\begin{array}{llllll}6.45573 \mathrm{E}+01 & 6.84450 \mathrm{E}+01 & 7.32972 \mathrm{E}+01 & 7.60474 \mathrm{E}+01 & 7.88380 \mathrm{E}+01 & 8.10995 \mathrm{E}+01\end{array}$

45 Ratio of selected To Base Compressor Speed

$\begin{array}{lllllll}1.05770 \mathrm{E}+00 & 1.04504 \mathrm{E}+00 & 1.03590 \mathrm{E}+00 & 1.03761 \mathrm{E}+00 & 1.04440 \mathrm{E}+00 & 1.08669 \mathrm{E}+00\end{array}$

$\begin{array}{lllllll}1.07028 \mathrm{E}+00 & 1.05493 \mathrm{E}+00 & 1.04251 \mathrm{E}+00 & 1.04338 \mathrm{E}+00 & 1.04974 \mathrm{E}+00 & 1.09327 \mathrm{E}+00\end{array}$

$\begin{array}{llllll}1.08695 \mathrm{E}+00 & 1.06740 \mathrm{E}+00 & 1.05063 \mathrm{E}+00 & 1.04982 \mathrm{E}+00 & 1.05483 \mathrm{E}+00 & 1.09815 \mathrm{E}+00\end{array}$

46 Ratio of Selected To Base Motor/Drive Efficiency W/O SGH Effects

$1.03357 \mathrm{E}+009.98576 \mathrm{E}-019.81426 \mathrm{E}-019.72309 \mathrm{E}-019.69342 \mathrm{E}-0199.90916 \mathrm{E}-01$

$\begin{array}{llllll}1.06223 \mathrm{E}+00 & 1.02117 \mathrm{E}+00 & 9.92973 \mathrm{E}-01 & 9.82709 \mathrm{E}-01 & 9.72365 \mathrm{E}-01 & 9.95464 \mathrm{E}-01\end{array}$

$\begin{array}{llllll}1.69554 \mathrm{E}+00 & 1.02117 \mathrm{E}+00 & 1.00676 \mathrm{E}+00 & 9.98833 \mathrm{E}-01 & 9.75599 \mathrm{E}-01 & 9.98854 \mathrm{E}-01\end{array}$

47 Estimated Suction Gas Superheating From Base Compressor Motor (F)

$\begin{array}{lllllll}2.73914 \mathrm{E}+01 & 2.24473 \mathrm{E}+01 & 2.01112 \mathrm{E}+01 & 1.92578 \mathrm{E}+01 & 2.04035 \mathrm{E}+01 & 3.04001 \mathrm{E}+01\end{array}$

$\begin{array}{llllll}2.59180 \mathrm{E}+01 & 2.10590 \mathrm{E}+01 & 1.76504 \mathrm{E}+01 & 1.60270 \mathrm{E}+01 & 1.60266 \mathrm{E}+01 & 2.16923 \mathrm{E}+01\end{array}$

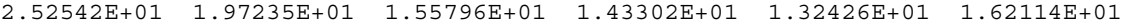

48 Estimated Suction Gas Superheating From Selected Comp. Motor (F)

$\begin{array}{lllllll}1.80946 \mathrm{E}+01 & 1.86559 \mathrm{E}+01 & 1.88381 \mathrm{E}+01 & 1.86052 \mathrm{E}+01 & 1.93147 \mathrm{E}+01 & 2.59263 \mathrm{E}+01\end{array}$

$\begin{array}{llllll}1.48152 \mathrm{E}+01 & 1.53599 \mathrm{E}+01 & 1.54188 \mathrm{E}+01 & 1.45074 \mathrm{E}+01 & 1.49230 \mathrm{E}+01 & 1.81631 \mathrm{E}+01\end{array}$

$\begin{array}{llllll}1.23538 \mathrm{E}+01 & 1.29229 \mathrm{E}+01 & 1.24968 \mathrm{E}+01 & 1.18184 \mathrm{E}+01 & 1.21496 \mathrm{E}+01 & 1.34000 \mathrm{E}+01\end{array}$

49 Efficiency Multiplier Due To Differential SGH Effects

$\begin{array}{llllll}1.02429 \mathrm{E}+00 & 1.00994 \mathrm{E}+00 & 1.00334 \mathrm{E}+00 & 1.00172 \mathrm{E}+00 & 1.00286 \mathrm{E}+00 & 1.01142 \mathrm{E}+00\end{array}$

$\begin{array}{llllll}1.03026 \mathrm{E}+00 & 1.01556 \mathrm{E}+00 & 1.00611 \mathrm{E}+00 & 1.00408 \mathrm{E}+00 & 1.00303 \mathrm{E}+00 & 1.01084 \mathrm{E}+00\end{array}$

$\begin{array}{lllllll}1.03666 \mathrm{E}+00 & 1.01936 \mathrm{E}+00 & 1.00882 \mathrm{E}+00 & 1.00722 \mathrm{E}+00 & 1.00315 \mathrm{E}+00 & 1.00804 \mathrm{E}+00\end{array}$

50 Mass Flow Rate Multiplier Due To Differential SGH Effects

$\begin{array}{lllllll}1.02412 \mathrm{E}+00 & 1.00986 \mathrm{E}+00 & 1.00332 \mathrm{E}+00 & 1.00170 \mathrm{E}+00 & 1.00284 \mathrm{E}+00 & 1.01135 \mathrm{E}+00\end{array}$

$\begin{array}{llllll}1.02972 \mathrm{E}+00 & 1.01530 \mathrm{E}+00 & 1.00602 \mathrm{E}+00 & 1.00412 \mathrm{E}+00 & 1.00300 \mathrm{E}+00 & 1.00945 \mathrm{E}+00\end{array}$

$\begin{array}{llllll}1.03574 \mathrm{E}+00 & 1.01893 \mathrm{E}+00 & 1.00865 \mathrm{E}+00 & 1.00709 \mathrm{E}+00 & 1.00309 \mathrm{E}+00 & 1.00793 \mathrm{E}+00\end{array}$ 


\begin{tabular}{|c|c|c|c|c|c|}
\hline & & & & & \\
\hline & $\mathrm{E}+$ & $\mathrm{E}-\mathrm{C}$ & & & \\
\hline+00 & $7 E+00$ & $E+00$ & $4+00$ & & \\
\hline o of & Selec & & ow Rat & SGH Ef & \\
\hline$E+00$ & $4 \mathrm{E}+00$ & & $1.03938 \mathrm{E}+00$ & $1.04737 \mathrm{E}+00$ & 1 \\
\hline $0 F+00$ & $08 E+00$ & $78 \mathrm{E}+00$ & $04768 \mathrm{~F}$ & $1.05288 \mathrm{E}+00$ & \\
\hline & & & & & \\
\hline Ratio of & $\mathrm{Sel}$ & cess & With & SGH & \\
\hline$E-01$ & $24 E-01$ & $9.99976 \mathrm{E}-01$ & $9.99988 \mathrm{E}-01$ & 9.99981 & $E-01$ \\
\hline 994 & E- 01 & $3 E-01$ & 00 & & \\
\hline & $584 E-01$ & & 9. & & \\
\hline 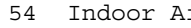 & Flow Rate & $(\mathrm{cfm})$ & & & \\
\hline $91666 \mathrm{E}+02$ & $333 E+02$ & 2 & $6 \mathrm{E}+02$ & 02 & 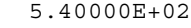 \\
\hline 7.916 & $E+02$ & 2 & & & \\
\hline+02 & $\mathrm{E}+02$ & $E+02$ & & & . \\
\hline T & Speed & rpm) & & & \\
\hline .500 & $\mathrm{E}+02$ & 8.2 & +02 & 02 & 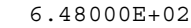 \\
\hline 9.500 & +02 & 2 & & & \\
\hline & & & & & 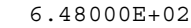 \\
\hline Perce & ominal & Indoor Blowe & r Frequency & & \\
\hline .7962 & $E+01$ & 1 & 01 & 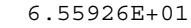 & \\
\hline+01 & +01 & 7.6 & & & \\
\hline & $3 E+01$ & 7.67 & 1 & 01 & i. \\
\hline Tndonr & ir Face Veloc & ity (ft/min) & & & \\
\hline 2.025 & $5 E+02$ & 1.77 & & & \\
\hline & +02 & 1.7 & & & \\
\hline 2.029 & $35 E+02$ & $1.77179 \mathrm{E}$ & 02 & 1.5 & 1.3 \\
\hline Tn & ir Sur & locity & & & \\
\hline 3.668 & $7 \mathrm{E}+02$ & 3.20194 & 02 & & \\
\hline & +02 & 2 & & & \\
\hline 3.66 & $7 E+02$ & 3.20 & 2 & & 2 . \\
\hline$r \mathrm{~A}$ & $-S$ & Transf & ficient & & \\
\hline $8.64594 \mathrm{E}+00$ & $66 \mathrm{E}+00$ & $7.87398 \mathrm{E}+00$ & $7.48083 \mathrm{E}+00$ & 7. & 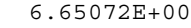 \\
\hline $8.66 c$ & $E+00$ & 7.88 & & & \\
\hline 8.6 & $44 \mathrm{E}+00$ & $7.90642 \mathrm{E}+00$ & & 7. & 6. \\
\hline Indoor $\mathrm{A}$ & Pressu & ure Dro & $\mathrm{E} \mathrm{H} 2$ & & \\
\hline 3.12 & 2 . & 2.4 & & & \\
\hline & $E-01$ & & & & \\
\hline 3.079 & $44 \mathrm{E}-01$ & $2.40106 E-01$ & $36 \mathrm{E}-01$ & & 1. \\
\hline & & & & li & \\
\hline 1.450 & 1.45 & 1.4 & 0 & & \\
\hline & & & & & \\
\hline 1.45 & $00 E+00$ & $1.45000 \mathrm{E}+00$ & $0 \mathrm{E}+00$ & 1.2 & 1. \\
\hline & & & & & \\
\hline 9.540 & $4 E-01$ & $9 \mathrm{E}-01$ & $E-01$ & 9.3 & .30 \\
\hline 9.41 & 9. & 9.3 & 9. & 9. & .2 \\
\hline $9.23 .0-3$ & 9.20 & 9.1 & & 9.14 & 9.13 \\
\hline & & & & & \\
\hline 7.6528 & +00 & $6 \mathrm{E}+00$ & & & \\
\hline 00 & & & & & \\
\hline & 6.6 & 0 & & & \\
\hline 64 & & Indo & & & \\
\hline 4.574581 & 4.056 & 3.566371 & $8 \mathrm{E}+01$ & 2 . & \\
\hline- & & & & & \\
\hline 4 & & & & & \\
\hline & & & & & \\
\hline 2.150 & $\mathrm{E}-01$ & -01 & $\Xi-01$ & & .15 \\
\hline $2.15000 \mathrm{E}-01$ & $0 \mathrm{E}-01$ & $2.15000 \mathrm{E}-01$ & $2.15000 \mathrm{E}-01$ & DOE-01 & 2.150 \\
\hline $2.15000 \mathrm{E}-01$ & $2.15000 \mathrm{E}-01$ & $2.15000 \mathrm{E}-01$ & $2.15000 \mathrm{E}-01$ & 2.15 & 2.1500 \\
\hline $1 \%$ cot & ncy & $y$ of Selec & oor Drive & $\left(\frac{\circ}{0}\right)$ & \\
\hline $7.82382 \mathrm{E}+01$ & 7.5 & 7.32 & $801 E+01$ & & \\
\hline 7.819 & 7.5 & 7.3 & & & \\
\hline 7.81162 & $7.57995 \mathrm{E}+01$ & $.29577 \mathrm{E}+01$ & $6.95622 \mathrm{E}+01$ & $6.66428 \mathrm{E}+01$ & 6.368 \\
\hline 67 Motor/Dr & 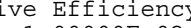 & y of Base Ind & loor Drive (\%) & & \\
\hline & 1. & 1. & & & \\
\hline & & & & & \\
\hline ה & $0 \mathrm{E}+02$ & $00000 \mathrm{E}$ & 2 & & \\
\hline
\end{tabular}




\begin{tabular}{|c|c|c|c|c|c|}
\hline & & & & & \\
\hline $.52072 \mathrm{E}+01$ & $3.41903 E+01$ & $3.29636 \mathrm{E}+01$ & $3.14011 \mathrm{E}+$ & $3.00588 E+01$ & $2.87032 \mathrm{E}+\mathrm{C}$ \\
\hline & $E+01$ & & & & \\
\hline+01 & $3.41098 E+01$ & $E+01$ & $\pi$ & & $E+$ \\
\hline Outdoor & ir Flow Rate & $(\mathrm{cfm})$ & & & \\
\hline $80982 E+03$ & $1.69069 \mathrm{E}+03$ & $.57156 \mathrm{E}+03$ & $1.45244 \mathrm{E}+03$ & $1.33331 \mathrm{E}+03$ & $1.21418 \mathrm{E}+0$ \\
\hline .809 & $9 E+03$ & & & & \\
\hline & $069 E+03$ & & & & \\
\hline Outdoor & an Speed (rpm & & & & \\
\hline $53 c$ & $0 \mathrm{E}+02$ & $0 E+02$ & 2 & 02 & $E+0$ \\
\hline & $\mathrm{OE}+02$ & & & & \\
\hline 2 & 02 & 2 & & 02 & 3.7100 \\
\hline t & of Nominal & Dutdoor Fan & uency & & \\
\hline 703 & 6 . & $50 \mathrm{E}$ & & & \\
\hline 1 & 6. & & & & \\
\hline 6.703 & $182 \mathrm{E}+\mathrm{r}-\mathrm{r}-\mathrm{s}$ & 5.8 & & 01 & 60 \\
\hline Out & ir Face Veloc & city & & & \\
\hline 9998 & $316 \mathrm{E}+02$ & $77=$ & & & \\
\hline 2 & 1. & & & & \\
\hline .999 & 1. & 1.7 & & & \\
\hline $\mathrm{Ou}$ & ir & $(\mathrm{ft} / \mathrm{m}$ & & & \\
\hline 216 & $46 \mathrm{E}+02$ & $77 E+02$ & & & \\
\hline 216 & 3. & 2 & & & \\
\hline .21 & $6 \mathrm{E}+02$ & $7 E+02$ & . & & \\
\hline Out & de Heat & Transfer & Eic & & \\
\hline .767 & $44 \mathrm{E}+00$ & $\mathrm{LE}+00$ & 7. & & \\
\hline & & & & & \\
\hline 8.64 & $743 E+00$ & 7.9 & & & \\
\hline Or & ir- & ure & & & \\
\hline 5.874 & 5. & 4 & & & \\
\hline 1.18 & 1. & 9.3 & 8 & 3. & 2 \\
\hline 1.156 & 1.0 & $\mathrm{E}-02$ & 7. & & \\
\hline ( & Coil & & & & \\
\hline 1.450 & $1.45000 \mathrm{E}+00$ & 00 & 0 & & \\
\hline 1.45 & & & & & \\
\hline 1.450 & $00 \mathrm{E}$ & & & & \\
\hline 77 Ou & in $\mathrm{D}-\mathrm{a}$ & n Drar & 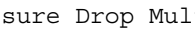 & & \\
\hline 1.029 & $449 \mathrm{E}+00$ & 97E-01 & $E-01$ & 1 & 1 \\
\hline $1.00^{\circ}$ & 9. & 9.7 & 9. & 9. & 9. \\
\hline 9.871 & 9 . & 99E-01 & 9. & 9.2 & 8 . \\
\hline & & & & & \\
\hline 6.30 & & & & & \\
\hline 1.14 & & & & & \\
\hline 1.113 & $9.91460 \mathrm{E}+00$ & $8.75164 \mathrm{E}+00$ & $7.64894 \mathrm{E}$ & 6.6 & 2 . \\
\hline & & & & & \\
\hline 3.939 & 3. & $1 \mathrm{E}+01$ & 2 & & \\
\hline 7.16 & & 5. & & & \\
\hline 1 & & & & & \\
\hline $\mathrm{Re}$ & Non & & & & \\
\hline 1.570 & 1. & 1.5 & 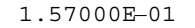 & 1.57 & \\
\hline 1.57 & 1 . & 1.5 & $00 \mathrm{E}-01$ & 1 & 1 . \\
\hline 1.570 & $00 \mathrm{E}-01$ & $1.57000 \mathrm{E}-01$ & $E-01$ & 1.57 & 1 . \\
\hline & & & & & \\
\hline 7 & & & & & \\
\hline & & & & & \\
\hline 7.43 & 7. & 7.17 & 7 & & \\
\hline & & & & & \\
\hline 1.00 & 1. & 1.0 & 1 & & \\
\hline & & & & & \\
\hline 1.0 & 1. & 1.0 & & 1 & \\
\hline & ri & ive Effic & $\mathrm{y}$ of & $\mathrm{Ou}$ & \%) \\
\hline 2.894 & 1 & 2.7 & 1 & 01 & \\
\hline & & & & & \\
\hline & 3 & 3.2 & & & \\
\hline & 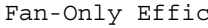 & & & & \\
\hline+01 & $96 E+01$ & 4 . & & & \\
\hline & & & & & \\
\hline & & & & & \\
\hline
\end{tabular}




\begin{tabular}{|c|c|c|c|c|c|}
\hline \multicolumn{6}{|c|}{85 Outdoor Fan Specific Speed } \\
\hline $1.97159 \mathrm{E}+05$ & 1.94 & & $1.88466 \mathrm{E}+05$ & $1.85211 \mathrm{E}+05$ & $1.81771 \mathrm{E}+0$ \\
\hline $1.16212 \mathrm{E}+05$ & $1.14536 \mathrm{E}+05$ & $1.12766 \mathrm{E}+05$ & $1.10897 \mathrm{E}+05$ & $1.89313 E+05$ & $1.85836 \mathrm{E}+05$ \\
\hline 1. $18635 \mathrm{E}+05$ & $1.16922 \mathrm{E}+05$ & $1.15113 \mathrm{E}+05$ & $1.13217 \mathrm{E}+05$ & $1.11232 \mathrm{E}+05$ & $1.89821 \mathrm{E}+05$ \\
\hline \\
\hline $7.50985 \mathrm{E}+00$ & $7.35836 \mathrm{E}+00$ & $7.17066 \mathrm{E}+00$ & $6.96274 \mathrm{E}+00$ & $6.91199 \mathrm{E}+00$ & $7.33606 \mathrm{E}+00$ \\
\hline $7.30869 \mathrm{E}+00$ & $7.15395 \mathrm{E}+00$ & $7.00757 \mathrm{E}+00$ & $6.89639 E+00$ & $6.85434 \mathrm{E}+00$ & $7.02440 \mathrm{E}+00$ \\
\hline $7.47282 \mathrm{E}+00$ & $7.33289 \mathrm{E}+00$ & $7.20861 \mathrm{E}+00$ & & & \\
\hline \\
\hline $1.21600 \mathrm{E}+00$ & $1.07633 \mathrm{E}+00$ & $9.39395 \mathrm{E}-01$ & $8.21744 \mathrm{E}-01$ & $6.39803 \mathrm{E}-01$ & $3.85069 \mathrm{E}-01$ \\
\hline 1. $70160 \mathrm{E}+00$ & $1.53953 \mathrm{E}+00$ & $1.37303 \mathrm{E}+00$ & $1.18212 \mathrm{E}+00$ & 9.33278 E01 & $6.24370 \mathrm{E}-01$ \\
\hline $2.22647 \mathrm{E}+00$ & $2.04173 E+00$ & $1.85073 \mathrm{E}+00$ & $1.59404 \mathrm{E}+00$ & $1.26948 \mathrm{E}+00$ & 8.91257E01 \\
\hline \\
\hline $6.52690 \mathrm{E}-01$ & $5.73228 \mathrm{E}-01$ & $5.02736 \mathrm{E}-01$ & $4.44119 \mathrm{E}-01$ & $3.57799 \mathrm{E}-01$ & 2.42 \\
\hline $9.17941 \mathrm{E}-01$ & $8.24142 \mathrm{E}-01$ & 7. $32112 \mathrm{E}-01$ & $6.33391 \mathrm{E}-01$ & $5.13124 \mathrm{E}-01$ & $3.68625 \mathrm{E}-01$ \\
\hline $1.23416 \mathrm{E}+00$ & $1.11726 \mathrm{E}+00$ & $1.00307 \mathrm{E}+00$ & $8.65020 \mathrm{E} 01$ & $7.05802 \mathrm{E}-01$ & 5.301 \\
\hline \multicolumn{6}{|c|}{89 Fraction of $\mathrm{F}$} \\
\hline $1.00000 \mathrm{E}+00$ & $1.00000 \mathrm{E}+00$ & $1.00000 \mathrm{E}+00$ & & $E+00$ & $0 E+00$ \\
\hline $1.00000 \mathrm{E}+00$ & $1.00000 \mathrm{E}+00$ & $1.00000 \mathrm{E}+00$ & $1.00000 \mathrm{E}+00$ & $\mathrm{E}+00$ & $E+00$ \\
\hline $1.00000 \mathrm{E}+00$ & $.00000 \mathrm{E}+00$ & $1.00000 \mathrm{E}+00$ & $1.00000 \mathrm{E}+00$ & 1.0 & $E+00$ \\
\hline \multicolumn{6}{|l|}{90 Required } \\
\hline $3.53549 \mathrm{E}-02$ & $3.31155 \mathrm{E}-02$ & $3.08688 \mathrm{E}-02$ & $2.88252 \mathrm{E}-02$ & 2.5 & 2.06 \\
\hline $4.28018 \mathrm{E}-02$ & $4.06544 \mathrm{E}-02$ & $3.83227 \mathrm{E}-02$ & $3.54764 \mathrm{E}-02$ & $3.14364 \mathrm{E}-02$ & 2.5 \\
\hline \multicolumn{5}{|c|}{91 Required Simple Orifice Effective KA Product (In2) } & $3.16^{7}$ \\
\hline $6.19236 \mathrm{E}-04$ & $5.45346 \mathrm{E}-04$ & $4.79289 \mathrm{E}-04$ & $4.24049 \mathrm{E}-04$ & $3.42261 \mathrm{E}-04$ & 2.3 \\
\hline $8.63958 \mathrm{E}-04$ & $7.78723 \mathrm{E}-04$ & $6.94135 \mathrm{E}-04$ & $6.02487 \mathrm{E}-04$ & $4.89690 \mathrm{E}-04$ & 3.527 \\
\hline $1.14839 \mathrm{E}-03$ & $1.04565 \mathrm{E}-03$ & $9.43637 \mathrm{E}-04$ & $8.18356 \mathrm{E}-04$ & $6.71279 \mathrm{E}-04$ & $5.06409 \mathrm{E}-04$ \\
\hline \multicolumn{6}{|c|}{92 Evaporator Exit Refrigerant Superheat (F) Or Quality $($ ) } \\
\hline \multicolumn{6}{|c|}{$-9.94918 \mathrm{E}-01-9.93846 \mathrm{E}-01-9.92568 \mathrm{E}-01-9.91164 \mathrm{E}-01-9.88259 \mathrm{E}-01-9.81177 \mathrm{E}-01$} \\
\hline \multicolumn{6}{|l|}{$-9.96792 \mathrm{E}-01$} \\
\hline \multirow{2}{*}{\multicolumn{6}{|c|}{$\begin{array}{l}-9.98036 \mathrm{E}-01-9.97576 \mathrm{E}-01-9.97055 \mathrm{E}-01-9.95913 \mathrm{E}-01-9.94326 \mathrm{E}-01 \\
93 \text { Compressor Inlet Refrigerant Superheat (F) Or Ouality } t \text { ) }\end{array}$}} \\
\hline & & & & & \\
\hline \multicolumn{5}{|c|}{93 Compressor Inlet Refrigerant Superheat (F) Or Quality t) } & $1.00000 \mathrm{E}+00$ \\
\hline $1.00000 \mathrm{E}+00$ & $1.00000 \mathrm{E}+00$ & $1.00000 \mathrm{E}+00$ & $1.00000 \mathrm{E}+00$ & $1.00000 \mathrm{E}+00$ & $\mathrm{OE}+00$ \\
\hline $1.00000 \mathrm{E}+00$ & $1.00000 \mathrm{E}+00$ & $1.00000 \mathrm{E}+00$ & $1.00000 \mathrm{E}+00$ & 0 & \\
\hline \multicolumn{6}{|c|}{94 Compressor Exit Refrigerant Superheat (F) Or Quality $($ ) } \\
\hline $9.28456 \mathrm{E}+01$ & $8.66525 \mathrm{E}+01$ & $8.09977 \mathrm{E}+01$ & $6.95736 \mathrm{E}+0 \tilde{1}$ & $6.26807 \mathrm{E}+01$ & 6 \\
\hline $7.96038 E+01$ & $7.47014 \mathrm{E}+01$ & 6.78 & & & \\
\hline $7.22503 E+01$ & $6.82708 \mathrm{E}+01$ & $6.05123 \mathrm{E}+01$ & $5.12229 \mathrm{E}+01$ & $4.41918 \mathrm{E}+01$ & $9 \mathrm{E}+01$ \\
\hline 95 Condense & Exit Refr & igerant Subcoc & oling (F) Or & Quality $($ ) & \\
\hline $2.40163 \mathrm{E}+01$ & $2.12248 \mathrm{E}+01$ & $1.84009 \mathrm{E}+01$ & $1.56017 \mathrm{E}+01$ & $1.28011 \mathrm{E}+01$ & $7 E+01$ \\
\hline 2.40206 & $2.12044 \mathrm{E}+01$ & 01 & & & \\
\hline 2.3990 & $2.12010 \mathrm{E}+01$ & 1.84 & & & \\
\hline Flow & trol & Subc & oling & Qualit & \\
\hline $3.85271 \mathrm{E}+01$ & $3.81667 \mathrm{E}+01$ & 3.83 & 01 & 4 & +01 \\
\hline $3.38741 \mathrm{E}+01$ & $3.26723 \mathrm{E}+01$ & $3.18529 \mathrm{E}+01$ & 3. & 3 & $\Xi+01$ \\
\hline 3.06879 & $2.91100 \mathrm{E}+01$ & $2.77840 \mathrm{E}+01$ & & & 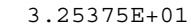 \\
\hline & rant Temperatu & re At Flow Con & - T & & \\
\hline $5.76814 \mathrm{E}+01$ & $5.51873 \mathrm{E}+01$ & $5.22573 E+01$ & $4.91361 \mathrm{E}+01$ & $4.20865 \mathrm{E}+$ & +01 \\
\hline $6.74846 \mathrm{E}+01$ & $6.58362 \mathrm{E}+01$ & $6.37567 \mathrm{E}+01$ & $6.04868 \mathrm{E}+01$ & $\mathrm{E}+01$ & $E+01$ \\
\hline 7. $75333 \mathrm{E}+01$ & $7.61461 \mathrm{E}+01$ & $7.42104 \mathrm{E}+01$ & $5 E+01$ & $E+01$ & $5 E+01$ \\
\hline & & & & & \\
\hline $9.48881 \mathrm{E}+00$ & $1.02611 \mathrm{E}+01$ & $9 \mathrm{E}+01$ & $9 E+01$ & 1.2419 & \\
\hline $2.21796 \mathrm{E}+01$ & $2.29095 \mathrm{E}+01$ & & & & +01 \\
\hline $3.45797 \mathrm{E}+01$ & $3.53631 \mathrm{E}+01$ & 3.611 & $E+01$ & 3. & $3 E+01$ \\
\hline & rant Discharge & & & Exit & \\
\hline $1.89600 \mathrm{E}+02$ & $1.80445 \mathrm{E}+02$ & $1.71932 \mathrm{E}+02$ & $1.57839 \mathrm{E}+02$ & $1.47671 \mathrm{E}+02$ & $09 E+02$ \\
\hline $1.81906 \mathrm{E}+02$ & $1.73986 \mathrm{E}+02$ & 1.640 & & & +02 \\
\hline 1.81940 & $1.74752 \mathrm{E}+02$ & $1.63507 \mathrm{E}+02$ & $\mathrm{E}+02$ & & +02 \\
\hline ReIrlger & tion $\mathrm{P}$ & ressure At Com & npres: & & \\
\hline $4.60435 \mathrm{E}+01$ & $4.67660 \mathrm{E}+01$ & $4.74104 \mathrm{E}+01$ & $4.80901 \mathrm{E}+01$ & 4.8 & +01 \\
\hline 5.90421 & $5.98642 \mathrm{E}+01$ & & & & \\
\hline $7.42568 \mathrm{E}+01$ & $7.53082 \mathrm{E}+01$ & $7.63236 \mathrm{E}+01$ & $7.76244 \mathrm{E}+01$ & $E+01$ & $8 E+01$ \\
\hline & anc & Pre & Comp & & \\
\hline 2.01361 & $1.93195 \mathrm{E}+02$ & $5 E+02$ & $06 E+02$ & 1.7 & \\
\hline 2.1734 & $2.08540 \mathrm{E}+02$ & +02 & & & \\
\hline $2.40050 \mathrm{E}+02$ & $2.29983 E+02$ & $2.19407 \mathrm{E}+02$ & $2.06492 \mathrm{E}+02$ & $1.92379 \mathrm{E}+02$ & $44 E+02$ \\
\hline
\end{tabular}




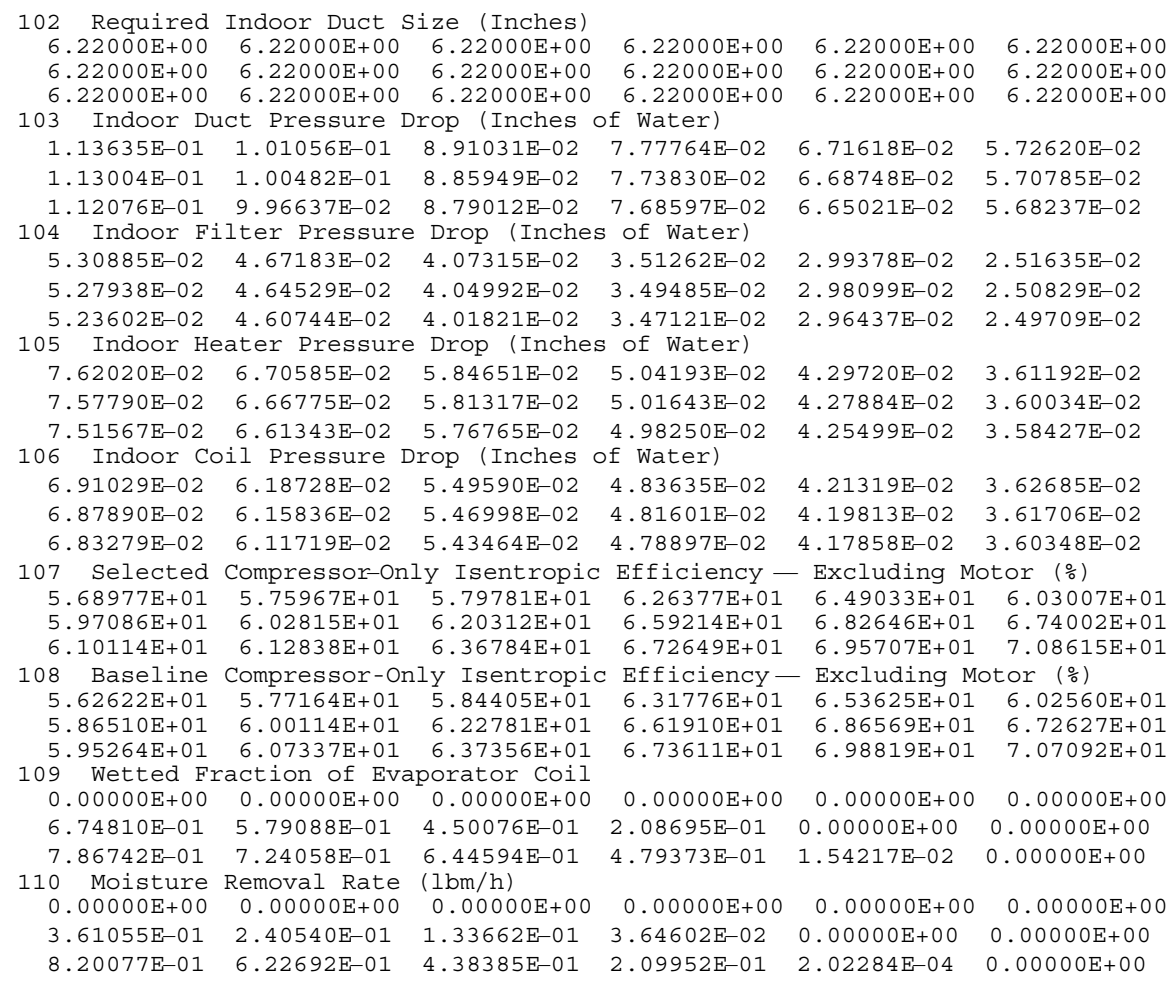





\section{APPENDIX D \\ DEFINITIONS OF CONSTANTS ASSIGNED IN BLOCK DATA}

A number of variables and constants are used by the Heat Pump Design Model that are unlikely to be changed very often, and consequently they are simply assigned values rather than being specified with each set of input data. They have been brought together in the BLOCK DATA subroutine and given values which are in turn passed to the subroutines where they are used via common blocks. These data are divided into several categories organized by function.

\section{Assignment of Unit Numbers for Input and Output}

Input Unit Numbers

IOCHZR for reading 'CONCHZ' and 'HPDATA' data files, 5

IOCNTR for reading 'CONTRL' data files (optional), 24

Output Unit Numbers

IOCONW for printing the input echo and the output listing, 6

IOSSP for punching a steady-state performance data file of the form required for the ORNL Annual Performance Factor Model, 7

IOCONP for punching contour data files 'CONGEN' or 'CONSPD' (from Figure CDG1), 8

\section{Physical Air-Side Parameters}

PA atmospheric pressure, $14.7 \mathrm{lbf} / \mathrm{in}^{2}$

RAU universal gas constant, $53.34 \mathrm{ft}-1 \mathrm{bf} / \mathrm{lbm}-{ }^{\circ} \mathrm{R}$

AFILTR flow area of filter on indoor unit, $2.78 \mathrm{ft}^{2}$

AHEATR cross-sectional area of resistance heater section in indoor unit, (usually equal to indoor blower exit area), $1.28 \mathrm{ft}^{2}$

RACKS number of resistance heater racks, 3.0 


\section{Data For Loss-and-Efficiency-Based Compressor Model}

Compressor Motor Efficiency Correlation

CETAM coefficients for the $0^{\text {th }}$ through $5 \mathrm{t}^{\mathrm{h}}$ order terms of the fit of the compressor motor efficiency as a function of the fractional motor load (Eq. 4.29*), 0.4088, 2.5138, $-4.6289,4.5884,-2.3666$, and 0.48324

RPMSLR slope of linear fit for fraction of no-load compressor motor speed as a function of fraction of full load power, -0.042 (see Eq. $4.24 *$ )

Compressor Volumetric Efficiency Parameters

ETAVLA intercept for the fit of theoretical minus actual volumetric efficiencies as a linear function of the correlating parameter given by Davis and Scott, -0.0933

ETAVLB slope of the fit of theoretical minus actual volumetric efficiencies as a linear function of the correlating parameter given by Davis and Scott, 0.733

\section{Data For Map-Based Compressor Model}

Shell Inlet Superheat Correction Parameters

SUCFAC suction gas heating factor $\mathrm{F}_{\text {sh }}$ used in Eq. 4.6*, 0.33

VOLFAC volumetric efficiency correction factor $\mathrm{F}_{\mathrm{v}}$ used in Eq. $4.4^{*}, 0.75$

Parameters for Converting Between Induction and ECM Compressor Motors

CSLPNM assumed nominal compressor slip speed at rated horsepower for the selected drive, $150 \mathrm{rpm}$

NPINDC number of poles for compressor induction motor, 2

MPOLCM multiplier to convert number of induction motor poles to number of poles for compressor ECM, 2

*The equation numbers cited throughout the BLOCK DATA variable definitions refer to a previous ORNL Heat Pump Model documentation report (Fischer and Rice 1983). 
Factors For Estimating Suction Gas Superheat Effects Of Different Motors

LOCOOL logical variable used to omit suction gas superheat corrections if motor is not lowside cooled, .TRUE.

HTFRAC estimated fraction of the shaft input power (heat from non-motor sources) that contributes to suction gas heating, 0.05

DAMPER damping factor on total suction gas heating from motor cooling and from heat transfer from the compressor body and discharge line, 0.75

PM-ECM Motor Characteristics (Used for Motor Temperature Corrections)

ETSTAT estimate of motor stator temperature, $40.0{ }^{\circ} \mathrm{C}$

ETROTR estimate of motor rotor temperature, $55.0^{\circ} \mathrm{C}$

ETREF reference temperature for motor data, $25.0{ }^{\circ} \mathrm{C}$

ETCOEF magnet flux temperature coefficient $\left(-0.20 \% /{ }^{\circ} \mathrm{C}\right)$

EFORMF approximate average form factor, 1.01

$\operatorname{ESPDNM}(\mathrm{J})$ motor nominal speed (rpm), 5400., 6900.

ETQRAT(J) rating point (design cooling load) torque (oz-ft), 64.0, 50.0

ERTREF(J) motor stator resistance (line-line) at reference temperature (ohms), 0.648, 0.371

EACOEF(J) slope of torque / current relationship, 0.205, 0.263

$\operatorname{EBCOEF}(\mathrm{J}) \quad$ intercept of torque / current relationship, 0.6, 0.3

where $(\mathrm{I}=\mathrm{A} * \mathrm{~T}+\mathrm{B})$ for two motor speeds $\mathrm{J}=1,2$

which provide 2 points from which to interpolate to other nominal speeds

\section{Fan and Fan Motor Parameters}

Data for Outdoor Fan Efficiency Representation

COFAN constant term for the fit of outdoor fan static efficiency to fan specific speed, -3.993

CIFAN coefficient for the linear term of the fit of outdoor fan static efficiency to the fan specific speed, 4.266

C2FAN coefficient for the quadratic term of the fit of outdoor fan static efficiency to fan specific speed, -1.024 
Fan Power Reference Temperatures

TRFIDF(1) reference temperature for indoor fan power in cooling mode, $80.0^{\circ} \mathrm{F}$

$\operatorname{TRFIDF}(2)$ reference temperature for indoor fan power in heating mode, $70.0^{\circ} \mathrm{F}$

TRFODF(1) reference temperature for outdoor fan power in cooling mode, $95.0^{\circ} \mathrm{F}$

$\operatorname{TRFODF}(2)$ reference temperature for outdoor fan power in heating mode, $47.0^{\circ} \mathrm{F}$

Parameters for Converting Between Induction and ECM Fan Motors

SLPNMI indoor-blower assumed nominal slip speed at rated horsepower, $120 \mathrm{rpm}$

SLPNMI outdoor-fan assumed nominal slip speed at rated horsepower, $120 \mathrm{rpm}$

NPOLEI number of poles for indoor-blower induction motor, 6

NPOLEO number of poles for outdoor-fan induction motor, 6

MPOLEI multiplier to convert number of induction motor poles to number of poles for indoorblower ECM, 2

MPOLEO multiplier to convert number of induction motor poles to number of poles for outdoor-fan ECM, 2

\section{Iteration Convergence Criteria (Default Values)}

AMBCON Convergence parameter for the iteration on evaporator inlet air temperature, $0.20^{\circ} \mathrm{F}$

CNDCON Convergence parameter for the iteration on condenser exit subcooling(or on exit quality $* 200)-$ used when IREFC $=0$ on Line $6\left(\mathrm{~F}^{\circ}\right)$; also the quantity $\{2 *$ CNDCON $\}$ is used as the convergence parameter for the charge balancing iteration when ICHRGE $=2,0.20^{\circ} \mathrm{F}$

FLOCON Convergence parameter for iteration on refrigerant mass flow rate - used when IREFC $>0$ on Line 6 (equivalent $\mathrm{F}^{\circ}$ ) value is specified as if it were in degrees $\mathrm{F}$ and is scaled internally (by $1 / 20^{\text {th }}$ ) to give a mass flow convergence factor, $0.20 \mathrm{~F}^{\circ}$

EVPCON Convergence parameter for iteration on evaporator exit superheat (or on exit quality * 500); Also the quantity $\{2 *$ EVPCON $\}$ is used as the convergence parameter for the charge balancing iteration when ICHRGE $=1,0.50 \mathrm{~F}^{\circ}$

CONMST Convergence parameter for iterations on evaporator tube wall temperatures in subroutine EVAP and dew-point temperature in subroutine XMOIST, $0.003 \mathrm{~F}^{\circ}$ 


\section{Iteration Convergence Criteria (continued)}

CMPCON Convergence parameter for iteration on suction gas enthalpy in the efficiency-andloss compressor model $(\mathrm{Btu} / \mathrm{lbm})$ - only used when ICOMP $=1$ on Line $8,0.05 \mathrm{~F}^{\circ}$

TOLH Tolerance parameter used by refrigerant routines in calculating properties of superheated vapor when converging on a known enthalpy value (Btu/lbm), 0.001

TOLS Tolerance parameter used by refrigerant routines in calculating properties of superheated vapor when converging on a known entropy value $\left(\mathrm{Btu} / \mathrm{lbm} /{ }^{\circ} \mathrm{R}\right)$, 0.00005

\section{Refrigerant Specification (Default)}

NR $\quad$ refrigerant number, 22

Refrigerant-Side Heat Transfer Correlation for Condenser Vapor Region

CIR, C3R, and C5R

coefficients for single-phase heat transfer coefficient

(Eq. 6.2*), 1.10647, $3.5194 \times 10^{-7}$, and 0.01080

C2R, C4R, and C6R

exponents for single-phase heat transfer coefficient

(Eq. 6.3*), $-0.78992,1.03804$, and -0.13750

XLLR lower limit on the Reynolds number for laminar flow of refrigerant, 3,500

ULR upper limit for the Reynolds number for turbulent flow of refrigerant, 6,000

\section{Refrigerant Tubing Parameter}

E roughness of interior tube walls, $5 \times 10^{-6} \mathrm{ft}$

\section{Evaporator Dryout Criterion}

XDO refrigerant quality at which dryout occurs in the evaporator, 0.75 


\section{Refrigerant Flow Control Parameters}

Thermostatic Expansion Valve Constants (Set for R22 as Default)

BLEEDF bypass or bleed factor coefficient used to compute TXV parameters when condenser subcooling is held fixed, 1.15

DPRAT rated pressure drop across the TXV at the design conditions, 100 psi for R-22 and $\mathrm{R}-502,60$ psi for R-12

NZTBOP switch to bypass nozzle and distributor tube pressure drop calculations when calculating TXV parameters if the condenser subcooling is held fixed, 0

STATIC static superheat setting used to compute the TXV parameters when the condenser subcooling is held fixed, $6.0 \mathrm{~F}^{\circ}$

SUPRAT rated operating superheat used to compute the TXV parameters when the condenser subcooling is held fixed, $11.0 \mathrm{~F}^{\circ}$

TERAT rated evaporating temperature for the TXV, $40.0^{\circ} \mathrm{F}$

TLQRAT rated liquid refrigerant temperature at the inlet to the $\mathrm{TXV}, 100.0^{\circ} \mathrm{F}$

XLTUBE length of distributor tubes (if used), 30 inches

Capillary Tube Parameter

NCAP number of capillary tubes used to compute capillary tube flow factor, $\varphi$, when condenser subcooling is held fixed, 1 


\title{
APPENDIX E
}

\section{DESCRIPTION OF NEW SUBROUTINES ADDED SINCE THE MARK III VERSION}

\author{
New Compressor-Drive-Performance Routines - \\ Inverter- and Sine-Wave-Driven Induction Motors (IDIM and SWDIMs) \\ and Permanent-Magnet-Electronically-Commutated-Motors (PM-ECMs) \\ (in general order of increasing drive efficiency)
}

CMPFGN computes efficiency reduction factor for first generation inverter drives compared to pure sine wave performance at the same frequency - function of compressor frequency (15 to $90 \mathrm{~Hz}$ ) and operation mode (heating or cooling) — integral $\mathrm{Hp}$ size

CMPSOA computes efficiency reduction factor for state-of-the-art inverter drives compared to pure sine wave performance at the same frequency - function of compressor frequency $(15$ to $90 \mathrm{~Hz}$ ) and operation mode (heating or cooling) — integral Hp size

SWDIM interpolates the motor efficiency and speed of a variable-frequency, 2-pole hermetic, sine-wave-driven induction motor (SWDIM) as a function of fractional full load ( 0.2 to 2.0$)$, frequency ratio (0.25 to 1.5$)$, and Volts/Hz multiplier (0.9 to 1.1$)$ - integral Hp size

ITRIND iterates to find sine-wave-driven induction motor efficiency and speed given electrical input power and drive frequency

ITRECM iterates to find PM-ECM motor efficiency given electrical input power and drive speed

ECMCMP interpolates the combined drive/motor efficiency of a variable-frequency compressor PM-ECM (4-pole hermetic) as a function of fractional full load (0.2 to 1.9 of full load) and drive frequency ratio ( 0.2 to 1.15 of nominal $)$ - integral Hp size

ECMTMP corrects ECM motor efficiency for hermetic operating temperature effects as a function of fractional rated torque and operating speed ratio

PROPCM computes refrigerant property values needed to convert compressor-map isentropic and volumetric efficiency values to power and mass flow rate, respectively

\section{New Fan-Drive-Performance Routines - \\ Inverter- and Sine-Wave-Driven Induction Motors (IDIM and SWDIMs) \\ and Permanent-Magnet-Electronically-Commutated-Motors (PM-ECMs)}

(in general order of increasing drive efficiency) 


\section{New Fan-Drive-Performance Routines — (continued)}

FANFGN computes modulating blower combined-motor-and-drive efficiency for a first generation inverter-driven system (fractional $\mathrm{Hp}$ size)

FANSOA computes modulating blower combined-motor-and-drive efficiency for a state-of-theart inverter-driven system (fractional $\mathrm{Hp}$ size)

FANSWV computes modulating blower combined-motor-and-drive efficiency for a sine-wavedriven system (fractional Hp size)

ECMBLW interpolates the combined drive/motor efficiency of a variable-frequency blower PMECM (12-pole) as a function of fractional full load ( 0.2 to 1.6 of full load) and drive speed (300 to $1300 \mathrm{rpm}$ )

ECMTRQ routine to calculate PM-ECM fan drive efficiency as a function of drive speed and air-side pressure drop (similar in function to ITRIND AND ITRECM for the compressor except that iteration is not required because blower torque is calculated directly from first principles rather than derived from required power input in the case of the compressor); also calculates required motor size if user-requested

\section{Refrigerant-Charge-Inventory-Related Routines}

(in order of occurrence in structure diagram of heat pump model)

\section{General Charge Inventory Computations}

INVENT calculates total low- and high-side refrigerant mass at steady-state and equilibrium (off-cycle) conditions, prints summary of refrigerant mass in each component

ZEROCH root-finding routine for the charge balancing outermost iteration loop of the heat pump model

GUESS1 routine which determines two values of evaporator superheat (or condenser subcooling) which require refrigerant charges that bracket the required charge

CHARGM function routine called by ZEROCH and GUESS1 which in turn calls the heat pump model subroutine HPDM and calculates and prints, as required, the difference in refrigerant charge between the calculated and the specified values

ACCUML calculates refrigerant liquid level and mass in a suction line accumulator accommodates $\mathrm{j}$-tube holes at two user-specified heights

HXCHRG general purpose routine to calculate refrigerant mass in single and two-phase sections of a tube-and-fin heat exchanger 


\section{General Charge Inventory Computations (continued)}

AVEDEN general purpose routine to calculate the average liquid and vapor densities in the twophase refrigerant regions of evaporators and condensers; uses numerical integration of void fraction method specified by MVOID (on line 4 of the HPDATA file) and an exponential heat flux assumption given by function DNORMF - except if MVOID $=0$ in which case a much faster (but less accurate) analytical solution for Zivi's method with constant heat flux is used

QAGS standard FORTRAN subroutine for the computation of a definite integral, used to integrate the void fraction weighting function DWTF and the heat flux weighting function DNORMF over a range of refrigerant qualities

DWTF void-fraction weighting function which calls the user-selected void fraction model at a given refrigerant quality and weights the resultant value with the qualitydependent heat flux weighting factor

DNORMF heat flux weighting function which accounts for a variable heat flux (and therefore variable air-to-refrigerant $\Delta \mathrm{T}$ ) as a function of refrigerant quality — this includes the effect of a variable refrigerant-side heat transfer coefficient

HRTPC calculates the local condensation coefficient as a function of refrigerant quality over the range from 0.0 to 1.0

LCHTC calculates the local condensation coefficient as a function of refrigerant quality over the range from 0.05 to 0.95 using the Travis, Baron, and Rosenhow correlation for annular flow

HRTPE calculates the local evaporation coefficient as a function of refrigerant quality over the range from 0.0 to 1.0 as described in ORNL/CON-80/R1; also is a routine which, besides subroutine EHTC, uses the refrigerant dryout quality (increased from the 0.65 value reported in $\mathrm{CON}-80$ to a present value of 0.75 )

Void-Fraction Function Routines (for further information see Rice 1987, ASHRAE Transactions)

HOMOG homogenous void fraction method - assumes no vapor slip

ZIVI Zivi method (simplest slip formulation) — similar to the default method (if MVOID is set to 0 on line 4 of the HPDATA file) except that there a constant heat flux is also assumed instead of the exponentially-varying value that is applied to this and all of the following void-fraction methods

LOCKRT Lockhart-Martinelli void fraction method

THOM Thom/Ahrens void fraction method ( a modified version of the Martinelli-Nelson method) 
Void-Fraction Function Routines (for further information see Rice 1987, ASHRAE Transactions) (continued)

BARCZY Baroczy void fraction method

PREMOL Premoli void fraction method (mass-flux dependent), only configured at present for R22 — needs surface tension properties for use with other refrigerants)

TANDON Tandon void fraction method (mass-flux dependent)

HUGHMK Hughmark void fraction method (mass-flux dependent)

ZEROZM zero-finding routine for internal iterations required in Hughmark void fraction method

ZMATCH computes the functional values of the Hughmark void fraction method based on builtin tables

\section{Air-Side Heat-Transfer and Pressure-Drop Correlations}

Air-Side Heat Transfer

ZIGHTM calculates augmentation factor for the air-side heat transfer coefficient due to fin patternation with specific zig-zag fin designs

NUAFF used in function ZIGHTM to correct a Nussult number ratio as a function of fin spacing and Graetz number

SINTRP interpolation in a single independent variable using a three point lagrangian method (for use with function ZIGHTM)

\section{Air-Side Pressure Drop}

KLOSS calculates contraction and expansion losses entering and leaving a finned heat exchanger (based on Kays and London correlations)

ZIGPDM calculates a multiplying factor for air pressure drop of specific zig-zag fin surfaces relative to an unpatterned fin

\section{Front-End Routines For Contour Data Generation}

CONDRV main program and first-level driving routine, reads $\mathrm{CONCHZ}$ input data file directly and calls DATAIN to read HPDATA file, also calls CONDAT to punch general contour data files 


\section{Front-End Routines For Contour Data Generation (continued)}

APFDRV second-level driver routine, reads ambient / speed / control data file 'CONTRL' and performs selected and dual-mode ambient-vs-speed performance mapping, can punch data file of the form required for the ORNL Annual Performance Factor Model; can generate contour data sets for selected indoor and outdoor ambients and relative humidities whereas with CONCHZ users can only select ambients with a uniform grid and fixed relative humidity

SSDRV third-level driver routine controlling the individual calls to the ORNL Modulating Heat Pump Design Model

DATAIN modified version of original DATAIN which is now called from CONDRV and defers assignment of input values for the condenser and the evaporator to subroutine HX

HX converts indoor and outdoor heat exchanger data from input file HPDATA into condenser and evaporator values

TRNVAL assigns contour grid values of independent variables (defined in Table XXX) specified in CONCHZ to the appropriate program variables and performs any necessary adjustment of related parameters (such as to maintain a constant total heat exchanger area)

NEWVAL routine that provides user-specified operational control of design variables as a function of either outdoor ambient temperature or compressor frequency

DPVLSS saves values of steady-state dependent parameters (defined in Table YYY) computed by the heat pump model — in arrays suitable for use by CONDAT in selecting which are to be punched in output data sets

APF (presently not included) calculates annual performance factor (APF) for set of speed versus ambient data generated by APFDRV

DPVAPF (presently not used) saves values of seasonal performance variables computed by the ORNL Annual Performance Factor Model — in arrays suitable for use by CONDAT in selecting which are to be punched in output data sets

CONDAT generalized routine for punching contour data sets of parameters that have been userselected in input data set CONCHZ 


\begin{abstract}
All Input/Output Data Files and Default Unit Numbers (Set in BLOCK DATA )
(as identified on structure diagram of MODCON program)

Input* Unit Numbers Purpose

CONCHZ 5 Contour Selection Data File

HPDATA $5 \quad$ Heat Pump Specification Data File

CONTRL 24 (optional) Ambient / Speed / Control Data File For Selected and Dual-Mode Ambient-Vs-Speed Performance Mapping

Output Unit Numbers Purpose

PRINT $6 \quad$ Program Input Echo and Output Listing of Type Selected in Data File HPDATA

APFSS $\quad 7$ (optional) Steady-State Performance Data File of the Form Required for the ORNL Annual Performance Factor Model

CONGEN 8

Contour Data Generation File of the Independent and Dependent Variables Selected in Data File CONCHZ

CONSPD $\quad 8$ (optional)

Contour Data Generation File of the Independent and Dependent Variables Selected in Data File CONTRL

APFDYN not yet in use Dynamic Loss Data Needed along with Data File APFSS to run the ORNL Annual Performance Factor Model
\end{abstract}

\footnotetext{
*The order of input data file calls is CONCHZ, HPDATA, then CONTRL. However, design and operating parameters set initially in HPDATA, if selected as parametric variables, are overridden in calls to routine TRNVAL, defined by the selected parametric inputs set in CONCHZ, and optionally by calls to input data file CONTRL from routine APFDRV.
} 


\section{APPENDIX F \\ DESCRIPTION OF SUBROUTINES USED FOR THE BASIC ORNL HEAT PUMP MODEL}

HPDM original main program which serves as driving program for high- and low-side computations and contains iterative loop converging on evaporator inlet air temperature

BLOCK DATA assigns default values, values to constants, and infrequently changed parameters

CALC calculates geometric constants for both heat exchangers

CAPTUB refrigerant flow control model for capillary tube flow rate or sizing

CHTC calculates refrigerant-side heat transfer coefficient for the two-phase region of the condenser

CMPMAP computes refrigerant mass flow and compressor power consumption from compressor map data

CNDNSR serves as driving routine for COMP, COND and FLOBAL and returns the difference between the calculated and specified condenser subcooling or between the compressor and expansion device refrigerant mass flow rates

COMP computes refrigerant mass flow rate and compressor power consumption from efficiency and loss parameters

COND calculates total condenser heat transfer rate, air and refrigerant properties and refrigerant and air-side pressure drops for fixed inlet refrigerant conditions

DPF determines an approximate dew-point temperature for a given vapor pressure of moist air

DPFSOL calculates the difference between the known saturation pressure of water vapor at the tube wall and the saturation pressure corresponding to an estimated, or given tube wall temperature

DPLINE determines the single-phase pressure drop in the refrigerant lines

EFFCT computes the difference in condenser effectiveness values between the general effectiveness equation and the specific cross-flow effectiveness equation as a function of the fraction of the coil, fv, containing superheated refrigerant vapor 
EHTC calculates refrigerant-side heat transfer coefficient for the two-phase region of the evaporator

EVAP determines the heat transfer, moisture removal, outlet air temperatures and humidities from one circuit of the evaporator for given heat transfer coefficients and saturation temperatures at the beginning and end of the two-phase region

EVAPR calculates evaporator heat transfer rate, air and refrigerant properties, and refrigerant and air-side pressure drops for fixed exit refrigerant conditions

EVPTR serves as a driving routine for EVAPR and returns the difference between the specified evaporator superheat and the calculated value

$\mathrm{EXCH}$ determines the heat transfer and outlet temperatures for one circuit of the condenser for given heat transfer coefficients and saturation temperatures at the beginning and end of the two-phase region

EXF determines the effectiveness of a cross-flow heat exchanger using the effectiveness - NTU method

FANFIT calculates combined fan-fan motor efficiency given air-side pressure drop and volumetric air-flow rate

FLOBAL determines refrigerant conditions at the inlet to the flow control device and drives the expansion device models

FRICT computes the general Moody friction factor for single phase flow in tubes

GUESS2 brackets a solution prior to using a root finder by shifting end points by factors of 10

GUESS3 brackets a solution prior to using a root finder by shifting end points by constant step

INTER interpolate in a single dimension using Lagrangian polynomial

HAIR computes air-side heat transfer coefficient for smooth fin and tube geometry

MUKCP calculates viscosity, thermal conductivity, and specific heat of 14 refrigerants

MUKCPA calculates viscosity, thermal conductivity, and specific heat of air

ORIFIC refrigerant flow control model for computing the refrigerant mass flow rate or sizing of a short-tube orifice

OUTPUT prints a detailed summary of output data 
PDAIR calculates air-side pressure drop for smooth, wavy, or louvered fin-and-tube heat exchangers

PDROP determines single- and two-phase pressure drops for flow in heat exchanger tubes

PVSF calculates partial pressure of water vapor in saturated air

SATPRP evaluates the saturation thermodynamic properties of a specified refrigerant

SEFF determines surface efficiency for a hexagonal shaped fin surface

SLAG computes single-precision Lagrangian interpolation in two dimensions from tabulated data

SPFHT calculates refrigerant specific heats at constant pressure and volume and specific heat ratio

SPHTC computes single-phase heat transfer coefficient for laminar, transition, or turbulent gas flow from an abrupt contraction entrance

SPHTC2 computes single-phase heat transfer coefficient for fully developed liquid or gas flow

SPVOL evaluates specific volume of superheated refrigerant

SUPCOR calculates power and mass flow correction factors for map-based compressor model to correct for superheat level

TABLES assigns constants for selected refrigerant for use in the thermodynamic property subroutines

TAOSOL computes the exit air temperature from the region of the evaporator where moisture removal occurs

TRIAL determines thermodynamic properties of superheated refrigerant vapor given two known properties

TSAT calculates saturation temperature of refrigerant given saturation pressure

TWISOL used to compute the wall temperature at which moisture removal begins on the leading edge of the evaporator

TWOSOL used to compute the wall temperature at the exit from the evaporator

TXV refrigerant flow control model for computing the refrigerant mass flow rate or sizing for a thermostatic expansion valve 
VAPOR determines thermodynamic properties of superheated refrigerant vapor given temperature and pressure

WBF

determines wet-bulb temperature of moist air

WTSFIT computes coefficients for a quadratic fit of wall temperature to enthalpy of moist air

XMOIST calculates dew point temperature, humidity ratio enthalpy, and wet-bulb temperature or relative humidity of moist air

ZERO's each of these routines solves for the root, or zero, of a function from two points which bracket the solution using bisection and Newton's method 


\section{APPENDIX G \\ COMPRESSOR-MAP-FITTING PROGRAM 'MAPFIT'}

This program is used to generate the compressor map performance coefficients for use with the model. The program requires power and mass flow rate (or capacity) data as a function of saturated condensing and evaporating temperatures (MAPIN.DAT). The resulting sets of coefficients represent biquadratic representations of power and mass flow rate as a function of saturation temperatures. Alternative representations of isentropic efficiency as a function of saturation temperature and volumetric efficiency as a function of discharge pressure and pressure ratio can also be generated by proper setting of the input options.

This version of MAPFIT can process compressor data for single or multiple speeds. The program can also accept map data where either the superheat or return gas temperature is specified and it can convert the data to another user-specified superheat level prior to the curve fitting.

In addition to an output listing (MAPOUT.DAT) showing the results of the curve fitting for a sample case, a file is generated (MAPCOEF.DAT) of the form needed for insertion into the heat pump specification data file 'HPDATA' given in Table B.1 for lines 9.0-9.7.

\section{Input Data Definitions and Format}

Listing G.1 describes the specific input data and format requirements for single- or variable-speed data sets. A number of input switches are provided to identify the type of compressor data provided and the type of curve fits and data conversions desired.

\section{Sample Input File (Regular and Annotated)}

A sample MAPFIT input file for a single-speed compressor is given in Listing G.2 followed by an annotated version in Listing G.3 which includes the input variable names referenced in Listing G.1.

\section{Sample Output Listing and File (Regular and Annotated)}

A sample of the tabular output from the program is given in Listing G.4 where the input map data are echoed followed by tables and summary statistics comparing the calculated values for power, mass flow, isentropic, and volumetric efficiency with those from the biquadratic curve fit representation. Last, the output file generated by the program for use as input to the heat pump model is described in Listing G.5 with actual and annotated versions of the sample file given in Listings G.6 and G.7. 



\title{
Listing G.1. Input Format Description for MAPFIT Program
}

\author{
INPUT DESCRIPTION FOR PROGRAM MAPFIT
}

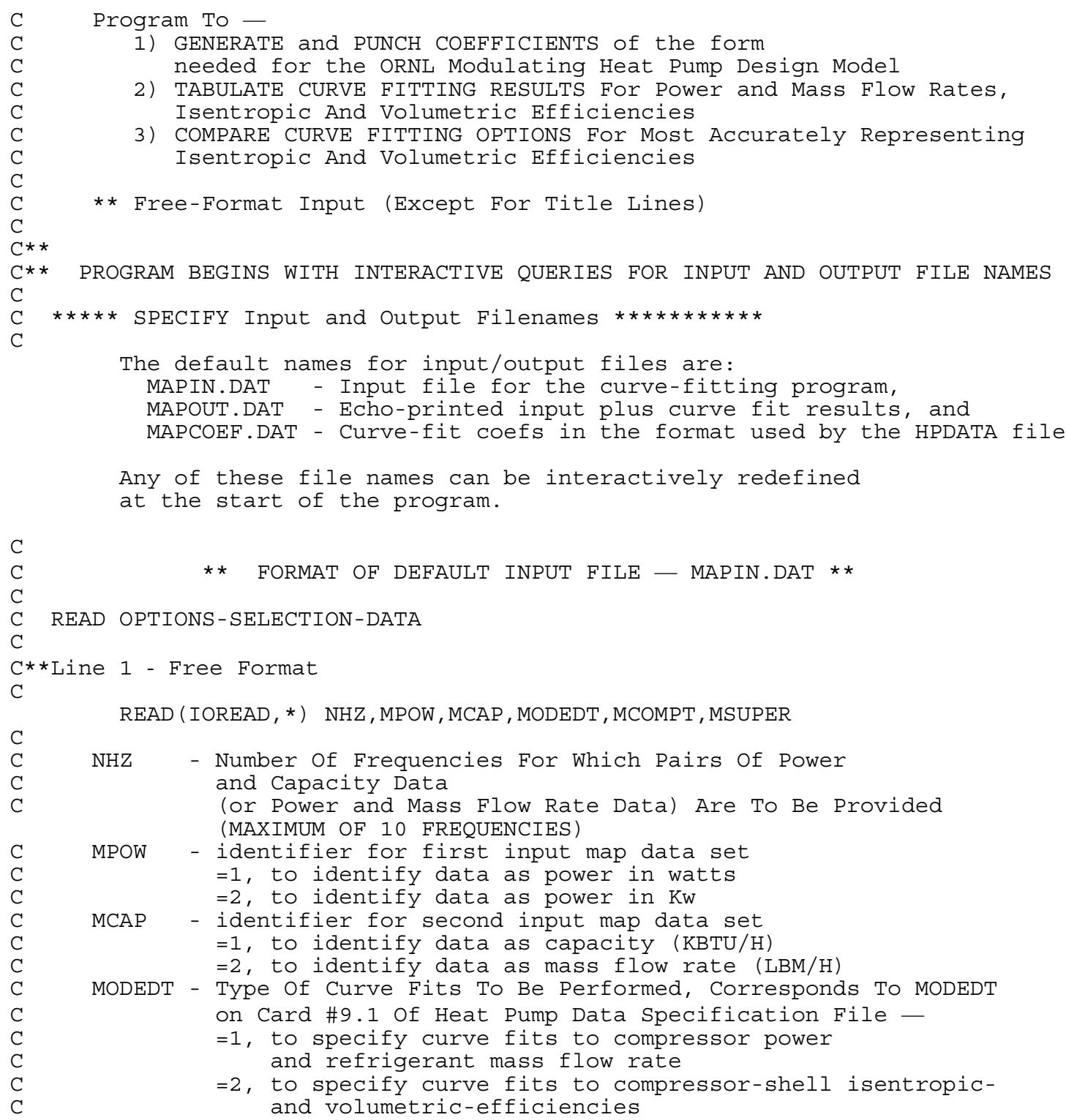




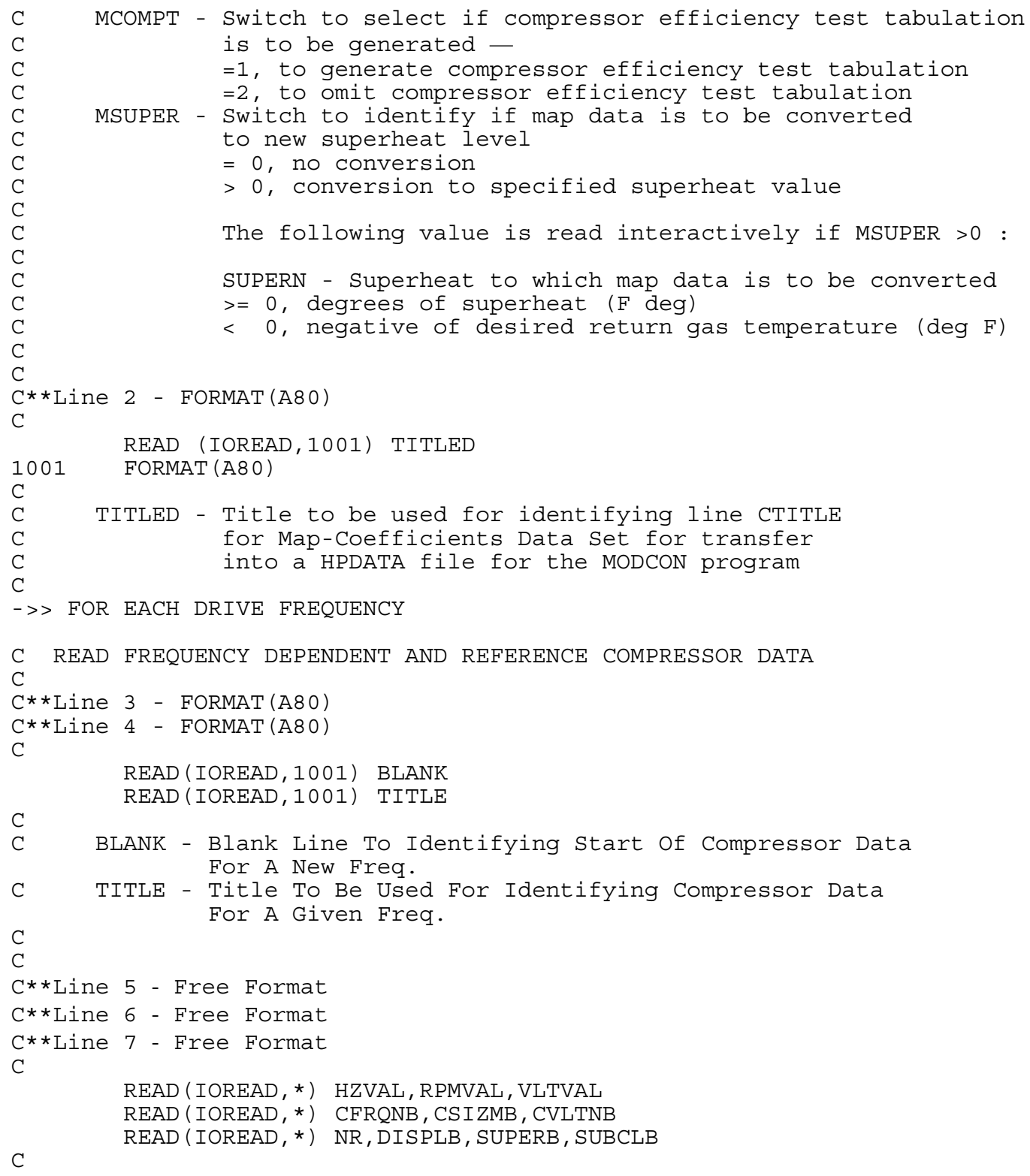




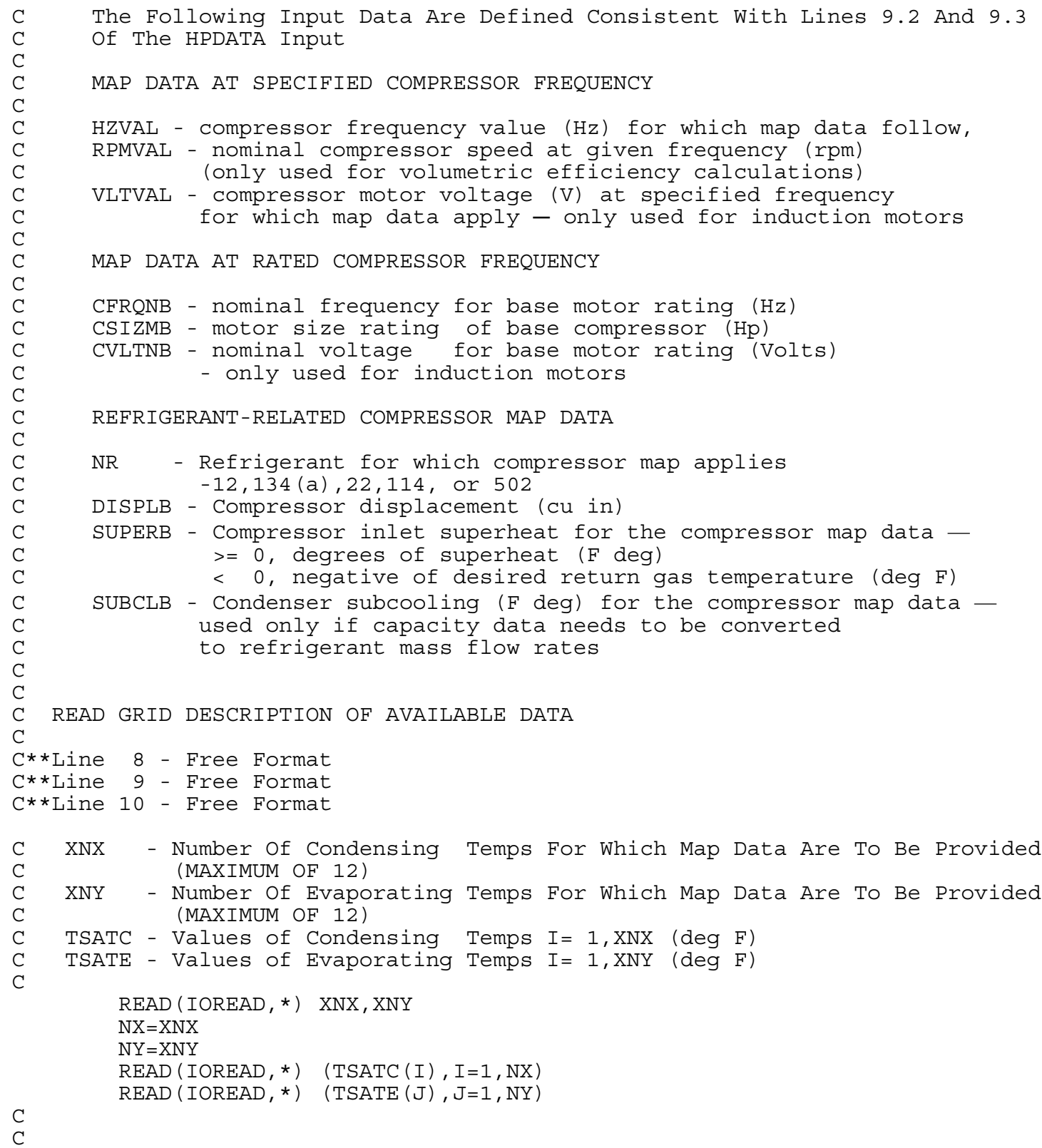




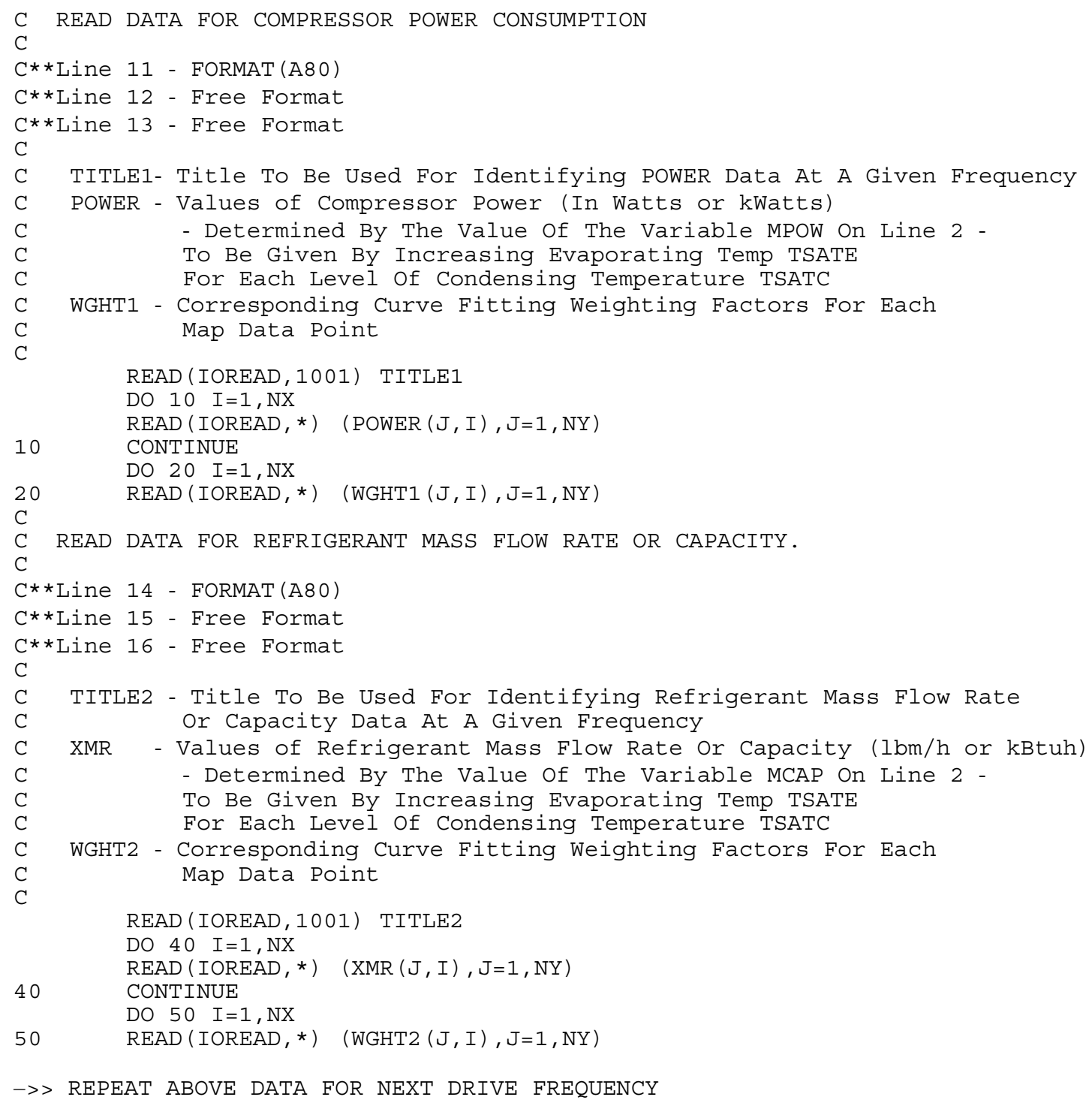




\section{Listing G.2. Sample Input File for MAPFIT Program}

FILE: MAPIN.DAT

$\begin{array}{lllllll}1 & 1 & 2 & 1 & 1 & 0\end{array}$

SAMPLE SINGLE-SPEED RECIP COMPRESSOR, HEATING MODE DATA

SAMPLE SINGLE-SPEED RECIP COMPRESSOR, 60 HZ CALORIMETER DATA

$60 . \quad 3450.240$.

60. 2.75240 .

$\mathrm{R}-22 \quad 3.64 \quad 10$.

$4.0000 \quad 12.000$

$80.000 \quad 90.000$

$100.00 \quad 110.00$

$10.000 \quad 15.000 \quad 20.000 \quad 25.000$

SAMPLE MAP DATA FOR POWER CONSUMPTION (W)

$\begin{array}{lll}1605.0 & 1725.2 & 1860.6\end{array}$

$\begin{array}{llll}1454.4 & 1598.5 & 1731.7 & 1871.5\end{array}$

$\begin{array}{llll}2236.4 & 2345.7 & 2442.0 & 2536.1\end{array}$

$\begin{array}{llll}1439.2 & 1587.6 & 1740.4 & 1888.9\end{array}$

$\begin{array}{llll}2295.1 & 2417.4 & 2531.1 & 2644.8\end{array}$

1419.6

$1583.3 \quad 1751.3$

1910.6
2768.7

2358.1

2500.1

1.0000

$1.0000-1.0000$

1.0000

1.0000

1.0000

1.0000

1.0000

1.0000

1.0000

1.0000

1.0000

1.0000

1.0000

1.0000

1.0000

1.0000

1.0000

1.0000

1.0000

1.0000

1.0000

1.0000

1.000

1.0000

1.0000

1. 0000

1.0000

1.0000

$0.0000 \quad 5.0000$

$30.000 \quad 35.000$

FOR HEATING MODE OPERATION

$\begin{array}{ll}1980.8 & 2092.3\end{array}$

$2538.9 \quad 2606.9$

$2002.5 \quad 2124.9$

$2621.5 \quad 2698.2$

$2028.6 \quad 2164.0$

$2743.2 \quad 2841.7$

$2063.4 \quad 2216.2$

$2886.7 \quad 3000.4$

$1.0000 \quad 1.0000$

$1.0000 \quad 1.0000$

$1.0000 \quad 1.0000$

$1.0000 \quad 1.0000$

$1.0000 \quad 1.0000$

$1.0000 \quad 1.0000$

$1.0000 \quad 1.0000$

$1.0000 \quad 1.0000$

SAMPLE MAP DATA FOR MASS FLOW RATE (LBM/HR)

87.926

108.84

131.94

160.48

FOR HE

1.0000

263.50

306.73

355.40

410.06

189.55

224.63

80.308

123.77

152.32

467.43

534.06

339.08

387.75

181.94

217.01

71.602

91.430

115.07

438.05

142.52

171.05

495.43

280.06

323.30

371.42

421.18

204.49

62.349

83.268

106.36

133.82

161.80

476.38

353.47

399.41

194.70

308.61

1.0000

452.44

1.0000

1.0000

1.0000

1.0000

1.0000

1.0000

1.0000

1.0000

1.0000

1.0000

1.0000

1.0000

1.0000

1.0000

1.0000

1. 0000

1.0000

1.0000

1.0000

1.0000

1.0000

1.0000

1.0000

1.0000

1.0000

1.0000

.0000

1.0000

1.0000

1.0000

1.0000

1.0000

1.0000

1.0000
1.0000

1.0000
1.0000

1.0000
1.0000

OPERATION 



\section{Listing G.3. Sample Input File for MAPFIT Program — Annotated}

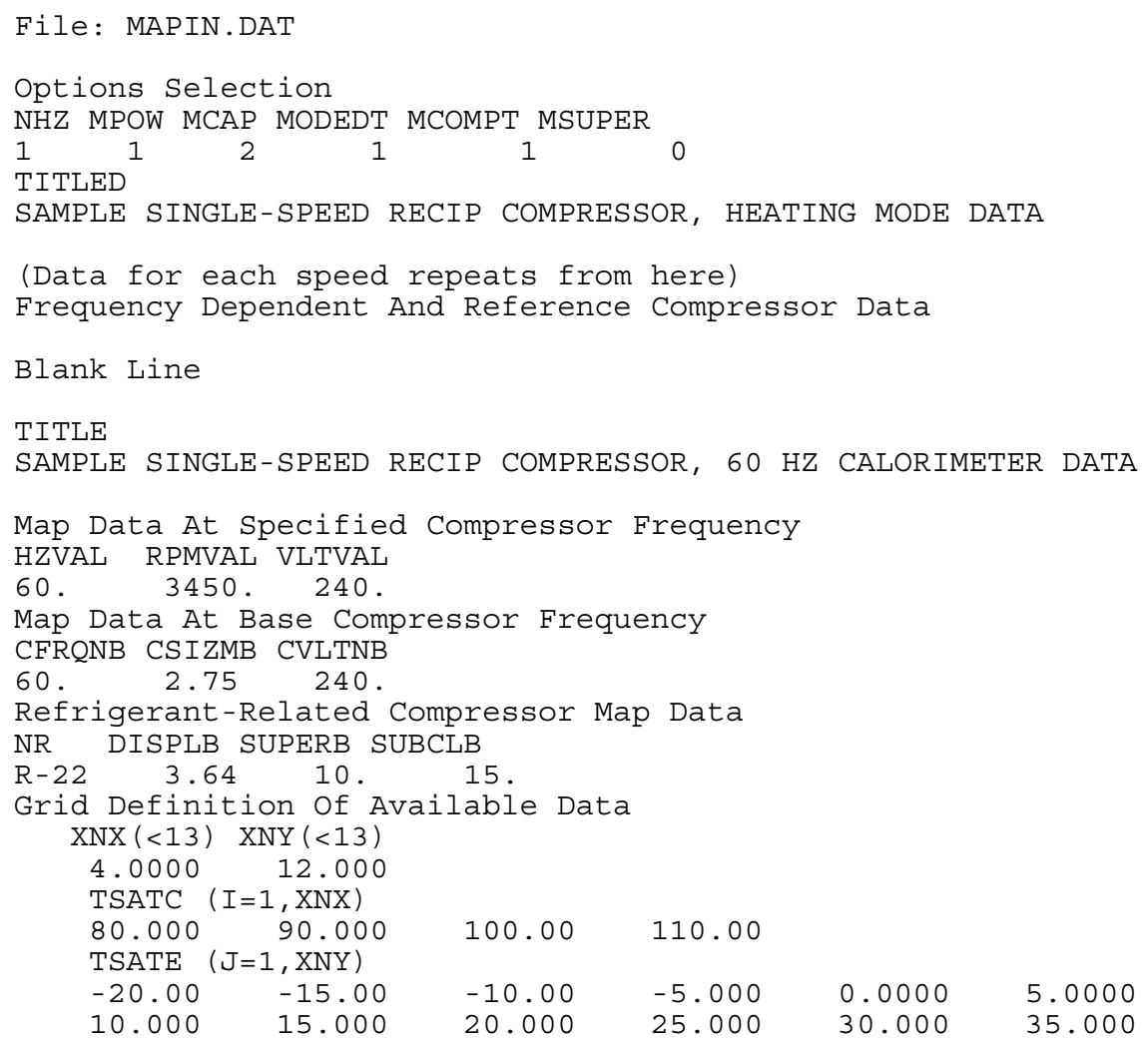




\section{Listing G.3. Sample Input File for MAPFIT Program — Annotated (continued)}

\begin{tabular}{|c|c|c|c|c|c|}
\hline \multicolumn{6}{|c|}{ TITLE1 (for power data) } \\
\hline SAMPLE MAP & TA FOR & ER CONS & TION $(\mathrm{W})$ & FOR HEATING & MODE OPERATION \\
\hline \multirow{2}{*}{\multicolumn{6}{|c|}{$\begin{array}{l}\text { Power Data (W or kW as selected by MPOW on line 1) } \\
\text { POWER (XNY, } 1 \text { ) }\end{array}$}} \\
\hline & & & & & \\
\hline 1467.4 & 1605.0 & 1725.2 & 1860.6 & 1980.8 & 2092.3 \\
\hline 2195.1 & 2293.5 & 2381.1 & 2464.4 & 2538.9 & 2606.9 \\
\hline \multicolumn{6}{|c|}{ POWER (XNY, 2) } \\
\hline 1454.4 & 1598.5 & 1731.7 & 1871.5 & 2002.5 & 2124.9 \\
\hline 2236.4 & 2345.7 & 2442.0 & 2536.1 & 2621.5 & 2698.2 \\
\hline \multicolumn{6}{|c|}{ POWER (XNY, 3) } \\
\hline 1439.2 & 1587.6 & 1740.4 & 1888.9 & 2028.6 & 2164.0 \\
\hline 2295.1 & 2417.4 & 2531.1 & 2644.8 & 2743.2 & 2841.7 \\
\hline \multicolumn{6}{|c|}{ POWER (XNY, XNX) } \\
\hline 1419.6 & 1583.3 & 1751.3 & 1910.6 & 2063.4 & 2216.2 \\
\hline 2358.1 & 2500.1 & 2635.5 & 2768.7 & 2886.7 & 3000.4 \\
\hline \multicolumn{6}{|c|}{ Weighting Data } \\
\hline \multicolumn{6}{|c|}{ WGHT1 (XNY, 1) } \\
\hline 1.0000 & 1.0000 & 1.0000 & 1.0000 & 1.0000 & 1.0000 \\
\hline 1.0000 & 1.0000 & 1.0000 & 1.0000 & 1.0000 & 1.0000 \\
\hline \multicolumn{6}{|c|}{ WGHT1 (XNY, 2) } \\
\hline 1.0000 & 1.0000 & 1.0000 & 1.0000 & 1.0000 & 1.0000 \\
\hline 1.0000 & 1.0000 & 1.0000 & 1.0000 & 1.0000 & 1.0000 \\
\hline \multicolumn{6}{|c|}{ WGHT1 (XNY, 3) } \\
\hline 1.0000 & 1.0000 & 1.0000 & 1.0000 & 1.0000 & 1.0000 \\
\hline 1.0000 & 1.0000 & 1.0000 & 1.0000 & 1.0000 & 1.0000 \\
\hline \multicolumn{6}{|c|}{ WGHT1 (XNY, XNX) } \\
\hline 1.0000 & 1.0000 & 1.0000 & 1.0000 & 1.0000 & 1.0000 \\
\hline 1.0000 & 1.0000 & 1.0000 & 1.0000 & 1.0000 & 1.0000 \\
\hline
\end{tabular}




\section{Listing G.3. Sample Input File for MAPFIT Program — Annotated (continued)}

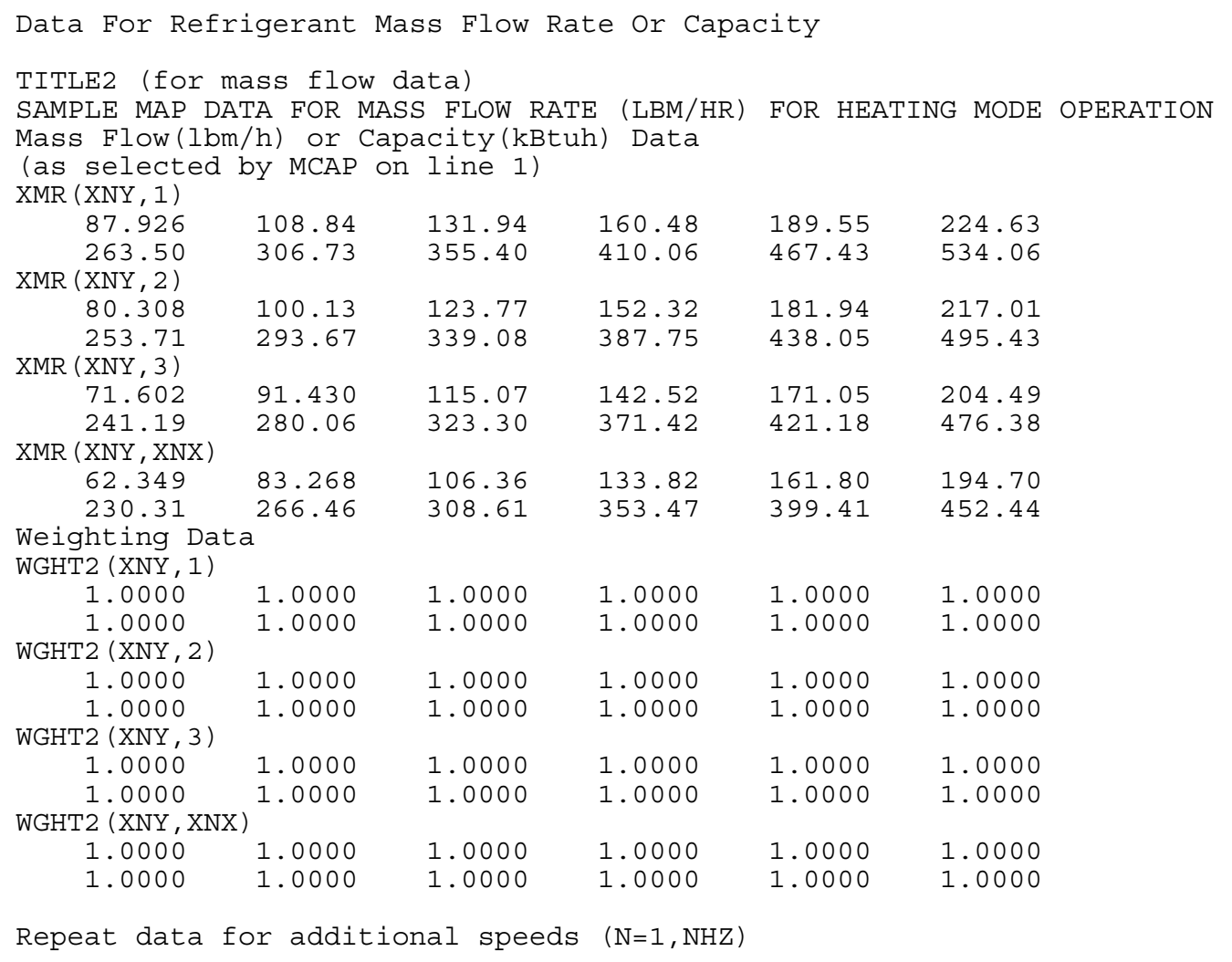





\section{Listing G.4. Sample Output Listing for MAPFIT Program}

FILE: MAPOUT.DAT

SAMPLE SINGLE-SPEED RECIP COMPRESSOR, HEATING MODE DATA

SAMPLE MAP DATA FOR POWER CONSUMPTION (W) FOR HEATING MODE OPERATION INPUT DATA FOR MAP COMPRESSOR POWER CONSUMPTION:

$\begin{array}{lrl}\text { MOTOR DRIVE FREQUENCY } & 60.0 \mathrm{HZ} \\ \text { MOTOR NOMINAL SPEED } & 3450.0 \mathrm{RPM} \\ \text { MOTOR VOLTAGE } & 240.0 \mathrm{VOLTS} \\ \text { REFRIGERANT } & \mathrm{R}-22 \\ \text { COMPRESSOR DISPLACEMENT } & 3.6400 \mathrm{CU} \text { IN } \\ \text { MAP SUBCOOLING VALUE } & 15.00 \mathrm{~F} \\ \text { MAP SUPERHEAT VALUE } & 10.00 \mathrm{~F}\end{array}$

COMPRESSOR POWER CONSUMPTION INPUT DATA IS IN WATTS - IT HAS BEEN CONVERTED TO KILOWATTS

EVAPORATING

TEMPERATURE

\section{$(\mathrm{F})$}

\begin{tabular}{c} 
CONDENSING \\
80.00 \\
\hline 1.4674 \\
1.0000 \\
1.6050 \\
1.0000 \\
1.7252 \\
1.0000 \\
1.8606 \\
1.0000 \\
1.9808 \\
1.0000 \\
2.0923 \\
1.0000 \\
2.1951 \\
1.0000 \\
2.2935 \\
1.0000 \\
2.3811 \\
1.0000 \\
2.4644 \\
1.0000 \\
2.5389 \\
1.0000 \\
2.6069 \\
1.0000
\end{tabular}

90.00

\begin{tabular}{rll}
\hline-20.0 & I & DATA \\
& I & WEIGHT \\
-15.0 & I & DATA \\
-10.0 & I & WEIGHT \\
& I & WEIGHT \\
-5.0 & I & DATA \\
& I & WEIGHT \\
.0 & I DATA \\
& I WEIGHT \\
5.0 & I & DATA \\
& I & WEIGHT \\
10.0 & I & DATA \\
& I WEIGHT \\
15.0 & I & DATA \\
& I & WEIGHT \\
20.0 & I & DATA \\
& I WEIGHT \\
25.0 & I & DATA \\
& I & WEIGHT \\
30.0 & I & DATA \\
& I & WEIGHT \\
35.0 & I & DATA \\
& I & WEIGHT
\end{tabular}

1.4544
1.0000
1.5985
1.0000
1.7317
1.0000
1.8715
1.0000
2.0025
1.0000
2.1249
1.0000
2.2364
1.0000
2.3457
1.0000
2.4420
1.0000
2.5361
1.0000
2.6215
1.0000
2.6982
1.0000

(F)

\begin{tabular}{|c|c|}
\hline 0 & 110.00 \\
\hline 1.4392 & 1.4196 \\
\hline 1.0000 & 1.0000 \\
\hline 1.5876 & 1.5833 \\
\hline 1.0000 & 1.0000 \\
\hline 1.7404 & 1.7513 \\
\hline 1.0000 & 1.0000 \\
\hline 1.8889 & 1.9106 \\
\hline 1.0000 & 1.0000 \\
\hline 2.0286 & 2.0634 \\
\hline 1.0000 & 1.0000 \\
\hline 2.1640 & 2.2162 \\
\hline 1.0000 & 1.0000 \\
\hline 2.2951 & 2.3581 \\
\hline 1.0000 & 1.0000 \\
\hline 2.4174 & 2.5001 \\
\hline 1.0000 & 1.0000 \\
\hline 2.5311 & 2.6355 \\
\hline 1.0000 & 1.0000 \\
\hline 2.6448 & 2.7687 \\
\hline 1.0000 & 1.0000 \\
\hline 2.7432 & 2.8867 \\
\hline 1.0000 & 1.0000 \\
\hline 2.8417 & 3.0004 \\
\hline 1.0000 & 1.0000 \\
\hline
\end{tabular}




\section{Listing G.4. Sample Output Listing for MAPFIT Program (continued)}

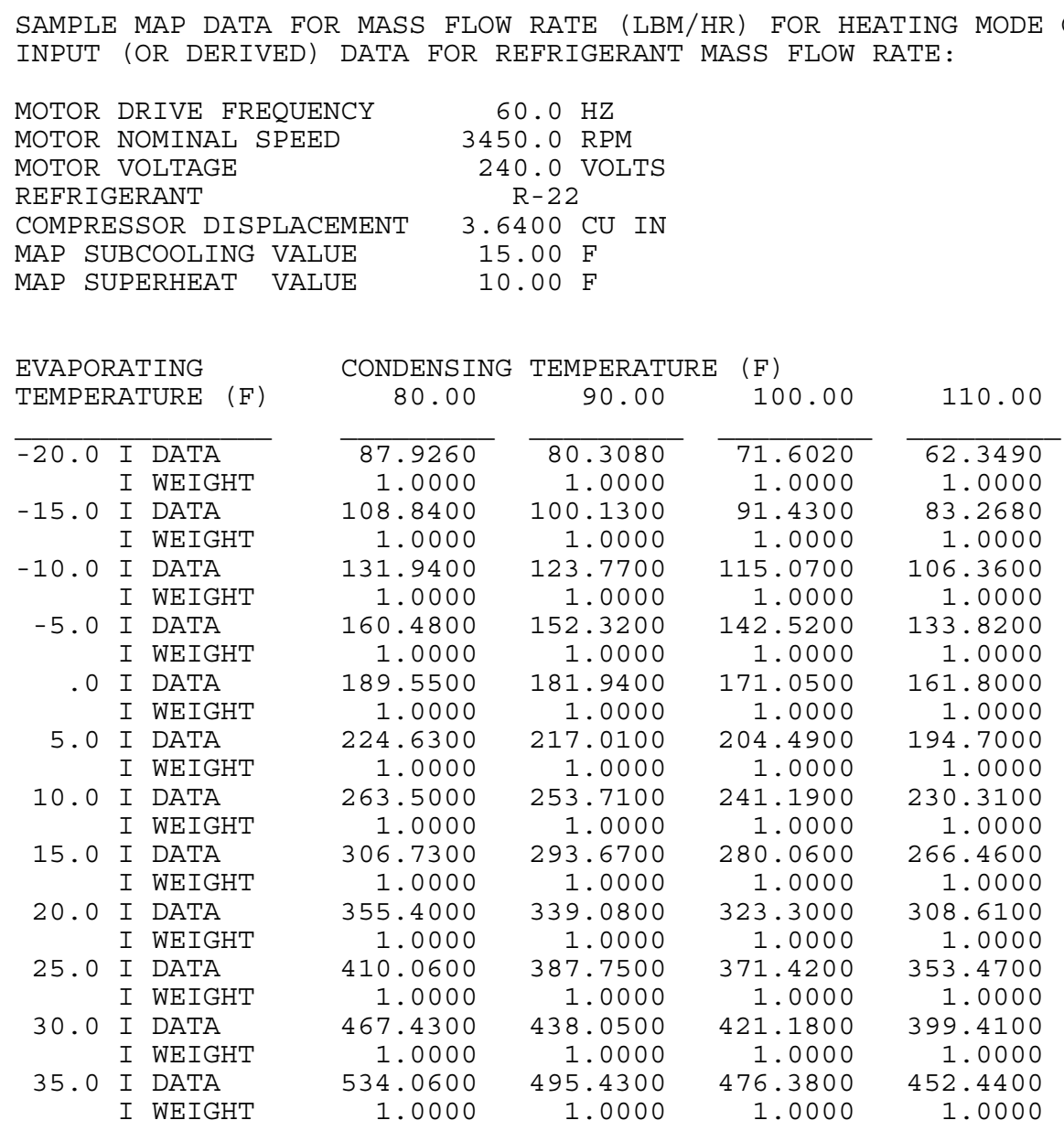




\section{Listing G.4. Sample Output Listing for MAPFIT Program (continued)}

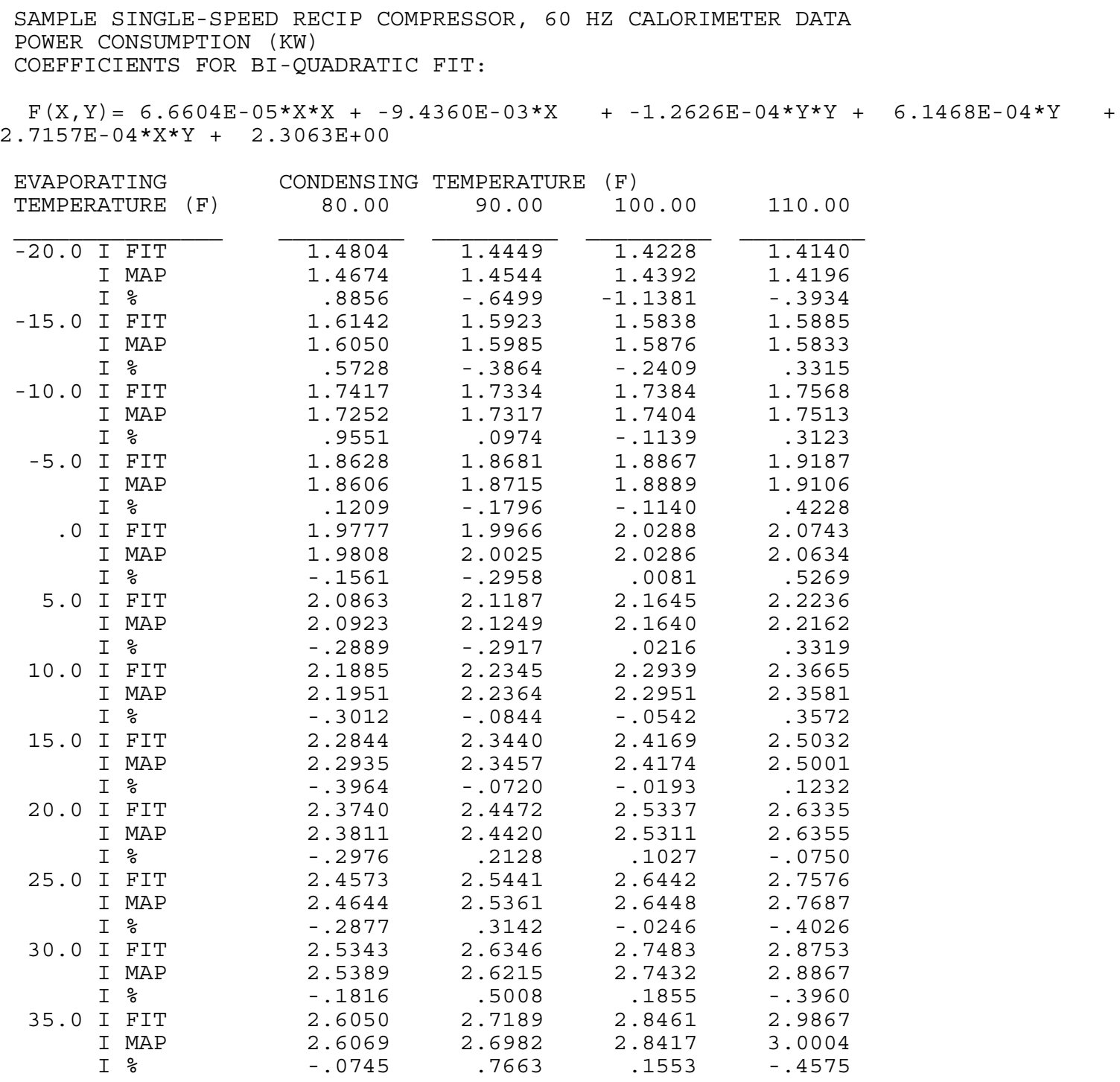

THE MAXIMUM \% VARIATION FROM THE MAP VALUE

1.1381

THE WEIGHTED AVERAGE OF THE ABSOLUTE VALUES OF THE \% VARIATIONS .3058

THE WEIGHTED AVERAGE OF THE VARIATIONS

THE STANDARD DEVIATION FROM THE AVERAGE $\%$ VARIATION

$-.0014$

.3980 


\section{Listing G.4. Sample Output Listing for MAPFIT Program (continued)}

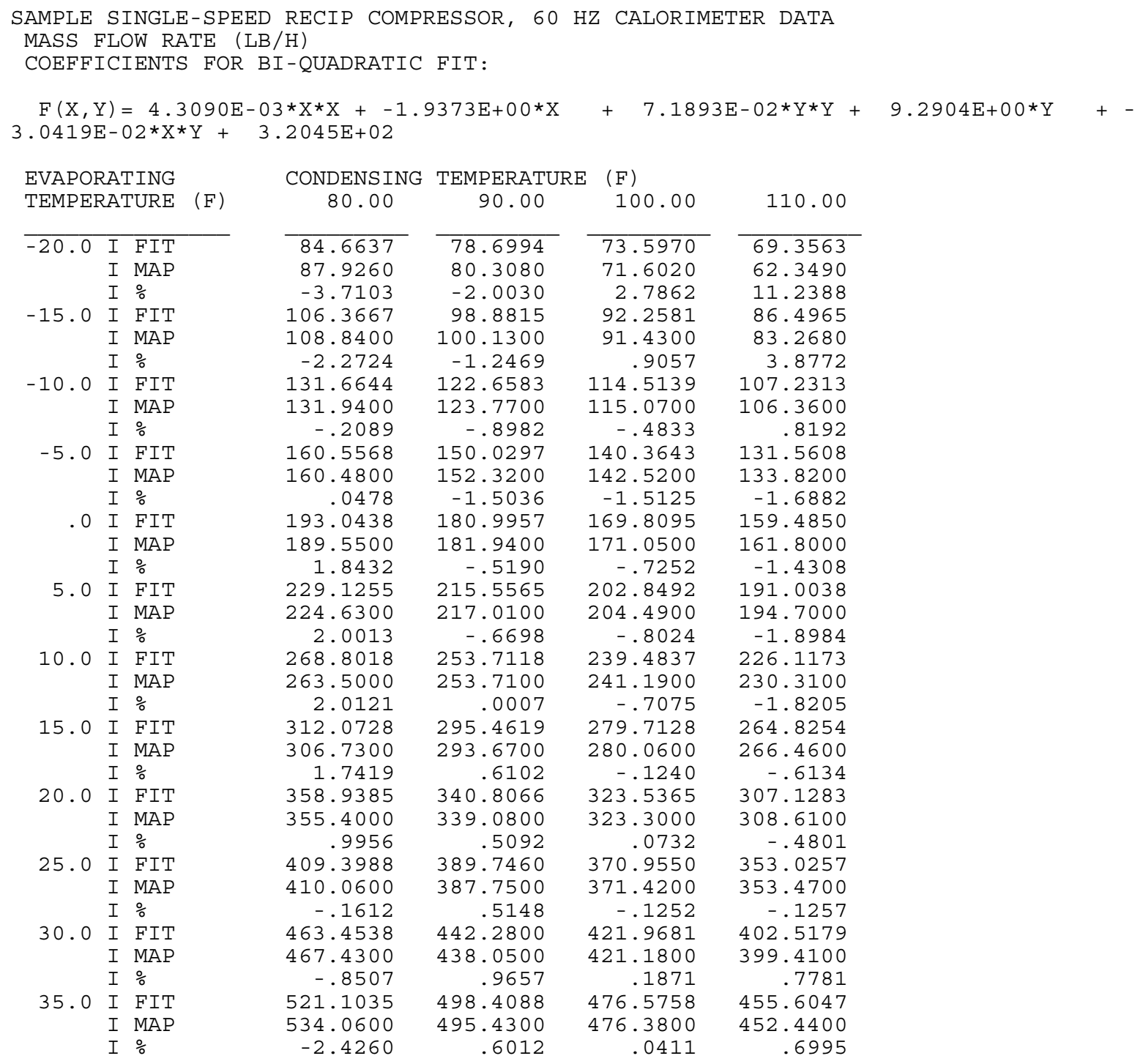

THE MAXIMUM $\%$ VARIATION FROM THE MAP VALUE

THE WEIGHTED AVERAGE OF THE \% VARIATIONS

1.2970

.0884

2.1667 


\section{Listing G.4. Sample Output Listing for MAPFIT Program (continued)}

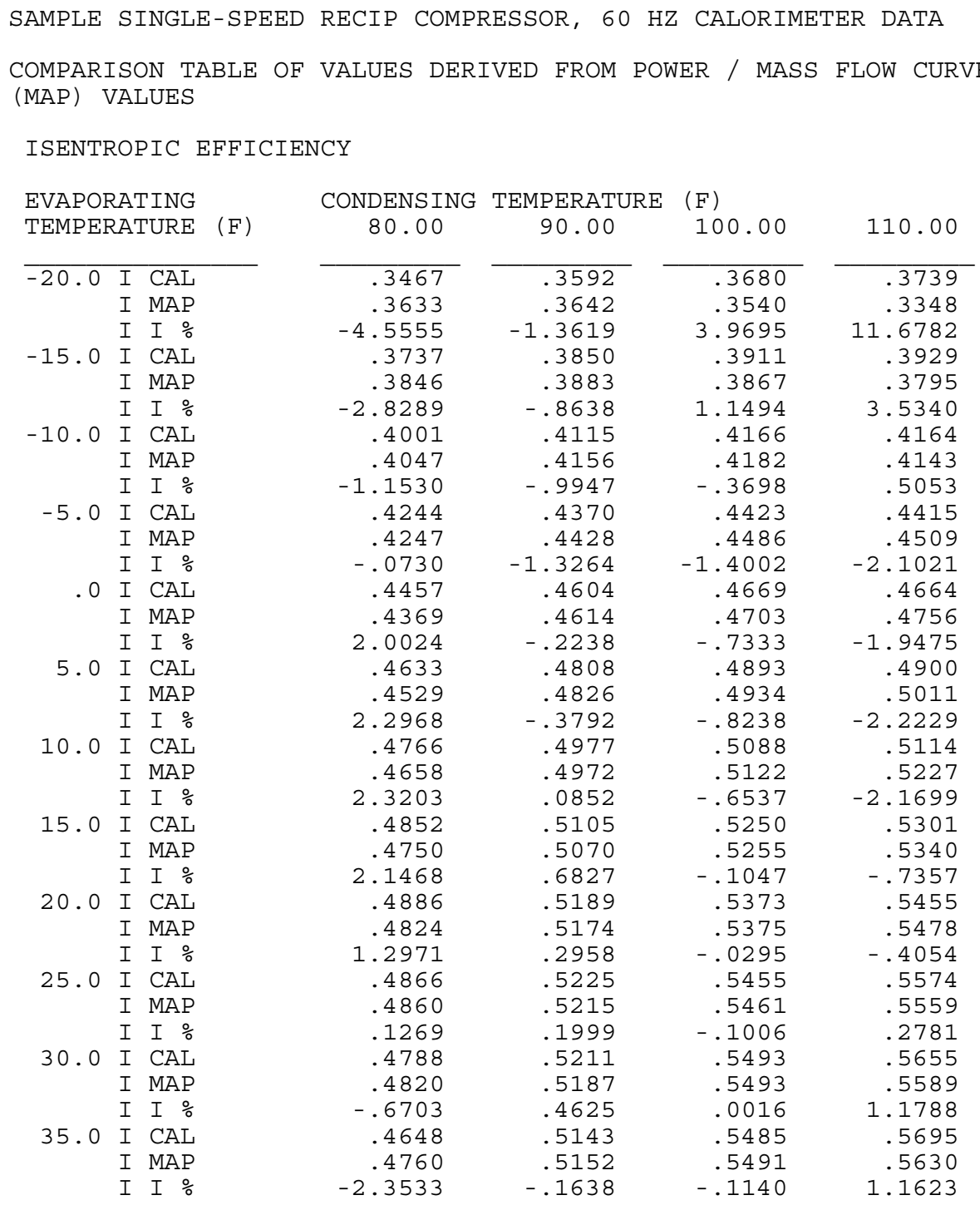

THE MAXIMUM $\%$ VARIATION FROM THE MAP VALUE

THE WEIGHTED AVERAGE OF THE \% VARIATIONS

1.3799

THE WEIGHTED AVERAGE OF THE \% VARIATIONS

.0940

2.3264 


\section{Listing G.4. Sample Output Listing for MAPFIT Program (continued)}

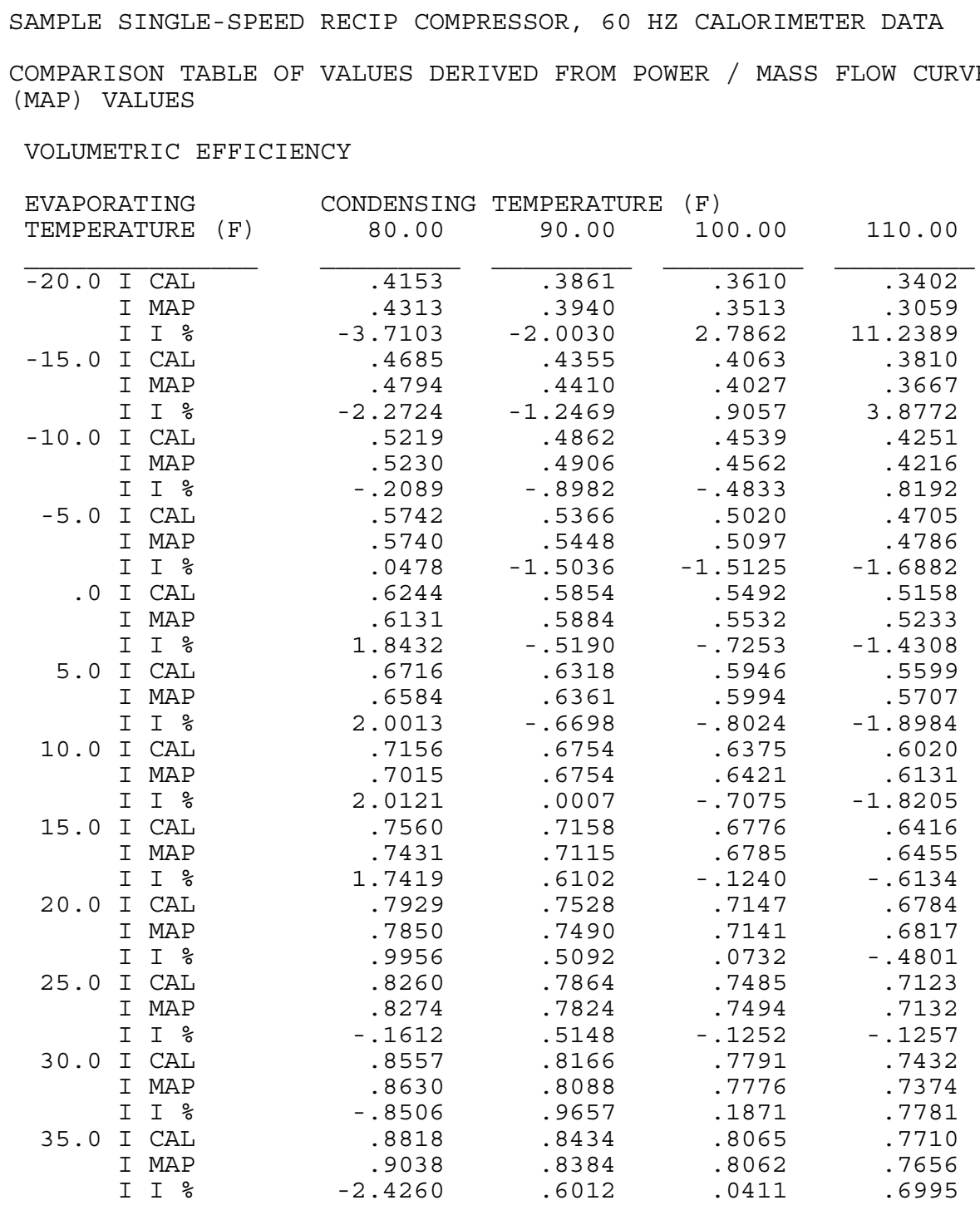

THE MAXIMUM \% VARIATION FROM THE MAP VALUE

11.2389

THE WEIGHTED AVERAGE OF THE ABSOLUTE VALUES OF THE \% VARIATIONS

1.2970

THE WEIGHTED AVERAGE OF THE

THE STANDARD DEVIATION FROM THE AVERAGE \% VARIATION

2.1667 


\section{Listing G.5. Output Format Description for MAPFIT Program}

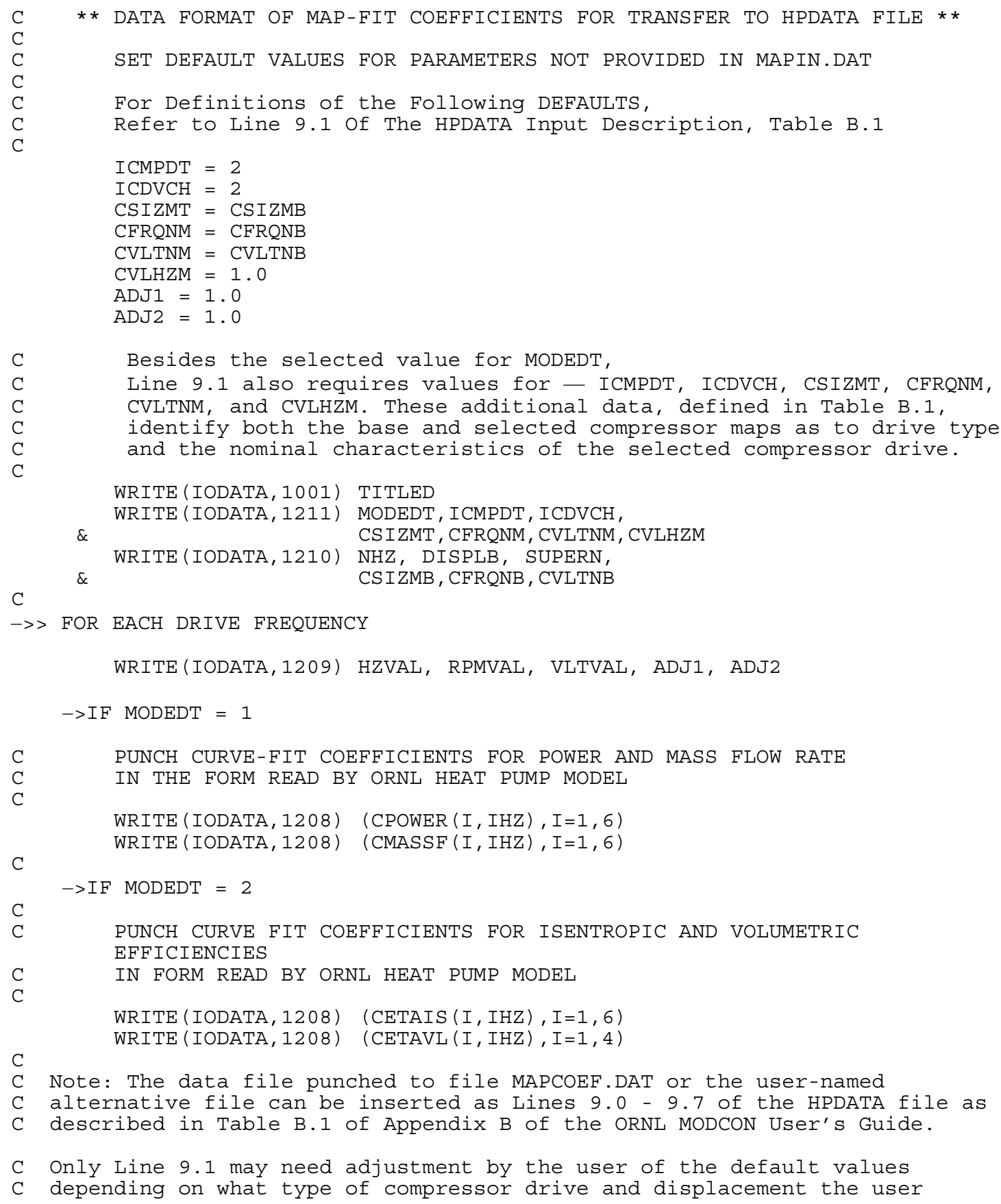





\section{Listing G.6. Sample Output File for MAPFIT Program}

FILE: MAPCOEF.DAT

*** SAMPLE OUTPUT DATA FILE FROM ORNL MAPFIT PROGRAM IN FORMAT NEEDED FOR USE IN ORNL HEAT PUMP DATA INPUT

SAMPLE SINGLE-SPEED RECIP COMPRESSOR, HEATING MODE DATA

$\begin{array}{lrrrrrr}1 & 2 & 2 & 2.7500 & 60.0000 & 240.0000 & 1.0000\end{array}$

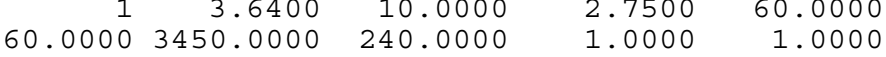

$6.660 \mathrm{E}-05-9.436 \mathrm{E}-03-1.263 \mathrm{E}-04 \quad 6.147 \mathrm{E}-04 \quad 2.716 \mathrm{E}-04 \quad 2.306 \mathrm{E}+00$

$4.309 \mathrm{E}-03-1.937 \mathrm{E}+00 \quad 7.189 \mathrm{E}-02 \quad 9.290 \mathrm{E}+00-3.042 \mathrm{E}-02 \quad 3.205 \mathrm{E}+02$ 



\section{Listing G.7. Sample Output File for MAPFIT Program — Annotated}

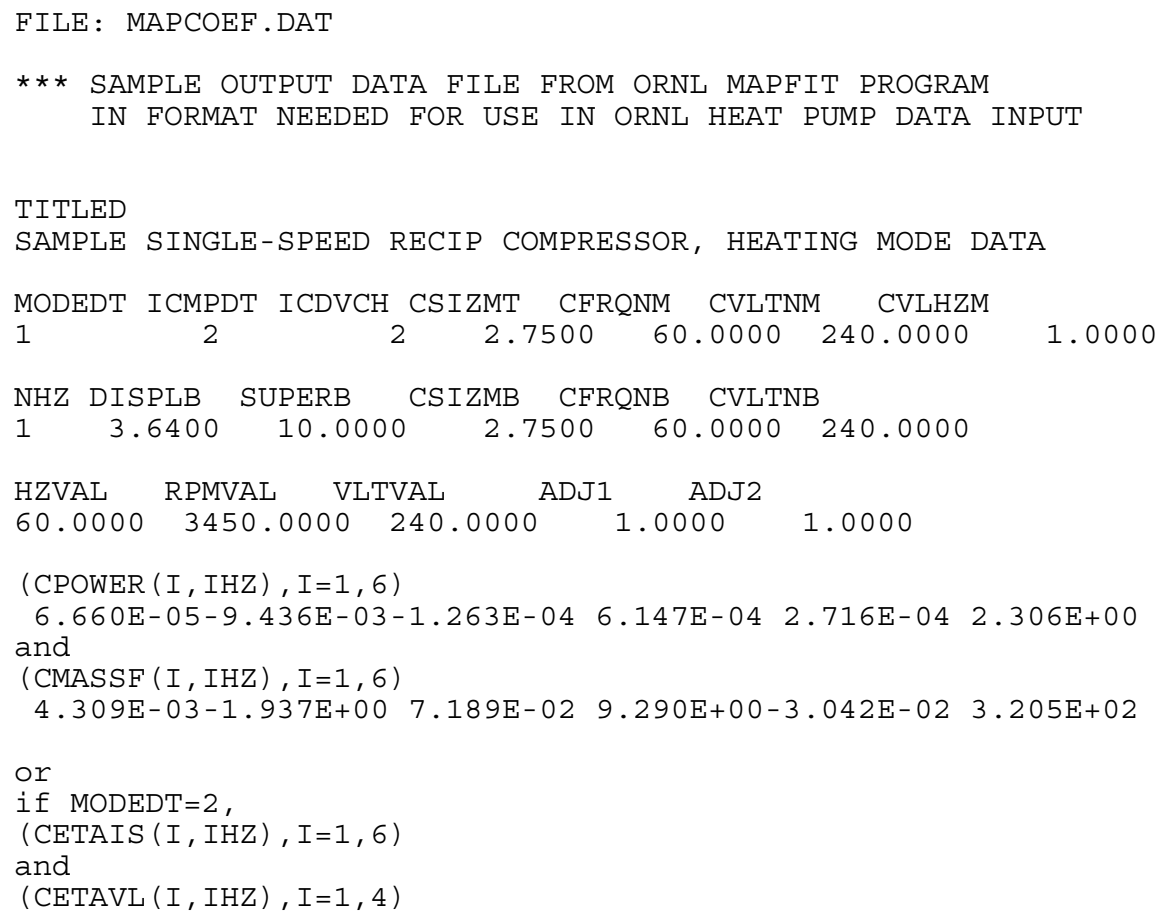





\section{APPENDIX H}

\section{AMBIENT/SPEED/CONTROL DATA FILE 'CONTRL' FOR SELECTED AND DUAL-MODE AMBIENT-vs-SPEED PERFORMANCE MAPPING}

\section{Input Data Definitions and Format}

The 'CONTRL' data file is an optional additional input file which can be used in special circumstances when more control in needed over the ambient temperatures and relative humidities at which heat pump performance is to be evaluated. It can also be used to generate ambient vs compressor speed data sets for both heating and cooling conditions in one run with full operational variable control. The data file was developed originally to provide a means of generating performance data suitable for the ORNL Annual Performance Factor / Loads Model. As such, it is provided more as a special purpose option than as an integral part of the basic design tool package.

Table H.1 describes the input data requirements for the optional CONTRL data file. The operational variable specification used in CONTRL is identical to that for the CONCHZ data file (although potential users should note that the required data format is different). This input data file is read by the default unit number of 24 although this can be easily changed in the BLOCK DATA routine with reference to Appendix D.

One known inconsistency with the present version is that if temperatures are selected that are not on regular grid intervals, a set of performance data will be punched which contains the starting and ending temperature values and the number of temperatures but no information about what actual temperatures were used within the temperature range. As such, these data sets should not be used to generate contour plots unless the header values are edited to reflect the actual temperatures used for each grid location. Alternatively, a separate version of the CONDAT routine could be written to pass the correct, more detailed, heading information to the version of the CONDAT routine called from the APFDRV routine (to generate the CONSPD dataset as shown in Figure CDG1).

\section{Sample Input File (Regular and Annotated)}

This section contains regular and annotated listings, Listings H.1 and H.2, respectively, of a sample 'CONTRL' data file. The regular listing represents the data set as directly used by the model while the annotated version of the same data set is labeled with the variable names as described in Table H.1. The annotated listing is provided as a visual reference to users modifying existing data sets.

The selected example given by file RATING.CTL can be used to generate heating and cooling performance data at the DOE rating conditions for variable speed heat pumps. Operational characteristics which are approximately optimal for the sample heat pump given by the heat pump specification file OFFDES.HPS are included in the CONTRL data set. (These were obtained from the benchmark performance analysis of Rice [1991].) The resultant performance data at low, intermediate, and high speeds, as required for the various ambients, can be used to generate DOE HSPF and SEER ratings for selected DOE regions. 



\section{Table H.1. Description of Optional CONTRL Input Data to MODCON Program}

(Required Only If MODEGN $=3,4$, or 5 in CONCHZ Data File)

Variable Name Variable Description

Sample Value

OPERATIONAL CONTROL DATA

>> Loop Over Heating and Cooling Mode Data $->\mathrm{M}=1,2$

>>>> Heating Mode Data $(\mathrm{M}=1)$

\section{a) Ambient Data}

Operational Line \#1 FORMAT(I3)

NTMPSS(M) number of ambient temperatures for which $\quad 2$ heating $(\mathrm{M}=1)$ or cooling $(\mathrm{M}=2)$ performance is required

Operational Lines

"I=1,NTPMSS(M)" FORMAT(6F8.3)

$\begin{array}{lrr}\text { TOUT(I,M) } & \text { ambient temperature }\left({ }^{\circ} \mathrm{F}\right) & 17.0\end{array}$

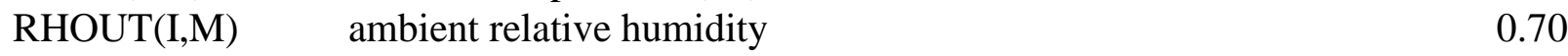

$\begin{array}{lll}\mathrm{TIN}(\mathrm{I}, \mathrm{M}) & \text { indoor thermostat setting }\left({ }^{\circ} \mathrm{F}\right) & 70.0\end{array}$

$\begin{array}{ll}\text { RHIN }(\mathrm{I}, \mathrm{M}) \quad \text { indoor design relative humidity } & 0.50\end{array}$

$\begin{array}{lll}\mathrm{TSE}(\mathrm{I}, \mathrm{M}) & \text { estimate of compressor inlet saturation temperature }\left({ }^{\circ} \mathrm{F}\right) & 10.0\end{array}$

TSC(I,M) estimate of compressor outlet saturation temperature $\left({ }^{\circ} \mathrm{F}\right) \quad 10.0$

\section{b) Compressor Frequency Data}

Operational Line \#

"NTPMSS(M)+2" FORMAT(I3)

NFRQSS(M) number of compressor speeds at which steady-stateheating-mode $\quad 4$ $(\mathrm{M}=1)$ or cooling-mode $(\mathrm{M}=2)$ heat pump data are required;

- value is set to 1 internally if load/frequency iteration is used

Operational Line \#

"NTPMSS(M)+3" FORMAT(6F8.3)

$\begin{array}{lll}\text { CMFRLO(M) } & \text { lowest compressor frequency }(\mathrm{Hz}) & 60.0\end{array}$

$\begin{array}{lll}\text { CMFRHI(M) } & \text { highest compressor frequency }(\mathrm{Hz}) & 240.0\end{array}$

CMFRRF(M) reference compressor frequency $(\mathrm{Hz})$ for frequency ratio calculation 120.0

- if load/frequency iteration is not used;

initial guess for required compressor frequency $(\mathrm{Hz})$

- if load/frequency iteration is used (not yet operational) 


\section{c) Control Variable Data}

Operational Line \#

"NTPMSS(M)+4" FORMAT(I3)

NVAL(M) number of control variables to be user-specified $\quad 1$

Operational Lines

"J=1,NVAL(M)" FORMAT(2I3,2X,6F8.3)

$\mathrm{NFUN}(\mathrm{J}, \mathrm{M}) \quad$ integer value selecting controlled parameter " $\mathrm{y}$ " where $\mathrm{y}=\mathrm{f}(\mathrm{x}) \quad 1$

$=1$, for compressor inlet superheat $\left(\mathrm{F}^{\circ}\right)$

$=2$, for condenser exit subcooling $\left(\mathrm{F}^{\circ}\right)$

$=3$, for indoor blower frequency $(\mathrm{Hz})$

$=4$, for outdoor fan frequency $(\mathrm{Hz})$

$=5$, for building load $(\mathrm{kBtuh} / \mathrm{h})$ — not fully operational

$\mathrm{NIND}(\mathrm{J}, \mathrm{M}) \quad$ integer value selecting controlling parameter " $\mathrm{x}$ " 1

$=1$, for ambient temperature $\left({ }^{\circ} \mathrm{F}\right)$

$=2$, for compressor frequency $(\mathrm{Hz})$

Coefficients of linear control algorithm of the form $y=\left(y_{2}-y_{1}\right) /\left(x_{2}-x_{1}\right) \cdot\left(x-x_{1}\right)+y_{1}$

$\begin{array}{lll}\operatorname{VINDEP}(\mathrm{J}, 1, \mathrm{M}) \quad \text { selected value of } \mathrm{x}_{1} & 17.0\end{array}$

$\operatorname{VINDEP}(\mathrm{J}, 2, \mathrm{M}) \quad$ selected value of $\mathrm{x}_{2} \quad 47.0$

$\operatorname{VDEPEN}(\mathrm{J}, 1, \mathrm{M}) \quad$ prescribed value of $\mathrm{y}_{1} \quad 5.0$

$\begin{array}{lll}\operatorname{VDEPEN}(\mathrm{J}, 2, \mathrm{M}) & \text { prescribed value of } \mathrm{y}_{2} & 20.0\end{array}$

$\begin{array}{ll}\operatorname{VDEPLO}(\mathrm{J}, \mathrm{M}) \quad \text { minimum-allowable value of } \mathrm{y}_{1} & 0.0\end{array}$

$\operatorname{VDEPHI}(\mathrm{J}, \mathrm{M}) \quad$ maximum-allowable value of $\mathrm{y}_{2} \quad 30.0$

>>>> Repeat For Cooling Mode Data $(\mathrm{M}=2)$

a) Ambient Data :

NTMPSS(M),

Lines $\mathrm{I}=1$, NTMPSS(M)

TOUT(I,M),RHOUT(I,M),TIN(I,M),RHIN(I,M), TSE(I,M),TSC(I, M)

\section{b) Compressor Frequency Data :}

NFRQSS(M)

CMFRLO(M), CMFRHI(M), CMFRRF(M) 


\section{c) Control Variable Data :}

NVAL(M)

Lines $\mathrm{J}=1, \mathrm{NVAL}(\mathrm{M})$

NFUN(J,M),NIND(J,M),VINDEP(J,1,M),VINDEP(J,2,M), . . . . VDEPEN(J,1,M),VDEPEN(J,2,M), VDEPLO(J,M), VDEPHI(J,M)

>> Loop Complete Over Operational Parameter Data

\section{OUTPUT CONTROL DATA}

\section{Steady-State Performance Data Output}

Output Line \#1 FORMAT(I3)

IPUNCH Integer flag to select if steady-state performance data file is to be created 1

$\neq 1$, no data file is desired

$=1$, steady-state data file will be created in a format suitable for use in the ORNL APF Model

\section{Supplemental Contour Data Sets}

>> Loop Over Heating and Cooling Mode Data $->\mathrm{M}=1,2$

>>>> Heating Mode Data $(\mathrm{M}=1)$

\section{a) Ambients :}

Output Line \#2 FORMAT(I3,F8.3)

NAMBCN(M) If $\geq 0$, number of supplemental ambients $\quad 1$

If $=-1$, indicates value of $\operatorname{REFX}(\mathrm{M})$ is to be read

If $=-99$, shortcut way to indicate that no supplemental ambient or frequency data sets are desired

REFX(M) Reference ambient value for secondary ambient-vs-frequency contour data set [only used if $\operatorname{NAMBCN}(\mathrm{M})=-1$ ]

Output Line \#3 FORMAT(20I3)

(if $\mathrm{NAMBCN}(\mathrm{M})>0$ )

IAMBCN(M) Ordinal numbers of selected ambients relative to NTMPSS(M) 


\section{b) Compressor Frequencies :}

Output Line \#4 FORMAT(I3,F8.3)

NFRQCN(M) If $\geq 0$, number of supplemental frequencies $\quad 1$

If $=-1$, indicates value of $\mathrm{REFY}(\mathrm{M})$ is to be read

REFY(M) Reference frequency value for secondary ambient-vs-frequency contour data set [only used if NFRQCN $(\mathrm{M})=-1$ ]

Output Line \#5 FORMAT(20I3)

(if NFRQCN(M) > 0)

IFRQCN(M) Ordinal numbers of selected frequencies relative to NFRQSS(M)

>>>> Repeat For Cooling Mode Data (M=2), If NAMBCN(1) > -99

a) Ambients :

$\operatorname{NAMBCN}(\mathrm{M}), \operatorname{REFX}(\mathrm{M})$

$\operatorname{IAMBCN}(\mathrm{M})$

b) Compressor Frequencies :

NFRQCN(M), REFY(M)

$\operatorname{IFRQCN}(\mathrm{M})$

>> Loop Complete Over Output Data 


\section{Listing H.1. Sample Control Data File 'CONTRL' - Selected Heating And Cooling Ambients With Operational-Variable Control}

File: RATING.CTL

\begin{tabular}{|c|c|c|c|c|c|c|c|}
\hline 04 & & & & & & & \\
\hline 17.0 & & 0.68 & 70.0 & 0.58 & 8.0 & 95.0 & \\
\hline 35.0 & & 0.70 & 70.0 & 0.58 & 28.0 & 95.0 & \\
\hline 47.0 & & 0.72 & 70.0 & 0.58 & 40.0 & 90.0 & \\
\hline 62.0 & & 0.72 & 70.0 & 0.58 & 55.0 & 90.0 & \\
\hline 06 & & & & & & & \\
\hline $\begin{array}{l}50 \\
04\end{array}$ & & 180.0 & 180.0 & & & & \\
\hline 1 & 2 & 50.0 & 180.0 & 1.0 & 1.0 & 1.0 & 1.0 \\
\hline 2 & 2 & 50.0 & 180.0 & 10.0 & 24.0 & 10.0 & 24.0 \\
\hline 3 & 2 & 50.0 & 180.0 & 64.8 & 95.0 & 64.8 & 95.0 \\
\hline 4 & 2 & 50.0 & 180.0 & 37.1 & 55.3 & 37.1 & 55.3 \\
\hline 04 & & & & & & & \\
\hline 67.0 & & 0.40 & 80.0 & 0.52 & 55.0 & 90.0 & \\
\hline 82.0 & & 0.40 & 80.0 & 0.52 & 55.0 & 90.0 & \\
\hline 87.0 & & 0.40 & 80.0 & 0.52 & 48.0 & 115.0 & \\
\hline 95.0 & & 0.40 & 80.0 & 0.52 & 48.0 & 115.0 & \\
\hline 06 & & & & & & & \\
\hline 50 & & 180.0 & 180.0 & & & & \\
\hline 04 & & & & & & & \\
\hline 1 & 2 & 50.0 & 180.0 & 10.0 & 10.0 & 10.0 & 10.0 \\
\hline 2 & 2 & 50.0 & 180.0 & 5.0 & 15.0 & 5.0 & 15.0 \\
\hline 3 & 2 & 50.0 & 180.0 & 45.6 & 108.0 & 45.6 & 108.0 \\
\hline 4 & 2 & 50.0 & 180.0 & 53.0 & 82.5 & 53.0 & 82.5 \\
\hline 01 & & & & & & & \\
\hline-1 & 17 & & & & & & \\
\hline-1 & 18 & .0 & & & & & \\
\hline-1 & 95 & & & & & & \\
\hline-1 & 18 & .0 & & & & & \\
\hline
\end{tabular}



Listing H.2. Annotated Sample Control Data File 'CONTRL' Selected Heating and Cooling Ambients With Operational-Variable Control

\section{File: RATING.CTL}

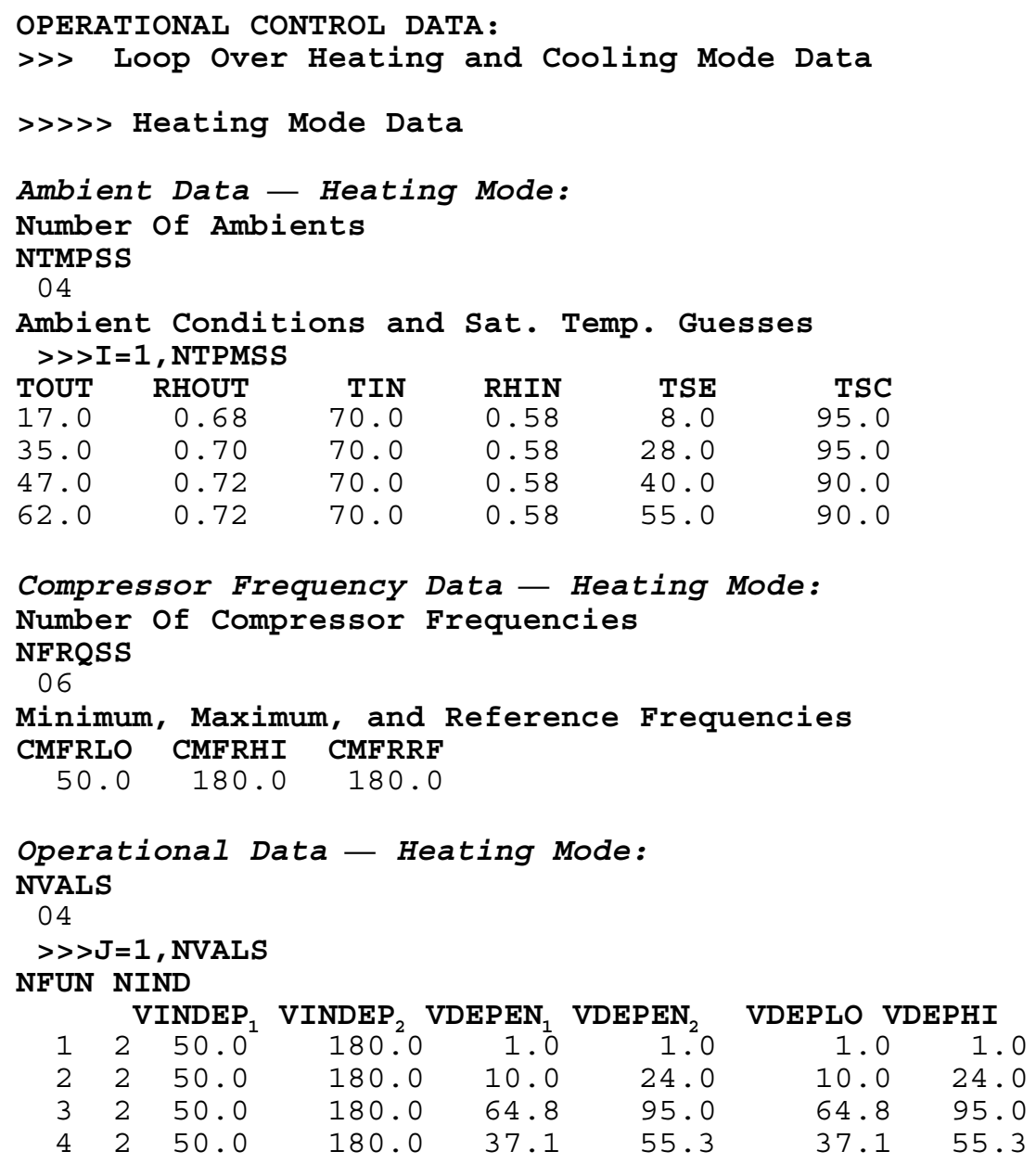




\section{Listing H.2. Annotated Sample Control Data File 'CONTRL' - Selected Heating And Cooling Ambients With Operational-Variable Control (continued)}

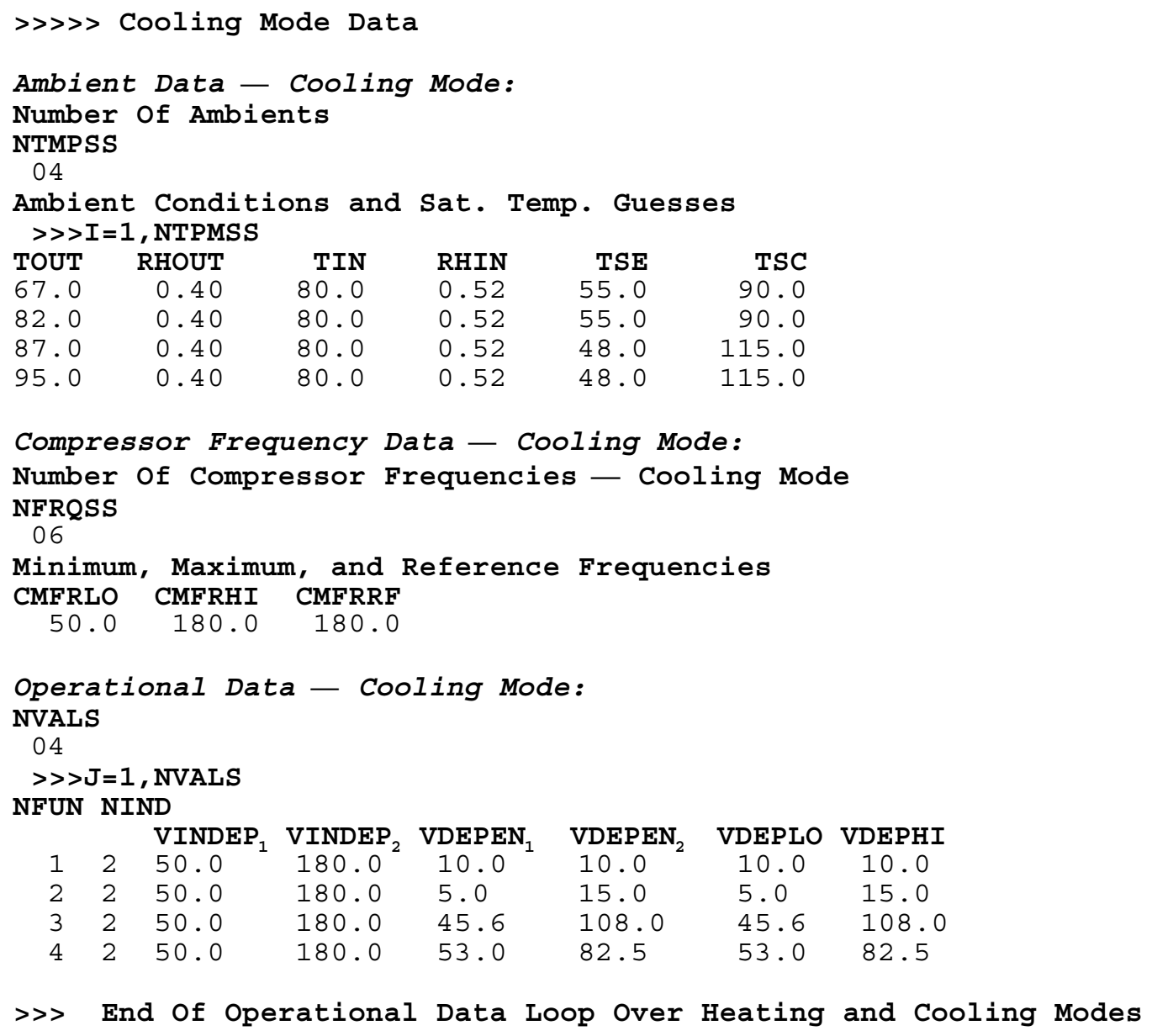




\section{Listing H.2. Annotated Sample Control Data File 'CONTRL' - Selected Heating And Cooling Ambients With Operational-Variable Control (continued)}

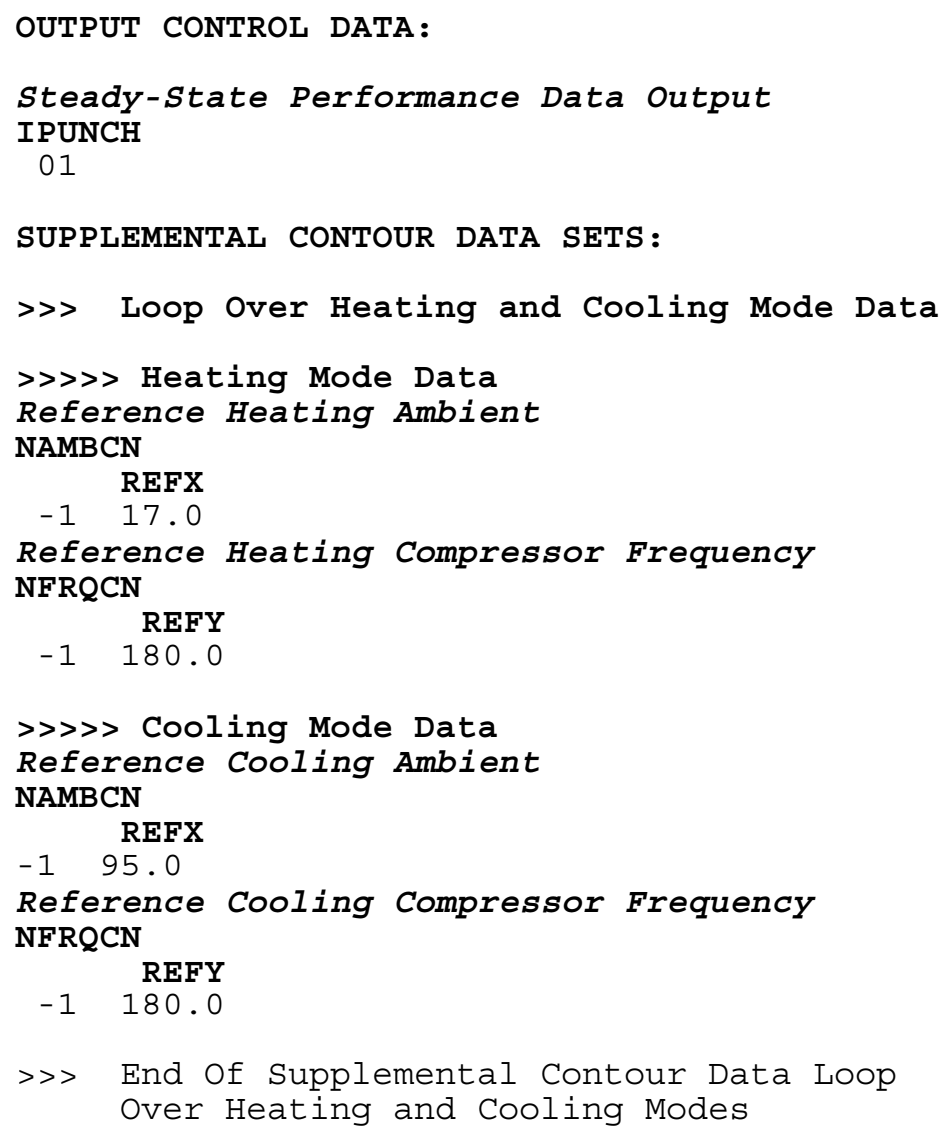

